\title{
Ceramide transporters in neuroinflammation and neurodegenerative diseases
}

Citation for published version (APA):

Mencarelli, C. M. (2012). Ceramide transporters in neuroinflammation and neurodegenerative diseases. [Doctoral Thesis, Maastricht University]. Maastricht University. https://doi.org/10.26481/dis.20120627cm

Document status and date:

Published: 01/01/2012

DOI:

$10.26481 /$ dis. $20120627 \mathrm{~cm}$

Document Version:

Publisher's PDF, also known as Version of record

\section{Please check the document version of this publication:}

- A submitted manuscript is the version of the article upon submission and before peer-review. There can be important differences between the submitted version and the official published version of record.

People interested in the research are advised to contact the author for the final version of the publication, or visit the DOI to the publisher's website.

- The final author version and the galley proof are versions of the publication after peer review.

- The final published version features the final layout of the paper including the volume, issue and page numbers.

Link to publication

\footnotetext{
General rights rights.

- You may freely distribute the URL identifying the publication in the public portal. please follow below link for the End User Agreement:

www.umlib.nl/taverne-license

Take down policy

If you believe that this document breaches copyright please contact us at:

repository@maastrichtuniversity.nl

providing details and we will investigate your claim.
}

Copyright and moral rights for the publications made accessible in the public portal are retained by the authors and/or other copyright owners and it is a condition of accessing publications that users recognise and abide by the legal requirements associated with these

- Users may download and print one copy of any publication from the public portal for the purpose of private study or research.

- You may not further distribute the material or use it for any profit-making activity or commercial gain

If the publication is distributed under the terms of Article $25 \mathrm{fa}$ of the Dutch Copyright Act, indicated by the "Taverne" license above, 
Ceramide transporters in neuroinflammation and neurodegenerative diseases 
Copyright: (C) Chiara Mencarelli, Maastricht 2012

ISBN: 978-90-9026751-7

Ceramide transporters in neuroinflammation and neurodegenerative diseases

All rights are reserved. No part of this book may be reproduced in any form or by any electronic means, including information, storage and retrieval systems, without permission in writing from copyright holder.

Cover design: Hans Duimel

Typesetting and layout: Hans Duimel

Printed by GVO drukkers \& vormgevers B.V. | Ponsen \& Looijen 


\title{
Ceramide transporters in neuroinflammation and neurodegenerative diseases
}

\author{
DISSERTATION \\ To obtain the degree of Doctor \\ at the Maastricht University, \\ on authority of the Rector Magnificus, \\ Prof. Dr. G.P.M.F. Mols \\ in accordance with the decision of the Board of Deans, \\ to be defended in public
}

On Wednesday $27^{\text {th }}$ of June 2012 at 10.00 o' clock by

\section{Chiara Mencarelli}

Born the $26^{\text {th }}$ of January 1983 in Italy 


\section{Supervisors:}

Prof. Dr M.H. De Baets

Prof. Dr. H.W.M. Steinbusch

\section{Co-supervisor:}

Dr. P. Martínez-Martínez

\section{Assessment Committee:}

Prof. Dr. W.A. Buurman (Chairman)

Prof. Dr. T.M. Hackeng

Prof. Dr. J. Walter (University of Bonn)

Prof. Dr. H.J.M.F.G. Aerts (University of Amsterdam)

Dr. B.P.F. Rutten

The studies described in this thesis were supported by a Marie Curie Host Fellowship MEST-CT-2005-020589 


\section{Contents}

General introduction

Chapter 1

The ceramide transporter (CERT) and the Goodpasture antigen

binding protein (GPBP). One protein - one function?

Chapter 2

51

Ceramide function in the brain: when a slight tilt is enough

Chapter 3

The expression of the Goodpasture antigen-binding protein (ceramide transporter) in adult rat brain

\section{Chapter 4}

Unchanged expression of the ceramide transfer protein in the acute 6-OHDA neurodegenerative model.

Chapter 5

The Goodpasture antigen-binding protein / Ceramide transporter binds to human serum amyloid P-component and is present in brain amyloid plaques.

Chapter 6

Goodpasture antigen-binding protein (GPBP) down modulates A $\beta$ aggregation in vitro and decreases toxicity of $A \beta$ to neurons

Summary and general discussion

Curriculum vitae

List of publications 201

Acknowledgments 205 



\section{Abbreviations}

$\begin{array}{ll}\text { aa } & \text { amino acid(s) } \\ \text { AD } & \text { Alzheimer's disease } \\ \text { APP } & \text { Amyloid precursor protein } \\ \text { CHO } & \text { Chinese hamster ovary } \\ \text { CERT } & \text { Ceramide transporter } \\ \text { CERT } & \text { Ceramide transporter long (isoform) } \\ \text { CNS } & \text { Central nervous system } \\ \text { ER } & \text { Endoplasmic reticulum } \\ \text { FAPP2 } & \text { Four-phosphate-adaptor protein 2 } \\ \text { FFAT } & \text { two phenylalanine amino acids 'FF' in an acidic tract motif } \\ \text { GlcCer } & \text { Glucosylceramide } \\ \text { GPBP } & \text { Goodpasture antigen-binding protein } \\ \text { GP } & \text { Goodpasture } \\ \text { GPS } & \text { Goodpasture syndrome } \\ \text { GSLS } & \text { Glycosphingolipids } \\ \text { OLGs } & \text { Oligodendrocytes } \\ \text { OSBP } & \text { Oxysterol-binding protein } \\ \text { NFkB } & \text { nuclear factor kappa B } \\ \text { NGF } & \text { Nerve growth factor } \\ \text { PC } & \text { Phosphatidylcholine } \\ \text { PD } & \text { Parkinson's disease } \\ \text { PH } & \text { Pleckstrin homology } \\ \text { Pol K } & \text { DNA polymerase k } \\ \text { PRD } & \text { Proline rich domain } \\ \text { SAP } & \text { Serum Amyloid P component } \\ \text { SM } & \text { Sphingomyelin } \\ \text { SMase } & \text { Sphingomyelinase } \\ \text { SMS } & \text { Sphingomyelin synthase } \\ \text { SPR } & \text { Surface plasma resonance } \\ \text { SR } & \text { Serine repeat motif } \\ \text { START } & \text { Steroidogenic acute regulatory protein (StAR)-related lipid transfer } \\ \text { TNF } \alpha & \text { Tumor necrosis factor alpha } \\ \text { VAPs } & \text { Vesicle associated-ER proteins } \\ & \end{array}$



General introduction 
Ceramide is an important bioactive lipid that is involved in many of the most critical cellular processes, ranging from regulation of cell growth to cell cycle arrest and apoptosis. Ceramide levels are finely regulated within the cell and alteration of the sphingolipid-ceramide profile has significant relevance in the development of many age-related, neurological and/or neuroinflammatory diseases. Ceramide transporter (CERT) and Goodpasture antigen binding protein (GPBP) are the only proteins known to shuttle ceramide within the cell. By implication, it is very likely that these proteins are involved in the molecular mechanisms underlying ceramide-mediated signaling cascades. These two isoforms, almost identical in their sequence and highly conserved in evolution, differ in various properties such as tissue and cellular localization, temporal pattern of expression and mode of action. Indeed, this diversity is reflected by their research history, with GPBP and CERT discovered and characterized in the apparently unrelated fields of autoimmunity and lipid chemistry.

Goodpasture antigen-binding protein (GPBP) is a non conventional serinthreonin kinase isolated for the first time in the context of a rare autoimmune disease known as Goodpasture Syndrome (GPS). This disorder affects mostly kidney, lung and choroid plexus in the brain. GPBP was found to bind and phosphorylate the self-antigen against which the antibodymediated inflammatory response is directed. Specifically, the target of the autoantibody attack is the C-terminal noncollagenous-1 (NC1) domain of the $\alpha 3$-chain of the type IV collagen (a3-(IV) NC1), also known as Goodpasture antigen (GPA). This autoimmune reaction results in deposits of autoantibodies along the alveolar and glomerular basement membranes, causing lung hemorrhage and rapidly progressive glomerulonephritis, the two cardinal clinical manifestations of GPS. Although the function of this protein in the autoimmune response of GPS has remained elusive, GPBP phosphorylation of GPA could regulate molecular processing and organization of specific structural protein domains, which may lead to the autoimmune response. In line with this role, high expression levels of GPBP are found in many autoimmune diseases in which antigens may arise from abnormal protein domain organization. However, the fact that GPBP takes its name from GPS is unfortunate and even misleading because this protein probably plays an important general role in cell physiology and immunology, not just the disease state.

More recently, a shorter variant of GPBP was shown to be responsible for the transport of the lipid ceramide within the cell (between the ER and the 
Golgi apparatus) and was thus termed ceramide transporter (CERT). GPBP and CERT were therefore characterized in very different contexts and it is difficult to correlate the intracellular function of the lipid carrier CERT with the capacity of GPBP to bind and phosphorylate proteins at the extracellular level. Notably, both isoforms have ceramide binding capability. Many reports have emphasized the role of ceramide in neurodegenerative disorders and ceramide transporters are likely to represent pivotal proteins for brain homeostasis and disease processes. However, until recently there had been little research into the expression, regulation and function of these ceramide associated proteins. In this thesis we first aimed to investigate GPBP and CERT cellular localization and expression in normal rat brain and establish whether levels of these proteins were altered in models of both acute brain injury and chronic neurodegenerative diseases. Subsequently, in an effort to investigate the function of GPBP, we aimed to delineate cellular and molecular mechanisms underlying its interaction with proteins associated with neuronal degeneration and immune system response.

Chapter 1 reviews the current state of knowledge on GPBP and CERT, including the molecular and biochemical characterization of GPBP in the field of autoimmunity, as well as the fundamental research on CERT in ceramide transport. Also the functions of these proteins in different biological and pathological processes are discussed.

In chapter 2, we present a detailed overview of ceramide biology, including structure, physical properties and metabolism, followed by recent data on the role of ceramide as a lipid second messenger in key events of cell physiology. Finally, we highlight the relevance of ceramide in the progression of different neurodegenerative diseases.

In chapter 3, we have investigated the localization of GPBP and CERT in adult rat brain under basal conditions. Using four different antibodies directed against distinct epitopes shared by the two isoforms, we described the cellular localization and expression pattern of GPBP and CERT throughout the rat brain.

In chapter 4, in order to analyze a possible role of these proteins in neuroinflammation and neurodegeneration, we have examined whether levels of GPBP and CERT were altered in 6-hydroxydopamine (6-OHDA)lesioned rat, a well-known acute model of Parkinson's disease (PD). No differences in GPBP/CERT expression was detected between the 6-OHDA injected and the control brains. However, injection of 6-OHDA induces acute effects which differ significantly from the chronic progressive course of PD 
that is characterized by protein aggregates and dysregulation of sphingolipid metabolism. Therefore, in order to further investigate a possible role for GPBP and CERT in chronic and progressive neuronal degeneration and inflammation, we next examined human and transgenic mouse Alzheimer's disease (AD) brain tissues that better represent the characteristic clinical and pathological features of neurodegenerative diseases, such as progressive loss of neurons and deposition of aggregated proteins.

In chapter 5 we have investigated whether GPBP binds directly to human serum amyloid $\mathrm{P}$ component (SAP), a protein concentrated in all types of amyloid deposits. We undertook an immunohistochemistry study of $A D$ human brains to reveal whether the cellular localization of GPBP and CERT are altered in the disease state and whether these proteins localize in the amyloid plaques of $A D$ brains. This chapter raises the important question of whether GPBP-SAP interaction could have a role in disease progression and whether GPBP could be involved in the cellular response to misfolded or aggregated proteins. This is examined further in chapter 6 where we have investigated the role of GPBP in the processing of the Alzheimer amyloid precursor protein (APP) using an in vitro model with elevated levels of secreted amyloid- $\beta$ (A $\beta$ ) peptide. Firstly, we were able to specifically describe the cellular localization of the GPBP isoform in normal rat brain. Secondly, we tested the hypothesis whether GPBP might interact with APP and $A \beta_{1-42}$ peptide. Finally, we have investigated how this interaction has a direct influence upon the in vitro aggregation pattern of $A \beta_{1-42}$ and how GPBP takes part in the cellular response against $A \beta$-induced toxicity in cultured neurons. 


\section{Chapter 1}

\section{The ceramide transporter (CERT) and the Goodpasture antigen-binding protein (GPBP). One protein - one function?}

Chiara Mencarelli, Mario Losen, Caroline Hammels, Jochen De Vry, Matthijs K.C. Hesselink, Harry W.M. Steinbusch, Marc H. De Baets, and Pilar Martínez-Martínez 


\begin{abstract}
The Goodpasture antigen-binding protein (GPBP) and its splice variant the ceramide transporter (CERT) are multifunctional proteins that have been found to play important roles in brain development and biology. However, the function of GPBP and CERT is controversial because of their involvement in two apparently unrelated research fields: GPBP was initially isolated as a protein associated with collagen IV in patients with the autoimmune disease Goodpasture syndrome. Subsequently, a splice variant lacking a serine-rich domain of 26 amino acids (GPBP 26 ) was found to mediate the cytosolic transport of ceramide and was therefore (re)named CERT. The two splice forms likely carry out different functions in specific sub-cellular localizations. Selective GPBP knockdown induces extensive apoptosis and tissue loss in the brain of zebrafish. GPBP/GPBP $\triangle 26$ knock-out mice die as a result of structural and functional defects in ER and mitochondria. Because both mitochondria and ceramide play an important role in many biological events that regulate neuronal differentiation, cellular senescence, proliferation and cell death, we propose that GPBP and CERT are pivotal in neurodegenerative processes.

In this review, we discuss the current state of knowledge on GPBP and CERT, including the molecular and biochemical characterization of GPBP in the field of autoimmunity as well as the fundamental research on CERT in ceramide transport, biosynthesis, localization, metabolism and cell homeostasis.
\end{abstract}




\section{Introduction: CERTain facts about GPBPs}

GPBPs are widely distributed in the central nervous system (CNS), where they are involved in brain development and homeostasis. Different GPBP isoforms are expressed in the cell. GPBP/CERT with 26 additional amino acids (aa) (Ex11+) (Raya et al., 1999) and GPBP $\Delta 26 / C E R T$ without 26 aa (Ex11-) (Hanada et al., 2003) have been studied in detail.

These proteins were characterized in the context of two different biological processes: GPBP/CERT L was initially isolated in 1999 by Raya and colleagues and named as Goodpasture antigen-binding protein (Raya et al., 1999). Goodpasture's syndrome is a strictly human disorder caused by antibodies directed against the non-collagenous (NC1) domain of the $\alpha 3$-chain of collagen type IV ( $\alpha 3$ (IV) NC1 domain). Collagen is a major component of the extracellular matrix. The auto-antibodies cause rapid functional disruption of the basement membrane of lungs, kidneys and the choroid plexus (Salama et al., 2001). GPBP is a soluble extracellular protein which binds and phosphorylates the antigen in this syndrome. Its expression is increased in other spontaneous autoimmune disorders including Goodpasture's syndrome, lupus erythematosus, pemphigoid and lichen planus (Raya et al., 2000), suggesting that GPBP might be an important protein in autoimmune disorders, where autoantigens arise from abnormal protein domain organization.

Subsequently, in 2003, Hanada and colleagues showed that a spliced variant of GPBP which lacks a serine-rich domain composed of 26 aa residues was responsible for the cytosolic trafficking of ceramide from the endoplasmic reticulum (ER), to the Golgi apparatus. Hence, this isoform was termed as CERT (Hanada et al., 2003). Since the longer isoform also has ceramide transport properties in vitro, GPBP was renamed as CERT (Hanada et al., 2003).

Thus far it is not clear how the extracellular function of GPBP/CERT $T_{L}$, which is related to immune complex-mediated pathogenesis, can be conciliated with the critical role of the protein as a cytosolic ceramide transporter. Much of the literature involving GPBPs does not distinguish between the different protein variants and generally refers solely to GPBP $\triangle 26 / C E R T$. This lack of differentiation between the isoforms hampers the interpretation and understanding of results and poses the risk of neglecting genuine functional differences between them. Here we will refer to both splice isoforms as GPBPs, to the longer splicing variant as GPBP/CERT $T_{L}$ and to the shorter splicing variant as GPBP $\triangle 26 / C E R T$. Despite the difference of 26 amino acids, 
GPBP/CERT and GPBP $\triangle 26 / C E R T$ have undistinguishable molecular weights when analyzed by gelectrophoresis. However, they are not the only isoforms found in the cell. Smaller and bigger molecular weight isoforms have been described, which result from an alternative initiation translation site and poststranslational modifications. Each of these isoforms are addressed specifically below.

In this review we comprehensively summarize the current knowledge about GPBPs including their structure, properties and functions. Finally, we will focus on recent findings which delineate an intriguing picture of biological and pathological processes, defining GPBPs as pivotal proteins for brain homeostasis and disease processes

\section{Molecular and biochemical characterization of GPBPs}

\section{Two splicing variants: 26 amino acids of difference}

GPBP/CERT $T_{L}$ and GPBP $\triangle 26 / C E R T$ are alternatively spliced variants of 624 and 598 aa respectively that are identical in sequence, except for the 26 aa serine rich domain (SR2) that is not present in the shorter isoform (Raya et al., 2000). GPBPs are phylogenetically highly conserved during evolution between lower vertebrates and mammals at the amino acid level (Fig. 1). This holds true also for the 26 aa of exon 11 as such, suggesting that the two isoforms perform crucial and distinct physiological functions.

GPBP has three distinct functional domains; the pleckstrin homology (PH) domain, the MIDDLE REGION and the START domain (Fig. 2). The amino terminal $\sim 120$ aa region contains the $\mathrm{PH}$ domain that targets the protein to the Golgi apparatus (Hanada et al., 2003). The PH domain recognizes a specific isomer of phosphatidylinositol phosphates (PIP), namely PI4P which confers Golgi targeting in mammalian cells (Levine and Munro, 2002).

The mutation G67E in the PH domain present in Chinese hamster ovary (CHO) mutant cell line LY-A, destroys the PI4P binding activity of this domain, resulting in an impaired ER-Golgi ceramide transport (Hanada et al., 2003). The MIDDLE REGION of 250 aa contains a coiled-coil motif that might play a role in self oligomerization (Raya et al., 2000). Moreover, the presence in this domain of a FFAT motif (comprising two phenylalanine amino acids 'FF' in an acidic tract) is essential for GPBPs ER targeting (Kawano et al., 2006). FFAT interaction with vesicle associated-ER proteins (VAPS) is a common mechanism where proteins, most of which are involved in lipid metabolism, target ER membranes (Loewen et al., 2003). The GPBPs' FFAT motif interacts with the ER resident type II membrane protein VAP, VAP-A and VAP-B. Mutations in the FFAT motif of GPBP $\triangle 26 / C E R T$ destroy the VAP- 


\begin{tabular}{|c|c|c|c|}
\hline $\begin{array}{l}\text { Drosophila } \\
1 \text { isoform }\end{array}$ & EAREEFGIGAEATS - - - - - - - - - - HA I W PEIDR V C K EQ L H & CERT & 601 \\
\hline $\begin{array}{l}\text { Danio rerio } \\
2 \text { isoforms }\end{array}$ & DTFSSISTQKYLTKPHSHTSSLSSVDLISASDEVHRS F Q VEEMVHSHMT & $\begin{array}{l}\text { GPBP } \\
\text { CERT }\end{array}$ & $\begin{array}{l}620 \\
594\end{array}$ \\
\hline $\begin{array}{l}\text { Mus musculus } \\
2 \text { isoforms }\end{array}$ & DAFSSVGTHRFVQKPYSRSSSMSSIDLVSASDDVHRFSAQVEEMVQNHMN & $\begin{array}{l}\text { GPBP } \\
\text { CERT }\end{array}$ & $\begin{array}{l}624 \\
598\end{array}$ \\
\hline $\begin{array}{l}\text { Rattus norveg } \\
2 \text { isoforms }\end{array}$ & DAFSSVGTHRFVQKPYSRSSSMSSIDLVSASDDVHRFSAQVEEMVQNHMN & $\begin{array}{l}\text { GPBP } \\
\text { CERT }\end{array}$ & $\begin{array}{l}624 \\
598\end{array}$ \\
\hline $\begin{array}{l}\text { Homo sapiens } \\
2 \text { isoforms }\end{array}$ & DAFSSVGTHRFVQKPYSRSSSMSSIDLVSASDDVHRESAQVEEMVQNHMT & $\begin{array}{l}\text { GPBP } \\
\text { CERT }\end{array}$ & $\begin{array}{l}624 \\
598\end{array}$ \\
\hline & $11 \mathrm{ex}$ & & \\
\hline
\end{tabular}

Figure 1 Aminoacid sequence aligment of GPBPs in various species. In Drosophila only the GPBP $\triangle 26 /$ CERT exists.

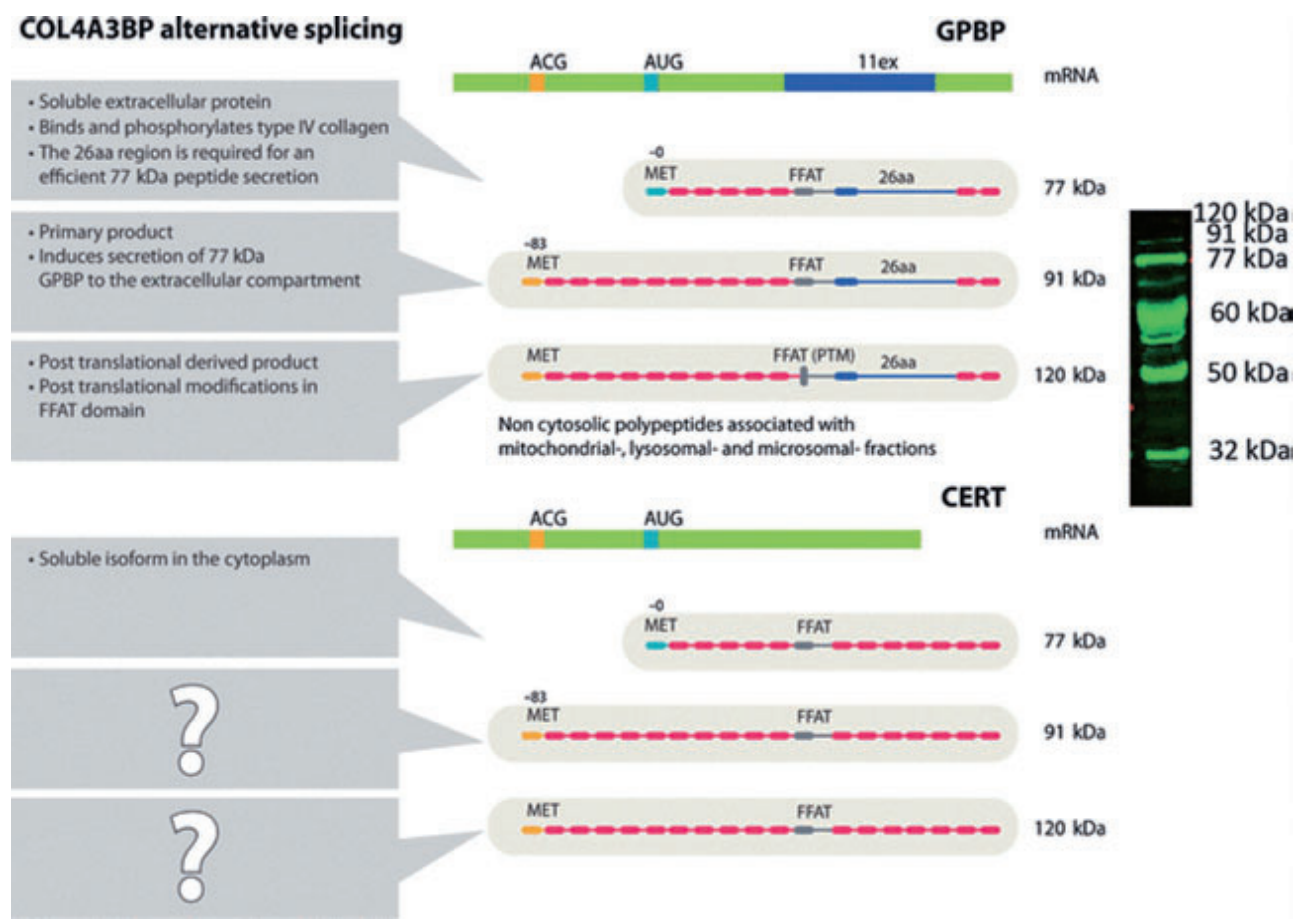

Figure 2 GPBP/CERT $T_{L}$ and GPBP $\triangle 26 / C E R T$ domains: N-terminal Pleckstrin homology (PH) domain. Middle region (MD) with two serine-rich domains (SR1, SR2) and FFAT motif (double phenylalanine in an acidic tract); the 11th exon, encoding SR2, is deleted in GPBP $\Delta 26 / C E R T$. C-terminal steroidogenic acute regulatory protein related lipid transfer domain (START). Molecular transfer model of ceramide from ER to the trans-Golgi region by CERT mediated pathway and by vesicular-dependent minor pathway.

GPBP $\triangle 26 / C E R T$ interaction and, consequently, the GPBP $\triangle 26 / C E R T$ mediated ER to Golgi transport of ceramide in cells (Kawano et al., 2006). The carboxyl terminal of 230 aa is a START (steroidogenic acute regulatory 
protein-related lipid transfer) domain. This is a structural region that forms a deep lipid-binding pocket that can extract ceramide from membranes and transfer the bound ceramide to other membranes (Alpy and Tomasetto, 2005; Tsujishita and Hurley, 2000). GPBPs can transfer natural ceramide isoforms (C16-dihydroceramide, C16-phytoceramide) and various ceramide molecular species having C14-C20 amide-acyl chains (Kumagai et al., 2005). However, GPBPs can not extract any other lipid type such as sphingosine, sphingomyelin (SM), phosphatidilcholine (PC) or cholesterol (Hanada et al., 2003).

GPBPs receives multiple phosphorylations at a serine repeat motif (SR1) that is also present in the GPBP $\triangle 26 /$ CERT isoform and is located after the PH domain (Kumagai et al., 2007). The hyperphosphorylation at the SR1 domain down regulates the ER to Golgi transport by repressing the PI4P binding ability of the PH domain and the ceramide transfer activity of the START domain (Kumagai et al., 2007).

Loss of SM and cholesterol from the plasma membrane induces the dephosphorylation of the SR1 motif to activate GPBP $\Delta 26 / C E R T$ to target both the ER and the Golgi membranes (Kumagai et al., 2007). However, further studies are needed to elucidate how SM/cholesterol rafts affect the phosphorylation of GPBP $\triangle 26 / C E R T$. The serine rich domain consisting of 26 aa (SR2) located before the START domain is only present in the GPBP/CERT isoform and constitutes the crucial site that differentiates the two isoproteins (Raya et al., 2000).

\section{One gene, two splicing variants, many isoproteins}

The human gene encoding GPBPs, COL4A3BP, is located in chromosomal $5 q 13.3$ region and consists of 17 exons. The controversy over GPBP isoforms undoubtedly reflects the complex arrangement of this gene: its mRNA undergoes alternative processing either of exon splicing or rare protein translation initiation, giving rise to multiple proteins (Fig. 3).

GPBP/CERT $T_{L}$ and GPBP $\triangle 26 / C E R T$ which are derived from alternative splicing as mentioned above, exist in turn as different isoforms resulting from the use of two translation initiation codons: the classical AUG codon and the rare in frame ACG codon located upstream (-83) of the known AUG start (Revert et al., 2008). We will refer to the additional GPBP/CERT $T_{L}$ isoprotein resulting from ACG translation initiation as GPBP/CERT $\Sigma 128$, since 128 additional amino acids are present at the amino terminus of the protein. It is not yet known if also the GPBP 26 /CERT mRNA is subject to the alternative translation initiation.

A small number of mammalian mRNAs initiate translation from a non-AUG 

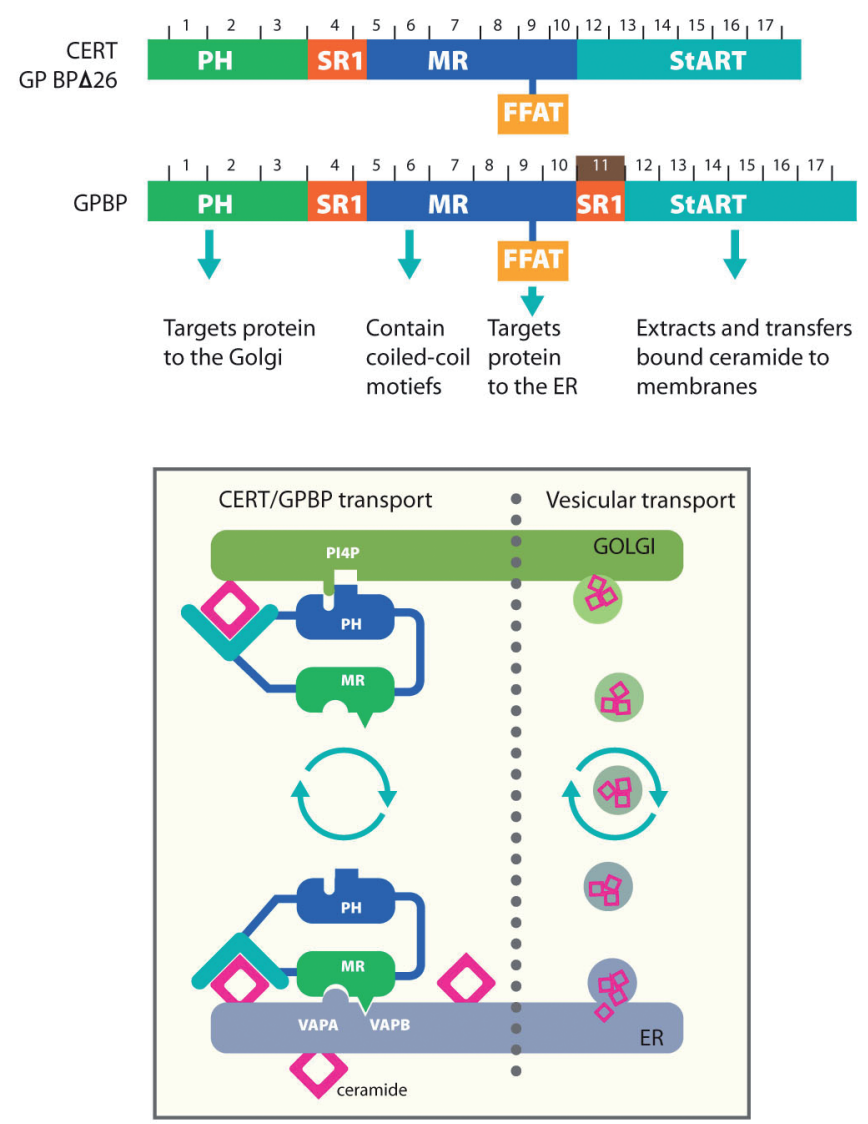

Figure $3 \mathrm{GPBP} / \mathrm{CERT}_{\mathrm{L}}$ is expressed as multiple isoforms because of an alternative translation initiation. GPBP mRNA, in addition to the traditional initiation codon, has a non-canonical translation initiation site (ACG) located upstream of the known AUG. These conventional and alternative start sites result, respectively, in the synthesis of two polypeptides of 77 and $91 \mathrm{kDa}$, harboring different amino terminal domains that confer distinct functions to the isoforms and control their localizations. The GPBP/CERT $91 \mathrm{kDa}$ product (GPBPS128) partly enters the secretory pathway where undergoes covalent modifications to yield a $120 \mathrm{kDa}$ polypeptide. Similarly, GPBP $\Delta 26 / \mathrm{CERT}$ possibly exists as different isoforms resulting from canonical $(77 \mathrm{kDa}$ ) and non-canonical (91 kDa and $120 \mathrm{kDa}) \mathrm{mRNA}$ translation initiation. Western blot analysis for GPBP proteins (modified from Mencarelli et al. 2009) in rat cortical extract shows the presence of high molecular weight isoforms together with other lower molecular bands products previously described, probably generated from the proteolysis of the higher molecular weight isoforms.

codon, in addition to initiating at a downstream in-frame AUG codon. Such mRNAs encode regulatory proteins such as proto-oncogenes, transcription factors, kinases, or growth factors. Their translation initiation results in the synthesis of proteins harbouring different amino terminal domains potentially conferring on these isoforms distinct functions (Touriol et al., 2003). 
GPBP/CERT $T_{L}$ alternative initiation codons generate two primary polypeptides of 77 and $91 \mathrm{kDa}$, respectively (Fig. 3), leading to the synthesis of two protein isoforms with differential transcriptional activities and different sub-cellular localizations as has been described previously for proteins of the c-myc, FGF and VEFG families (Meiron et al., 2001; Prats et al., 1989; Touriol et al., 2003). The 77 kDa polypeptide, resulting from canonical translation, is secreted extracellularly. It is soluble and interacts with type IV collagen in the extracellular matrix. The 26-residue Ser-rich region is critical for GPBP/CERT secretion (Revert et al., 2008) and the FFAT domain is essential for GPBP/CERT $T_{L}$ to enter the secretory pathway (Revert et al., 2008).

The GPBP/CERT $\Sigma 128$ isoform resulting in the $91 \mathrm{kDa}$ isoprotein remains associated to membranes and it has been suggested that it regulates the secretion of $77 \mathrm{kDa}$ GPBP/CERT (Revert et al., 2008).

GPBP/CERT $L 128$ enters the secretory pathway where it undergoes covalent modifications to yield a $120 \mathrm{kDa}$ polypeptide. However the type(s) of posttranslational modification(s) that this isoform harbors is not yet known. In eukaryotes the existence of bifunctional genes where a single transcript serves as the template for synthesis of both a cytoplasmic isoform and a mitochondrial isoform has also been postulated (Wang et al., 2003). Each of these genes encodes mRNAs with distinct 5-ends which are generated from two alternative in-frame initiation codons. Interestingly, the mitochondrial forms can be translated from non-AUG codons on the long mRNA, whereas the cytosolic forms are translated from the second in-frame AUG on the short mRNA. As a consequence, the mitochondrial enzymes have the same polypeptide sequences as their cytosolic counterparts, except for a short amino-terminal mitochondrial targeting sequence (Chen et al., 2009; Tang et al., 2004). Although so far no direct evidence has been obtained to verify this hypothesis, recent discoveries indicated a possible role of GPBPs in mitochondrial function (Wang et al., 2009). So far only a cytoplasmic $77 \mathrm{kDa}$ iosform of GPBP $\triangle 26 / C E R T$ has been described; however it is possible that also alternative translation initiation isoforms with the amino acids encoded by exon 11 exist.

\section{A busy gene promoter}

COLAA3BP has been found to localize head-to-head with POLK, the gene encoding DNA polymerase $\mathrm{k}$ (Pol K) (Granero et al., 2005). Thus, the promoters of $C O L 4 A 3 B P$ and Pol $\mathrm{K}$ are overlapping and bidirectional. Pol $\mathrm{K}$ is a DNA polymerase that enhances the frequency of spontaneous mutations and it plays a role in repairing DNA damage by facilitating base pairing at 
aberrant replication forks (Ohashi et al., 2000; Zhang et al., 2000). These mutations are important when they are introduced into the immunoglobulin genes of $B$ cells, because they lead to a variety of mutant antibodies with can be selected for high affinity binding to antigens (Faili et al., 2004). This specific arrangement suggests the possibility that Pol K and GPBPs are partners in specific cell programs. An augmented expression of both COLAA3BP and POLK has been found in patients suffering from skin autoimmune processes (Granero et al., 2005; Raya et al., 2000).

The bidirectional POLK/COLAABBP promoter can be activated at three different regulatory elements; an Sp1 site, a TATA-like sequence and a nuclear factor kappa B (NFkB)-like site. When Sp1 and NFkB form a complex containing predominantly Sp1 compared to NFkB, the transcription is more efficient in the $P O L K$ direction. It was shown that tumor necrosis factor (TNF) induced the transcription of this promoter in the COLAA3BP direction (Granero et al., 2005). TNF is a crucial pro-inflammatory cytokine mediating many aspects of immunity (McCoy and Tansey, 2008). Thus the interaction of TNF with the promoter of COL4A3BP might explain the increased expression of GPBPs found in several autoimmune disorders. COL4A3BP promoter activation by other cytokines has not been reported to our knowledge.

\section{Functional differences between GPBP/CERTL and CERT/GPBP $\Delta 26$}

Despite the similarity of GPBP/CERT and CERT/GPBP 26 with respect to their domain organization, several observations suggest important functional differences between these two splice variants.

Both GPBP/CERT $T_{\mathrm{L}}$ and CERT/GPBP $\triangle 26$ exist as oligomers under native conditions: they self-associate in vivo to form high molecular weight aggregates mainly stabilized by non-covalent bonds. The presence of the 26residue-serine rich motif in GPBP/CERT increases this interaction and the specific kinase activity. Moreover, it allows GPBP/CERT $T_{L}$ to be secreted extracellularly where it exists as a soluble form (Revert et al., 2008). GPBP/CERT $T_{L}$ is able to bind collagen type IV with high affinity, in contrast to GPBP $\triangle 26 / C E R T$ which has low-affinity binding to collagen (Raya et al., 2000). It was demonstrated that GPBP/CERT $T_{L}$ is a non-conventional serine/threonin kinase active towards extracellular matrix proteins that might contribute to their proper organization and supramolecular assembly.

GPBP $\triangle 26 / C E R T$ is the most common transcript in cells and widely expressed in normal human tissues, whereas GPBP/CERT $T_{L}$ shows preferential expression in brain, skeletal muscle and heart. Moreover, GPBP/CERT $T_{L}$ is expressed in tissues targeted by autoimmune responses including human 
alveolar and glomerular basement membrane, the biliary ducts and the Langerhans islets (Raya et al., 2000). Overexpression of GPBP/CERT in mice causes dissociation of the glomerular basement membrane and subsequent accumulation of IgA in the absence of an evident autoimmune response (Revert et al., 2007).

Both isoforms can mediate ceramide transfer from the ER to the Golgi complex (Hanada et al., 2003), a process critical for the synthesis and maintenance of normal levels of sphingolipids in mammalian cells. However the question remains if GPBP/CERT is able to transport ceramide to other subcellular localizations including the extracellular milieu and if the function as a ceramide transporter is related to collagen interaction.

Various animal models have clearly pointed the different role of the two splicing variants. In zebrafish GPBP/CERT $T_{L}$ is mostly expressed at early stages of embryogenesis compared to GPBP $\triangle 26 / C E R T$, and its knockdown selectively induces apoptosis in muscle and brain during early development (Granero-Molto et al., 2008). In Drosophila only the GPBP $\Delta 26 / C E R T$ isoform is present (Fig. 3). Loss of functional GPBP $\triangle 26 /$ CERT in these flies resulted in changes in membrane properties and decreased physiological functions caused by increased oxidative stress. In contrast they did not develop neuronal degeneration in the brain and the aged phenotype that the animals show is not due to specific damage in the nervous system (Rao et al., 2007). Homologs of key enzymes belonging to the sphingolipid metabolic pathway have been discovered in Drosophila melanogaster, making this an optimal model to study the effects of dysregulation of sphingolipid metabolism on nervous system development, function and integrity. Therefore, the presumed lack of GPBP/CERT $T_{L}$ isoform here would indeed merit further investigation.

In rat brain GPBPs are widely distributed and have a higher expression levels in neurons compared to other cell types (Mencarelli et al., 2009). The presence of high levels of ceramide and its related metabolic enzymes in neurons throughout the brain might require a strong expression of its transporter. Which specific isoform is responsible for this generalized brain expression still remains to be investigated.

\section{GPBPs, FAPP2 and OSBP1: a structure in common}

The intense interest elicited by the lipid-transfer proteins over the last few years has been driven by the crucial role of lipids in cell, tissue and organ physiology as demonstrated by many human diseases that involve the disruption of lipid metabolism. Like GPBPs, other proteins with putative lipid 
transfer activity are potentially able to mediate lipid metabolic pathways and membrane trafficking events in the cell. Specifically, two of them share similar protein domain organizations with GPBPs: oxysterol-binding protein (OSBP) (Ridgway et al., 1992) and phosphatidylinositol four-phosphateadaptor protein 2 (FAPP2) (Godi et al., 2004) which are both characterized by a highly homologous N-terminal plecktrin homology $(\mathrm{PH})$ domain that binds PI4P at the Golgi complex. Beside the PH domain, they also have a distinct lipid binding/transfer domain at their C-terminus (Fig. 4).

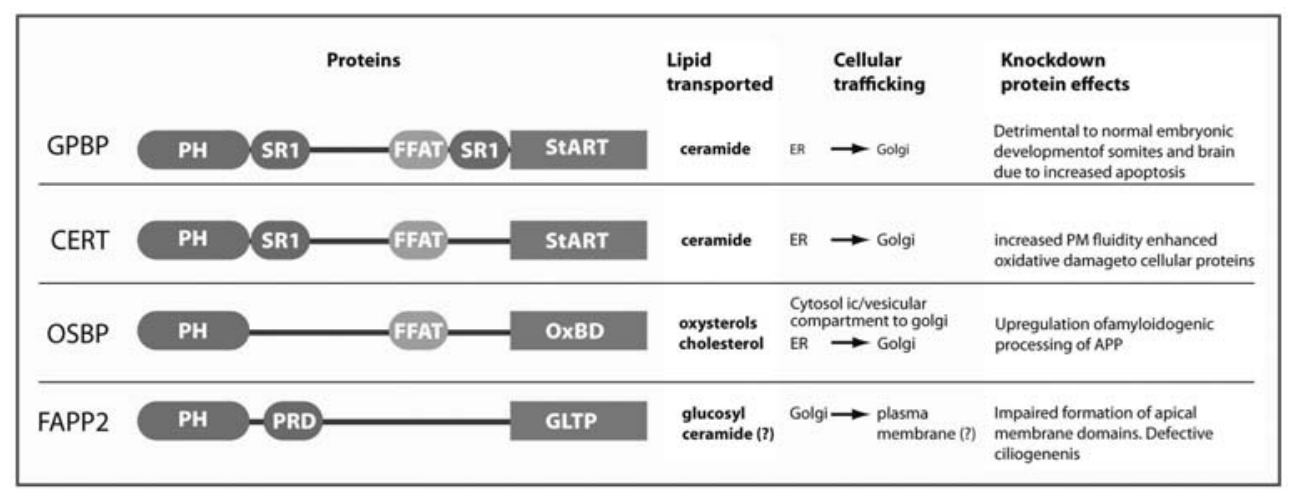

Figure 4 Domain organization of lipid binding/transfer proteins GPBPs, OSBP1 and FAPP2. PH (pleckstrine homology domain), SR1/SR2 (serine rich domain), PRD (proline rich domain), FFAT (two phenylalanine in an acidic tract), GLTP (glycolipid transfer protein domain), START (StART related lipid transfer domain), OSBP (oxysterol binding domain)

OSBP1 is a member of a family of sterol-binding proteins with roles in lipid metabolism, regulation of secretory vesicle generation and signal transduction (Lagace et al., 1997; Lagace et al., 1999). It is an 807 aa protein that comprises, besides an N-terminal PH domain, a FFAT motif that binds the integral ER membrane proteins VAP-A and VAP-B, and an oxysterolbinding domain (OxBD). The other members of the family are referred to as OSBP-related proteins (ORPs), with a highly conserved OSBP-type sterolbinding domain at the C-terminus (Lehto and Olkkonen, 2003), each subject to tissue-specific transcriptional regulation (Lehto et al., 2001).

OSBP1 acts at the interface between the ER and the Golgi complex and could be a mammalian sterol-transfer protein (Ridgway et al., 1992). Consistent with the high cholesterol content of the brain, OSBP1 and many other ORPs are highly expressed in the CNS (Laitinen et al., 1999).

FAPP2 is a 507aa protein, with an N-terminal PH domain, a proline rich domain (PRD) and a glycolipid-transfer-protein (GLTP) homology domain at its C-terminus. The presence of this GLTP domain raises the interesting 
possibility that FAPP2 itself is a glucosylceramide (GlcCer) transporter towards appropriate sites for the synthesis of complex glycosphingolipids (GSLs) (D'Angelo et al., 2007). GSLs constitute a major component of neuronal cells and are thought to be essential for brain function, as GSL deficiency has been shown to lead to a down-regulation of gene expression sets involved in brain development and homeostasis. This trafficking function of FAPP2 indicates a crucial role for this protein in determining the lipid composition of the neuronal plasma membrane.

Considering that these proteins have similar binding partners at the Golgi apparatus (the PI4P through their PH domain) and at the ER (VAPs through FFAT domain of GPBPA26/CERT and OSBP1), a probable cross-interaction between them is possible.

According to this, it has been shown that OSBP1 can regulate sphingomyelin synthesis by interacting with GPBP 26 /CERT, promoting its binding with VAPs and consequently enhancing GPBP $\triangle 26 /$ CERT-dependent ceramide transport to the Golgi complex (Perry and Ridgway, 2006). A mutant of OSBP1 was found to limit transport of a fluorescent ceramide analogue to sites in the ER, suggesting that the function of OSBP1 involves the transport of ceramide from ER to the Golgi sites where sphingomyelin synthase is active (Wyles et al., 2002). The shift of OSBP1 to a Golgi location upon $250 \mathrm{H}$ (hydroxycholesterol) treatment of cells coincides with Golgi translocation and activation of GPBP $\triangle 26 /$ CERT (Perry and Ridgway, 2006). Thus, localization of GPBP $\triangle 26 /$ CERT at the Golgi apparatus seems to be OSBPdependent and correlated with increased SM synthesis and ceramide transport (Perry and Ridgway, 2006). Taken together these observations suggest that OSBP1 acts as a sterol sensor whose function is to integrate, possibly via regulation of GPBP $\Delta 26 / C E R T$ function, the cellular sterol status with sphingomyelin metabolism (Olkkonen et al., 2006).

\section{A pleiotropic ceramide}

Ceramide is a precursor for the biosynthesis of all complex sphingolipids, as it is a product of their degradation. It is composed of an N-acylated (14 to 26 carbons) sphingosine (18 carbons). It has been suggested that ceramide and other sphingolipids found in the phospholipid bilayer membranes are not only building blocks that confer structural rigidity by virtue of their ability to form strong hydrogen bonds (Zhang et al., 2009). Besides their structural role, sphingolipids participate in a variety of activities in diverse cellular and developmental events and they seem to act as lipid second messengers involved in many biological events spanning from cell growth (Jayadev and Hannun, 1996; Schwarz and Futerman, 1997; Spiegel and Merrill, 1996), 
apoptosis (Bose et al., 1995; Gulbins et al., 1995; Haimovitz-Friedman et al., 1997; Hannun and Obeid, 1995), lifespan (Cutler and Mattson, 2001; Hannun, 1996; Wang et al., 1999), and vesicular trafficking to neuronal differentiation and functioning (Bieberich et al., 2001; Toman et al., 2000). Moreover, data in the fields of immunology, endocrinology and neurobiology also suggest a fundamental involvement of ceramide in the onset of several diseases (Mathias et al., 1998; Merrill et al., 1997; Pandey et al., 2007; Venable et al., 1995). These aspects will be discussed more extensively later on.

Ceramide production can occur in different ways: de novo synthesis by a synthase, sphingomyelin-(SM) hydrolysis by various sphingomyelinases (SMases) or recycling of sphingolipids by different hydrolases (Perry and Hannun, 1998). Enzymes involved in each of these ceramide generation pathways are located in distinct subcellular compartments. Since ceramide is very hydrophobic compared to other lipid species, its concentrations in the cytosol are extremely low and its molecule is usually trapped in the membrane where it is formed (Venkataraman and Futerman, 2000). This hydrophobicity tends to isolate pools of ceramide in different subcellular compartments. It has been proposed that the compartmentalization of ceramide might have regulatory functions in the cell (Bionda et al., 2004; Kolesnick et al., 2000; Liu and Anderson, 1995). The discovery of ceramidase enzymes in most of the organelles (ER, Golgi, mitochondria, lisosome and plasma membrane) (El Bawab et al., 2000; Li et al., 1999; Mao et al., 2003; Tani et al., 2005; Xu et al., 2006) support this view. To better understand the involvement of GPBPs in cellular biology it is important to review all the different ways of ceramide production inside the cell.

\section{De novo synthesis of ceramide}

De novo synthesis of ceramide requires coordinate action of different enzymes along a subsequent series of reactions which occur both at the cytosolic surface of the ER (Perry and Hannun, 1998) (Fig. 5 (1)) and in the mitochondrial outer and inner membranes (Fig. 5 (1)) (Bionda et al., 2004; Shimeno et al., 1998). The de novo ceramide biosynthesis, which starts with the condensation of a serine and a fatty acyl-coA, involves the key enzyme ceramide synthase (Ichikawa et al., 1996) which catalyzes the acylation of either sphinganine to form dihydroceramide or sphingosine to form ceramide. In mammals ceramide synthase, in contrast to the rest of the enzymes of sphingolipid metabolism, exists as a family of multiple isoforms, six in humans and mice and each isoform exhibits varying substrate selectivity and cell specificity (Venkataraman and Futerman, 2000). This 
pathway needs several hours to generate detectable amounts of ceramide (Bose et al., 1995). Once formed, ceramide is delivered to the luminal surface of the Golgi membrane for sphingomyelin and glycosphingolipid synthesis (Fukasawa et al., 1999; Kumagai et al., 2005). There are at least two pathways by which ceramide is transported from the ER to the Golgi compartment: an ATP and cytosol dependent major pathway (non vesicular, GPBP $\Delta 26 / C E R T$ mediated) (Hanada et al., 2003) and an ATP or cytosol independent minor pathway (vesicular transport) (Brugger et al., 2000). Once in the Golgi apparatus, ceramide can serve as a precursor for glycosphingolipids or it can be converted to sphingomyelin (SM) by SM synthase 1 (SMS), that is localized in the trans Golgi region (Fig. 5 (2)) and catalyzes the transfer of phospatidylcholine to ceramide to produce SM (Yamaoka et al., 2004).

The downregulation of CERT by RNA interference resulted in a significant but incomplete reduction of basal SM synthesis but it has no effect on glycosphingolipid synthesis (Hanada et al., 2003; Huitema et al., 2004). Ceramide destined for the formation of SM reaches the Golgi by an ATPdependent, vesicle-independent transport pathway mediated by GPBP $\triangle 26 / C E R T$ and a minor ATP-independent transport vesicular pathway (Fukasawa et al., 1999; Funakoshi et al., 2000; Hanada et al., 2003; van Meer and Holthuis, 2000). On the other hand ceramide destined for conversion to glucosylceramide (GlcCer) (Fig. 5 (3)) appears to reach the Golgi only by vesicular transport (Huwiler et al., 2000). This suggests separate ceramide transport pathways for GlcCer and SM synthesis. GlcCer synthase has been detected in both the ER and Golgi compartments (Schweizer et al., 1994); therefore the synthesis of GlcCer may not depend exclusively on the ER-toGolgi transport of ceramide. In this regard it is noteworthy that GPBP $\triangle 26 / C E R T$ transfer activity varies according to the acyl chain lengths of the ceramides. It preferentially transfers $\mathbf{C} 16-18$ ceramides rather than longer ceramides (Kumagai et al., 2005). This correlates with the presence of a C16-18 acyl chain SM in many tissues and cell lines. Through vesicular transport, SM and glycosphingolipids reach the plasma membrane where resides the enzyme SMS2 (Fig. 5 (4)), required for SM homeostasis regulation of the intracellular levels of ceramide in plasma membranes (Huitema et al., 2004).

From there, these lipids travel towards the outer, non-cytosolic surface of the plasma membrane and all membranes of the endocytic system, where they are eventually degraded. 


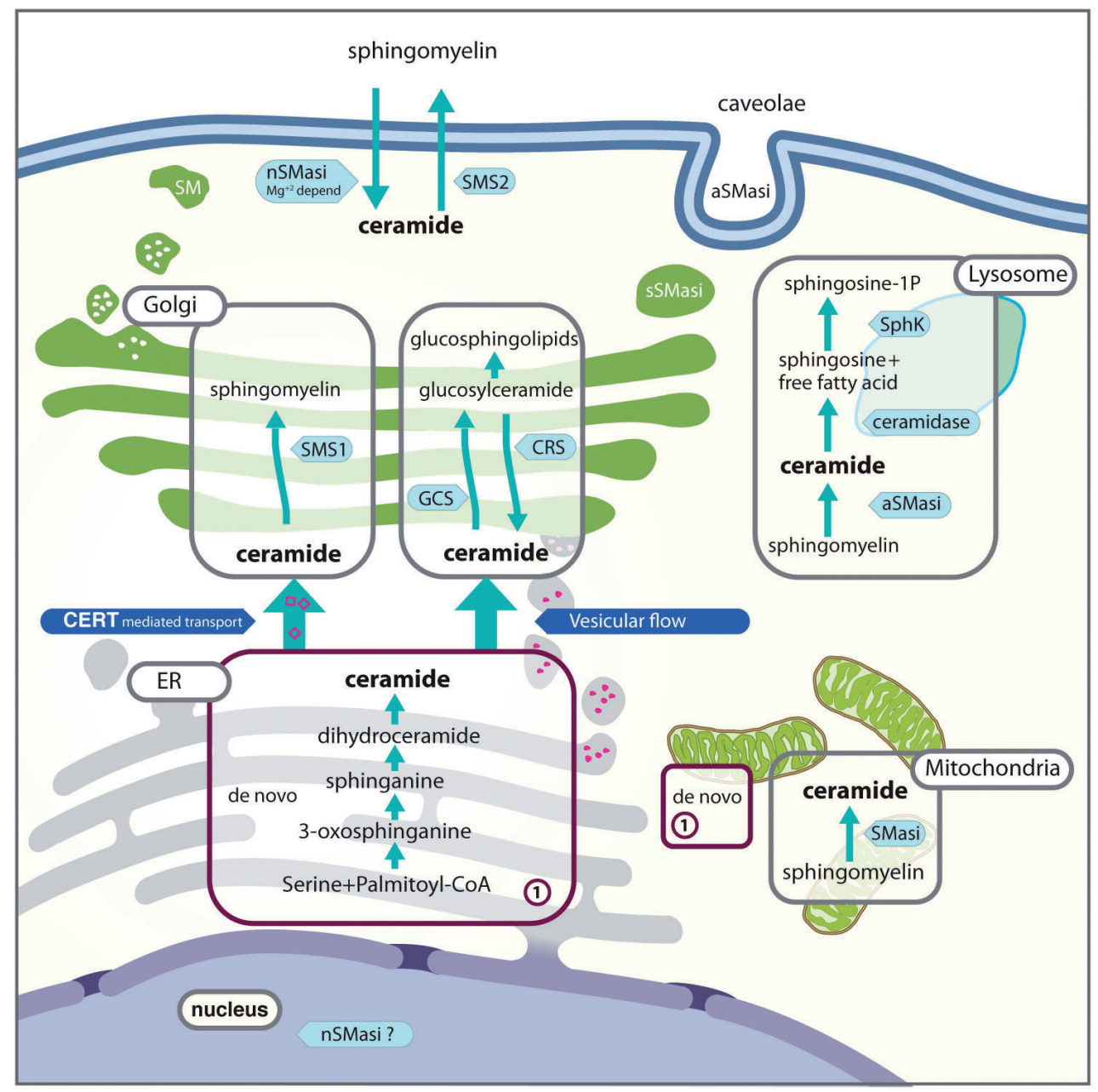

Figure 5 Ceramide can be generated by the activity of two general metabolic pathways. (i) The anabolic pathway that occurs at the cytosolic surface of the ER from condensation of serine with acyl CoA and acylation of the sphingoid base [de novo synthesis (1)]; once formed, ceramide is delivered to the luminal side of the Golgi apparatus and converted to sphingomyelin by SMS1 (2) that catalyzes the transfer of phosphocholine involving the hydrolysis of phosphotidylcholine (PPC) to diacylglycerol (DAG); ceramide is also converted to glycosylceramide by (GlcCer) glucosylceramide synthase (GCS) (3). GlcCer is further converted to more complex glycosphingolipids. There are separate ceramide transporters for the SM and GlcCer synthesis, GPBPs for the former and vesicular flow for the latter. (ii) The catabolic pathway, that takes place at the membrane of different organelles in which ceramide is formed by the degradation of sphingomyelin by different sphingomyelinases (SMases) $(4,5)$. Ceramide is also formed by the degradation of glycosphingolipids that occur in lysosome compartments: hydrolisis of ceramide by ceramidases releases sphingosine, which can be further converted to sphingosine1-phosphate by sphingosine kinase (Sphk) (5). Metabolism of cerebrosides by cerebrosidase (CRS) also generates ceramide (6). Ceramide is also present in mitochondria where it is synthesized via de novo pathway and/or activity of the acid sphingomyelinase $(1,4)$. 


\section{Ceramide catabolic pathway}

In contrast to the multi-step de novo pathway, the catabolic pathway for ceramide generation involves the action of a single class of enzymes namely sphingomyelinases (SMases). These enzymes are homologues of phospholipase $\mathrm{C}$, which hydrolyses the phosphodiester bond of SM yielding ceramide and phosphocholine (Levade et al., 1986). Moreover, if the de novo synthesis is found in the ER and in the mitochondria, the sphingomyelin hydrolysis occurs in a variety of membranous systems (Levade and Jaffrezou, 1999).

Currently five different enzymes have been identified and categorized in acid, neutral and alkaline SMases that differ in catalytic properties, subcellular localization, biological effects and probably in their mode of regulation (Huwiler et al., 2000).

Acidic SMase (A-SMase) (Fig. 5 (5)) was the first sphingomyelin-hydrolysing enzyme to be purified and it was originally described as an endosomal/lysosomal hydrolase $(\mathrm{pH} 4.5-5)$ required for the turnover of cellular membranes (Gatt et al., 1966). Sphingolipids, that reach lysosomes via caveolar and or clathrin-dependent endocytosis, are mainly catabolised within these organelles.

Impaired sphingolipid degradation, besides affecting a large variety of cellular processes, has drastic effects on the nervous system, leading to neurodegeneration, shortened lifespan and early death. In line with this, several lipid storage disorders are associated with significant progressive brain degeneration, as discussed below.

\section{Ceramide and GPBPs in mitochondria}

Mitochondria contain ceramide with a three-fold higher concentration in the outer membranes than the inner membranes (Ardail et al., 2001). These organelles also contain the enzymes responsible for the synthesis (Shimeno et al., 1998) and hydrolysis of ceramide (El Bawab et al., 2000). The synthesis of ceramide occurs in the mitochondrial outer and inner membranes (Fig. 5 (1 and 4)) (Bionda et al., 2004). Thus mitochondria have mechanisms for regulating the level of ceramide. Importantly, mitochondrial ceramide levels have been shown to be elevated prior to the induction phase of apoptosis (Birbes et al., 2005; Rodriguez-Lafrasse et al., 2001; Siskind, 2005; Thomas et al., 1999). In fact, many death signals, including TNF- $\alpha$, influence mitochondria function through the activation of pro-apoptotic members of the Bcl-2 family (Gross et al., 1998).

TNF treatment of cells resulted in increased mitochondrial ceramide levels 
that were associated with Bax translocation to mitochondria (Birbes et al., 2005). Interestingly TNF is also able to increase the mRNA levels of GPBPs (Granero et al., 2005).

It is important to mention that most of the experiments with cells and isolated mitochondria have been carried out using short chain permeable ceramides in which an acetyl or hexanoyl group replaces the natural longchain fatty acid (C2- and C6-ceramide). Ceramides have been reported to have numerous effects on mitochondria, including the inhibition and/or activation of the activities of various components of the mitochondrial electron transport chain (Gudz et al., 1997; Siskind and Colombini, 2000), the enhanced generation of reactive oxygen species (Zamzami et al., 1995) and release of intermembrane space proteins (Ghafourifar et al., 1999), probably by forming large protein permeable channels in planar phospholipid and mitochondrial outer membranes (Siskind, 2005).

For GPBPs also a function in mitochondria integrity has been described: mice lacking both GPBP/CERT $T_{L}$ and GPBP $\triangle 26 / C E R T$ die early in embryogenesis as a result of structural and functional defects not only in the ER but also in the mitochondria: both organelles show proliferation, vesiculation and engorgement appearing aberrant with gross structural changes and functional defects (Wang et al., 2009). The impact of deficient ceramide transporters on mitochondrium integrity and functioning is a surprising finding. These results point to GPBPs as important effectors for mitochondrial homeostasis. They could exert their action in principally two different, albeit interconnected, mechanisms: either transferring directly ceramide outside the mitochondrium or shuttling this hydrophobic lipid within its complex structure. In both views the loss of GPBPs could lead to the detected changes in the physiological state of this organelle. The doublemembrane system divides the mitochondrium in two aqueous compartments, the intermembrane space and the matrix. Due to the highly insoluble nature of ceramide, there is a large energy barrier inhibiting the movement of the molecule in these compartments that could give an explanation for the presence of the ceramide transporters (Goni and Alonso, 2006; Small, 1970; Sot et al., 2005). Ceramide and its related enzymes could presumably affect membrane dynamics and contribute to crista reorganization (Montes et al., 2002; Scorrano et al., 2002; Veiga et al., 1999). Mitochondrial membrane reassembly is required to control many metabolic processes. Maintenance of normal crista structure is essential for mitochondrial function (Mannella, 2006). Generation of the characteristic cristae appearance has been linked to the conduction of protons that 
participate indirectly in ATP synthesis in mitochondrial respiration (Arnoult et al., 2005; Paumard et al., 2002). In all these dynamic events GPBPs could quickly redistribute ceramide.

The lack of CERT/GPBP $\Delta 26$ in Drosophila, which as aforementioned does not have the CERT/GPBP $\mathrm{L}$ isoform, affects plasma membrane fluidity and initiates oxidative stress. Flies are viable and fertile even though they die prematurely as a result of accelerated aging (Rao et al., 2007). The impact of GPBPs knock-out on mouse embryos causes a series of pathological changes in ER and mitochondria. This different development in mice supports the idea that it is the lack of the GPBP/CERT isoform which is responsible for this phenotype rather than CERT/GPBP $\triangle 26$ which is mostly involved in the transfer of lipids in different intracellular compartments to ensure correct lipid synthesis and distribution (Hanada et al., 2007).

$\mathrm{CHO}$ cells (Ly-A) which carry a missense mutation in the PH domain of CERT/GPBP $\triangle 26$ do not show mitochondrial defects but only impairment of SM synthesis (Funakoshi et al., 2000) since the latter is strictly dependent on CERT transport of ceramide (Hanada et al., 2003). So it is intriguing to speculate that as these cells do not have mitochondrial impairments, maybe the GPBPs isoforms related to mitochondria do not need the PH domain to be functional in these specific organelles. This would also explain why GPBPs are expressed as different isoforms (Revert et al., 2008).

These studies suggest intimate and direct connections between ceramide, GPBPs and mitochondria. Interestingly, tissues that show a higher expression of GPBP/CERT $T_{L}$ are brain, muscle and testis, organs that are by definition highly dependent on aerobic metabolism. The CNS has an immense metabolic demand because neurons are highly differentiated cells that need large amounts of ATP for maintenance of ionic gradients across the cell membranes and for neurotransmission (Kann and Kovacs, 2007). Since most neuronal ATP is generated by oxidative metabolism, neurons critically depend on mitochondrial function and oxygen supply (Kann and Kovacs, 2007). In concordance with this neurons contain high levels of GPBPs (Mencarelli et al., 2009).

\section{Ceramide and GPBPs in the central nervous system}

Among the tissues of the body, the nervous system is one of the richest in lipid content. Sphingolipids and other complex glycosphingolipids are highly represented in the brain where they were first discovered more than a century ago by J. L. W. Thudichum (1884) (van Echten-Deckert and Herget, 2006). They do not only have a structural function but they act as important 
molecular tools in regulating multiple biochemical cell activities (Hannun and Obeid, 2002; Radin, 2003; Tepper et al., 1999).

Ceramide has been implicated as a prominent mediator in a remarkable array of cellular processes through a variety of complex pathways induced by numerous agonists and environmental stimuli. Neurons, as might be expected, share with other cell types the same wide range of responses mediated by this pleiotropic lipid.

The nervous system comprises many events of morphological and biochemical changes during the entire adult life. Generation, shaping and reshaping of the complex spatial organization, neuronal and glia differentiation, processes of synaptogenesis and neuritogenesis are typical phenomena characterizing the nervous system (Nieto-Sampedro and NietoDiaz, 2005). In all these regulated events, of primary importance is the membrane lipid composition which determines cell surface properties (Simons and Ehehalt, 2002). Ceramide modulates membrane structure and dynamics, associates with cholesterol and other sphingolipids and forms microdomains called lipid rafts. In neurons, lipid rafts accumulate preferentially on somal and axonal membranes and in the post-synaptic sites (Suzuki, 2002). Lipid rafts play an important role in neuronal adhesion and in the modulation of neuronal ion channels, neurotransmitter receptors and in neurotransmitter release (Chamberlain et al., 2001).

Besides its structural role, ceramide involvement in cellular signaling has been extensively studied in the CNS and it has become clear that ceramide content and its spatial/temporal distribution change to some extent during aging, neuronal survival and apoptosis. Interestingly, information is beginning to emerge pointing to ceramide levels as triggers of neural development, differentiation, rate of growth and other cellular physiological events.

In neurons an increase in ceramide level, originating from neosynthesis and/or SM degradation, inhibits their proliferation and concomitantly induces differentiation (Riboni et al., 1995). In glioma cells, elevated ceramide levels cause growth arrest and process formation (Dobrowsky et al., 1994). The raised intracellular ceramide levels occur very early and persist during the differentiation of the cell. Normal ceramide levels are reestablished after cell differentiation indicating a key role for ceramide in this process (Riboni et al., 1995).

While ceramide stimulates cell differentiation in unspecialized cells, in postmitotic neurons ceramide acts preferentially by accelerating the transition of neuronal development stages. 
Maturation of cultured granule neurons is associated with an increase of ceramide levels in sphingolipid rich domains (Prinetti et al., 2001) and ceramide seems to be essential for cell axon and dendritic growth of neurons. Ceramide signaling in hippocampal neurons in culture elicits the early transition of a rounded cell lacking neurites towards one exhibiting small extended lamellopodia and minor processes (Brann et al., 1999). Ceramide is also required for the subsequent axonal elongation of neurons in order to acquire the normal mature phenotype (Brann et al., 1999; Ledesma et al., 1999; Mitoma et al., 1999). This effect of ceramide is dosedependent; lower concentrations of the lipid stimulate cellular growth whereas higher concentrations induce cell death (Furuya et al., 1998; Irie and Hirabayashi, 1998). However, ceramide synthesized de novo is not involved in axonal outgrowth since the development of hippocampal neurons is not altered by treatment with fumonisin B1, an inhibitor of the ceramide de novo synthesis. In contrast, the ceramide responsible for neuronal development is generated via a neutral-SMase ( $\mathrm{N}$-SMase) in response to nerve growth factor (NGF) (Brann et al., 1999), a member of the neurotrophin family that controls the development of the nervous system in the embryo and the maintenance of nervous tissue and neural transmission in the adult (Levi-Montalcini, 1987). The binding of the NGF to the p75 receptor induces N-SMase activation (Brann et al., 1999). N-SMase is the major form of SMase found in the brain and its expression increases in rat brain with neuronal maturation (Spence and Burgess, 1978). A-SMase (reviewed in section "Ceramide catabolic pathway") is highly expressed in brain cells but its expression level does not change significantly during development (Spence and Burgess, 1978). A-SMase activation appears to mediate signaling pathways that induce programmed cell death. Many studies have presented evidence of ceramide production via A-SMase in response to apoptotic signals, most notably generated by members of the NGF/tumor necrosis factor receptor family (Kronke, 1999; Verheij et al., 1996). A-SMase-deficient mice mimic the lethal, neurovisceral form of the human sphingomyelin storage disease, known as Niemann-Pick disease (Otterbach and Stoffel, 1995) (review in the next section).

Excitotoxic cell death, induced after an intense exposure of the neuronal cell to glutamate or related excitatory amino acids (Choi, 1992), is partially abolished in A-SMase-deficient neurons. On the other hand, A-SMasedeficient and wild type neurons are both susceptible to NGF induced apoptosis (Furuya et al., 1998; Irie and Hirabayashi, 1998). It has been suggested that $\mathrm{N}$-SMase responds also to high ceramide levels inducing 
neuronal death rather than accelerating axonal outgrowth (Brann et al., 2002).

The fate of the cell seems to depend exclusively on intracellular ceramide levels (Brann et al., 1999). Interestingly, in immature neurons apoptosis is induced even at lower doses of ceramide than in mature neurons (Furuya et al., 1998; Mitoma et al., 1998). Probably, at certain levels and depending on developmental stages, ceramide reaches a threshold required for an apoptotic response.

Experimental manipulations that increase intracellular ceramide level (e.g. exposure to exogenous ceramide analogs or treatment with bacterial SMases) potently induce apoptosis in differentiating mammalian cells (Hannun and Obeid, 1995).

There is good evidence that ceramide synthesized de novo also plays an important role in neuronal death with the same apoptotic features as ceramide generated from SM. Indeed, the inhibition of the de novo biosynthesis by fumonisin B1 stops apoptosis induced by DNA-damaging agents and TNF. A considerable amount of programmed cell death takes place in the nervous system during development. In neurodegenerative diseases neuronal death also occurs extensively. Neurons may use different apoptotic mechanisms during development or pathological conditions and ceramide metabolism seems to be a crucial target in both physiological death and disease. In summary, ceramides have both a structural and a signaling function in the brain. At present the potential role of ceramide metabolism points to questions yet to be addressed and more in depth studies of the ceramide transporters in the CNS will stimulate new avenues of research in this exciting area.

\section{Ceramide in neurodegenerative diseases}

A balance between specific sphingolipids is essential for neuronal function (Buccoliero and Futerman, 2003). When the sphingolipid metabolism is dysregulated as in Gaucher, Krabbe or Niemann-Pick disease, neurodegeneration occurs (Jeyakumar et al., 2002).

Gaucher disease (GD) is caused by mutations in the gene encoding for glucosylceramidase, an enzyme that catalyzes the hydrolytic cleavage of glucose from glucocerebrosides to form ceramides during lysosomal degradation of sphingolipids (Brady et al., 1965). Without glucosylceramidase, glucocerebroside and related lipids can build up to toxic levels within cells. Abnormal accumulation and storage of these lipids could affect calcium homeostasis and contribute to synuclein aggregation, 
neurodegenerative changes and neuronal loss (Manning-Bog et al., 2009; Pelled et al., 2005).

Krabbe disease is cause by a deficiency of the lysosomal enzyme galactosylceramidase, which is needed for the conversion of galactosylceramide to ceramide. The disease is characterized by myelin disorganization (Pastores, 2009) resulting from accumulation of incompletely metabolized galactosylceramide.

Niemann-Pick disease refers to a group of lipid storage disorders as well. In the $A$ and $B$ subtype SMase is deficient with the consequent accumulation of sphingomyelin (Brady et al., 1966). Type $C$ is characterized by excessive intracellular accumulation of unesterified cholesterol (Blanchette-Mackie et al., 1988). The subtypes of this disease have an extremely varied clinical presentation, but all are characterized by a range of progressive neurological manifestations (Futerman and van Meer, 2004).

In Farber disease, an increase in ceramide levels, resulting from ceramidase deficiency, leads to mental retardation and motor dysfunction (Bar et al., 2001). It is characterized by an accumulation of lipids and patients frequently die before the age of 2 years.

Beside genetic mutations that affect the functionality of the enzymes involved in the sphyngolipid metabolism, many stress signals can induce ceramide overproduction, like cytokines ( $T N F \alpha$, interleukin $1 \beta$, Fas ligand), nitric oxide (NO), and environmental stresses (UV/ionizing radiation, heat shock and oxidative stress) (Hannun, 1996; Hannun and Obeid, 1995; Jayadev et al., 1995; Venable et al., 1995; Verheij et al., 1996). Interestingly, all the pathways involved in ceramide generation participate in response to these agents (Fig. 5) (Hannun and Luberto, 2000; Kolesnick and Kronke, 1998). The precise nature of ceramide-intracellular targets is controversial and varies depending on the cell types.(Hannun, 1996; Kolesnick and Hannun, 1999; Okazaki et al., 1998; Pettus et al., 2002)

Many reports have emphasized the role of ceramide in neurodegenerative disorders to the extent that serum ceramides have been indicated as early predictors of cognitive impairment (Mielke et al., 2008). Alterations in ceramide levels were also detected in the cerebrospinal fluid of AD patients due to inhibition of the ceramide-metabolizing enzyme GlcCer synthase (Satoi et al., 2005). It has been found that AD brains contain approximately three fold more ceramide when compared to age matched controls (Cutler et al., 2004). Brain regions with extensive $\beta$-amyloid plaques (cortex and hippocampus) were characterized by higher ceramide levels and decreased SM content (Cutler et al., 2004) and the activity of the enzyme ceramidase 
was found to be elevated, perhaps in response to high ceramide concentration (Huang et al., 2004). A shift in sphingolipid metabolism towards upregulation of gene expression of the enzymes controlling de novo synthesis of ceramide and downregulation of the enzymes involved in glycosphingolipid synthesis was also evident in early stages of AD.

In vitro exposure of hippocampal neurons to $A \beta$ peptide induces membrane oxidative stress resulting in perturbed ceramide metabolism. Several studies have shown that $A \beta$ induces apoptosis via the SM/ceramide pathway in various brain cells including human and rat primary neurons (Jana and Pahan, 2004; Malaplate-Armand et al., 2006), rat oligodendrocytes (Cheng et al., 2003; Lee et al., 2004; Malaplate-Armand et al., 2006; Zeng et al., 2005), rat astrocytes and glial cells (Ayasolla et al., 2004) and murine neuroblastoma cells (Obeid et al., 1993; Satoi et al., 2005). The composition of lipid rafts including SM, cholesterol and ceramide controls amyloid processing and aggregation. It was shown that $\beta$ - and $\gamma$-cleavage of APP occurs inside rafts and both $\beta$ - and $\gamma$-secretase are lipid raft associated (Rajendran and Simons, 2005; Simons and Vaz, 2004; Vetrivel et al., 2004). The accumulation of $A \beta$ peptide derived from this process starts in early endosomes and has been shown to be subsequently released into the extracellular space in association with exosomes (Rajendran et al., 2006). Ceramide is highly enriched in exosomes and -possibly thanks to its cone-shaped structure- it regulates biogenesis and dynamics of membrane budding (Trajkovic et al., 2008). Whether ceramide per se also plays a role in mediating $A \beta$ aggregation/disaggregation remains unknown.

OSBP1, which regulates ceramide transport and SM synthesis, has been found to be involved in the regulation of amyloid precursor protein (APP) processing (Zerbinatti et al., 2008). Overexpression of OSBP1 downregulates the amyloidogenic processing of APP: the presence of OSBP1 at the Golgi complex triggers ceramide transporter activity leading to increased SM synthesis and consequently reducing ceramide levels. Knockdown of OSBP1 has the opposite effect, thus an increase of ceramide and reduced SM synthesis, leading to increased $A \beta$ production and aggregation (Zerbinatti et al., 2008). However, the role of OSBP1 in amyloid processing and regulation of ceramide levels is still under discussion.Together with the abovementioned processing of APP, also post translational refolding of normal prion protein is affected by the content of sphingomyelin, cholesterol and ceramide in lipid rafts at the level of the plasmatic membrane (Baron et al., 2002; Kivipelto et al., 2001; Simons et al., 2001; Taraboulos et al., 1995). If this is the case, abnormal composition of the lipid 
rafts could cause a defective protein folding and trigger consequently the protein aggregation process, a hallmark of many neurodegenerative diseases. Ceramides have also been implicated in the pathological death of neurons that occurs in Parkinson's disease (PD) (Brugg et al., 1996). Dopaminergic neurons in primary cultures derived from the mesencephalon, a primary region of neuronal degeneration in PD, undergo apoptosis through a ceramide-dependent mechanism (Brugg et al., 1996). TNF $\alpha$ receptors have been found on dopaminergic neurons that degenerate in PD and TNF $\alpha$-immunoreactive glia have been detected in close proximity to degenerating neurons (Boka et al., 1994). Importantly, TNF induces COLAA3BP expression by regulating the interaction of NFkB with the COL4A3BP promotor (Granero et al., 2005). NFkB has also been found to be augmented in the nucleus of dopaminergic neurons in parkinsonian patients. Thus, it is expected that the augmented levels of TNF and of NFkB will activate $C O L A A 3 P B$ leading to an increase in GPBPs levels. Higher levels of the ceramide transporter in this context might help to reduce the abnormal ceramide concentration and therefore attenuate downstream effects of ceramide. Moreover, some of the genes involved in the genetics of Lewy body disease are strictly linked to ceramide metabolism (for review, see (Bras et al., 2008)). In this regard it has been reported that a knockdown of the ceramide synthase LASS2 in Caenorhabditis elegans, results in increased alpha-synuclein inclusions (van Ham et al., 2008). Therefore, ceramide and its transporters could play a role in protein inclusions formation.

Moreover, Sidransky and colleagues found that heterozygous mutations that occur in the enzyme glucosylcerebrosidase predispose to PD (Aharon-Peretz et al., 2004; Bras et al., 2009) and Lewy body disorders (Mata et al., 2008) (Sidransky et al., 2009). Glucosylcerebrosidase is an enzyme that catalyzes the breakdown of the lipid glucosylcerebroside, which is highly enriched in the brain, to ceramide and glucose. This correlation between an increase of ceramide content and the onset of the disease reveals a strong association between ceramide metabolism and PD.

Cellular ceramide levels are also important in the regulation of cellular senescence (Venable et al., 1995). Endogenous levels of ceramide increase considerably if compared with other lipids as cells enter the senescence phase (Mouton and Venable, 2000) and exogenous doses of ceramide are able to induce a senescent phenotype in young cultured cells (Lightle et al., 2000; Mouton and Venable, 2000). Age-related increases in brain ceramide and neutral SMase levels have also been reported (Palestini et al., 1993). The 
expression of the ceramide transporter in the CNS is widespread, with high levels of GPBPs immunoreactivity in neurons of the cortex, hippocampus, the basal ganglia, the olfactory bulb and some nuclei of the thalamus, the hypothalamus and the septal area (Mencarelli et al., 2009). Interestingly, glial cells do not show immunoreactivity for GPBPs suggesting that in this cell type GPBPs are present at lower levels. In zebrafish, specific knockdown of GPBP/CERT is detrimental to normal embryonic development. In this model the brain is affected, showing a clear reduction of the myelinated tracts, thin axons, hydrocephaly of the 4 ventricles and apoptosis leading to brain tissue loss (Granero-Molto et al., 2008).

Taken together, these findings document the significance of ceramides in the pathophysiology of diverse neurological diseases. GPBPs are regulators of ceramide which could contribute actively to induce profound changes in cellular metabolism. The pathways that link this putative second messenger to neuronal dysfunction remain elusive. Sorting through these complex interrelationships will be essential to better understand neurodegeneration in the CNS.

\section{Conclusion}

The present review brings together our current knowledge concerning the isoproteins GPBP/CERT $T_{L}$ and CERT/GPBP $\triangle 26$, that have generated controversy regarding their roles in several cellular processes. Although our understanding on their nature is still incomplete, the existing data allows us to distinguish the two isoforms by diverse functions in the nervous system. A deeper knowledge of the complexity of ceramides and GPBPs in cell signaling will increase our understanding of cell dynamics in various CNS disorders, opening new opportunities for drug development and therapies for neurodegenerative diseases.

\section{Take home messages}

GPBP/CERT $T_{L}$ and GPBP $\triangle 26 / C E R T$ are two splice variants of 624 and 598 aa respectively. GPBP/CERT $T_{L}$, in turn exists in two alternative translation initiation isoforms, i.e. GPBP/CERT and GPBP $\triangle 28$.

The isoproteins have identical amino acid sequences, except for the presence of a 26 amino acid serine-rich domain in the GPBP/CERT $T_{L}$ isoforms and 128 additional amino acids in the GPBP $\triangle 128$ isoform.

All isoforms function as ceramide transfer proteins. 
GPBP/CERT $T_{L}$ is expressed in tissues targeted by autoimmune responses. Increased expression of GPBP/CERTL has been associated with immune complex-mediated pathogenesis.

Increased GPBP/CERT $T_{L}$ expression induces type IV collagen disorganization and deposits of immunoglobulin A in glomerular basement membrane. GPBP $\triangle 26 / C E R T$ is a more common splice variant widely expressed throughout the body.

GPBP/CERT $T_{L}$ and GPBP $\triangle 26 / C E R T$, in turn, exist as different isoforms resulting from canonical (77 kDa) and noncanonical (91 kDa) mRNA translation initiation.

The $77 \mathrm{kDa}$ GPBP/CERT behaves as a soluble secretable protein and the 91$\mathrm{kD}$ GPBP/CERT $T_{\mathrm{L}}$ as a membrane-bound protein. The $77 \mathrm{GPBP} \triangle 26 / \mathrm{CERT}$ is a cytosolic isoforms.

TNF increases the mRNA levels of GPBPs.

GPBP/CERT $T_{L}$ and GPBP $\triangle 26 / C E R T$ are differentially expressed during embryogenesis in zebrafish with GPBP/CERT $T_{L}$ expressed at the earlier stage than GPBP $\triangle 26 /$ CERT.

Specific GPBP/CERT $T_{L}$ knockdown results in loss of myelinated tracks in the CNS and to extensive apoptosis and tissue loss in the brain.

GPBP $\triangle 26 / C E R T$ knockdown in Drosophila does not lead to neuronal degeneration in the brain but in changes in membrane properties that increase oxidative stress.

Mice lacking both GPBP/CERT $T_{L}$ and GPBP $\triangle 26 / C E R T$ die prematurely cause structural and functional defects in the ER and mitochondria.

Neurons express more GPBPs, than astroglial cells.

Expression levels of GPBPs were observed widely throughout the brain.

GPBPs share similar protein domain organization with two other lipid binding/transfer proteins, OSBP1 and FAPP2.

GPBPs are regulators of ceramide and could be involved in molecular mechanisms underlying ceramide-mediated signaling cascades.

\section{Acknowledgement}

Part of the work of MKC Hesselink and P Martínez-Martínez has been funded by an innovative pilot grant funded by the DFN (Grant number 2011.11.008). 


\section{References}

Aharon-Peretz, J., Rosenbaum, H., Gershoni-Baruch, R., 2004. Mutations in the glucocerebrosidase gene and Parkinson's disease in Ashkenazi Jews. N Engl J Med 351, 1972-1977.

Alpy, F., Tomasetto, C., 2005. Give lipids a START: the StAR-related lipid transfer (START) domain in mammals. J Cell Sci 118, 2791-2801.

Ardail, D., Popa, I., Alcantara, K., Pons, A., Zanetta, J.P., Louisot, P., Thomas, L., Portoukalian, J., 2001. Occurrence of ceramides and neutral glycolipids with unusual long-chain base composition in purified rat liver mitochondria. FEBS Lett 488, 160-164.

Arnoult, D., Grodet, A., Lee, Y.J., Estaquier, J., Blackstone, C., 2005. Release of OPA1 during apoptosis participates in the rapid and complete release of cytochrome $\mathrm{c}$ and subsequent mitochondrial fragmentation. J Biol Chem 280, 35742-35750.

Ayasolla, K., Khan, M., Singh, A.K., Singh, I., 2004. Inflammatory mediator and beta-amyloid (25-35)induced ceramide generation and iNOS expression are inhibited by vitamin E. Free Radic Biol Med 37, 325-338.

Bar, J., Linke, T., Ferlinz, K., Neumann, U., Schuchman, E.H., Sandhoff, K., 2001. Molecular analysis of acid ceramidase deficiency in patients with Farber disease. Hum Mutat 17, 199-209.

Baron, G.S., Wehrly, K., Dorward, D.W., Chesebro, B., Caughey, B., 2002. Conversion of raft associated prion protein to the protease-resistant state requires insertion of $\operatorname{PrP}$-res $(\operatorname{PrP}(\mathrm{Sc}))$ into contiguous membranes. EMBO J 21, 1031-1040.

Bieberich, E., MacKinnon, S., Silva, J., Yu, R.K., 2001. Regulation of apoptosis during neuronal differentiation by ceramide and b-series complex gangliosides. J Biol Chem 276, 44396-44404.

Bionda, C., Portoukalian, J., Schmitt, D., Rodriguez-Lafrasse, C., Ardail, D., 2004. Subcellular compartmentalization of ceramide metabolism: MAM (mitochondria-associated membrane) and/or mitochondria? Biochem J 382, 527-533.

Birbes, H., Luberto, C., Hsu, Y.T., El Bawab, S., Hannun, Y.A., Obeid, L.M., 2005. A mitochondrial pool of sphingomyelin is involved in TNFalpha-induced Bax translocation to mitochondria. Biochem J 386, 445-451.

Blanchette-Mackie, E.J., Dwyer, N.K., Amende, L.M., Kruth, H.S., Butler, J.D., Sokol, J., Comly, M.E., Vanier, M.T., August, J.T., Brady, R.O., et al., 1988. Type-C Niemann-Pick disease: low density lipoprotein uptake is associated with premature cholesterol accumulation in the Golgi complex and excessive cholesterol storage in lysosomes. Proc Natl Acad Sci U S A 85, 80228026.

Boka, G., Anglade, P., Wallach, D., Javoy-Agid, F., Agid, Y., Hirsch, E.C., 1994. Immunocytochemical analysis of tumor necrosis factor and its receptors in Parkinson's disease. Neurosci Lett 172, 151-154.

Bose, R., Verheij, M., Haimovitz-Friedman, A., Scotto, K., Fuks, Z., Kolesnick, R., 1995. Ceramide synthase mediates daunorubicin-induced apoptosis: an alternative mechanism for generating death signals. Cell 82, 405-414.

Brady, R.O., Kanfer, J.N., Mock, M.B., Fredrickson, D.S., 1966. The metabolism of sphingomyelin. II. Evidence of an enzymatic deficiency in Niemann-Pick diseae. Proc Natl Acad Sci U S A 55, 366369.

Brady, R.O., Kanfer, J.N., Shapiro, D., 1965. Metabolism of Glucocerebrosides. li. Evidence of an Enzymatic Deficiency in Gaucher's Disease. Biochem Biophys Res Commun 18, 221-225.

Brann, A.B., Scott, R., Neuberger, Y., Abulafia, D., Boldin, S., Fainzilber, M., Futerman, A.H., 1999. Ceramide signaling downstream of the p75 neurotrophin receptor mediates the effects of nerve growth factor on outgrowth of cultured hippocampal neurons. J Neurosci 19, 81998206.

Brann, A.B., Tcherpakov, M., Williams, I.M., Futerman, A.H., Fainzilber, M., 2002. Nerve growth factorinduced p75-mediated death of cultured hippocampal neurons is age-dependent and transduced through ceramide generated by neutral sphingomyelinase. J Biol Chem 277, 98129818. 
Bras, J., Paisan-Ruiz, C., Guerreiro, R., Ribeiro, M.H., Morgadinho, A., Januario, C., Sidransky, E., Oliveira, C., Singleton, A., 2009. Complete screening for glucocerebrosidase mutations in Parkinson disease patients from Portugal. Neurobiol Aging 30, 1515-1517.

Bras, J., Singleton, A., Cookson, M.R., Hardy, J., 2008. Emerging pathways in genetic Parkinson's disease: Potential role of ceramide metabolism in Lewy body disease. FEBS J 275, 5767-5773.

Brugg, B., Michel, P.P., Agid, Y., Ruberg, M., 1996. Ceramide induces apoptosis in cultured mesencephalic neurons. J Neurochem 66, 733-739.

Brugger, B., Sandhoff, R., Wegehingel, S., Gorgas, K., Malsam, J., Helms, J.B., Lehmann, W.D., Nickel, W., Wieland, F.T., 2000. Evidence for segregation of sphingomyelin and cholesterol during formation of COPI-coated vesicles. J Cell Biol 151, 507-518.

Buccoliero, R., Futerman, A.H., 2003. The roles of ceramide and complex sphingolipids in neuronal cell function. Pharmacol Res 47, 409-419.

Chamberlain, L.H., Burgoyne, R.D., Gould, G.W., 2001. SNARE proteins are highly enriched in lipid rafts in PC12 cells: implications for the spatial control of exocytosis. Proc Natl Acad Sci U S A 98, 5619-5624.

Chen, S.J., Ko, C.Y., Yen, C.W., Wang, C.C., 2009. Translational efficiency of redundant ACG initiator codons is enhanced by a favorable sequence context and remedial initiation. J Biol Chem 284, 818-827.

Cheng, X.P., Wang, B.R., Liu, H.L., You, S.W., Huang, W.J., Jiao, X.Y., Ju, G., 2003. Phosphorylation of extracellular signal-regulated kinases $1 / 2$ is predominantly enhanced in the microglia of the rat spinal cord following dorsal root transection. Neuroscience 119, 701-712.

Choi, D.W., 1992. Excitotoxic cell death. J Neurobiol 23, 1261-1276.

Cutler, R.G., Kelly, J., Storie, K., Pedersen, W.A., Tammara, A., Hatanpaa, K., Troncoso, J.C., Mattson, M.P., 2004. Involvement of oxidative stress-induced abnormalities in ceramide and cholesterol metabolism in brain aging and Alzheimer's disease. Proc Natl Acad Sci U S A 101, 2070-2075.

Cutler, R.G., Mattson, M.P., 2001. Sphingomyelin and ceramide as regulators of development and lifespan. Mech Ageing Dev 122, 895-908.

D'Angelo, G., Polishchuk, E., Di Tullio, G., Santoro, M., Di Campli, A., Godi, A., West, G., Bielawski, J., Chuang, C.C., van der Spoel, A.C., Platt, F.M., Hannun, Y.A., Polishchuk, R., Mattjus, P., De Matteis, M.A., 2007. Glycosphingolipid synthesis requires FAPP2 transfer of glucosylceramide. Nature 449, 62-67.

Dobrowsky, R.T., Werner, M.H., Castellino, A.M., Chao, M.V., Hannun, Y.A., 1994. Activation of the sphingomyelin cycle through the low-affinity neurotrophin receptor. Science 265, 1596-1599.

El Bawab, S., Roddy, P., Qian, T., Bielawska, A., Lemasters, J.J., Hannun, Y.A., 2000. Molecular cloning and characterization of a human mitochondrial ceramidase. J Biol Chem 275, 21508-21513.

Faili, A., Aoufouchi, S., Weller, S., Vuillier, F., Stary, A., Sarasin, A., Reynaud, C.A., Weill, J.C., 2004. DNA polymerase eta is involved in hypermutation occurring during immunoglobulin class switch recombination. J Exp Med 199, 265-270.

Fukasawa, M., Nishijima, M., Hanada, K., 1999. Genetic evidence for ATP-dependent endoplasmic reticulum-to-Golgi apparatus trafficking of ceramide for sphingomyelin synthesis in Chinese hamster ovary cells. J Cell Biol 144, 673-685.

Funakoshi, T., Yasuda, S., Fukasawa, M., Nishijima, M., Hanada, K., 2000. Reconstitution of ATP- and cytosol-dependent transport of de novo synthesized ceramide to the site of sphingomyelin synthesis in semi-intact cells. J Biol Chem 275, 29938-29945.

Furuya, S., Mitoma, J., Makino, A., Hirabayashi, Y., 1998. Ceramide and its interconvertible metabolite sphingosine function as indispensable lipid factors involved in survival and dendritic differentiation of cerebellar Purkinje cells. J Neurochem 71, 366-377.

Futerman, A.H., van Meer, G., 2004. The cell biology of lysosomal storage disorders. Nat Rev Mol Cell Biol 5, 554-565.

Gatt, S., Barenholz, Y., Roitman, A., 1966. Isolation of rat brain lecithinase-A, specific for the alpha'position of lecithin. Biochem Biophys Res Commun 24, 169-172.

Ghafourifar, P., Klein, S.D., Schucht, O., Schenk, U., Pruschy, M., Rocha, S., Richter, C., 1999. Ceramide induces cytochrome $\mathrm{c}$ release from isolated mitochondria. Importance of mitochondrial redox 
state. J Biol Chem 274, 6080-6084.

Godi, A., Di Campli, A., Konstantakopoulos, A., Di Tullio, G., Alessi, D.R., Kular, G.S., Daniele, T., Marra, P., Lucocq, J.M., De Matteis, M.A., 2004. FAPPs control Golgi-to-cell-surface membrane traffic by binding to ARF and Ptdlns(4)P. Nat Cell Biol 6, 393-404.

Goni, F.M., Alonso, A., 2006. Biophysics of sphingolipids I. Membrane properties of sphingosine, ceramides and other simple sphingolipids. Biochim Biophys Acta 1758, 1902-1921.

Granero-Molto, F., Sarmah, S., O'Rear, L., Spagnoli, A., Abrahamson, D., Saus, J., Hudson, B.G., Knapik, E.W., 2008. Goodpasture antigen-binding protein and its spliced variant, ceramide transfer protein, have different functions in the modulation of apoptosis during zebrafish development. J Biol Chem.

Granero, F., Revert, F., Revert-Ros, F., Lainez, S., Martinez-Martinez, P., Saus, J., 2005. A human-specific TNF-responsive promoter for Goodpasture antigen-binding protein. Febs J 272, 5291-5305.

Gross, A., Jockel, J., Wei, M.C., Korsmeyer, S.J., 1998. Enforced dimerization of BAX results in its translocation, mitochondrial dysfunction and apoptosis. EMBO J 17, 3878-3885.

Gudz, T.I., Tserng, K.Y., Hoppel, C.L., 1997. Direct inhibition of mitochondrial respiratory chain complex III by cell-permeable ceramide. J Biol Chem 272, 24154-24158.

Gulbins, E., Bissonnette, R., Mahboubi, A., Martin, S., Nishioka, W., Brunner, T., Baier, G., BaierBitterlich, G., Byrd, C., Lang, F., et al., 1995. FAS-induced apoptosis is mediated via a ceramideinitiated RAS signaling pathway. Immunity 2, 341-351.

Haimovitz-Friedman, A., Kolesnick, R.N., Fuks, Z., 1997. Ceramide signaling in apoptosis. Br Med Bull 53, 539-553.

Hanada, K., Kumagai, K., Tomishige, N., Kawano, M., 2007. CERT and intracellular trafficking of ceramide. Biochim Biophys Acta 1771, 644-653.

Hanada, K., Kumagai, K., Yasuda, S., Miura, Y., Kawano, M., Fukasawa, M., Nishijima, M., 2003. Molecular machinery for non-vesicular trafficking of ceramide. Nature 426, 803-809.

Hannun, Y.A., 1996. Functions of ceramide in coordinating cellular responses to stress. Science 274 , $1855-1859$.

Hannun, Y.A., Luberto, C., 2000. Ceramide in the eukaryotic stress response. Trends Cell Biol 10, 73-80.

Hannun, Y.A., Obeid, L.M., 1995. Ceramide: an intracellular signal for apoptosis. Trends Biochem Sci 20, 73-77.

Hannun, Y.A., Obeid, L.M., 2002. The Ceramide-centric universe of lipid-mediated cell regulation: stress encounters of the lipid kind. J Biol Chem 277, 25847-25850.

Huang, Y., Tanimukai, H., Liu, F., Iqbal, K., Grundke-Iqbal, I., Gong, C.X., 2004. Elevation of the level and activity of acid ceramidase in Alzheimer's disease brain. Eur J Neurosci 20, 3489-3497.

Huitema, K., van den Dikkenberg, J., Brouwers, J.F., Holthuis, J.C., 2004. Identification of a family of animal sphingomyelin synthases. EMBO J 23, 33-44.

Huwiler, A., Kolter, T., Pfeilschifter, J., Sandhoff, K., 2000. Physiology and pathophysiology of sphingolipid metabolism and signaling. Biochim Biophys Acta 1485, 63-99.

Ichikawa, S., Sakiyama, H., Suzuki, G., Hidari, K.I., Hirabayashi, Y., 1996. Expression cloning of a cDNA for human ceramide glucosyltransferase that catalyzes the first glycosylation step of glycosphingolipid synthesis. Proc Natl Acad Sci U S A 93, 4638-4643.

Irie, F., Hirabayashi, Y., 1998. Application of exogenous ceramide to cultured rat spinal motoneurons promotes survival or death by regulation of apoptosis depending on its concentrations. J Neurosci Res 54, 475-485.

Jana, A., Pahan, K., 2004. Fibrillar amyloid-beta peptides kill human primary neurons via NADPH oxidase-mediated activation of neutral sphingomyelinase. Implications for Alzheimer's disease. J Biol Chem 279, 51451-51459.

Jayadev, S., Hannun, Y.A., 1996. Ceramide: role in growth inhibitory cascades. J Lipid Mediat Cell Signal 14, 295-301.

Jayadev, S., Liu, B., Bielawska, A.E., Lee, J.Y., Nazaire, F., Pushkareva, M., Obeid, L.M., Hannun, Y.A., 1995. Role for ceramide in cell cycle arrest. J Biol Chem 270, 2047-2052.

Jeyakumar, M., Butters, T.D., Dwek, R.A., Platt, F.M., 2002. Glycosphingolipid lysosomal storage diseases: therapy and pathogenesis. Neuropathol Appl Neurobiol 28, 343-357. 
Kann, O., Kovacs, R., 2007. Mitochondria and neuronal activity. Am J Physiol Cell Physiol 292, C641-657.

Kawano, M., Kumagai, K., Nishijima, M., Hanada, K., 2006. Efficient trafficking of ceramide from the endoplasmic reticulum to the Golgi apparatus requires a VAMP-associated protein-interacting FFAT motif of CERT. J Biol Chem 281, 30279-30288.

Kivipelto, M., Helkala, E.L., Laakso, M.P., Hanninen, T., Hallikainen, M., Alhainen, K., Soininen, H., Tuomilehto, J., Nissinen, A., 2001. Midlife vascular risk factors and Alzheimer's disease in later life: longitudinal, population based study. BMJ 322, 1447-1451.

Kolesnick, R., Hannun, Y.A., 1999. Ceramide and apoptosis. Trends Biochem Sci 24, 224-225; author reply 227.

Kolesnick, R.N., Goni, F.M., Alonso, A., 2000. Compartmentalization of ceramide signaling: physical foundations and biological effects. J Cell Physiol 184, 285-300.

Kolesnick, R.N., Kronke, M., 1998. Regulation of ceramide production and apoptosis. Annu Rev Physiol 60, 643-665.

Kronke, M., 1999. Involvement of sphingomyelinases in TNF signaling pathways. Chem Phys Lipids $102,157-166$.

Kumagai, K., Kawano, M., Shinkai-Ouchi, F., Nishijima, M., Hanada, K., 2007. Interorganelle trafficking of ceramide is regulated by phosphorylation-dependent cooperativity between the $\mathrm{PH}$ and START domains of CERT. J Biol Chem 282, 17758-17766.

Kumagai, K., Yasuda, S., Okemoto, K., Nishijima, M., Kobayashi, S., Hanada, K., 2005. CERT mediates intermembrane transfer of various molecular species of ceramides. J Biol Chem 280, 64886495.

Lagace, T.A., Byers, D.M., Cook, H.W., Ridgway, N.D., 1997. Altered regulation of cholesterol and cholesteryl ester synthesis in Chinese-hamster ovary cells overexpressing the oxysterolbinding protein is dependent on the pleckstrin homology domain. Biochem J 326 ( Pt 1), 205-213.

Lagace, T.A., Byers, D.M., Cook, H.W., Ridgway, N.D., 1999. Chinese hamster ovary cells overexpressing the oxysterol binding protein (OSBP) display enhanced synthesis of sphingomyelin in response to 25-hydroxycholesterol. J Lipid Res 40, 109-116.

Laitinen, S., Olkkonen, V.M., Ehnholm, C., Ikonen, E., 1999. Family of human oxysterol binding protein (OSBP) homologues. A novel member implicated in brain sterol metabolism. J Lipid Res 40, 2204-2211.

Ledesma, M.D., Brugger, B., Bunning, C., Wieland, F.T., Dotti, C.G., 1999. Maturation of the axonal plasma membrane requires upregulation of sphingomyelin synthesis and formation of protein-lipid complexes. EMBO J 18, 1761-1771.

Lee, J.T., Xu, J., Lee, J.M., Ku, G., Han, X., Yang, D.I., Chen, S., Hsu, C.Y., 2004. Amyloid-beta peptide induces oligodendrocyte death by activating the neutral sphingomyelinase-ceramide pathway. J Cell Biol 164, 123-131.

Lehto, M., Laitinen, S., Chinetti, G., Johansson, M., Ehnholm, C., Staels, B., Ikonen, E., Olkkonen, V.M., 2001. The OSBP-related protein family in humans. J Lipid Res 42, 1203-1213.

Lehto, M., Olkkonen, V.M., 2003. The OSBP-related proteins: a novel protein family involved in vesicle transport, cellular lipid metabolism, and cell signalling. Biochim Biophys Acta 1631, 1-11.

Levade, T., Jaffrezou, J.P., 1999. Signalling sphingomyelinases: which, where, how and why? Biochim Biophys Acta 1438, 1-17.

Levade, T., Salvayre, R., Douste-Blazy, L., 1986. Sphingomyelinases and Niemann-Pick disease. J Clin Chem Clin Biochem 24, 205-220.

Levi-Montalcini, R., 1987. The nerve growth factor 35 years later. Science 237, 1154-1162.

Levine, T.P., Munro, S., 2002. Targeting of Golgi-specific pleckstrin homology domains involves both Ptdlns 4-kinase-dependent and -independent components. Curr Biol 12, 695-704.

Li, C.M., Park, J.H., He, X., Levy, B., Chen, F., Arai, K., Adler, D.A., Disteche, C.M., Koch, J., Sandhoff, K., Schuchman, E.H., 1999. The human acid ceramidase gene (ASAH): structure, chromosomal location, mutation analysis, and expression. Genomics 62, 223-231.

Lightle, S.A., Oakley, J.I., Nikolova-Karakashian, M.N., 2000. Activation of sphingolipid turnover and chronic generation of ceramide and sphingosine in liver during aging. Mech Ageing Dev 120, 111-125. 
Liu, P., Anderson, R.G., 1995. Compartmentalized production of ceramide at the cell surface. J Biol Chem 270, 27179-27185.

Loewen, C.J., Roy, A., Levine, T.P., 2003. A conserved ER targeting motif in three families of lipid binding proteins and in Opi1p binds VAP. Embo J 22, 2025-2035.

Malaplate-Armand, C., Florent-Bechard, S., Youssef, I., Koziel, V., Sponne, I., Kriem, B., LeiningerMuller, B., Olivier, J.L., Oster, T., Pillot, T., 2006. Soluble oligomers of amyloid-beta peptide induce neuronal apoptosis by activating a CPLA2-dependent sphingomyelinase-ceramide pathway. Neurobiol Dis 23, 178-189.

Mannella, C.A., 2006. The relevance of mitochondrial membrane topology to mitochondrial function. Biochim Biophys Acta 1762, 140-147.

Manning-Bog, A.B., Schule, B., Langston, J.W., 2009. Alpha-synuclein-glucocerebrosidase interactions in pharmacological Gaucher models: a biological link between Gaucher disease and parkinsonism. Neurotoxicology 30, 1127-1132.

Mao, C., Xu, R., Szulc, Z.M., Bielawski, J., Becker, K.P., Bielawska, A., Galadari, S.H., Hu, W., Obeid, L.M., 2003. Cloning and characterization of a mouse endoplasmic reticulum alkaline ceramidase: an enzyme that preferentially regulates metabolism of very long chain ceramides. J Biol Chem 278, 31184-31191.

Mata, I.F., Samii, A., Schneer, S.H., Roberts, J.W., Griffith, A., Leis, B.C., Schellenberg, G.D., Sidransky, E., Bird, T.D., Leverenz, J.B., Tsuang, D., Zabetian, C.P., 2008. Glucocerebrosidase gene mutations: a risk factor for Lewy body disorders. Arch Neurol 65, 379-382.

Mathias, S., Pena, L.A., Kolesnick, R.N., 1998. Signal transduction of stress via ceramide. Biochem J 335 (Pt 3), 465-480.

McCoy, M.K., Tansey, M.G., 2008. TNF signaling inhibition in the CNS: implications for normal brain function and neurodegenerative disease. J Neuroinflammation 5, 45.

Meiron, M., Anunu, R., Scheinman, E.J., Hashmueli, S., Levi, B.Z., 2001. New isoforms of VEGF are translated from alternative initiation CUG codons located in its 5'UTR. Biochem Biophys Res Commun 282, 1053-1060.

Mencarelli, C., Hammels, C., Van Den Broeck, J., Losen, M., Steinbusch, H., Revert, F., Saus, J., Hopkins, D.A., De Baets, M.H., Steinbusch, H.W., Martinez-Martinez, P., 2009. The expression of the Goodpasture antigen-binding protein (ceramide transporter) in adult rat brain. J Chem Neuroanat 38, 97-105.

Merrill, A.H., Jr., Schmelz, E.M., Dillehay, D.L., Spiegel, S., Shayman, J.A., Schroeder, J.J., Riley, R.T., Voss, K.A., Wang, E., 1997. Sphingolipids--the enigmatic lipid class: biochemistry, physiology, and pathophysiology. Toxicol Appl Pharmacol 142, 208-225.

Mielke, M.M., Bandaru, V.V., Haughey, N.J., Rabins, P.V., Lyketsos, C.G., Carlson, M.C., 2008. Serum sphingomyelins and ceramides are early predictors of memory impairment. Neurobiol Aging.

Mitoma, J., Furuya, S., Hirabayashi, Y., 1999. [A novel metabolic interaction between neurons and glial cells through L-serine: an essential role for astroglia-derived L-serine in the survival and development of CNS neurons]. Seikagaku 71, 536-541.

Mitoma, J., Ito, M., Furuya, S., Hirabayashi, Y., 1998. Bipotential roles of ceramide in the growth of hippocampal neurons: promotion of cell survival and dendritic outgrowth in dose- and developmental stage-dependent manners. J Neurosci Res 51, 712-722.

Montes, L.R., Ruiz-Arguello, M.B., Goni, F.M., Alonso, A., 2002. Membrane restructuring via ceramide results in enhanced solute efflux. J Biol Chem 277, 11788-11794.

Mouton, R.E., Venable, M.E., 2000. Ceramide induces expression of the senescence histochemical marker, beta-galactosidase, in human fibroblasts. Mech Ageing Dev 113, 169-181.

Nieto-Sampedro, M., Nieto-Diaz, M., 2005. Neural plasticity: changes with age. J Neural Transm 112, 3-27.

Obeid, L.M., Linardic, C.M., Karolak, L.A., Hannun, Y.A., 1993. Programmed cell death induced by ceramide. Science 259, 1769-1771.

Ohashi, E., Bebenek, K., Matsuda, T., Feaver, W.J., Gerlach, V.L., Friedberg, E.C., Ohmori, H., Kunkel, T.A., 2000. Fidelity and processivity of DNA synthesis by DNA polymerase kappa, the product of the human DINB1 gene. J Biol Chem 275, 39678-39684. 
Okazaki, T., Kondo, T., Kitano, T., Tashima, M., 1998. Diversity and complexity of ceramide signalling in apoptosis. Cell Signal 10, 685-692.

Olkkonen, V.M., Johansson, M., Suchanek, M., Yan, D., Hynynen, R., Ehnholm, C., Jauhiainen, M., Thiele, C., Lehto, M., 2006. The OSBP-related proteins (ORPs): global sterol sensors for coordination of cellular lipid metabolism, membrane trafficking and signalling processes? Biochem Soc Trans 34, 389-391.

Otterbach, B., Stoffel, W., 1995. Acid sphingomyelinase-deficient mice mimic the neurovisceral form of human lysosomal storage disease (Niemann-Pick disease). Cell 81, 1053-1061.

Palestini, P., Masserini, M., Fiorilli, A., Calappi, E., Tettamanti, G., 1993. Age-related changes in the ceramide composition of the major gangliosides present in rat brain subcellular fractions enriched in plasma membranes of neuronal and myelin origin. J Neurochem 61, 955-960.

Pandey, S., Murphy, R.F., Agrawal, D.K., 2007. Recent advances in the immunobiology of ceramide. Exp Mol Pathol 82, 298-309.

Pastores, G.M., 2009. Krabbe disease: an overview. Int J Clin Pharmacol Ther 47 Suppl 1, S75-81.

Paumard, P., Vaillier, J., Coulary, B., Schaeffer, J., Soubannier, V., Mueller, D.M., Brethes, D., di Rago, J.P., Velours, J., 2002. The ATP synthase is involved in generating mitochondrial cristae morphology. EMBO J 21, 221-230.

Pelled, D., Trajkovic-Bodennec, S., Lloyd-Evans, E., Sidransky, E., Schiffmann, R., Futerman, A.H., 2005. Enhanced calcium release in the acute neuronopathic form of Gaucher disease. Neurobiol Dis $18,83-88$.

Perry, D.K., Hannun, Y.A., 1998. The role of ceramide in cell signaling. Biochim Biophys Acta 1436, 233-243.

Perry, R.J., Ridgway, N.D., 2006. Oxysterol-binding protein and vesicle-associated membrane proteinassociated protein are required for sterol-dependent activation of the ceramide transport protein. Mol Biol Cell 17, 2604-2616.

Pettus, B.J., Chalfant, C.E., Hannun, Y.A., 2002. Ceramide in apoptosis: an overview and current perspectives. Biochim Biophys Acta 1585, 114-125.

Prats, H., Kaghad, M., Prats, A.C., Klagsbrun, M., Lelias, J.M., Liauzun, P., Chalon, P., Tauber, J.P., Amalric, F., Smith, J.A., et al., 1989. High molecular mass forms of basic fibroblast growth factor are initiated by alternative CUG codons. Proc Natl Acad Sci U S A 86, 1836-1840.

Prinetti, A., Chigorno, V., Prioni, S., Loberto, N., Marano, N., Tettamanti, G., Sonnino, S., 2001. Changes in the lipid turnover, composition, and organization, as sphingolipid-enriched membrane domains, in rat cerebellar granule cells developing in vitro. J Biol Chem 276, 21136-21145.

Radin, N.S., 2003. Infections and glycolipids. Postgrad Med J 79, 185.

Rajendran, L., Honsho, M., Zahn, T.R., Keller, P., Geiger, K.D., Verkade, P., Simons, K., 2006. Alzheimer's disease beta-amyloid peptides are released in association with exosomes. Proc Natl Acad Sci U S A 103, 11172-11177.

Rajendran, L., Simons, K., 2005. Lipid rafts and membrane dynamics. J Cell Sci 118, 1099-1102.

Rao, R.P., Yuan, C., Allegood, J.C., Rawat, S.S., Edwards, M.B., Wang, X., Merrill, A.H., J., Acharya, U., Acharya, J.K., 2007. Ceramide transfer protein function is essential for normal oxidative stress response and lifespan. Proc Natl Acad Sci U S A 104, 11364-11369.

Raya, A., Revert-Ros, F., Martinez-Martinez, P., Navarro, S., Rosello, E., Vieites, B., Granero, F., Forteza, J., Saus, J., 2000. Goodpasture antigen-binding protein, the kinase that phosphorylates the goodpasture antigen, is an alternatively spliced variant implicated in autoimmune pathogenesis. J Biol Chem 275, 40392-40399.

Raya, A., Revert, F., Navarro, S., Saus, J., 1999. Characterization of a novel type of serine/threonine kinase that specifically phosphorylates the human goodpasture antigen. J Biol Chem 274, 12642-12649.

Revert, F., Merino, R., Monteagudo, C., Macias, J., Peydro, A., Alcacer, J., Muniesa, P., Marquina, R., Blanco, M., Iglesias, M., Revert-Ros, F., Merino, J., Saus, J., 2007. Increased Goodpasture antigen-binding protein expression induces type IV collagen disorganization and deposit of immunoglobulin A in glomerular basement membrane. Am J Pathol 171, 1419-1430.

Revert, F., Ventura, I., Martinez-Martinez, P., Granero-Molto, F., Revert-Ros, F., Macias, J., Saus, J., 2008. Goodpasture antigen-binding protein is a soluble exportable protein that interacts with 
type IV collagen. Identification of novel membrane-bound isoforms. J Biol Chem 283, 3024630255.

Riboni, L., Prinetti, A., Bassi, R., Caminiti, A., Tettamanti, G., 1995. A mediator role of ceramide in the regulation of neuroblastoma Neuro2a cell differentiation. J Biol Chem 270, 26868-26875.

Ridgway, N.D., Dawson, P.A., Ho, Y.K., Brown, M.S., Goldstein, J.L., 1992. Translocation of oxysterol binding protein to Golgi apparatus triggered by ligand binding. J Cell Biol 116, 307-319.

Rodriguez-Lafrasse, C., Alphonse, G., Broquet, P., Aloy, M.T., Louisot, P., Rousson, R., 2001. Temporal relationships between ceramide production, caspase activation and mitochondrial dysfunction in cell lines with varying sensitivity to anti-Fas-induced apoptosis. Biochem J 357, 407-416.

Salama, A.D., Levy, J.B., Lightstone, L., Pusey, C.D., 2001. Goodpasture's disease. Lancet 358, 917-920.

Satoi, H., Tomimoto, H., Ohtani, R., Kitano, T., Kondo, T., Watanabe, M., Oka, N., Akiguchi, I., Furuya, S., Hirabayashi, Y., Okazaki, T., 2005. Astroglial expression of ceramide in Alzheimer's disease brains: a role during neuronal apoptosis. Neuroscience 130, 657-666.

Schwarz, A., Futerman, A.H., 1997. Distinct roles for ceramide and glucosylceramide at different stages of neuronal growth. J Neurosci 17, 2929-2938.

Schweizer, A., Clausen, H., van Meer, G., Hauri, H.P., 1994. Localization of O-glycan initiation, sphingomyelin synthesis, and glucosylceramide synthesis in Vero cells with respect to the endoplasmic reticulum-Golgi intermediate compartment. J Biol Chem 269, 4035-4041.

Scorrano, L., Ashiya, M., Buttle, K., Weiler, S., Oakes, S.A., Mannella, C.A., Korsmeyer, S.J., 2002. A distinct pathway remodels mitochondrial cristae and mobilizes cytochrome $c$ during apoptosis. Dev Cell 2, 55-67.

Shimeno, H., Soeda, S., Sakamoto, M., Kouchi, T., Kowakame, T., Kihara, T., 1998. Partial purification and characterization of sphingosine $\mathrm{N}$-acyltransferase (ceramide synthase) from bovine liver mitochondrion-rich fraction. Lipids 33, 601-605.

Sidransky, E., Nalls, M.A., Aasly, J.O., Aharon-Peretz, J., Annesi, G., Barbosa, E.R., Bar-Shira, A., Berg, D., Bras, J., Brice, A., Chen, C.M., Clark, L.N., Condroyer, C., De Marco, E.V., Durr, A., Eblan, M.J., Fahn, S., Farrer, M.J., Fung, H.C., Gan-Or, Z., Gasser, T., Gershoni-Baruch, R., Giladi, N., Griffith, A., Gurevich, T., Januario, C., Kropp, P., Lang, A.E., Lee-Chen, G.J., Lesage, S., Marder, K., Mata, I.F., Mirelman, A., Mitsui, J., Mizuta, I., Nicoletti, G., Oliveira, C., Ottman, R., Orr-Urtreger, A., Pereira, L.V., Quattrone, A., Rogaeva, E., Rolfs, A., Rosenbaum, H., Rozenberg, R., Samii, A., Samaddar, T., Schulte, C., Sharma, M., Singleton, A., Spitz, M., Tan, E.K., Tayebi, N., Toda, T., Troiano, A.R., Tsuji, S., Wittstock, M., Wolfsberg, T.G., Wu, Y.R., Zabetian, C.P., Zhao, Y., Ziegler, S.G., 2009. Multicenter analysis of glucocerebrosidase mutations in Parkinson's disease. $\mathrm{N}$ Engl J Med 361, 1651-1661.

Simons, K., Ehehalt, R., 2002. Cholesterol, lipid rafts, and disease. J Clin Invest 110, 597-603.

Simons, K., Vaz, W.L., 2004. Model systems, lipid rafts, and cell membranes. Annu Rev Biophys Biomol Struct 33, 269-295.

Simons, M., Keller, P., Dichgans, J., Schulz, J.B., 2001. Cholesterol and Alzheimer's disease: is there a link? Neurology 57, 1089-1093.

Siskind, L.J., 2005. Mitochondrial ceramide and the induction of apoptosis. J Bioenerg Biomembr 37, 143-153.

Siskind, L.J., Colombini, M., 2000. The lipids C2- and C16-ceramide form large stable channels. Implications for apoptosis. J Biol Chem 275, 38640-38644.

Small, D.M., 1970. Surface and bulk interactions of lipids and water with a classification of biologically active lipids based on these interactions. Fed Proc 29, 1320-1326.

Sot, J., Goni, F.M., Alonso, A., 2005. Molecular associations and surface-active properties of short- and long-N-acyl chain ceramides. Biochim Biophys Acta 1711, 12-19.

Spence, M.W., Burgess, J.K., 1978. Acid and neutral sphingomyelinases of rat brain. Activity in developing brain and regional distribution in adult brain. J Neurochem 30, 917-919.

Spiegel, S., Merrill, A.H., Jr., 1996. Sphingolipid metabolism and cell growth regulation. FASEB J 10, 1388-1397.

Suzuki, T., 2002. Lipid rafts at postsynaptic sites: distribution, function and linkage to postsynaptic 
density. Neurosci Res 44, 1-9.

Tang, H.L., Yeh, L.S., Chen, N.K., Ripmaster, T., Schimmel, P., Wang, C.C., 2004. Translation of a yeast mitochondrial tRNA synthetase initiated at redundant non-AUG codons. J Biol Chem 279, 49656-49663.

Tani, M., Igarashi, Y., Ito, M., 2005. Involvement of neutral ceramidase in ceramide metabolism at the plasma membrane and in extracellular milieu. J Biol Chem 280, 36592-36600.

Taraboulos, A., Scott, M., Semenov, A., Avrahami, D., Laszlo, L., Prusiner, S.B., 1995. Cholesterol depletion and modification of $\mathrm{COOH}$-terminal targeting sequence of the prion protein inhibit formation of the scrapie isoform. J Cell Biol 129, 121-132.

Tepper, A.D., de Vries, E., van Blitterswijk, W.J., Borst, J., 1999. Ordering of ceramide formation, caspase activation, and mitochondrial changes during CD95- and DNA damage-induced apoptosis. J Clin Invest 103, 971-978.

Thomas, R.L., Jr., Matsko, C.M., Lotze, M.T., Amoscato, A.A., 1999. Mass spectrometric identification of increased C16 ceramide levels during apoptosis. J Biol Chem 274, 30580-30588.

Toman, R.E., Spiegel, S., Faden, A.I., 2000. Role of ceramide in neuronal cell death and differentiation. J Neurotrauma 17, 891-898.

Touriol, C., Bornes, S., Bonnal, S., Audigier, S., Prats, H., Prats, A.C., Vagner, S., 2003. Generation of protein isoform diversity by alternative initiation of translation at non-AUG codons. Biol Cell 95, 169-178.

Trajkovic, K., Hsu, C., Chiantia, S., Rajendran, L., Wenzel, D., Wieland, F., Schwille, P., Brugger, B., Simons, M., 2008. Ceramide triggers budding of exosome vesicles into multivesicular endosomes. Science 319, 1244-1247.

Tsujishita, Y., Hurley, J.H., 2000. Structure and lipid transport mechanism of a StAR-related domain. Nat Struct Biol 7, 408-414.

van Echten-Deckert, G., Herget, T., 2006. Sphingolipid metabolism in neural cells. Biochim Biophys Acta 1758, 1978-1994.

van Ham, T.J., Thijssen, K.L., Breitling, R., Hofstra, R.M., Plasterk, R.H., Nollen, E.A., 2008. C. elegans model identifies genetic modifiers of alpha-synuclein inclusion formation during aging. PLoS Genet 4, e1000027.

van Meer, G., Holthuis, J.C., 2000. Sphingolipid transport in eukaryotic cells. Biochim Biophys Acta $1486,145-170$.

Veiga, M.P., Arrondo, J.L., Goni, F.M., Alonso, A., 1999. Ceramides in phospholipid membranes: effects on bilayer stability and transition to nonlamellar phases. Biophys J 76, 342-350.

Venable, M.E., Lee, J.Y., Smyth, M.J., Bielawska, A., Obeid, L.M., 1995. Role of ceramide in cellular senescence. J Biol Chem 270, 30701-30708.

Venkataraman, K., Futerman, A.H., 2000. Ceramide as a second messenger: sticky solutions to sticky problems. Trends Cell Biol 10, 408-412.

Verheij, M., Bose, R., Lin, X.H., Yao, B., Jarvis, W.D., Grant, S., Birrer, M.J., Szabo, E., Zon, L.I., Kyriakis, J.M., Haimovitz-Friedman, A., Fuks, Z., Kolesnick, R.N., 1996. Requirement for ceramideinitiated SAPK/JNK signalling in stress-induced apoptosis. Nature 380, 75-79.

Vetrivel, K.S., Cheng, H., Lin, W., Sakurai, T., Li, T., Nukina, N., Wong, P.C., Xu, H., Thinakaran, G., 2004. Association of gamma-secretase with lipid rafts in post-Golgi and endosome membranes. J Biol Chem 279, 44945-44954.

Wang, C.C., Chang, K.J., Tang, H.L., Hsieh, C.J., Schimmel, P., 2003. Mitochondrial form of a tRNA synthetase can be made bifunctional by manipulating its leader peptide. Biochemistry 42 , 1646-1651.

Wang, X., Rao, R.P., Kosakowska-Cholody, T., Masood, M.A., Southon, E., Zhang, H., Berthet, C., Nagashim, K., Veenstra, T.K., Tessarollo, L., Acharya, U., Acharya, J.K., 2009. Mitochondrial degeneration and not apoptosis is the primary cause of embryonic lethality in ceramide transfer protein mutant mice. J Cell Biol 184, 143-158.

Wang, Y.M., Seibenhener, M.L., Vandenplas, M.L., Wooten, M.W., 1999. Atypical PKC zeta is activated by ceramide, resulting in coactivation of NF-kappaB/JNK kinase and cell survival. J Neurosci Res 55, 293-302. 
Wyles, J.P., McMaster, C.R., Ridgway, N.D., 2002. Vesicle-associated membrane protein-associated protein-A (VAP-A) interacts with the oxysterol-binding protein to modify export from the endoplasmic reticulum. J Biol Chem 277, 29908-29918.

Xu, R., Jin, J., Hu, W., Sun, W., Bielawski, J., Szulc, Z., Taha, T., Obeid, L.M., Mao, C., 2006. Golgi alkaline ceramidase regulates cell proliferation and survival by controlling levels of sphingosine and S1P. FASEB J 20, 1813-1825.

Yamaoka, S., Miyaji, M., Kitano, T., Umehara, H., Okazaki, T., 2004. Expression cloning of a human cDNA restoring sphingomyelin synthesis and cell growth in sphingomyelin synthase-defective lymphoid cells. J Biol Chem 279, 18688-18693.

Zamzami, N., Marchetti, P., Castedo, M., Decaudin, D., Macho, A., Hirsch, T., Susin, S.A., Petit, P.X., Mignotte, B., Kroemer, G., 1995. Sequential reduction of mitochondrial transmembrane potential and generation of reactive oxygen species in early programmed cell death. J Exp Med 182, 367-377.

Zeng, C., Lee, J.T., Chen, H., Chen, S., Hsu, C.Y., Xu, J., 2005. Amyloid-beta peptide enhances tumor necrosis factor-alpha-induced iNOS through neutral sphingomyelinase/ceramide pathway in oligodendrocytes. J Neurochem 94, 703-712.

Zerbinatti, C.V., Cordy, J.M., Chen, C.D., Guillily, M., Suon, S., Ray, W.J., Seabrook, G.R., Abraham, C.R., Wolozin, B., 2008. Oxysterol-binding protein-1 (OSBP1) modulates processing and trafficking of the amyloid precursor protein. Mol Neurodegener 3, 5 .

Zhang, Y., Li, X., Becker, K.A., Gulbins, E., 2009. Ceramide-enriched membrane domains--structure and function. Biochim Biophys Acta 1788, 178-183.

Zhang, Y., Yuan, F., Wu, X., Wang, M., Rechkoblit, O., Taylor, J.S., Geacintov, N.E., Wang, Z., 2000. Errorfree and error-prone lesion bypass by human DNA polymerase kappa in vitro. Nucleic Acids Res 28, 4138-4146. 


\section{Chapter 2}

Ceramide function in the brain: when a slight tilt is enough

Chiara Mencarelli and Pilar Martínez-Martínez 


\section{Abstract}

Ceramide, the precursor of all complex sphingolipids, is a potent signalling molecule which mediates key events of cellular phatophysiology. In the nervous system, the sphingolipid metabolism has an important impact. Neurons are polarized cells and their normal functions, such as neuronal connectivity and synaptic transmission, rely on selective trafficking of molecules across plasma membrane. Sphingolipids are abundant on neural cellular membranes and represent potent regulators of brain homeostasis. Ceramide intracellular levels are fine-tuned and alteration of the sphingolipid-ceramide profile contributes to the development of agerelated, neurological and neuroinflammatory diseases.

The purpose of this review is to guide the reader towards a better understanding of the sphingolipid-ceramide pathway system. First, ceramide biology is presented including structure, physical properties and metabolism. Second, we describe the function of ceramide as a lipid second messenger in cell physiology. Finally, we highlight the relevance of sphingolipids and ceramide in the progression of different neurodegenerative diseases. 


\section{Introduction}

Ceramides are a family of lipid molecules which consist of sphingoid longchain base linked to a fatty acid via an amide bond. Ceramides differ from each other by length, hydroxylation and saturation of both the sphingoid base and fatty acid moieties.

Sphingoid bases are of three general chemical types: sphingosine, dihydrosphingosine (commonly known as "sphinganine", as it will be addressed in this review) and phytosphingosine. Based on the nature of the sphingoid base backbone, we can distinguish 3 main subgroups in the ceramide family: the compound named ceramide contains sphingosine, which has a trans-double bond at the $\mathrm{C} 4-5$ position in the sphingoid base backbone; dihydroceramide, the inactive precursor of ceramide, contains sphinganine which presents a saturated sphingoid backbone devoid of the 4,5-transdouble bond; phytoceramide, the yeast counterpart of the mammalian ceramide, contains phytosphingosine which has a hydroxyl group at the $\mathrm{C} 4$ position (1) (Figure 1).

The fatty acid components of ceramides vary widely in composition, but they are typically long. Their acyl chain lengths range from 14 to 26 carbon atoms (or greater), although the most common fatty acids are palmitic (C16:0) and stearic (C18:0) non-hydroxy fatty acids. The fatty acids are commonly saturated or mono-unsaturated. -Hydroxylated fatty acids (a hydroxyl group at the $\mathrm{C}-2$ position) and $\alpha$-hydroxy fatty acid (a hydroxyl group on the terminal $\mathrm{C}$ atom) are often present as well (2).

\section{Activation of Ceramide}

Small changes in the molecular structure of ceramide moiety can regulate its biological function. Dihydroceramide is an early intermediate in the de novo ceramide biosynthesis. Considered the innocuous precursor of ceramide, dihydroceramide differs from ceramide only by reduction of the C4-5 trans double bond in the sphingoid backbone making it inactive (3) or very weakly active (4) when compared with ceramide moiety. The introduction of a trans-double bond between $\mathrm{C} 4$ and $\mathrm{C} 5$ results in a biologically active molecule. This double bond is introduced by the enzyme (dihydro)-ceramide desaturase which is localized in the cytosolic leaflet of endoplasmic reticulum (ER) membrane $(5,6)$. In this way cells can fine-tune the amount of biologically active ceramide. The presence of the double bond in the sphingosine chain determines the tilt of ceramides in the membrane and enables the lipid to interact with enzymes such as hydrolases and phosphatases (11). 

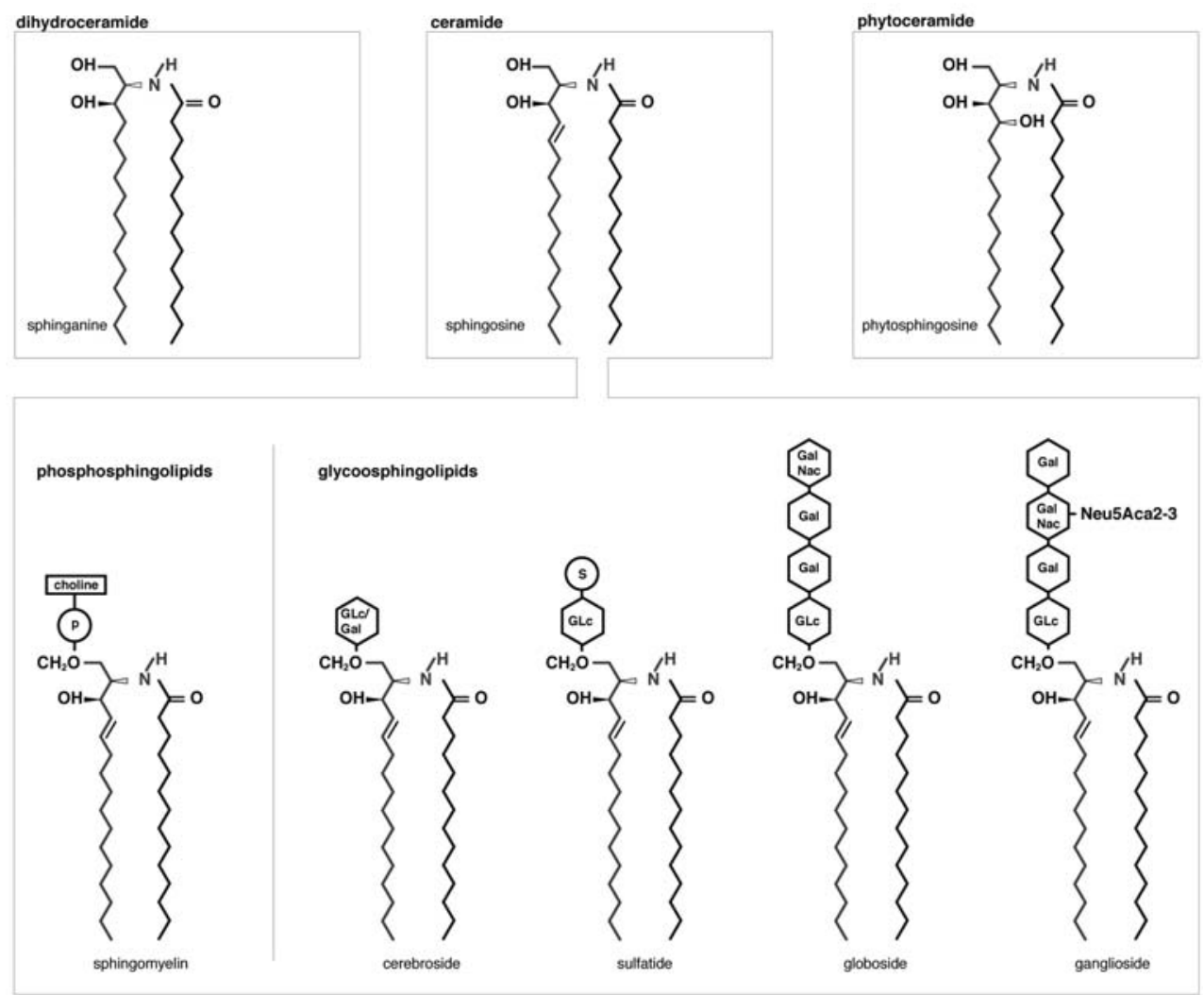

Figure 1 Chemical structure of sphingoid bases (sphinganine, sphingosine, phytosphingosine) and ceramide species (dihydroceramide, ceramide and phytoceramide).

The typical phosphosphingolipid in mammalian cells is sphingomyelin, synthetized by the transfer of the phosphorylcholine moiety to the C-1 hydroxyl group of ceramides. Alternatively, modification of a ceramide by addition of one or more sugars directly connected at the primary alcohol group yields complex glycosphingolipids. This class of lipid comprises: cerebrosides, sulfatides, globosides and gangliosides. Cerebrosides have a single monosaccharide (glucose or galactose) as polar head group. Sulfatides are the sulfuric acid esters of galactocerebrosides. Globosides contain multiple sugar moieties. Gangliosides have a complex oligosaccharide with one or more sialic acids as polar head.

Moreover, unsaturation in the sphingoid backbone augments intramolecular hydration/hydrogen bonding in the polar region. This may allow the close packing of the ceramide molecules which exhibit a tighter intramolecular interaction than comparable lipids (7-9). This higher packing density of ceramides within the lipid bilayer affects the physical properties of membranes (10).

\section{Short chain ceramide}

Synthetic short-chain ceramides ( $\mathrm{N}$-acyl chains of 2 to 8 carbon atoms) are commonly used to mimic the mechanisms of action of naturally occurring 
long-chain ceramides which are highly hydrophobic compounds. Shortchain ceramides are water soluble and membrane-permeable and can be easily used as experimental tools within living cells (12-16). Small amounts of C2-ceramide are normal components in brain (10 pmol/g) and liver (25 $\mathrm{pmol} / \mathrm{g}$ ) (17) although the metabolic origin and physiological activity of this short ceramide are uncertain.

NMR characterization of $\mathrm{C}-2$ and $\mathrm{C}-18$ ceramides showed that the conformation of the polar region of the two molecules is the same (8). Since the interaction between ceramides and their ligand molecules probably occurs through the polar head, the maintenance of the headgroup conformation irrespective of $\mathrm{N}$-acyl chain length is enough for $\mathrm{C}-2$ ceramides to reproduce most of the long-chain ceramides signaling effects. However, the length of the fatty acyl chain modifies significantly the biophysical properties of the ceramide moieties (18) and in some reports long- and short-chain ceramides have been found to have different biological effects $(19,20)$.

The major difference between short and long ceramides is in the geometrical shapes they adopt at the membrane level that consequentially gives rise to different behaviors. The hydrophobic portion of C-2 is smaller than the polar headgroup. Therefore, $\mathrm{C}-2$ has a shape that favors a positive curvature in lipid monolayer (21). Long chain ceramides are cone shaped molecules with opposite geometrical properties which induce a negative curvature of the two halves of the bilayer towards the aqueous milieu, leading to membrane trafficking via vesiculation and fusion $(22,23)$. Moreover, long-chain ceramides increase the order of the acyl chains in the bilayers, thus decreasing fluidity and stabilizing the membrane (24-26). Conversely, short-chain ceramides perturb the structural order of the lipid bilayer. Long chain ceramides are immiscible with phospholipids, while short chain ceramides mix much better and are therefore able to spontaneously overcome membrane barriers (27). Once inside the cell since they possess the appropriate stereochemistry, short ceramides might bind target proteins normally inaccessible for the longer species. On the contrary, naturally occurring long-ceramides are eminently hydrophobic even compared to other lipid species and as a consequence their concentrations in the cytosol are extremely low. This hydrophobicity of ceramides justifies the need for a ceramide transfer protein (CERT) in cells (28). CERT localises inside the cell and modulation of its activity may result in significant changes in ceramide levels (put ref for your paper). Therefore, since short chain ceramides behaves as soluble amphiphiles (29), they are suspected to have cellular effects that cannot be extrapolated to natural ceramide species (mainly 
insoluble amphiphiles) and their use might lead to confusion on the role of ceramide in cellular signaling.

\section{Ceramides as precursors of sphingolipids}

Free ceramides are molecules known to exert a wide range of biological functions in many of the most critical cellular events, including growth, differentiation, apoptosis and oncogenesis. Ceramides are the core structure of a class of complex lipid called sphingolipids, ubiquitous components of eukaryotic cell membranes (30). Sphingolipids were initially described in brain tissue in the second half of the 19th century (31). The name sphingolipids denotes their enigmatic (namely sphinx-like) nature that, despite intense research, still arouses unanswered questions. Sphingolipids have long been regarded as inactive and stable structural components of the membrane; however they are now well recognized to be biologically active in processes of cellular biology.

Sphingolipids are very heterogeneous and are classified depending on their structural combinations in long-chain (sphingoid) bases, amide-linked fatty acids (32) and hundreds of headgroup variants (33).

Sphingolipids are generated by attachment of different polar headgroups at the primary alcohol group $(\mathrm{C} 1-\mathrm{OH})$ of a ceramide molecule. Depending on the type of polar group, two major classes are classified: phosphosphingolipids and glycosphingolipids (Figure 1). The typical phosphosphingolipid in mammalian cells is sphingomyelin (SM), synthetized by the transfer of the phosphorylcholine moiety (from phosphatidylcholine) to the $\mathrm{C}-\mathrm{HOH}$ of ceramides.

Alternatively, modification of a ceramide by addition of one or more sugars yields complex glycosphingolipids. As a result of the great heterogeneity in the glycan moiety, among glycosphingolipids, much variation exists. The basic structure for a glycosphingolipid is a monosaccharide, usually glucose or galactose, attached directly to the ceramide portion of the molecule, resulting in glucosylceramide (glucocerebroside) and galactosylceramide (galactocerebroside), respectively. When a single monosaccharide is present, the glycosphingolipid is referred to as a cerebroside (also known as monoglycosylceramides). The sulfuric acid esters of galactosylceramide are the sulfatides. Galactosylceramide and sulfatide are highly enriched in oligodendrocytes and myelin-forming cells compared to other membranes (34). By contrast glucosylceramide are not normally found in neuronal cell membranes. The core glycan moiety may be further extended by additional monosaccharides which allow the classification of GSLs into subtypes 
according to their specific tetrasaccharide core structures: ganglio-, globo-, lacto- and (neo)lacto-series GSLs.

Globosides represent cerebrosides that contain additional carbohydrates predominantly galactose, glucose or GalNAc. Gangliosides are very similar to globosides except that they also contain a sialic acid residue such as $\mathrm{N}$ acetylneuraminic acid ('NANA' or 'SA' or 'Neu5Ac' or 'NeuAc'). Gangliosides comprise approximately $5 \%$ of brain lipids and are mainly present in astroglia, followed by neurons and oligodendrocytes. Polar carbohydrate chains of glycosphingolipids extend toward the extracellular milieu, forming specific patterns on the surface of cells, contributing to cell recognition during differentiation, development and immune reaction (35). These different types of sphingolipids can be converted back to ceramide by the removal of the polar headgroup by specific enzymes.

\section{Ceramide generation}

Ceramides can be produced in cells either via the de novo synthesis or via hydrolysis of complex sphingolipids (36). The activation of different catabolic enzymes yields ceramide within a few minutes whereas the de novo synthesis produces ceramide in several hours (37). Different extra- and intracellular stimuli dictate the pathway used for ceramide generation resulting in distinct subcellular localization of ceramide and different biochemical and cellular responses.

\section{De novo synthesis of ceramide takes place in the ER}

In animal cells, ceramide is de novo-synthesized on the cytoplasmic face of the smooth endoplasmic reticulum $(E R)(5,38)$ and in mitochondria $(39,40)$. The de novo synthesis of ceramides in eukaryotes begins with the condensation of serine and palmitoyl-CoA to form 3-ketosphinganine, through the action of serine palmitoyl transferase (SPT) (Figure 2). This enzyme is composed of two subunits: Lcb1 and Lcb2. Mutations in the human Lcb1 gene underlie hereditary autonomous neuropathy, a neurodegenerative disorder of the peripheral nervous system (41).

Subsequently 3-keto-sphinganine is reduced to the sphingoid base sphinganine, which is subsequently $\mathrm{N}$-acylated by (dihydro)-ceramide synthase (CerS) to form dihydroceramide. The enzyme (dihydro)-ceramide desaturase introduces the double bond to the position $\mathrm{C} 4$ to form mammalian type ceramides $(6,42)$.

Cers represents a key enzyme in the pathway for de novo sphingolipid biosynthesis. Interestingly, these highly conserved transmembrane proteins 
are also known as human homologues of yeast longevity assurance gene (LASS1).

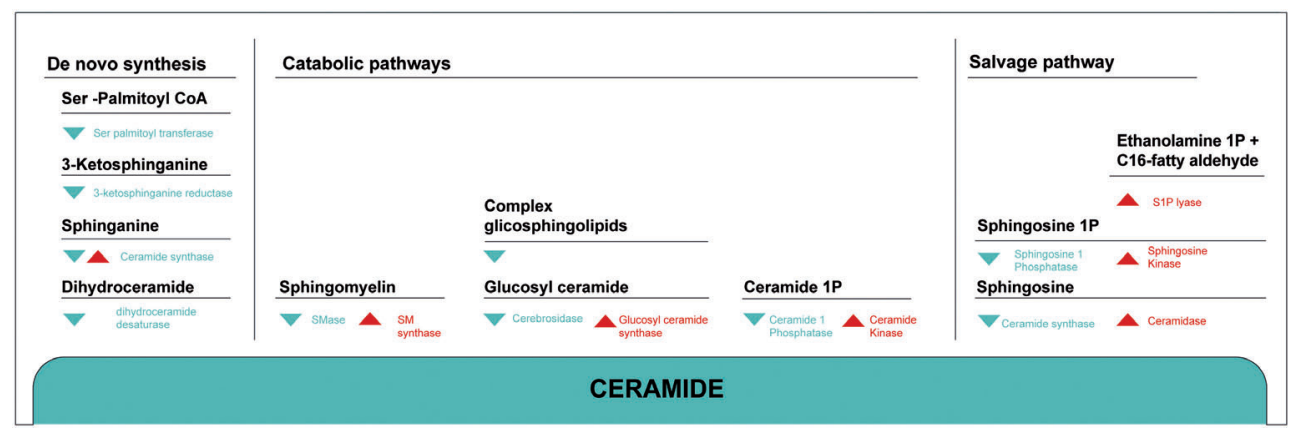

Figure 2 Overview of the metabolic pathways involved in the synthesis of endogenous ceramide. Ceramide can be formed by de novo synthesis, by degradation of complex SLs or by re-acylation of sphingoid long-chain bases (salvage pathway). The de novo pathway involves several enzymatic steps. Through catabolic pathways ceramide is generated by either hydrolysis of the membrane lipid sphingomyelin by the SMase enzymes or by lysosomal breackdown of complex glicosphingolipids. Ceramide itself is degraded by ceramidase to regenerate sphingoid bases. The sphingosine formed is then phosphorylated and finally degraded to phosphoethanolamine and C16-fatty aldehyde by the action of the sphingosine-1-phospate (S1P) lyase.

A salvage pathway uses the enzyme ceramide synthase to produce ceramide from sphingosine. Once generated, ceramide can serve as a substrate for the synthesis of sphingomyelin and glycosphingolipids or be converted into various metabolites such as sphingosine or ceramide-1phosphate.

Six different CerSs (CerS1-6) have been identified in vertebrates and plants (43), whereas most of the other enzymes involved in sphingolipids metabolism exist in only one or two isoforms (43). Each CerS regulates the de novo synthesis of endogenous ceramides with a high degree of fatty acid specificity. In line with the presence of multiple CerSs, ceramides occur with a broad fatty acids length distribution inside the cell. Although some CerSs are ubiquitously expressed, other isoforms present a very specific distribution among tissues, according to the need of each tissue for specific ceramide species $(44,45)$. CerS1 specifically generates C18 ceramide and is highly expressed in the brain and skeletal muscles but is almost undetectable in other tissues. CerS2 mainly generates $\mathrm{C} 20-26$ ceramides and has been found to have the highest expression of all CerSs in oligodendrocytes and Schwann cells especially during myelination. The selectivity of different CerS isoforms to synthesize different ceramide species is important since ceramides with specific acyl chain lengths might mediate different responses within cells (43). Fumonisins are toxic mycotoxins with a very similar structure to sphingosine or sphinganine which is a substrate for CerS. Since these fungal metabolites are able to 
inhibit CerS reaction, they are extensively used to study the role of ceramide generated through the de novo pathway in the ER (46). On the contrary, the mitochondrial CerS is not affected by fumonisins, suggesting that its activity is distinct from the ER resident enzyme $(39,40)$.

Neo-synthesized ceramides subsequently traffic from the luminal face of the ER to the Golgi compartment where different polar heads are incorporated into the ceramide molecule to form complex sphingolipids (47).

\section{Ceramide transport from ER to the Golgi}

The high hydrophobicity and low polarity of ceramide moiety limit free ceramide to circulate inside the cell or more generally in solution. This may explain the occurrence of several isoenzymes of ceramide biosynthesis at different subcellular sites and supports the view that the site of ceramide formation might determine its function.

On the other hand, the cell needs to transport ceramide from the ER to the Golgi compartment for the synthesis of glycosphingolipids and SM. Ceramides destined for conversion to glycosphingolipids appear to reach the Golgi only via the classical vesicular route (28). The step-wise addition of sugar groups to ceramides is catalyzed by membrane bound glycosyltransferases and it is restricted to the ER-Golgi complex (57). This process is followed by the exocytotic vesicular membrane flow of the growing molecules from the cytosolic side of the Golgi cisternae to the plasma membrane.

On the other hand, ceramides destined for the formation of SM reach the Golgi carried by the protein ceramide transporter (CERT) in a non-vesicular manner (28, 48-50).

CERT mediates the transfer of ceramides containing C14-C20 fatty acids but not longer-chain ceramides (58). This correlates with the presence of a C1420 acyl chain SM in many tissues and cell lines whereas glycosphingolipids are formed by longer ceramides. CERT, works as mediator of sphingolipids homeostasis. Loss of functional CERT in Drosophila affects plasma membrane fluidity and increases oxidative stress (59) and CERT is critical for mitochondrial and ER integrity (60). Interestingly, CERT has an alternatively spliced isoform characterized by the presence of an additional 26 amino acids domain, responsible for its localization at the plasma membrane and consequent secretion to the extracellular milieu, named $C_{E R T_{L}}$ or Goodpasture antigen binding protein (GPBP) (61). These two isoforms are differentially expressed during development. CERT $T_{L}$ is more abundant at early stages of embryonic maturation and its knockdown leads to severe developmental deficit in muscle and brain because of increased apoptosis 
(62). As development progresses, the initially very low levels of CERT, gradually increase. Both isoforms can be detected in adult brain (63).

Other reports showed elevated $\mathrm{CERT}_{\mathrm{L}}$ expression levels to be associated with several autoimmune disorder e.g. Lupus erythromatosus, multiple sclerosis, myasthenia gravis, Addison disease (64). An efficient execution of apoptotic signaling is important to inhibit inflammation and autoimmune responses against intracellular antigens (65) and modulation of CERT/CERT levels has a direct influence in ceramide levels and could be responsible for balancing cell death during embryogenesis and under pathophysiological condition.

Once delivered to the Golgi apparatus, ceramide spontaneously translocates from the cytosolic to the luminal leaflet for SM synthesis. Formation of SM from ceramide is catalyzed by sphingomyelin synthase (SMS) (51) that transfers the phosphocholine headgroup from phosphatidylcholine onto ceramide yielding SM as a final product and diacylglycerol (DAG) as a side product (52). As ceramide is a key metabolic intermediate for sphingolipids with an amide backbone, DAG is for glycerol-derived phospholipids

SMS exists in two isoforms, SMS1, faces the lumen of the cis/medial Golgi (futerman 1990,jeckel 1990, Kobayashi 1989) and it is responsible for the de novo synthesis of SM (53); SMS2 which resides in the plasma membrane (52),(54) could instead play a more specific role in signal transduction events. In neural cells the de novo SM is mostly synthesized at the plasma membrane and the production at the cis medial Golgi is less prominent (55, 56). This indicates that the subcellular localization of SM formation is cell type specific and that SMS activities may be involved in different biological processes.

\section{Catabolic pathways for ceramide production}

Beside the de novo pathway, significant contribution to intracellular ceramide levels occur also through hydrolysis of complex sphingolipids by activation of different hydrolases (66) (Figure 2).

Ceramides derived from SM catabolism require the activation of sphingomyelinases (SMase) (67), specific forms of phospholipase C, which hydrolyze the phosphodiester bond of SM yielding water soluble phosphorylcholine and ceramide (68). Several SMases have been characterized and classified by their $\mathrm{pH}$ optimum, subcellular distribution and regulation. The best studied of these SMases is the acid sphingomyelinase (aSMase) which exhibits an optimal enzymatic activity at $\mathrm{pH} 4.5-5$ (69). This lipase is localized in lysosomes and is required for the turnover of cellular membranes (70). ASMase is deficient in patients with 
the neurovisceral form (type A) of Niemann-Pick disease, with consequent abnormal accumulation of SM in many tissues of the body (71). Besides this lysosomal/endosomal aSMase, a secreted zinc-activated form of aSMase was first identified in serum (72) and found to be secreted by many cell types $(73,74)$. These two aSMases are differentially glycosylated and processed at the NH2-terminal (72) but they are products of the same gene (73). Neutral SMases (nSMase) are membrane bound enzymes with an optimal activity at a neutral $\mathrm{pH}$. Several isoforms have been characterized. NSMase 1 is localized in the membranes of the endoplasmic reticulum, $(75,76)$ and it is ubiquitously expressed and highly enriched in kidney (77). NSMase 2 has a different domain structure than nSMase 1 and is specifically highly expressed in brain $(78,79)(80)$. A third nSMase (nSMase 3 ) is ubiquitously present in all cell types and distributed mainly in the ER and Golgi membrane (81). NSMases are further classified as $\mathrm{Mg}^{2+} / \mathrm{Mn}^{2+}$ dependent or independent. An alkaline SMase exists only in intestinal cells and it is activated by bile salts (82). The function of these multiple isoforms is still elusive; however their membrane localization has lead to speculation that they may contribute to the modification of local microdomains in the membrane organization during vesicle formation, transport, and fusion $(83,84)$.

\section{Salvage pathway}

Ceramides can be generated by an alternative acyl-CoA-dependent route (Figure 2). This pathway relies upon the reverse activity of the enzyme ceramidase (CDase), which is called the "salvage pathway" since catabolic fragments are recycled for biosynthetic purposes $(85,86)$. As the name suggests, CDase catalyses the hydrolysis of ceramide to generate free sphingosine and fatty acid. Together with ceramide production, CDase regulates also sphingosine levels. In fact, it is important to note that whereas sphinganine is generated by de novo sphingolipid biosynthesis (Figure 2), free sphingosine seems to be derived only via turnover of complex sphingolipids, more specifically by hydrolysis of ceramide (5). The catabolism of ceramide takes place in lysosomes from where sphingosine can be released (87) in contrast to ceramide which does not appear to leave the lysosome (88). Free sphingosine is probably trapped at the endoplasmic reticulum-associated membranes where it undergoes re-acylation (condensation with a fatty-acylCoA) to again generate ceramide. This "reverse" activity is carried out by the same CDase $(88,89)$.

As with SMase, different CDases have been identified associated with different cellular compartments according to the $\mathrm{pH}$ at which they achieve optimal activity (acid, neutral and alkaline). Acid CDases (aCDase) are 
Iysosomal (90-92), whereas neutral/alkaline CDases (nCDase and alCDase) have been purified from mitochondria $(39,93)$ and nuclear membranes $(94)$. CDases have been isolated from soluble fractions of rat brain (95), mouse liver and human kidney. A purely alkaline CDase has been localized to the Golgi apparatus and ER $(96,97)$. Again, this variability in CDases subcelular localizations and distribution in tissues suggests that these enzymes may have diverse functions in the biology of the cell.

Neutral/alkaline CDases have been shown to catalyze the reverse reaction to generate ceramide from sphingosine and fatty acids $(89,96,98,99)$ whereas the acid isoform resides in lysosome. Mitochondria are also capable of generating ceramide via the action of reverse ceramidase $(39,93,100)$.

\section{Sphingosine 1-phosphate and ceramide 1-phosphate}

Phosphorylation/dephosphorylation reactions represent a mechanism through which cells respond to specific changes: the phosphorylated state of a molecule often exhibits effects that are diametrically different from those of the unphosphorylated state. Besides being used to resynthesize ceramide, sphingosine can be converted into sphingosine-1-phosphate (SP1) via sphingosine kinase, an enzyme that exists in the cytosol and ER (101, 102) (Figure 2). The terminal catabolism of sphingosine involves the action of SP1 lyase which degrades the SP1 to form ethanolamine phosphate and a fatty aldehyde (105). Sphingosine is associated with growth arrest (103) whereas its phosphorylated form, SP1, is able to promote cell proliferation and prevent programmed cell death (102, for a review 104).

Ceramide and S1P are two sphingolipids that exert effects of opposite nature in their regulation of apoptosis, differentiation, proliferation and cell migration $(106,107)$. The concentration of ceramide and S1P is counterbalanced by enzymes that convert one lipid to the other and their levels are believed to balance between cell viability and cell death.

However, this is not the only way the cell can balance to ensure tissue homeostasis. Ceramides can also be phosphorylated by the enzyme ceramide kinase to form ceramide-1-phosphate (Cer1P) (108-111). As expected, phosphorylation of ceramide in Cer1P allows a switch of ceramide properties: comprehensive studies indicate that Cer1P inhibits apoptosis and can induce cell survival (112-114).

Ceramide kinase (CERK) was first observed in brain synaptic vesicles (109) and found to be highly expressed in brain, heart, skeletal muscles and liver (108). It appears that at least two different CERK isoforms exist in neural tissue, a calcium dependent enzyme at the plasma membrane level and a second cytosolic enzyme $(115,116)$. The former enzyme localizes at 
synaptic-vesicles suggesting a possible role for CERK in neurotransmitter release $(108,109,117)$.

CERK specifically utilizes ceramide transported to the Golgi apparatus by CERT (118). Stable downregulation of CERT by RNA interference results in strong decrease in Cer1P levels, suggesting that Cer1P formation mostly relies on ceramide de novo synthesis (118). Together with CERK and Cer1P phosphatases, CERT could modulate an appropriate balance between the intracellular levels of ceramide and Cer1P. However it is important to mention that short-term pharmacological inhibition of CERT appears to slow down SM synthesis without decreasing Cer1P synthesis (119), suggesting either an alternative route for delivery of ceramide to CERK at the Golgi complex or a process which is dependent on long term responses.

Maintenance of equilibrium between ceramide and Cer1P seems to be crucial for cell and tissue homeostasis and accumulation of one or the other results in metabolic dysfunction and disease.

Recently, S1P was reported to function not only as an intracellular but also as an extracellular mediator of cell growth through endothelialdifferentiation gene family receptors (120). Cer1P could exert similar functions at the plasma membrane level. Further research is necessary to study if ceramide could reach the plasma membrane transported by $C E R T_{L}$ allowing plasmatic membrane CERK to form Cer1P.

\section{Plasma Membrane, not just a lipid bilayer}

\section{Structural organization of the membrane}

The plasma membrane is the densest structure of eukaryotic cells and it defines the outer limit of the cell with its environment. Far from being a passive skin around a cell, plasma membranes are highly dynamic structures with a central role in a vast array of cellular processes $(121,122)$.

Plasma membrane of eukaryotic cells comprises three major classes of lipids: glycerophospholipids, sphingolipids and sterols, principally cholesterol (123). Glycerophospholipids are the main building blocks of eukaryotic membranes and differ from sphingolipids (ceramide based lipids) in that they are built on a glycerol backbone. (124). Sphingolipid acyl chains are characteristically highly saturated, this allows them to pack tightly in the lipid bilayer and results in a liquid ordered phase with little opportunity for lateral movement or diffusion. This characteristic makes sphingolipids suitable to contribute heavily to the structure of the outer leaflet (30). Conversely, glycerophospholipids are rich in unsaturated acyl chains that are typically kinked, this means they pack loosely thus increasing the fluidity of 
the lipid bilayer. The inner leaflet has a higher content of unsaturated phospholipids. This lipid asymmetry in membranes accounts for the greater fluidity of the inner layer relative to the outer layer (Figure 3).

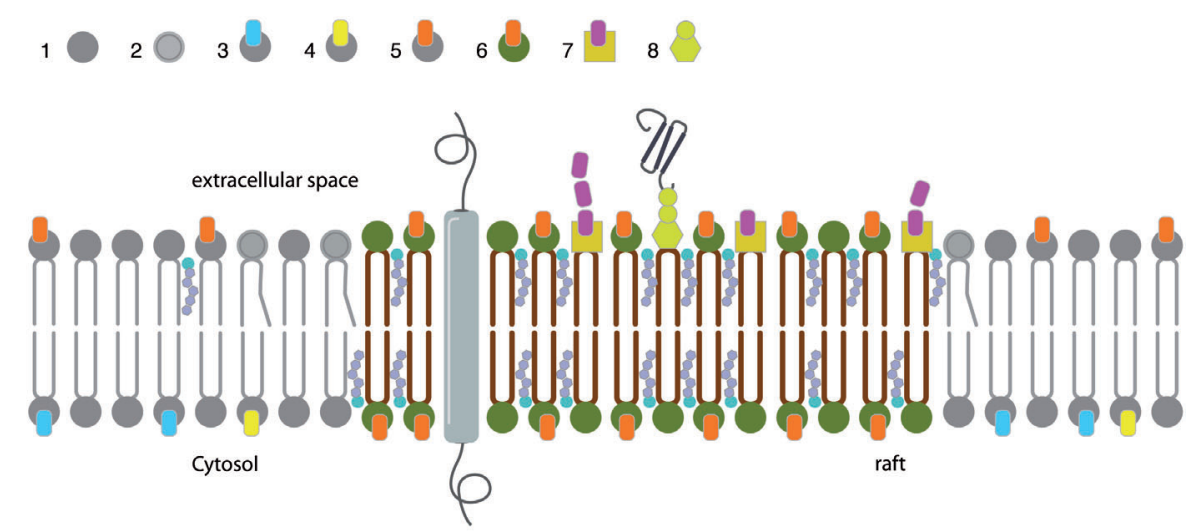

Figure 3 Schematic representation of lipid raft structures in a plasma membrane.

The phospholipid bilayer of cellular plasma membranes contains many different lipid components such as glycerophospholipids, sphingolipids and cholesterol. The compositions of the inner and outer membrane leaflets are different. The cytoplasmic monolayer is largely composed of aminophospholipids as phosphatidylserine (4) and phosphatidylethanolamine (3). By contrast, the choline-containing lipids SM (6) and phosphatidylcholine $(5)$ and a variety of glycolipids $(7,8)$ are significant components of the exofacial leaflet of plasma membranes [45]. Sphingomyelin (6) together with cholesterol and different glycosphingolipids $(7,8)$, form highly organized microdomains called lipid rafts on the plasma membrane. Since these microstructures are formed by lipid species with long saturated acyl chains, rafts are rigid platforms which float in the more fluid surrounding membrane that consists of phospholipids with saturated (1) and unsaturated (2) fatty acyl chains and less cholesterol. Lipids rafts are enriched in glycosylphosphatidylinositol (GPI)-anchored proteins (8) at their external surface and studded with transmembrane integral proteins.

Sphingolipids molar ratio relative to glycerophospholipids and cholesterol varies within cell types. For instance, glycosphingolipids are a very minor component in certain cell types such as erythrocytes but they have been shown to be particularly abundant in neurons and oligodendrocytes where they make up $30 \%$ of total lipids in myelin sheets $(125,126)$. Cholesterol affects the consistency of the plasma membrane making the outer surface firm and decreasing its permeability (127). With its rigid ring structure, cholesterol fills interstitial spaces between fatty acid chains of the nearest phospholipids, restricting their movement. At the same time cholesterol helps plasma membrane to maintain its fluidity, separating the long saturated fatty acid tails of phospholipids, avoiding their condensation. Despite the significance of ceramide metabolism in the synthesis and degradation of sphingolipids, ceramide content is normally very low in cell membrane and increases in ceramide concentration are highly localized and 
temporally regulated. The occurrence of ceramide in the lipid bilayer directly affects both the structural organization and the dynamic properties of the cell membrane $(10,128)$.

\section{Lipid rafts}

Many cellular processes such as endocytosis, exocytosis and membrane budding involve changes in membrane topology. While biological membranes are typically in a fluid or liquid-disordered state at physiological temperatures, combinatorial interactions between specific lipids drives the formation of dense, liquid-ordered domains, or 'lipid rafts' within membranes $(13,122,133,134)$ (Figure 3). The characteristics of these microdomains differ from those of the whole membrane. They are generally enriched in lipids with saturated acyl chains, especially SM and cholesterol which pack tightly within the lipid bilayer $(131,132)$. These separated regions seem to exist as preformed entities in the membrane of resting cells (129) and are present in different parts of the lipid bilayer (130).

The straight saturated acyl chains of sphingolipids in rafts are more extended than unsaturated chains of surrounding phospholipids and as a result lipid rafts extend $1 \mathrm{~nm}$ beyond the phospholipids background (135). The isolation of biologically relevant lipid rafts is problematic. In the past, highly saturated lipid rafts have been isolated based on their detergent resistance (136). More recently, it has been shown that these detergent resistant membranes (DRMs) are in fact a product of the extraction method and do not reflect any specific membrane structure. Therefore it is important to recognize that rafts are not equivalent to DRMs (137). The majority of studies have investigated lipid rafts mainly at the plasma membrane, due to their accessibility from the outside of the cell (138-140). However many intracellular organelles contain raft-like domains $(136,141$ 144). Membranes of the Golgi are rich in cholesterol/SM (145-147) and it has been suggested that rafts function in sorting of lipids and proteins in the secretory and endocytic pathways. In particular, raft like domains are thought to be abundant in the trans-Golgi $(144,148)$ and in late endosomes (143).

Lipid rafts are dynamic structures without any characteristic morphology (149): during the steady state, rafts may be very small, nanometers in diameter $(131,150,151)$ but upon proper stimuli they can coalesce into large domains making even micrometer-size rafts (151). The fundamental principle by which lipid rafts exert their functions is a segregation or concentration of specific membrane proteins and lipids to form distinct microdomains (139) that represent specialized signaling organelles within 
the plasma membrane (152). These dynamic membrane sites have been implicated in mechanisms of cell polarity (153), membrane trafficking including endocytosis $(141,154)$ and exocytosis (155-157) and in intracellular signaling $(152,158-160)$.

Proteins which localize into lipid rafts often show post-translational modifications with lipids such as glycosylphosphatidylinositol (GPI)-anchors, palmitoylation, prenylation, myristoylation, (161) or directly bind cholesterol or phospholipids as caveolins $(134,162)$ and annexins (163), respectively.

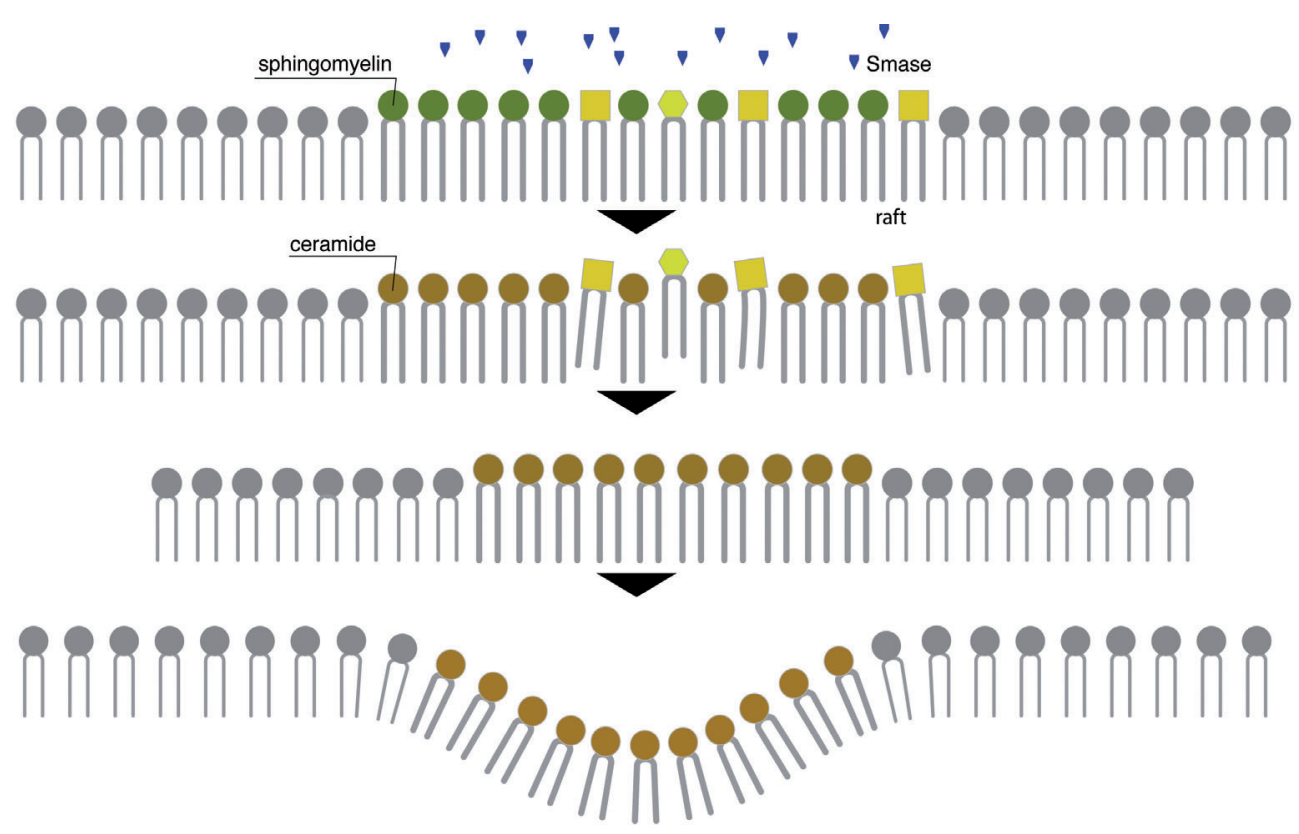

Figure 4 Scheme of lipid raft reorganization upon ceramide formation by SMase activity.

Hydrolysis of sphingomyelin through the enzyme Smase generates ceramide in the outer leaflet of the cell membrane. For its biochemical features, ceramide mixes poorly with the other rafts components and shows self-assembling capability in the membranous environment forming large distinct ceramide-enriched membrane platforms which serve to reorganize the cell membrane, resulting in clustering of activated receptor molecules.

\section{Ceramide enriched platforms}

As a highly hydrophobic second messenger, ceramide presumably acts at the level of lipid rafts in transducing external signal. Rafts are the primary site of action of the enzyme SMase that releases ceramide from SM (164) (Figure 4). The tight interaction between SM and cholesterol serves as the basis for raft formation. Ceramides, on the other hand, mix poorly with cholesterol and have a tendency to self associate and segregate into highly ordered 
microdomains $(13,165)$. The nature of ceramide has a strong impact on membrane structure. In fact, long chain saturated ceramide molecules are intermolecularly stabilized by hydrogen bonding and van der Waal forces $(25,166)$ and form gel or liquid ordered domains that induce lateral phase separation of ?uid phospholipid bilayers into regions of gel and liquidcrystalline (?uid) phases. Moreover, the small size of ceramide polar headgroup results in a low hydration and allows ceramide molecules to pack tightly avoiding any interference with surrounding lipids (167). In fact it has been shown that as little as $5 \mathrm{~mol} \%$ ceramide is sufficient to induce ceramide partitioning in the lipid bilayer and to drive the fusion of small inactive rafts into one or more large active ceramide-enriched membrane platforms (166).

Among lipids, diacylglycerol structurally seems to resemble ceramide. Both are very minor components of membrane being formed and removed rapidly at specific locations in response to signalling. As well as ceramides, diacylglycerols also give rise to phenomena of lateral phase separation in small domains within phospholipid bilayers. Both ceramide (10) and diacylglyercol (11) are non-lamellar forming lipids, which are important for cellular processes such as pore formation, vesicle fusion and budding, as well as membrane protein function. Both ceramide and diacylglycerol are lipid second messengers that play important roles in many signaling pathways. The amount of DAG formed can reach $2 \mathrm{~mol} \%$ in some physiological situations (Preiss 1986). DAG is known to induce structural changes in membrane at as little as $2 \mathrm{~mol} \%$ and appears to be generally more efficient than ceramide in the promotion of non lamellar lipidic phases. The fact that ceramide and DAG membrane effects differ from each other quantitatively rather than qualitatively suggests that the physical rather than the chemical properties of these compounds are responsible for the observed differences. If it is assumed that ceramides and diacylglycerols have a physiological role in the (transient) destabilization of the lamellar structures, the different potencies of the various lipid groups adds a new possibility in the modulation of membrane structure and dynamics.

The ceramide-enriched membrane platforms serve as clustering components to achieve a critical density of receptors involved in signaling. In fact, rafts are too small to engage in membrane processes $(152,168)$. This high density of receptors seems to be required for effective transmission of the signal into cells. For example, CD95 signaling is amplified a hundred-fold by the formation of ceramide-enriched membrane platforms (169).

The neuronal plasma membrane is particularly enriched in lipid rafts (170). More than $1 \%$ of total brain protein is recovered in a lipid raft fraction, 
whereas less than $0.1 \%$ of total protein is associated with lipid raft isolated from non neuronal tissues (171). In cultured neurons, lipid rafts are distributed throughout the cell surface including the soma and dendrites. As well as across cell types, lipid and protein raft composition differs according to neuronal developmental stage. Mature neuron lipid raft content is higher than that of immature neurons and astrocytes. (172). Synaptic proteins such as synaptophysin or synaptotagmin localize in lipid rafts $(173,174)$ and lipid rafts are critical for maintaining the stability of synapses and dendritic spines (175). Neurotransmitter signaling seems to occur through a clustering of receptors and receptor-activated signaling molecules within lipid rafts. Several lipid raft associated neurotransmitter receptors have been isolated from brain tissues, examples include: nicotinic acetylcholine receptors (176), gamma aminobutyric acid type B receptors (177), $\alpha$-amino-3-hydroxy-5methyl-4-isoxazolepropionic acid receptor and $\mathrm{N}$-methyl-D-aspartate receptors $(175,178,179)$. Aberrant organization of SM and cholesterol in rafts has been linked to loss of synapses and changes in nerve conduction (175). Depletion of sphingolipids or cholesterol leads to gradual loss of inhibitory and excitatory synapses and dendritic spines (175). Rafts also play an important role in neuronal cell adhesion (180), localization of neuronal ion channels $(181,182)$ and axon guidance $(183)$. In oligodendrocytes, rafts mediate the interaction between myelin associated glycoprotein on myelin and its receptor on neurons (184).

\section{Ceramide signaling in apoptosis}

Apoptosis is an essential process for normal embryonic development and to maintain cellular homeostasis within mature tissues. A proper balance between regulation of normal cell growth and cell death is the basis of life. Deregulated apoptosis is a feature of most pathological conditions such as neurodegeneration, auto immune disorders and cancers. In neurodegenerative diseases such as Alzheimer's, Parkinson's, Huntington's and Prion's diseases aggregated misfolded proteins contribute to the neuronal pathogenesis; in multiple sclerosis, autoimmune mechanisms accompany the demyelination; in HIV-associated dementia, viral products are crucial for neuronal demise. Factors affecting neurodegeneration can differ, but these devastating disorders are all characterized by a massive loss of specific populations of neurons or damage to neuronal transmission.

Premature death of terminally differentiated cells such as neurons and oligodendrocytes results in progressive and irreversible functional deficits since these post mitotic cells cannot be easily replaced (185). The role of ceramide in apoptosis is extensive and complex and despite intense 
investigations remains controversial (186). Increase of ceramide levels lead to cell death $(187,188)$; in contrast, depletion of ceramide can reduce the progression of apoptosis (189-191). However, ceramide is indispensable for proper function of the central nervous system (CNS) (192-194). Very likely its levels inside the cell determine its dual role: protection and cell sustenance at low concentrations but death and threat when over produced. This outlines the importance for cells to maintain a strict ceramide balance by a tight regulation of sphingolipid based signaling networks.

Ceramide can induce apoptosis via different routes and different intracellular organelles are the target of its action. SM hydrolysis by neutral and/or acid SMases is known to be a very important pathway for production of pro-apoptotic ceramides (195). However, the de novo synthesis pathway has also been reported to be relevant in the generation of a signaling pool of ceramide leading to cellular apoptosis (196-198). These two pathways can induce apoptosis independently or jointly (Figure 5).

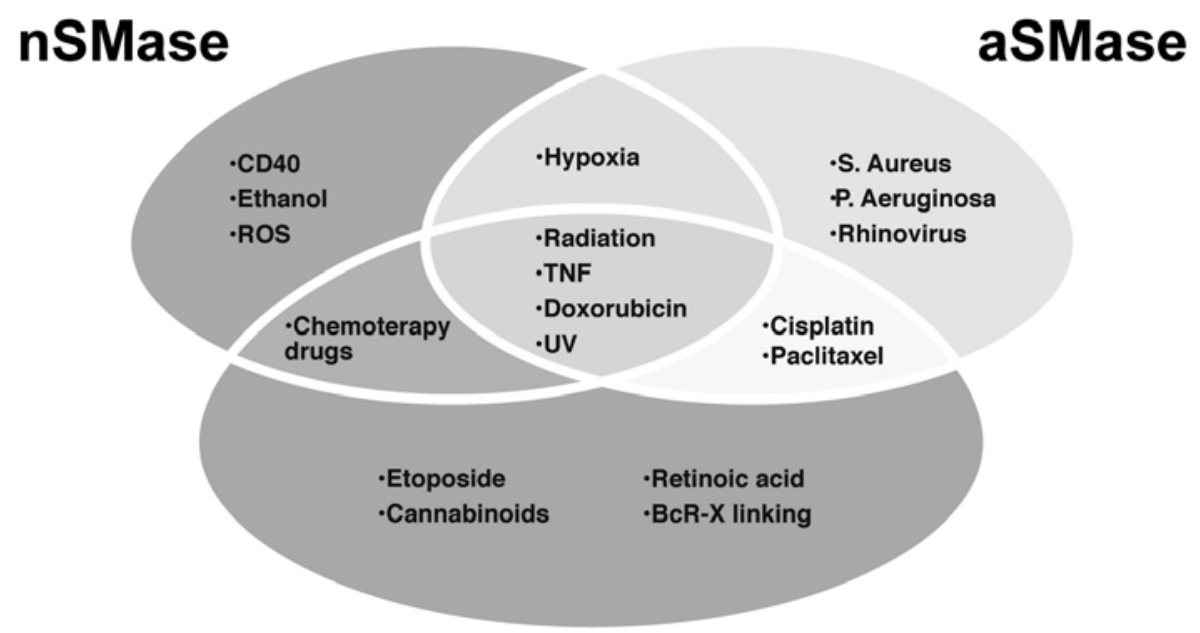

\section{De Novo}

Figure5 Ceramide production occurs in response to diverse apoptotic stimuli and with different mechanisms.

Many inducers of cell death activate one or more ceramide generation pathways. For example both SM hydrolysis (by either a nSMase or an aSMase) and the de novo pathway have been implicated in the actions of TNF $\alpha$, radiation, doxorubicin and UV. Ultimately,ceramide production results in cell death regardless of the pathway.

The sequential events involved in apoptosis signaling in ceramide catabolic pathway are: first the activation of SMases which generates a rapid and transient increase of ceramide and second, the generation of ceramide- 
enriched membrane platforms. In contrast, the ceramide de novo pathway requires multiple enzymatic steps and it is responsible for a slow but robust accumulation of ceramide over a period of several hours.

SMase activation occurs in response to stimulation of cell surface receptors of the tumor necrosis factor (TNF) receptor superfamily. These receptors transmit apoptotic signals initiated by specific ligands such as TNF alpha, TNF-related apoptosis-inducing ligand (TRAIL) and Fas ligands. TNF induced cellular responses are mediated by either one of the two TNF receptors, TNFR1 ( $p 55$ ) or TNFR2 (p75) which elicit different intracellular signals (199). SM hydrolysis in response to apoptotic signals involves both nSMase and aSMase but their activation occurs through different mechanisms (200, 201). The cytoplasmic tail of the TNFR1 contains two distinct portions that differently associate with nSMase or aSMase $(202,203)$. Activation of aSMase requires the C-terminal of the TNFR1 identified as death domain (DD) (204). DD associates with the adaptor protein TRADD (TNF receptor 1associated death domain) that together with another cytoplasmic protein, termed FADD/MORT-1 (205) induces activation of aSmase (206). ASMase is normally present in the endosomal/lysosomal compartment. However, upon phosphorylation by protein kinase C, aSMase translocates from its intracellular locations to the plasma membrane where it reaches SM (207). ASMase is reported to be functional at physiological $\mathrm{pH}$ after translocation to the plasma membrane (208). The ceramide produced by aSmase activates the aspartyl protease cathepsin D (209) that can subsequently cleave the pro-apoptotic Bcl-2 family member Bid. Activation of Bid induces cytochrome c release from mitochondria (210) and activation of caspase-9 and-3, leading to apoptotic cell death by the intrinsic pathway (211). Conversely, activation of nSMase requires a short motif adjacent to the DD of TNFR1, called neutral sphingomyelinase domain (NSD). The NSD binds an adaptor protein, FAN (factor associated with nSMAse) which couples nSMase to TNFR1 (212). The ceramide generated by nSMase leads to the activation of ceramide-activated protein kinase (CAPK) (14) and ceramideactivated protein phosphatases (CAPPs) (213), direct downstream targets of ceramide. CAPK, Ser/Thr protein kinase, is involved in the mitogen-activated protein kinase (MAPK) cascades that induce the extracellular-signal regulated kinases (ERK) activation. ERK cascade leads to cell cycle arrest and cell death.

CAPPs, which comprise the serine threonin protein phosphatases PP1 and PP2A (214), mediate the effect of ceramide on several substrate. Dephosphorylation and inactivation of retinoblastoma gene product (RB) 
(215) and antiapoptotic proteins such as Bcl-2 and Akt (216) and downregulation of the transcription factors c-Myc (217) and c-Jun (218) lead to apoptosis.

Although aSMase and nSMase seem to induce death receptor dependent and independent mediated apoptosis through apparently separate mechanisms, both enzymes are activated by the same stimuli, i.e. UV light (219), hypoxia $(220,221)$, radiation $(191,222)$, TNF-related apoptosisinducing ligands (223) and the DNA-damaging drug doxorubicine (224). Disruption of rafts or prevention of ceramide generation by inactivation of aSMase, renders cells resistant to receptor clustering and apoptosis indicating that aSMase plays an important role in death receptor-mediated apoptosis $(228,2,225)$. Accordingly, aSMase-deficient mice are resistant to the induction of apoptosis by CD95 (226) and TNF alpha signaling (227). However, selective activation of nSmase has been reported to occur for some apoptotic stimuli as CD40 (229), ethanol (230), free oxygen radicals (231) and chemotherapy drugs (232). In contrast, specific activation of aSMase with subsequent formation of ceramide-enriched membrane domains occurs after infection with Pseudomonas aeruginosa (233), Staphylococcus aureus (234) or rhinovirus (235).

Instead, exposition to the chemotherapeutic agent etoposide (198) and cannabinoids (236), retinoic acid (237) and B cell receptor ( $\mathrm{BCR}$ )-induced apoptosis (238) all involve a large increase in ceramide levels formed specifically through the de novo pathway (Figure 5). However, the downstream targets of the de novo ceramide dependent cell death are largely unknown.

In conclusion, evidence suggests that ceramide acts either by changing the physical state and organization of cellular membranes or by direct binding and activation of target proteins. The spatial reorganization of plasma membrane driven by generation of ceramide may serve to cluster signaling molecules and to amplify death signaling. However, rather than a specific mechanism for apoptosis induction, this process appears to represent a generic mechanism for transmembrane signaling. In fact, receptors that are not involved in apoptosis (IL5, LFA 1, CD28, CD20) (239) can activate the SMase signaling pathway with subsequent raft clustering into microdomains. Beside its effect at the level of cellular membranes, ceramide is capable of direct binding with components that lead to death as CAPP, CAPK, Protein Kinase $C-\xi$, cathepsin D (240) and mediate induction of signaling cascades that lead to apoptosis, growth arrest and inflammation. 


\section{Aging}

Sphingolipids hold a major role in regulating development and lifespan (241) and deregulation in sphingolipid metabolism increase the risk and progression of age-related neurodegenerative disease $(242,243)$. Since ceramide is the core of sphingolipids, its contribution to cellular pathophysiology is object of intense study. A close connection between ceramide levels and aging comes from studies carried on Saccharomyces cerevisiae where a gene involved in ceramide synthesis has been identified as a regulator of yeast longevity. This gene called longevity assurance homolog 1 (LAG1), together with LAC1, functions as a key components of CerS in vivo and in vitro (244) and its lost correlates with a marked increase in yeast lifespan (245). The human homolog LAG1Hs (CerS1) is highly expressed in the brain, testis and skeletal muscles and specifically generates C18-ceramide (43). This conclusion seems to be supported by cell culture studies where overexpression of CerS1 with increased C18-ceramide generation resulted in apoptosis (246). Interestingly, C18-ceramide generated by CerS1 was found to downregulate the expression of the enzyme telomerase (247). Telomerase functions by elongating the end of existing chromosomes and thus preventing cellular senescence. Since cellular aging is dependent on cell division, these enzymes play a critical role in long term viability of highly proliferative organ systems (248). Specifically c18-ceramide is able to mediate a negative regulation of the human Telomerase Reverse Transcriptase (hTERT) promoter, whereas different ceramides generated by other ceramide synthases do not have such a function. Telomerase is expressed in neurons in the brains of rodents during embryonic and early postnatal development and is subsequently downregulated (249). Terminally differentiated neurons are postmitotic, therefore there is not need to maintain the telomere length (250). However, telomerase is constitutively expressed in restricted regions of the hippocampus and the olfactory bulbs which are continuously supplied with neural stem and progenitor cells (251). These cells are required for adult neurogenesis throughout life because they produce new neurons and support brain cells. Therefore, besides the telomeric roles, telomerase was found to protect the post-mitotic neuronal cells from stress-induced apoptosis and may serve a neuron survival-promoting function in the developing brain and be important for regulating normal brain functions. Thus, the regulation that C18-ceramide seems to exert on telomerase expression may contribute to increase neuronal vulnerability of the adult brain in various age-related neurodegenerative disorders.

Several studies support the role of ceramide in inducing senescence and in 
activating genetic/biochemical pathways involved with aging. Accumulation of ceramide occurs normally during development and aging in single cells (252) and young cells treated with exogenous ceramide exhibit a senescentlike phenotype (253).

In addition, a significant change in ceramide metabolic enzyme activities seems to occur in specific organs or even in specific cell types with aging $(252,254)$. The activities of the sphingolipid catabolic enzymes (SMase and CDase) seem to change more robustly than that of the anabolic enzymes (SMS and CerS).

ASMase and nSMase activity significantly increase in rat brain during aging (255) demonstrating that aging is accompanied by an increase in SM turnover. NSMase was also reported to be dramatically activated in senescent fibroblasts (252). ACDase, nCDase and alCDase activities are increased specifically in brain tissue from aging rats and among the isoforms of CDases, alCDase shows the highest activity (255). Increase in the CDase activity in kidney and brain indicates an increase in the production of sphingosine and its contribution toward aging in these tissues. In contrast, CerS shows a lower activity, suggesting a minor contribution of ceramide de novo synthesis to ceramide accumulation (255).

\section{Ceramide and neurodegeneration}

\section{Lipid storage disorders}

Ceramide is defined as a central element in the metabolic pathways of sphingolipids. All sphingolipids are synthesized from ceramides and are hydrolyzed to ceramides. In addition to CDase and SMase, there are other hydrolytic enzymes which hydrolyze complex sphingolipids producing ceramides as product. More than ten specific acid exohydrolases are responsible for intracellular glycosphingolipids digestion in a stepwise action that takes place within the lysosome. Deficiency or malfunctioning of one of these enzymes results in accumulation of the corresponding lipid substrate in the lysosomal compartment leading to cellular enlargement, dysfunction and death. Due to its high synthesis of lipids, the brain is the organ mainly affected by accumulation of lipid products. Their abnormal storage and slow turnover results in severe dementia and mental retardation. Inherited metabolic disorders which have been linked to lysosomal dysfunction belong to a family of diseases identified as lysosomal storage disorders (LSDs). LSDs include Farber's disease, caused by the dysfunction of aCDase; Krabbe's disease (Globoid leukodystrophy), caused by the absence of GalCer/3-galactosidase; Gaucher's disease due to the absence of GlcCer/3- 
glucosidase and Niemann-Pick disease characterized by the absence of aSMase.

\section{Farber's disease}

Farber's disease is an inherited disorder characterized by high levels of ceramides due to deficient activity of lysosomal aCDase (256). The rate of ceramide synthesis is normal but ceramide resulting from degradation of complex sphingolipids cannot be hydrolyzed and it is confined into the lysosomal compartment (257). There is a significant correlation between the ceramide accumulated in situ and the severity of Farber disease (258). The abnormal ceramide storage in the brain results in neuronal dysfunction, leading to progressive neurologic deterioration. The inflammatory component of this disease consists in chronic granulomatous formations (259). Granuloma are small areas characterized by the presence of lymphocytes, monocites and plasma cells (260) and appear to result from a dysregulation of leukocyte functions. However, the sequence of molecular mechanisms leading from defect in ceramide metabolism to leukocyte dysregulation is still unknown.

\section{Krabbe's disease and Gaucher's disease}

Krabbe's disease is a disorder involving the white matter of the central and peripheral nervous systems. It is characterized by a deficiency in the lysosomal enzyme galactocerebrosidase (galactocerebroside betagalactosidase) which is necessary to digest galactocerebroside in myelin forming oligodendrocytes and Schwann cells (261). Abnormal storage of galactosylceramide due to the lack of this enzyme leads to myelinating-cell death. Since galactosylceramides are almost exclusively found in the myelin sheaths of nerve, apoptosis of myelin forming cells leads to a complete arrest of the myelin formation with consequent axonal degeneration. This accounts for the severe degeneration of motor skills observed in the disease.

Another glycosphingolipid called psychosine is normally broken down by galactoceramidase.

Psychosine is present in the normal brain tissues at very low concentrations, owing to its rapid breakdown to sphingosine and galactose by galactosylceramidase. In its absence, psychosine accumulates in the brain acting as cytotoxic metabolite (262) and therefore contributing to oligodendroglial cell death. Psychosine was also found to cause axonal degeneration in both the CNS and peripheral nervous system by disrupting lipid rafts (263). Myelin and/or oligodendrocyte debris produced by 
oligodendrocyte death in Krabbe's disease activates microglial cells, resident macrophages in the brain, which are the primary mediators of neuroinflammation (264).

Because a pathological hallmark of this rapidly progressive demyelinating disease is the presence of multinucleated macrophages (globoid cells) in the nervous system (265) the disease is also known as globoid cell leukodystrophy. However, the function of these cells is unclear.

Gaucher's disease is characterized by the lysosomal accumulation of glucosylceramide (glucocerebroside) due to defects in the gene encoding the lysosomal hydrolase glucosylceramidase, also called glucocerebrosidase (266). In the brain, glucocerebroside accumulates due to the turnover of complex lipids during brain development and the formation of the myelin sheath of nerves (267). The cells most severely affected are neurons because they process large amounts of gangliosides which are components of their membranes and synapses. Enzymes involved in ganglioside degradation are highly expressed in brain tissue and are of particular importance in the first few years of life when axons elongate, dendrites branch and synapses develop (267). Deficiency of these enzymes causes neuronal storage of gangliosides leading to loss of neurons and their axons, resulting in cortical atrophy and white matter degeneration. Cells and organs that do not process large amounts of gangliosides are either normal or show mild storage without cell damage.

Although glucocerebrosidase is present in lysosomes of all cell types, Gaucher's disease patients solely develop storage of glucocerebroside in cells of the mononuclear phagocyte system. Macrophages participate in the degradation of invading microbes, the natural turnover of blood cells and in tissue modeling. Because of this, it is not surprising that in many of the lysosomal storage disorders accumulation of storage material also takes a prominent place in tissue macrophages.

\section{Niemann pick's disease}

Defects in SM degradation results in a neurodegenerative condition known as Niemann-Pick disease (NP). This kind of disorder exists in three major forms. Both NP type A and type B are caused by defects in lysosomal aSMase activity. Affected individuals cannot convert SM to ceramide with consequent accumulation of SM (268). NP type C diseases are caused by defects in a protein that is located in membranes inside the cell and is involved in the movement of cholesterol and lipids within cells (269). A deficiency of this protein leads to the abnormal accumulation of cholesterol and glycolipids in lysosomes. 
Although the clinical presentation of NP type C disease is heterogeneous, most patients exhibit cerebellar atrophy, elevated liver and brain levels of cholesterol and SM as well as marked paucity of Purkinje cells and progressive degeneration of the CNS. Neuronal storage is accompanied with a variety of cellular inclusions as well as occasional presence of neurofibrillary tangles, meganeurites or axonal spheroids.

\section{Neurodegenerative dementia: Alzheimer', Parkinson' and Prion's diseases}

Neural cells are very complex morphologically. The large plasma membrane surfaces of neurons are important for neuronal trafficking, neuron-neuron communication and signalling transduction. During aging and neurodegeneration membrane dysregulation and dysfunction are often found. These alterations in membrane microenvironment occur very early in the CNS (270) (271). Heightened oxidative stress has a profound impact upon membrane lipid-protein organization and signal transduction (272). These changes might be at the basis of diseases such as Alzheimer's disease, Parkinson's disease (PD), synucleopathies, prion diseases, and other dementias.

Lipid rafts have been shown to be involved in the regulation of APP processing and in $A \beta$ peptide formation (273), and represent the principal sites within the membrane where $\beta$-secretase and $\gamma$-secretase generate the pathological amyloid $\beta$ peptide (274-278).

Other lipid raft components, such as the gangliosides GM1 and GM2, have been associated with induction of $A \beta$ transition from a $\alpha$-helix-rich structure to a $\beta$-sheet-rich conformation $(279,280)$. Ganglioside binding with $A \beta$ accelerates $A \beta$ fibril formation (281) which gradually causes membrane raft disruptions and thereby has profound consequences on signal transduction and neurotransmission.

Prion protein (PrPc) is a GPI-anchored protein (282) and together with its pathological variant associates with lipid rafts (283). Moreover, the conversion of PrPc into PrPSc has been shown to occur in these membrane domains (284). Alpha-synuclein associates specifically with lipid rafts (285) and abnormalities of lipid rafts in the frontal cortex occur during the development of PD pathology (286). Massive modification of fatty acid content gives rise to more viscous and liquid ordered rafts in PD brains than in the age-matched control group (286). Also, lipid rafts from AD brains exhibit aberrant lipid profiles compared to healthy brains (287).

Similar lipid changes are also observed in epilepsy and ischemia/stroke (288, 289). Elevations of intracellular ceramide levels, which may in turn be 
associated with induction of apoptotic cell death, have been reported in brain tissues and CSF of AD brain (290) together with reduced SM (291) and altered ganglioside levels (292). In line with this, increase of aCDase (293) and sSMase activity (294) has been detected in the brain of AD patients. The key enzyme in ceramide de novo synthesis, SPT, is regulated by APP processing (295) suggesting that this could be one of probably many mechanisms responsible for the alterations in lipid metabolism at the plasma membrane.

\section{Conclusion}

Ceramide is an important signaling molecule involved in the regulation of the development and death of neurons. The level of ceramide generated can dictate whether development is stimulated or whether apoptosis is induced. Ceramide is beneficial for early growth and development of neuronal cells $(297,298)$ and at low levels it has trophic effects promoting cell survival and division. Ceramide is a vital component in cellular signaling and regulates intra- and intercellular functioning. At higher concentrations however it is often toxic and supports pro-apoptotic actions in many cell types (299). Moreover the initial abnormal formation of ceramide can potently induce more ceramide accumulation in a self-sustaining way $(187,300)$. This induces drastic consequences leading to tissue damage and organ failure (301) The mechanisms by which ceramide induces these disparate effects is not known, but might involve activation of different downstream signaling pathways or its effects in membrane structure.

These apparently contradictory roles can be understood only when we consider ceramide formation as a balanced and vulnerable system. Ceramide is critical for normal cellular function but must be at proper levels. In healthy cells appropriate ceramide levels are maintained by a finely tuned and precisely coordinated ceramide metabolism. This is, however, a fine line to tread and deviation in either direction can have drastic consequences. Where ceramide is concerned, growth arrest or apoptosis are only a slight tilt away. 
References

1. Pruett, S. T., A. Bushnev, K. Hagedorn, M. Adiga, C. A. Haynes, M. C. Sullards, D. C. Liotta, and A. H. Merrill, Jr. 2008. Biodiversity of sphingoid bases ("sphingosines") and related amino alcohols. J Lipid Res 49:1621-1639.

2. Kolesnick, R. 2002. The therapeutic potential of modulating the ceramide/sphingomyelin pathway. J Clin Invest 110:3-8.

3. Bielawska, A., H. M. Crane, D. Liotta, L. M. Obeid, and Y. A. Hannun. 1993. Selectivity of ceramide-mediated biology. Lack of activity of erythro-dihydroceramide. J Biol Chem 268:2622626232.

4. Karasavvas, N., R. K. Erukulla, R. Bittman, R. Lockshin, and Z. Zakeri. 1996. Stereospecific induction of apoptosis in U937 cells by $\mathrm{N}$-octanoyl-sphingosine stereoisomers and $\mathrm{N}$-octylsphingosine. The ceramide amide group is not required for apoptosis. Eur J Biochem 236:729737.

5. Michel, C., and G. van Echten-Deckert. 1997. Conversion of dihydroceramide to ceramide occurs at the cytosolic face of the endoplasmic reticulum. FEBS Lett 416:153-155.

6. Michel, C., G. van Echten-Deckert, J. Rother, K. Sandhoff, E. Wang, and A. H. Merrill, Jr. 1997. Characterization of ceramide synthesis. A dihydroceramide desaturase introduces the 4,5-transdouble bond of sphingosine at the level of dihydroceramide. J Biol Chem 272:22432-22437.

7. Brockman, H. L., M. M. Momsen, R. E. Brown, L. He, J. Chun, H. S. Byun, and R. Bittman. 2004. The 4,5-double bond of ceramide regulates its dipole potential, elastic properties, and packing behavior. Biophys J 87:1722-1731.

8. Li, L., X. Tang, K. G. Taylor, D. B. DuPre, and M. C. Yappert. 2002. Conformational characterization of ceramides by nuclear magnetic resonance spectroscopy. Biophys J 82:2067-2080.

9. Yappert, M. C., and D. Borchman. 2004. Sphingolipids in human lens membranes: an update on their composition and possible biological implications. Chem Phys Lipids 129:1-20.

10. van Blitterswijk, W. J., A. H. van der Luit, R. J. Veldman, M. Verheij, and J. Borst. 2003. Ceramide: second messenger or modulator of membrane structure and dynamics? Biochem J 369:199-211.

11. Chalfant, C. E., Z. Szulc, P. Roddy, A. Bielawska, and Y. A. Hannun. 2004. The structural requirements for ceramide activation of serine-threonine protein phosphatases. J Lipid Res 45:496-506.

12. Venkataraman, K., and A. H. Futerman. 2000. Ceramide as a second messenger: sticky solutions to sticky problems. Trends Cell Biol 10:408-412.

13. Kolesnick, R. N., F. M. Goni, and A. Alonso. 2000. Compartmentalization of ceramide signaling: physical foundations and biological effects. J Cell Physiol 184:285-300.

14. Mathias, S., K. A. Dressler, and R. N. Kolesnick. 1991. Characterization of a ceramide-activated protein kinase: stimulation by tumor necrosis factor alpha. Proc Natl Acad Sci U S A 88:1000910013.

15. Huwiler, A., J. Brunner, R. Hummel, M. Vervoordeldonk, S. Stabel, H. van den Bosch, and J. Pfeilschifter. 1996. Ceramide-binding and activation defines protein kinase c-Raf as a ceramideactivated protein kinase. Proc Natl Acad Sci U S A 93:6959-6963.

16. Hannun, Y. A., and L. M. Obeid. 2002. The Ceramide-centric universe of lipid-mediated cell regulation: stress encounters of the lipid kind. J Biol Chem 277:25847-25850.

17. Van Overloop, H., Y. Denizot, M. Baes, and P. P. Van Veldhoven. 2007. On the presence of C2ceramide in mammalian tissues: possible relationship to etherphospholipids and phosphorylation by ceramide kinase. Biol Chem 388:315-324.

18. Sot, J., L. A. Bagatolli, F. M. Goni, and A. Alonso. 2006. Detergent-resistant, ceramide-enriched domains in sphingomyelin/ceramide bilayers. Biophys J 90:903-914.

19. Ghidoni, R., G. Sala, and A. Giuliani. 1999. Use of sphingolipid analogs: benefits and risks. Biochim Biophys Acta 1439:17-39.

20. Di Paola, M., T. Cocco, and M. Lorusso. 2000. Ceramide interaction with the respiratory chain of heart mitochondria. Biochemistry 39:6660-6668.

21. Helfrich, W. 1973. Elastic properties of lipid bilayers: theory and possible experiments. 
Z Naturforsch C 28:693-703.

22. Bigay, J., J. F. Casella, G. Drin, B. Mesmin, and B. Antonny. 2005. ArfGAP1 responds to membrane curvature through the folding of a lipid packing sensor motif. EMBO J 24:2244-2253.

23. Jao, C. C., A. Der-Sarkissian, J. Chen, and R. Langen. 2004. Structure of membrane-bound alphasynuclein studied by site-directed spin labeling. Proc Natl Acad Sci U S A 101:8331-8336.

24. Veiga, M. P., J. L. Arrondo, F. M. Goni, and A. Alonso. 1999. Ceramides in phospholipid membranes: effects on bilayer stability and transition to nonlamellar phases. Biophys $J$ 76:342-350.

25. Holopainen, J. M., M. Subramanian, and P. K. Kinnunen. 1998. Sphingomyelinase induces lipid microdomain formation in a fluid phosphatidylcholine/sphingomyelin membrane. Biochemistry 37:17562-17570.

26. Holopainen, J. M., J. Y. Lehtonen, and P. K. Kinnunen. 1997. Lipid microdomains in dimyristoylphosphatidylcholine-ceramide liposomes. Chem Phys Lipids 88:1-13.

27. Bai, J., and R. E. Pagano. 1997. Measurement of spontaneous transfer and transbilayer movement of BODIPY-labeled lipids in lipid vesicles. Biochemistry 36:8840-8848.

28. Hanada, K., K. Kumagai, S. Yasuda, Y. Miura, M. Kawano, M. Fukasawa, and M. Nishijima. 2003. Molecular machinery for non-vesicular trafficking of ceramide. Nature 426:803-809.

29. Sot, J., F. M. Goni, and A. Alonso. 2005. Molecular associations and surface-active properties of short- and long-N-acyl chain ceramides. Biochim Biophys Acta 1711:12-19.

30. Zachowski, A. 1993. Phospholipids in animal eukaryotic membranes: transverse asymmetry and movement. Biochem J 294 ( Pt 1):1-14.

31. Thudichum, J. L. W. 1884. The chemical constitution of the brain. Baillère, Tindall, and Cox, London.

32. Karlsson, K. A. 1970. Sphingolipid long chain bases. Lipids 5:878-891.

33. Sullards, M. C., J. C. Allegood, S. Kelly, E. Wang, C. A. Haynes, H. Park, Y. Chen, and A. H. Merrill, Jr. 2007. Structure-specific, quantitative methods for analysis of sphingolipids by liquid chromatography-tandem mass spectrometry: "inside-out" sphingolipidomics. Methods Enzymol 432:83-115.

34. Muse, E. D., H. Jurevics, A. D. Toews, G. K. Matsushima, and P. Morell. 2001. Parameters related to lipid metabolism as markers of myelination in mouse brain. $J$ Neurochem 76:77-86.

35. Satoh, M., Y. Fukushi, S. Kawamura, C. Ohyama, S. Saito, S. Orikasa, E. Nudleman, and S. Hakamori. 1992. Glycolipid expression in prostatic tissue and analysis of the antigen recognized by antiprostatic monoclonal antibody APG1. Urol Int 48:20-24.

36. Sandhoff, K., and T. Kolter. 2003. Biosynthesis and degradation of mammalian glycosphingolipids. Philos Trans R Soc Lond B Biol Sci 358:847-861.

37. Hannun, Y. A. 1996. Functions of ceramide in coordinating cellular responses to stress. Science 274:1855-1859.

38. Mandon, E. C., I. Ehses, J. Rother, G. van Echten, and K. Sandhoff. 1992. Subcellular localization and membrane topology of serine palmitoyltransferase, 3-dehydrosphinganine reductase, and sphinganine $\mathrm{N}$-acyltransferase in mouse liver. J Biol Chem 267:11144-11148.

39. Bionda, C., J. Portoukalian, D. Schmitt, C. Rodriguez-Lafrasse, and D. Ardail. 2004. Subcellular compartmentalization of ceramide metabolism: MAM (mitochondria-associated membrane) and/or mitochondria? Biochem J 382:527-533.

40. Shimeno, H., S. Soeda, M. Sakamoto, T. Kouchi, T. Kowakame, and T. Kihara. 1998. Partial purification and characterization of sphingosine $\mathrm{N}$-acyltransferase (ceramide synthase) from bovine liver mitochondrion-rich fraction. Lipids 33:601-605.

41. Dawkins, J. L., D. J. Hulme, S. B. Brahmbhatt, M. Auer-Grumbach, and G. A. Nicholson. 2001. Mutations in SPTLC1, encoding serine palmitoyltransferase, long chain base subunit-1, cause hereditary sensory neuropathy type I. Nat Genet 27:309-312.

42. Stoffel, W., and K. Bister. 1974. Studies on the desaturation of sphinganine. Ceramide and sphingomyelin metabolism in the rat and in BHK 21 cells in tissue culture. Hoppe Seylers Z Physiol Chem 355:911-923.

43. Pewzner-Jung, Y., S. Ben-Dor, and A. H. Futerman. 2006. When do Lasses (longevity assurance genes) become CerS (ceramide synthases)?: Insights into the regulation of ceramide synthesis. 
J Biol Chem 281:25001-25005.

44. Riebeling, C., J. C. Allegood, E. Wang, A. H. Merrill, Jr., and A. H. Futerman. 2003. Two mammalian longevity assurance gene (LAG1) family members, trh1 and trh4, regulate dihydroceramide synthesis using different fatty acyl-CoA donors. J Biol Chem 278:43452-43459.

45. Lahiri, S., and A. H. Futerman. 2005. LASS5 is a bona fide dihydroceramide synthase that selectively utilizes palmitoyl-CoA as acyl donor. J Biol Chem 280:33735-33738.

46. Marasas, W. F., R. T. Riley, K. A. Hendricks, V. L. Stevens, T. W. Sadler, J. Gelineau-van Waes, S. A. Missmer, J. Cabrera, O. Torres, W. C. Gelderblom, J. Allegood, C. Martinez, J. Maddox, J. D. Miller, L. Starr, M. C. Sullards, A. V. Roman, K. A. Voss, E. Wang, and A. H. Merrill, Jr. 2004. Fumonisins disrupt sphingolipid metabolism, folate transport, and neural tube development in embryo culture and in vivo: a potential risk factor for human neural tube defects among populations consuming fumonisin-contaminated maize. J Nutr 134:711-716.

47. Pomorski, T., S. Hrafnsdottir, P. F. Devaux, and G. van Meer. 2001. Lipid distribution and transport across cellular membranes. Semin Cell Dev Biol 12:139-148.

48. Fukasawa, M., M. Nishijima, and K. Hanada. 1999. Genetic evidence for ATP-dependent endoplasmic reticulum-to-Golgi apparatus trafficking of ceramide for sphingomyelin synthesis in Chinese hamster ovary cells. J Cell Biol 144:673-685.

49. Funakoshi, T., S. Yasuda, M. Fukasawa, M. Nishijima, and K. Hanada. 2000. Reconstitution of ATP- and cytosol-dependent transport of de novo synthesized ceramide to the site of sphingomyelin synthesis in semi-intact cells. J Biol Chem 275:29938-29945.

50. van Meer, G., and J. C. Holthuis. 2000. Sphingolipid transport in eukaryotic cells. Biochim Biophys Acta 1486:145-170.

51. Ullman, M. D., and N. S. Radin. 1974. The enzymatic formation of sphingomyelin from ceramide and lecithin in mouse liver. J Biol Chem 249:1506-1512.

52. Huitema, K., J. van den Dikkenberg, J. F. Brouwers, and J. C. Holthuis. 2004. Identification of a family of animal sphingomyelin synthases. EMBO J 23:33-44.

53. Futerman, A. H., B. Stieger, A. L. Hubbard, and R. E. Pagano. 1990. Sphingomyelin synthesis in rat liver occurs predominantly at the cis and medial cisternae of the Golgi apparatus. J Biol Chem 265:8650-8657.

54. Tafesse, F. G., P. Ternes, and J. C. Holthuis. 2006. The multigenic sphingomyelin synthase family. J Biol Chem 281:29421-29425.

55. Linke, T., G. Wilkening, F. Sadeghlar, H. Mozcall, K. Bernardo, E. Schuchman, and K. Sandhoff. 2001. Interfacial regulation of acid ceramidase activity. Stimulation of ceramide degradation by lysosomal lipids and sphingolipid activator proteins. J Biol Chem 276:5760-5768.

56. van Echten, G., R. Birk, G. Brenner-Weiss, R. R. Schmidt, and K. Sandhoff. 1990. Modulation of sphingolipid biosynthesis in primary cultured neurons by long chain bases. J Biol Chem 265:9333-9339.

57. Sandhoff, K., and G. van Echten. 1993. Ganglioside metabolism--topology and regulation. Adv Lipid Res 26:119-142.

58. Kumagai, K., S. Yasuda, K. Okemoto, M. Nishijima, S. Kobayashi, and K. Hanada. 2005. CERT mediates intermembrane transfer of various molecular species of ceramides. $J$ Biol Chem 280:6488-6495.

59. Rao, R. P., C. Yuan, J. C. Allegood, S. S. Rawat, M. B. Edwards, X. Wang, A. H. Merrill, Jr., U. Acharya, and J. K. Acharya. 2007. Ceramide transfer protein function is essential for normal oxidative stress response and lifespan. Proc Natl Acad Sci U S A 104:11364-11369.

60. Wang, X., R. P. Rao, T. Kosakowska-Cholody, M. A. Masood, E. Southon, H. Zhang, C. Berthet, K. Nagashim, T. K. Veenstra, L. Tessarollo, U. Acharya, and J. K. Acharya. 2009. Mitochondrial degeneration and not apoptosis is the primary cause of embryonic lethality in ceramide transfer protein mutant mice. J Cell Biol 184:143-158.

61. Mencarelli, C., M. Losen, C. Hammels, J. De Vry, M. K. Hesselink, H. W. Steinbusch, M. H. De Baets, and P. Martinez-Martinez. The ceramide transporter and the Goodpasture antigen binding protein: one protein--one function? J Neurochem 113:1369-1386.

62. Granero-Molto, F., S. Sarmah, L. O'Rear, A. Spagnoli, D. Abrahamson, J. Saus, B. G. Hudson, and 
E. W. Knapik. 2008. Goodpasture antigen-binding protein and its spliced variant, ceramide transfer protein, have different functions in the modulation of apoptosis during zebrafish development. J Biol Chem 283:20495-20504.

63. Mencarelli, C., C. Hammels, J. Van Den Broeck, M. Losen, H. Steinbusch, F. Revert, J. Saus, D. A. Hopkins, M. H. De Baets, H. W. Steinbusch, and P. Martinez-Martinez. 2009. The expression of the Goodpasture antigen-binding protein (ceramide transporter) in adult rat brain. J Chem Neuroanat 38:97-105.

64. Raya, A., F. Revert-Ros, P. Martinez-Martinez, S. Navarro, E. Rosello, B. Vieites, F. Granero, J. Forteza, and J. Saus. 2000. Goodpasture antigen-binding protein, the kinase that phosphorylates the goodpasture antigen, is an alternatively spliced variant implicated in autoimmune pathogenesis. J Biol Chem 275:40392-40399.

65. Zandman-Goddard, G., and M. Blank. 2002. Apoptosis and autoimmunity. Isr Med Assoc J 4:722724.

66. Perry, D. K., and Y. A. Hannun. 1998. The role of ceramide in cell signaling. Biochim Biophys Acta 1436:233-243.

67. Reynolds, C. P., B. J. Maurer, and R. N. Kolesnick. 2004. Ceramide synthesis and metabolism as a target for cancer therapy. Cancer Lett 206:169-180.

68. Okazaki, T., A. Bielawska, N. Domae, R. M. Bell, and Y. A. Hannun. 1994. Characteristics and partial purification of a novel cytosolic, magnesium-independent, neutral sphingomyelinase activated in the early signal transduction of 1 alpha,25-dihydroxyvitamin D3-induced HL-60 cell differentiation. J Biol Chem 269:4070-4077.

69. Schissel, S. L., X. Jiang, J. Tweedie-Hardman, T. Jeong, E. H. Camejo, J. Najib, J. H. Rapp, K. J. Williams, and I. Tabas. 1998. Secretory sphingomyelinase, a product of the acid sphingomyelinase gene, can hydrolyze atherogenic lipoproteins at neutral $\mathrm{pH}$. Implications for atherosclerotic lesion development. J Biol Chem 273:2738-2746.

70. Barnholz, Y., A. Roitman, and S. Gatt. 1966. Enzymatic hydrolysis of sphingolipids. II. Hydrolysis of sphingomyelin by an enzyme from rat brain. J Biol Chem 241:3731-3737.

71. Otterbach, B., and W. Stoffel. 1995. Acid sphingomyelinase-deficient mice mimic the neurovisceral form of human lysosomal storage disease (Niemann-Pick disease). Cell 81:10531061.

72. Spence, M. W., D. M. Byers, F. B. Palmer, and H. W. Cook. 1989. A new Zn2+-stimulated sphingomyelinase in fetal bovine serum. J Biol Chem 264:5358-5363.

73. Schissel, S. L., E. H. Schuchman, K. J. Williams, and I. Tabas. 1996. Zn2+-stimulated sphingomyelinase is secreted by many cell types and is a product of the acid sphingomyelinase gene. J Biol Chem 271:18431-18436.

74. Schissel, S. L., G. A. Keesler, E. H. Schuchman, K. J. Williams, and I. Tabas. 1998. The cellular trafficking and zinc dependence of secretory and lysosomal sphingomyelinase, two products of the acid sphingomyelinase gene. J Biol Chem 273:18250-18259.

75. Tomiuk, S., M. Zumbansen, and W. Stoffel. 2000. Characterization and subcellular localization of murine and human magnesium-dependent neutral sphingomyelinase. J Biol Chem 275:5710-5717.

76. Neuberger, Y., H. Shogomori, Z. Levy, M. Fainzilber, and A. H. Futerman. 2000. A lyso-platelet activating factor phospholipase $C$, originally suggested to be a neutral-sphingomyelinase, is located in the endoplasmic reticulum. FEBS Lett 469:44-46.

77. Tomiuk, S., K. Hofmann, M. Nix, M. Zumbansen, and W. Stoffel. 1998. Cloned mammalian neutral sphingomyelinase: functions in sphingolipid signaling? Proc Natl Acad Sci U S A 95:3638-3643.

78. Gatt, S., and T. Gottesdiner. 1976. Solubilization of sphingomyelinase by isotonic extraction of rat brain lysosomes. J Neurochem 26:421-422.

79. Rao, B. G., and M. W. Spence. 1976. Sphingomyelinase activity at pH 7.4 in human brain and a comparison to activity at pH 5.0. J Lipid Res 17:506-515.

80. Marchesini, N., C. Luberto, and Y. A. Hannun. 2003. Biochemical properties of mammalian neutral sphingomyelinase 2 and its role in sphingolipid metabolism. J Biol Chem 278:13775-13783.

81. Krut, O., K. Wiegmann, H. Kashkar, B. Yazdanpanah, and M. Kronke. 2006. Novel tumor necrosis factor-responsive mammalian neutral sphingomyelinase-3 is a C-tail-anchored protein. J Biol 
Chem 281:13784-13793.

82. Cheng, Y., H. D. Tauschel, A. Nilsson, and R. D. Duan. 1999. Ursodeoxycholic acid increases the activities of alkaline sphingomyelinase and caspase-3 in the rat colon. Scand J Gastroenterol 34:915-920.

83. Ybe, J. A., D. E. Wakeham, F. M. Brodsky, and P. K. Hwang. 2000. Molecular structures of proteins involved in vesicle fusion. Traffic 1:474-479.

84. Wakeham, D. E., J. A. Ybe, F. M. Brodsky, and P. K. Hwang. 2000. Molecular structures of proteins involved in vesicle coat formation. Traffic 1:393-398.

85. Smith, E. R., and A. H. Merrill, Jr. 1995. Differential roles of de novo sphingolipid biosynthesis and turnover in the "burst" of free sphingosine and sphinganine, and their 1-phosphates and $\mathrm{N}$-acylderivatives, that occurs upon changing the medium of cells in culture. J Biol Chem 270:1874918758.

86. Gillard, B. K., R. G. Clement, and D. M. Marcus. 1998. Variations among cell lines in the synthesis of sphingolipids in de novo and recycling pathways. Glycobiology 8:885-890.

87. Riboni, L., R. Bassi, A. Caminiti, A. Prinetti, P. Viani, and G. Tettamanti. 1998. Metabolic fate of exogenous sphingosine in neuroblastoma neuro2A cells. Dose-dependence and biological effects. Ann N Y Acad Sci 845:46-56.

88. Chatelut, M., M. Leruth, K. Harzer, A. Dagan, S. Marchesini, S. Gatt, R. Salvayre, P. Courtoy, and T. Levade. 1998. Natural ceramide is unable to escape the lysosome, in contrast to a fluorescent analogue. FEBS Lett 426:102-106.

89. Tani, M., N. Okino, S. Mitsutake, T. Tanigawa, H. Izu, and M. Ito. 2000. Purification and characterization of a neutral ceramidase from mouse liver. A single protein catalyzes the reversible reaction in which ceramide is both hydrolyzed and synthesized. J Biol Chem 275:3462-3468.

90. Gatt, S. 1963. Enzymic Hydrolysis and Synthesis of Ceramides. J Biol Chem 238:3131-3133.

91. Sugita, M., M. Willians, J. T. Dulaney, and H. W. Moser. 1975. Ceramidase and ceramide synthesis in human kidney and cerebellum. Description of a new alkaline ceramidase. Biochim Biophys Acta 398:125-131.

92. Bar, J., T. Linke, K. Ferlinz, U. Neumann, E. H. Schuchman, and K. Sandhoff. 2001. Molecular analysis of acid ceramidase deficiency in patients with Farber disease. Hum Mutat 17:199-209.

93. El Bawab, S., P. Roddy, T. Qian, A. Bielawska, J. J. Lemasters, and Y. A. Hannun. 2000. Molecular cloning and characterization of a human mitochondrial ceramidase. J Biol Chem 275:21508-21513.

94. Shiraishi, T., S. Imai, and Y. Uda. 2003. The presence of ceramidase activity in liver nuclear membrane. Biol Pharm Bull 26:775-779.

95. El Bawab, S., A. Bielawska, and Y. A. Hannun. 1999. Purification and characterization of a membrane-bound nonlysosomal ceramidase from rat brain. J Biol Chem 274:27948-27955.

96. Mao, C., R. Xu, Z. M. Szulc, A. Bielawska, S. H. Galadari, and L. M. Obeid. 2001. Cloning and characterization of a novel human alkaline ceramidase. A mammalian enzyme that hydrolyzes phytoceramide. J Biol Chem 276:26577-26588.

97. Birbes, H., S. El Bawab, L. M. Obeid, and Y. A. Hannun. 2002. Mitochondria and ceramide: intertwined roles in regulation of apoptosis. Adv Enzyme Regul 42:113-129.

98. Gatt, S., and M. M. Rapport. 1966. Enzymic hydrolysis of sphingolipids: Hydrolysis of ceramide lactoside by an enzyme from rat brain. Biochem J 101:680-686.

99. El Bawab, S., H. Birbes, P. Roddy, Z. M. Szulc, A. Bielawska, and Y. A. Hannun. 2001. Biochemical characterization of the reverse activity of rat brain ceramidase. A CoA-independent and fumonisin B1-insensitive ceramide synthase. J Biol Chem 276:16758-16766.

100. Siskind, L. J. 2005. Mitochondrial ceramide and the induction of apoptosis. J Bioenerg Biomembr 37:143-153.

101. Ghosh, T. K., J. Bian, and D. L. Gill. 1994. Sphingosine 1-phosphate generated in the endoplasmic reticulum membrane activates release of stored calcium. J Biol Chem 269:22628-22635.

102. Olivera, A., T. Kohama, L. Edsall, V. Nava, O. Cuvillier, S. Poulton, and S. Spiegel. 1999. Sphingosine kinase expression increases intracellular sphingosine-1-phosphate and promotes cell growth and survival. J Cell Biol 147:545-558.

103. Ballou, L. R., C. P. Chao, M. A. Holness, S. C. Barker, and R. Raghow. 1992. Interleukin-1-mediated 
PGE2 production and sphingomyelin metabolism. Evidence for the regulation of cyclooxygenase gene expression by sphingosine and ceramide. J Biol Chem 267:20044-20050.

104. Hla, T. 2003. Signaling and biological actions of sphingosine 1-phosphate. Pharmacol Res 47:401-407.

105. Stoffel, W., and G. Assmann. 1970. Metabolism of sphingosine bases. XV. Enzymatic degradation of 4t-sphingenine 1-phosphate (sphingosine 1-phosphate) to 2t-hexadecen-1-al and ethanolamine phosphate. Hoppe Seylers Z Physiol Chem 351:1041-1049.

106. Cuvillier, O., G. Pirianov, B. Kleuser, P. G. Vanek, O. A. Coso, S. Gutkind, and S. Spiegel. 1996. Suppression of ceramide-mediated programmed cell death by sphingosine-1-phosphate. Nature 381:800-803.

107. Spiegel, S., A. Olivera, and R. O. Carlson. 1993. The role of sphingosine in cell growth regulation and transmembrane signaling. Adv Lipid Res 25:105-129.

108. Sugiura, M., K. Kono, H. Liu, T. Shimizugawa, H. Minekura, S. Spiegel, and T. Kohama. 2002. Ceramide kinase, a novel lipid kinase. Molecular cloning and functional characterization. $J$ Biol Chem 277:23294-23300.

109. Bajjalieh, S. M., T. F. Martin, and E. Floor. 1989. Synaptic vesicle ceramide kinase. A calciumstimulated lipid kinase that co-purifies with brain synaptic vesicles. J Biol Chem 264:1435414360.

110. Kolesnick, R. N., and M. R. Hemer. 1990. Characterization of a ceramide kinase activity from human leukemia (HL-60) cells. Separation from diacylglycerol kinase activity. I Biol Chem 265:18803-18808.

111. Wijesinghe, D. S., N. F. Lamour, A. Gomez-Munoz, and C. E. Chalfant. 2007. Ceramide kinase and ceramide-1-phosphate. Methods Enzymol 434:265-292.

112. Gomez-Munoz, A., J. Y. Kong, B. Salh, and U. P. Steinbrecher. 2004. Ceramide-1-phosphate blocks apoptosis through inhibition of acid sphingomyelinase in macrophages. J Lipid Res 45:99-105.

113. Arana, L., P. Gangoiti, A. Ouro, M. Trueba, and A. Gomez-Munoz. Ceramide and ceramide 1phosphate in health and disease. Lipids Health Dis 9:15.

114. Gangoiti, P., M. H. Granado, L. Arana, A. Ouro, and A. Gomez-Munoz. Activation of protein kinase C-alpha is essential for stimulation of cell proliferation by ceramide 1-phosphate. FEBS Lett 584:517-524.

115. Bajjalieh, S., and R. Batchelor. 2000. Ceramide kinase. Methods Enzymol 311:207-215.

116. Mitsutake, S., T. J. Kim, Y. Inagaki, M. Kato, T. Yamashita, and Y. Igarashi. 2004. Ceramide kinase is a mediator of calcium-dependent degranulation in mast cells. J Biol Chem 279:17570-17577.

117. Shinghal, R., R. H. Scheller, and S. M. Bajjalieh. 1993. Ceramide 1-phosphate phosphatase activity in brain. J Neurochem 61:2279-2285.

118. Lamour, N. F., R. V. Stahelin, D. S. Wijesinghe, M. Maceyka, E. Wang, J. C. Allegood, A. H. Merrill, Jr., W. Cho, and C. E. Chalfant. 2007. Ceramide kinase uses ceramide provided by ceramide transport protein: localization to organelles of eicosanoid synthesis. J Lipid Res 48:1293-1304.

119. Boath, A., C. Graf, E. Lidome, T. Ullrich, P. Nussbaumer, and F. Bornancin. 2008. Regulation and traffic of ceramide 1-phosphate produced by ceramide kinase: comparative analysis to glucosylceramide and sphingomyelin. J Biol Chem 283:8517-8526.

120. Spiegel, S., and S. Milstien. 2000. Sphingosine-1-phosphate: signaling inside and out. FEBS Lett 476:55-57.

121. Sengupta, P., B. Baird, and D. Holowka. 2007. Lipid rafts, fluid/fluid phase separation, and their relevance to plasma membrane structure and function. Semin Cell Dev Biol 18:583-590.

122. Brown, D. A., and E. London. 1998. Functions of lipid rafts in biological membranes. Annu Rev Cell Dev Biol 14:111-136.

123. van Meer, G. 1989. Lipid traffic in animal cells. Annu Rev Cell Biol 5:247-275.

124. Op den Kamp, J. A. 1979. Lipid asymmetry in membranes. Annu Rev Biochem 48:47-71.

125. Buccoliero, R., and A. H. Futerman. 2003. The roles of ceramide and complex sphingolipids in neuronal cell function. Pharmacol Res 47:409-419.

126. Ogawa-Goto, K., and T. Abe. 1998. Gangliosides and glycosphingolipids of peripheral nervous system myelins--a minireview. Neurochem Res 23:305-310. 
127. Smondyrev, A. M., and M. L. Berkowitz. 1999. Structure of dipalmitoylphosphatidylcholine/cholesterol bilayer at low and high cholesterol concentrations: molecular dynamics simulation. Biophys J 77:2075-2089.

128. Cremesti, A. E., F. M. Goni, and R. Kolesnick. 2002. Role of sphingomyelinase and ceramide in modulating rafts: do biophysical properties determine biologic outcome? FEBS Lett 531:47-53.

129. Pralle, A., P. Keller, E. L. Florin, K. Simons, and J. K. Horber. 2000. Sphingolipid-cholesterol rafts diffuse as small entities in the plasma membrane of mammalian cells. J Cell Biol 148:997-1008.

130. Kusumi, A., and K. Suzuki. 2005. Toward understanding the dynamics of membrane-raft-based molecular interactions. Biochim Biophys Acta 1746:234-251.

131. London, E. 2002. Insights into lipid raft structure and formation from experiments in model membranes. Curr Opin Struct Biol 12:480-486.

132. Schroeder, R., E. London, and D. Brown. 1994. Interactions between saturated acyl chains confer detergent resistance on lipids and glycosylphosphatidylinositol (GPI)-anchored proteins: GPIanchored proteins in liposomes and cells show similar behavior. Proc Natl Acad Sci U S A 91:12130-12134.

133. Simons, K., and W. L. Vaz. 2004. Model systems, lipid rafts, and cell membranes. Annu Rev Biophys Biomol Struct 33:269-295.

134. Simons, K., and E. Ikonen. 1997. Functional rafts in cell membranes. Nature 387:569-572.

135. Henderson, R. M., J. M. Edwardson, N. A. Geisse, and D. E. Saslowsky. 2004. Lipid rafts: feeling is believing. News Physiol Sci 19:39-43.

136. Brown, D. A., and J. K. Rose. 1992. Sorting of GPI-anchored proteins to glycolipid-enriched membrane subdomains during transport to the apical cell surface. Cell 68:533-544.

137. Schon, A., and E. Freire. 1989. Thermodynamics of intersubunit interactions in cholera toxin upon binding to the oligosaccharide portion of its cell surface receptor, ganglioside GM1. Biochemistry 28:5019-5024.

138. Douglass, A. D., and R. D. Vale. 2005. Single-molecule microscopy reveals plasma membrane microdomains created by protein-protein networks that exclude or trap signaling molecules in $\mathrm{T}$ cells. Cell 121:937-950.

139. Harder, T., P. Scheiffele, P. Verkade, and K. Simons. 1998. Lipid domain structure of the plasma membrane revealed by patching of membrane components. J Cell Biol 141:929-942.

140. Ritchie, K., R. lino, T. Fujiwara, K. Murase, and A. Kusumi. 2003. The fence and picket structure of the plasma membrane of live cells as revealed by single molecule techniques (Review). Mol Membr Biol 20:13-18.

141. Gagescu, R., J. Gruenberg, and E. Smythe. 2000. Membrane dynamics in endocytosis: structure-function relationship. Traffic 1:84-88.

142. Dermine, J. F., S. Duclos, J. Garin, F. St-Louis, S. Rea, R. G. Parton, and M. Desjardins. 2001. Flotillin-1-enriched lipid raft domains accumulate on maturing phagosomes. I Biol Chem 276:18507-18512.

143. Fivaz, M., F. Vilbois, S. Thurnheer, C. Pasquali, L. Abrami, P. E. Bickel, R. G. Parton, and F. G. van der Goot. 2002. Differential sorting and fate of endocytosed GPI-anchored proteins. EMBO J 21:3989-4000.

144. Fullekrug, J., and K. Simons. 2004. Lipid rafts and apical membrane traffic. Ann N Y Acad Sci 1014:164-169.

145. Steer, C. J., M. Bisher, R. Blumenthal, and A. C. Steven. 1984. Detection of membrane cholesterol by filipin in isolated rat liver coated vesicles is dependent upon removal of the clathrin coat. J Cell Biol 99:315-319.

146. Coxey, R. A., P. G. Pentchev, G. Campbell, and E. J. Blanchette-Mackie. 1993. Differential accumulation of cholesterol in Golgi compartments of normal and Niemann-Pick type C fibroblasts incubated with LDL: a cytochemical freeze-fracture study. J Lipid Res 34:1165-1176.

147. Sobo, K., I. Le Blanc, P. P. Luyet, M. Fivaz, C. Ferguson, R. G. Parton, J. Gruenberg, and F. G. van der Goot. 2007. Late endosomal cholesterol accumulation leads to impaired intra-endosomal trafficking. PLoS One 2:e851.

148. Eberle, H. B., R. L. Serrano, J. Fullekrug, A. Schlosser, W. D. Lehmann, F. Lottspeich, D. 
Kaloyanova, F. T. Wieland, and J. B. Helms. 2002. Identification and characterization of a novel human plant pathogenesis-related protein that localizes to lipid-enriched microdomains in the Golgi complex. J Cell Sci 115:827-838.

149. Brown, D. A. 2006. Lipid rafts, detergent-resistant membranes, and raft targeting signals. Physiology (Bethesda) 21:430-439.

150. Abrami, L., M. Fivaz, T. Kobayashi, T. Kinoshita, R. G. Parton, and F. G. van der Goot. 2001. Crosstalk between caveolae and glycosylphosphatidylinositol-rich domains. J Biol Chem 276:3072930736.

151. Pierini, L. M., and F. R. Maxfield. 2001. Flotillas of lipid rafts fore and aft. Proc Natl Acad Sci U S A 98:9471-9473.

152. Simons, K., and D. Toomre. 2000. Lipid rafts and signal transduction. Nat Rev Mol Cell Biol 1:31-39.

153. Manes, S., E. Mira, C. Gomez-Mouton, R. A. Lacalle, P. Keller, J. P. Labrador, and A. C. Martinez. 1999. Membrane raft microdomains mediate front-rear polarity in migrating cells. EMBO J 18:6211-6220.

154. Holthuis, J. C., G. van Meer, and K. Huitema. 2003. Lipid microdomains, lipid translocation and the organization of intracellular membrane transport (Review). Mol Membr Biol 20:231-241.

155. Salaun, C., D. J. James, and L. H. Chamberlain. 2004. Lipid rafts and the regulation of exocytosis. Traffic 5:255-264.

156. Salaun, C., G. W. Gould, and L. H. Chamberlain. 2005. Lipid raft association of SNARE proteins regulates exocytosis in PC12 cells. J Biol Chem 280:19449-19453.

157. Mendez, A. J., G. Lin, D. P. Wade, R. M. Lawn, and J. F. Oram. 2001. Membrane lipid domains distinct from cholesterol/sphingomyelin-rich rafts are involved in the ABCA1-mediated lipid secretory pathway. J Biol Chem 276:3158-3166.

158. Anderson, R. G., and K. Jacobson. 2002. A role for lipid shells in targeting proteins to caveolae, rafts, and other lipid domains. Science 296:1821-1825.

159. Lingwood, D., and K. Simons. Lipid rafts as a membrane-organizing principle. Science 327:46-50.

160. Kasahara, K., and Y. Sanai. 2000. Functional roles of glycosphingolipids in signal transduction via lipid rafts. Glycoconj J 17:153-162.

161. Melkonian, K. A., A. G. Ostermeyer, J. Z. Chen, M. G. Roth, and D. A. Brown. 1999. Role of lipid modifications in targeting proteins to detergent-resistant membrane rafts. Many raft proteins are acylated, while few are prenylated. J Biol Chem 274:3910-3917.

162. Kurzchalia, T. V., and R. G. Parton. 1999. Membrane microdomains and caveolae. Curr Opin Cell Biol 11:424-431.

163. Babiychuk, E. B., K. Monastyrskaya, F. C. Burkhard, S. Wray, and A. Draeger. 2002. Modulating signaling events in smooth muscle: cleavage of annexin 2 abolishes its binding to lipid rafts. FASEB J 16:1177-1184.

164. Bollinger, C. R., V. Teichgraber, and E. Gulbins. 2005. Ceramide-enriched membrane domains. Biochim Biophys Acta 1746:284-294.

165. Megha, and E. London. 2004. Ceramide selectively displaces cholesterol from ordered lipid domains (rafts): implications for lipid raft structure and function. J Biol Chem 279:9997-10004.

166. Nurminen, T. A., J. M. Holopainen, H. Zhao, and P. K. Kinnunen. 2002. Observation of topical catalysis by sphingomyelinase coupled to microspheres. J Am Chem Soc 124:12129-12134.

167. Megha, P. Sawatzki, T. Kolter, R. Bittman, and E. London. 2007. Effect of ceramide N-acyl chain and polar headgroup structure on the properties of ordered lipid domains (lipid rafts). Biochim Biophys Acta 1768:2205-2212.

168. Harder, T., and K. R. Engelhardt. 2004. Membrane domains in lymphocytes - from lipid rafts to protein scaffolds. Traffic 5:265-275.

169. Grassme, H., A. Cremesti, R. Kolesnick, and E. Gulbins. 2003. Ceramide-mediated clustering is required for CD95-DISC formation. Oncogene 22:5457-5470.

170. Ledesma, M. D., B. Brugger, C. Bunning, F. T. Wieland, and C. G. Dotti. 1999. Maturation of the axonal plasma membrane requires upregulation of sphingomyelin synthesis and formation of protein-lipid complexes. EMBO J 18:1761-1771.

171. Maekawa, S., S. lino, and S. Miyata. 2003. Molecular characterization of the detergent-insoluble 
cholesterol-rich membrane microdomain (raft) of the central nervous system. Biochim Biophys Acta 1610:261-270.

172. Malchiodi-Albedi, F., V. Contrusciere, C. Raggi, K. Fecchi, G. Rainaldi, S. Paradisi, A. Matteucci, M. T. Santini, M. Sargiacomo, C. Frank, M. C. Gaudiano, and M. Diociaiuti. Lipid raft disruption protects mature neurons against amyloid oligomer toxicity. Biochim Biophys Acta 1802:406-415.

173. Gil, C., A. Soler-Jover, J. Blasi, and J. Aguilera. 2005. Synaptic proteins and SNARE complexes are localized in lipid rafts from rat brain synaptosomes. Biochem Biophys Res Commun 329:117-124.

174. Lv, J. H., L. He, and S. F. Sui. 2008. Lipid rafts association of synaptotagmin I on synaptic vesicles. Biochemistry (Mosc) 73:283-288.

175. Hering, H., C. C. Lin, and M. Sheng. 2003. Lipid rafts in the maintenance of synapses, dendritic spines, and surface AMPA receptor stability. J Neurosci 23:3262-3271.

176. Bruses, J. L., N. Chauvet, and U. Rutishauser. 2001. Membrane lipid rafts are necessary for the maintenance of the (alpha)7 nicotinic acetylcholine receptor in somatic spines of ciliary neurons. J Neurosci 21:504-512.

177. Becher, A., J. H. White, and R. A. Mcllhinney. 2001. The gamma-aminobutyric acid receptor B, but not the metabotropic glutamate receptor type-1, associates with lipid rafts in the rat cerebellum. J Neurochem 79:787-795.

178. Suzuki, T., J. Ito, H. Takagi, F. Saitoh, H. Nawa, and H. Shimizu. 2001. Biochemical evidence for localization of AMPA-type glutamate receptor subunits in the dendritic raft. Brain Res Mol Brain Res 89:20-28.

179. Besshoh, S., D. Bawa, L. Teves, M. C. Wallace, and J. W. Gurd. 2005. Increased phosphorylation and redistribution of NMDA receptors between synaptic lipid rafts and post-synaptic densities following transient global ischemia in the rat brain. J Neurochem 93:186-194.

180. Povlsen, G. K., and D. K. Ditlevsen. 2008. The Neural Cell Adhesion Molecule NCAM and Lipid Rafts. Neurochem Res.

181. Delling, M., E. Wischmeyer, A. Dityatev, V. Sytnyk, R. W. Veh, A. Karschin, and M. Schachner. 2002. The neural cell adhesion molecule regulates cell-surface delivery of G-protein-activated inwardly rectifying potassium channels via lipid rafts. J Neurosci 22:7154-7164.

182. Pristera, A., and K. Okuse. Building Excitable Membranes: Lipid Rafts and Multiple Controls on Trafficking of Electrogenic Molecules. Neuroscientist.

183. Kamiguchi, H. 2006. The region-specific activities of lipid rafts during axon growth and guidance. J Neurochem 98:330-335.

184. Vinson, M., O. Rausch, P. R. Maycox, R. K. Prinjha, D. Chapman, R. Morrow, A. J. Harper, C. Dingwall, F. S. Walsh, S. A. Burbidge, and D. R. Riddell. 2003. Lipid rafts mediate the interaction between myelin-associated glycoprotein (MAG) on myelin and MAG-receptors on neurons. $\mathrm{Mol}$ Cell Neurosci 22:344-352.

185. Copani, A., D. Uberti, M. A. Sortino, V. Bruno, F. Nicoletti, and M. Memo. 2001. Activation of cellcycle-associated proteins in neuronal death: a mandatory or dispensable path? Trends Neurosci 24:25-31.

186. Kolesnick, R., and Y. A. Hannun. 1999. Ceramide and apoptosis. Trends Biochem Sci 24:224-225; author reply 227.

187. Obeid, L. M., C. M. Linardic, L. A. Karolak, and Y. A. Hannun. 1993. Programmed cell death induced by ceramide. Science 259:1769-1771.

188. Novgorodov, S. A., Z. M. Szulc, C. Luberto, J. A. Jones, J. Bielawski, A. Bielawska, Y. A. Hannun, and L. M. Obeid. 2005. Positively charged ceramide is a potent inducer of mitochondrial permeabilization. J Biol Chem 280:16096-16105.

189. Bose, R., M. Verheij, A. Haimovitz-Friedman, K. Scotto, Z. Fuks, and R. Kolesnick. 1995. Ceramide synthase mediates daunorubicin-induced apoptosis: an alternative mechanism for generating death signals. Cell 82:405-414.

190. Dbaibo, G. S., W. El-Assaad, A. Krikorian, B. Liu, K. Diab, N. Z. Idriss, M. El-Sabban, T. A. Driscoll, D. K. Perry, and Y. A. Hannun. 2001. Ceramide generation by two distinct pathways in tumor necrosis factor alpha-induced cell death. FEBS Lett 503:7-12.

191. Santana, P., L. A. Pena, A. Haimovitz-Friedman, S. Martin, D. Green, M. McLoughlin, C. Cordon- 
Cardo, E. H. Schuchman, Z. Fuks, and R. Kolesnick. 1996. Acid sphingomyelinase-deficient human lymphoblasts and mice are defective in radiation-induced apoptosis. Cell 86:189-199.

192. Wang, E., W. P. Norred, C. W. Bacon, R. T. Riley, and A. H. Merrill, Jr. 1991. Inhibition of sphingolipid biosynthesis by fumonisins. Implications for diseases associated with Fusarium moniliforme. J Biol Chem 266:14486-14490.

193. Merrill, A. H., Jr., G. van Echten, E. Wang, and K. Sandhoff. 1993. Fumonisin B1 inhibits sphingosine (sphinganine) $\mathrm{N}$-acyltransferase and de novo sphingolipid biosynthesis in cultured neurons in situ. J Biol Chem 268:27299-27306.

194. Furuya, S., J. Mitoma, A. Makino, and Y. Hirabayashi. 1998. Ceramide and its interconvertible metabolite sphingosine function as indispensable lipid factors involved in survival and dendritic differentiation of cerebellar Purkinje cells. J Neurochem 71:366-377.

195. Tepper, A. D., P. Ruurs, T. Wiedmer, P. J. Sims, J. Borst, and W. J. van Blitterswijk. 2000. Sphingomyelin hydrolysis to ceramide during the execution phase of apoptosis results from phospholipid scrambling and alters cell-surface morphology. J Cell Biol 150:155-164.

196. Son, J. H., H. H. Yoo, and D. H. Kim. 2007. Activation of de novo synthetic pathway of ceramides is responsible for the initiation of hydrogen peroxide-induced apoptosis in HL-60 cells. J Toxicol Environ Health A 70:1310-1318.

197. Blazquez, C., I. Galve-Roperh, and M. Guzman. 2000. De novo-synthesized ceramide signals apoptosis in astrocytes via extracellular signal-regulated kinase. FASEB J 14:2315-2322.

198. Perry, D. K., J. Carton, A. K. Shah, F. Meredith, D. J. Uhlinger, and Y. A. Hannun. 2000. Serine palmitoyltransferase regulates de novo ceramide generation during etoposide-induced apoptosis. J Biol Chem 275:9078-9084.

199. MacEwan, D. J. 2002. TNF receptor subtype signalling: differences and cellular consequences. Cell Signal 14:477-492.

200. Wiegmann, K., S. Schutze, T. Machleidt, D. Witte, and M. Kronke. 1994. Functional dichotomy of neutral and acidic sphingomyelinases in tumor necrosis factor signaling. Cell 78:1005-1015.

201. Cifone, M. G., P. Roncaioli, R. De Maria, G. Camarda, A. Santoni, G. Ruberti, and R. Testi. 1995. Multiple pathways originate at the Fas/APO-1 (CD95) receptor: sequential involvement of phosphatidylcholine-specific phospholipase $C$ and acidic sphingomyelinase in the propagation of the apoptotic signal. EMBO J 14:5859-5868.

202. Adam, D., K. Wiegmann, S. Adam-Klages, A. Ruff, and M. Kronke. 1996. A novel cytoplasmic domain of the p55 tumor necrosis factor receptor initiates the neutral sphingomyelinase pathway. J Biol Chem 271:14617-14622.

203. Adam-Klages, S., R. Schwandner, D. Adam, D. Kreder, K. Bernardo, and M. Kronke. 1998. Distinct adapter proteins mediate acid versus neutral sphingomyelinase activation through the p55 receptor for tumor necrosis factor. J Leukoc Biol 63:678-682.

204. Tartaglia, L. A., T. M. Ayres, G. H. Wong, and D. V. Goeddel. 1993. A novel domain within the 55 kd TNF receptor signals cell death. Cell 74:845-853.

205. Hsu, H., H. B. Shu, M. G. Pan, and D. V. Goeddel. 1996. TRADD-TRAF2 and TRADD-FADD interactions define two distinct TNF receptor 1 signal transduction pathways. Cell 84:299-308.

206. Wiegmann, K., R. Schwandner, O. Krut, W. C. Yeh, T. W. Mak, and M. Kronke. 1999. Requirement of FADD for tumor necrosis factor-induced activation of acid sphingomyelinase. J Biol Chem 274:5267-5270.

207. Grassme, H., H. Schwarz, and E. Gulbins. 2001. Molecular mechanisms of ceramide-mediated CD95 clustering. Biochem Biophys Res Commun 284:1016-1030.

208. Zeidan, Y. H., and Y. A. Hannun. 2007. Activation of acid sphingomyelinase by protein kinase Cdelta-mediated phosphorylation. J Biol Chem 282:11549-11561.

209. Heinrich, M., M. Wickel, W. Schneider-Brachert, C. Sandberg, J. Gahr, R. Schwandner, T. Weber, P. Saftig, C. Peters, J. Brunner, M. Kronke, and S. Schutze. 1999. Cathepsin D targeted by acid sphingomyelinase-derived ceramide. EMBO J 18:5252-5263.

210. Scaffidi, C., I. Schmitz, J. Zha, S. J. Korsmeyer, P. H. Krammer, and M. E. Peter. 1999. Differential modulation of apoptosis sensitivity in CD95 type I and type II cells. J Biol Chem 274:2253222538. 
211. Heinrich, M., J. Neumeyer, M. Jakob, C. Hallas, V. Tchikov, S. Winoto-Morbach, M. Wickel, W. Schneider-Brachert, A. Trauzold, A. Hethke, and S. Schutze. 2004. Cathepsin D links TNF-induced acid sphingomyelinase to Bid-mediated caspase-9 and -3 activation. Cell Death Differ 11:550-563.

212. Adam, D., S. Adam-Klages, and M. Kronke. 1995. Identification of p55 tumor necrosis factor receptor-associated proteins that couple to signaling pathways not initiated by the death domain. J Inflamm 47:61-66.

213. Galadari, S., K. Kishikawa, C. Kamibayashi, M. C. Mumby, and Y. A. Hannun. 1998. Purification and characterization of ceramide-activated protein phosphatases. Biochemistry 37:11232-11238.

214. Dobrowsky, R. T., and Y. A. Hannun. 1993. Ceramide-activated protein phosphatase: partial purification and relationship to protein phosphatase 2A. Adv Lipid Res 25:91-104.

215. Dbaibo, G. S., M. Y. Pushkareva, S. Jayadev, J. K. Schwarz, J. M. Horowitz, L. M. Obeid, and Y. A. Hannun. 1995. Retinoblastoma gene product as a downstream target for a ceramide-dependent pathway of growth arrest. Proc Natl Acad Sci U S A 92:1347-1351.

216. Ruvolo, P. P., X. Deng, T. Ito, B. K. Carr, and W. S. May. 1999. Ceramide induces Bcl2 dephosphorylation via a mechanism involving mitochondrial PP2A. J Biol Chem 274:20296-20300.

217. Wolff, R. A., R. T. Dobrowsky, A. Bielawska, L. M. Obeid, and Y. A. Hannun. 1994. Role of ceramide-activated protein phosphatase in ceramide-mediated signal transduction. J Biol Chem 269:19605-19609.

218. Reyes, J. G., I. G. Robayna, P. S. Delgado, I. H. Gonzalez, J. Q. Aguiar, F. E. Rosas, L. F. Fanjul, and C. M. Galarreta. 1996. c-Jun is a downstream target for ceramide-activated protein phosphatase in A431 cells. J Biol Chem 271:21375-21380.

219. Zeidan, Y. H., B. X. Wu, R. W. Jenkins, L. M. Obeid, and Y. A. Hannun. 2008. A novel role for protein kinase Cdelta-mediated phosphorylation of acid sphingomyelinase in UV light-induced mitochondrial injury. FASEB J 22:183-193.

220. Hernandez, O. M., D. J. Discher, N. H. Bishopric, and K. A. Webster. 2000. Rapid activation of neutral sphingomyelinase by hypoxia-reoxygenation of cardiac myocytes. Circ Res 86:198-204.

221. Jin, J., Q. Hou, T. D. Mullen, Y. H. Zeidan, J. Bielawski, J. M. Kraveka, A. Bielawska, L. M. Obeid, Y. A. Hannun, and Y. T. Hsu. 2008. Ceramide generated by sphingomyelin hydrolysis and the salvage pathway is involved in hypoxia/reoxygenation-induced Bax redistribution to mitochondria in NT-2 cells. J Biol Chem 283:26509-26517.

222. Bruno, A. P., G. Laurent, D. Averbeck, C. Demur, J. Bonnet, A. Bettaieb, T. Levade, and J. P. Jaffrezou. 1998. Lack of ceramide generation in TF-1 human myeloid leukemic cells resistant to ionizing radiation. Cell Death Differ 5:172-182.

223. Luberto, C., D. F. Hassler, P. Signorelli, Y. Okamoto, H. Sawai, E. Boros, D. J. Hazen-Martin, L. M. Obeid, Y. A. Hannun, and G. K. Smith. 2002. Inhibition of tumor necrosis factor-induced cell death in MCF7 by a novel inhibitor of neutral sphingomyelinase. J Biol Chem 277:41128-41139.

224. Liu, Y. Y., J. Y. Yu, D. Yin, G. A. Patwardhan, V. Gupta, Y. Hirabayashi, W. M. Holleran, A. E. Giuliano, S. M. Jazwinski, V. Gouaze-Andersson, D. P. Consoli, and M. C. Cabot. 2008. A role for ceramide in driving cancer cell resistance to doxorubicin. FASEB J 22:2541-2551.

225. Thevissen, K., I. E. Francois, J. Winderickx, C. Pannecouque, and B. P. Cammue. 2006. Ceramide involvement in apoptosis and apoptotic diseases. Mini Rev Med Chem 6:699-709.

226. Kirschnek, S., F. Paris, M. Weller, H. Grassme, K. Ferlinz, A. Riehle, Z. Fuks, R. Kolesnick, and E. Gulbins. 2000. CD95-mediated apoptosis in vivo involves acid sphingomyelinase. J Biol Chem 275:27316-27323.

227. Garcia-Ruiz, C., A. Colell, M. Mari, A. Morales, M. Calvo, C. Enrich, and J. C. Fernandez-Checa. 2003. Defective TNF-alpha-mediated hepatocellular apoptosis and liver damage in acidic sphingomyelinase knockout mice. J Clin Invest 111:197-208.

228. Cremesti, A., F. Paris, H. Grassme, N. Holler, J. Tschopp, Z. Fuks, E. Gulbins, and R. Kolesnick. 2001. Ceramide enables fas to cap and kill. J Biol Chem 276:23954-23961.

229. Segui, B., N. Andrieu-Abadie, S. Adam-Klages, O. Meilhac, D. Kreder, V. Garcia, A. P. Bruno, J. P. Jaffrezou, R. Salvayre, M. Kronke, and T. Levade. 1999. CD40 signals apoptosis through FANregulated activation of the sphingomyelin-ceramide pathway. J Biol Chem 274:37251-37258.

230. Liu, J. J., J. Y. Wang, E. Hertervig, Y. Cheng, A. Nilsson, and R. D. Duan. 2000. Activation of neutral 
sphingomyelinase participates in ethanol-induced apoptosis in Hep G2 cells. Alcohol Alcohol 35:569-573.

231. Levy, M., S. S. Castillo, and T. Goldkorn. 2006. nSMase2 activation and trafficking are modulated by oxidative stress to induce apoptosis. Biochem Biophys Res Commun 344:900-905.

232. Jaffrezou, J. P., T. Levade, A. Bettaieb, N. Andrieu, C. Bezombes, N. Maestre, S. Vermeersch, A. Rousse, and G. Laurent. 1996. Daunorubicin-induced apoptosis: triggering of ceramide generation through sphingomyelin hydrolysis. EMBO J 15:2417-2424.

233. Grassme, H., V. Jendrossek, A. Riehle, G. von Kurthy, J. Berger, H. Schwarz, M. Weller, R. Kolesnick, and E. Gulbins. 2003. Host defense against Pseudomonas aeruginosa requires ceramide-rich membrane rafts. Nat Med 9:322-330.

234. Esen, M., B. Schreiner, V. Jendrossek, F. Lang, K. Fassbender, H. Grassme, and E. Gulbins. 2001. Mechanisms of Staphylococcus aureus induced apoptosis of human endothelial cells. Apoptosis 6:431-439.

235. Grassme, H., A. Riehle, B. Wilker, and E. Gulbins. 2005. Rhinoviruses infect human epithelial cells via ceramide-enriched membrane platforms. J Biol Chem 280:26256-26262.

236. Gomez del Pulgar, T., G. Velasco, C. Sanchez, A. Haro, and M. Guzman. 2002. De novosynthesized ceramide is involved in cannabinoid-induced apoptosis. Biochem J 363:183-188.

237. Kalen, A., R. A. Borchardt, and R. M. Bell. 1992. Elevated ceramide levels in GH4C1 cells treated with retinoic acid. Biochim Biophys Acta 1125:90-96.

238. Kroesen, B. J., B. Pettus, C. Luberto, M. Busman, H. Sietsma, L. de Leij, and Y. A. Hannun. 2001. Induction of apoptosis through B-cell receptor cross-linking occurs via de novo generated C16ceramide and involves mitochondria. J Biol Chem 276:13606-13614.

239. Gulbins, E. 2003. Regulation of death receptor signaling and apoptosis by ceramide. Pharmacol Res 47:393-399.

240. Heinrich, M., M. Wickel, S. Winoto-Morbach, W. Schneider-Brachert, T. Weber, J. Brunner, P. Saftig, C. Peters, M. Kronke, and S. Schutze. 2000. Ceramide as an activator lipid of cathepsin D. Adv Exp Med Biol 477:305-315.

241. Mattson, M. P., W. Duan, and N. Maswood. 2002. How does the brain control lifespan? Ageing Res Rev 1:155-165.

242. Cutler, R. G., and M. P. Mattson. 2001. Sphingomyelin and ceramide as regulators of development and lifespan. Mech Ageing Dev 122:895-908.

243. Kolter, T., and K. Sandhoff. 2006. Sphingolipid metabolism diseases. Biochim Biophys Acta 1758:2057-2079.

244. Schorling, S., B. Vallee, W. P. Barz, H. Riezman, and D. Oesterhelt. 2001. Lag1p and Lac1p are essential for the Acyl-CoA-dependent ceramide synthase reaction in Saccharomyces cerevisae. Mol Biol Cell 12:3417-3427.

245. D'Mello N, P., A. M. Childress, D. S. Franklin, S. P. Kale, C. Pinswasdi, and S. M. Jazwinski. 1994. Cloning and characterization of LAG1, a longevity-assurance gene in yeast. J Biol Chem 269:15451-15459.

246. Koybasi, S., C. E. Senkal, K. Sundararaj, S. Spassieva, J. Bielawski, W. Osta, T. A. Day, J. C. Jiang, S. M. Jazwinski, Y. A. Hannun, L. M. Obeid, and B. Ogretmen. 2004. Defects in cell growth regulation by C18:0-ceramide and longevity assurance gene 1 in human head and neck squamous cell carcinomas. J Biol Chem 279:44311-44319.

247. Wooten-Blanks, L. G., P. Song, C. E. Senkal, and B. Ogretmen. 2007. Mechanisms of ceramidemediated repression of the human telomerase reverse transcriptase promoter via deacetylation of Sp3 by histone deacetylase 1. FASEB J 21:3386-3397.

248. Lee, H. W., M. A. Blasco, G. J. Gottlieb, J. W. Horner, 2nd, C. W. Greider, and R. A. DePinho. 1998. Essential role of mouse telomerase in highly proliferative organs. Nature 392:569-574.

249. Blasco, M. A., W. Funk, B. Villeponteau, and C. W. Greider. 1995. Functional characterization and developmental regulation of mouse telomerase RNA. Science 269:1267-1270.

250. Prowse, K. R., and C. W. Greider. 1995. Developmental and tissue-specific regulation of mouse telomerase and telomere length. Proc Natl Acad Sci U S A 92:4818-4822.

251. Caporaso, G. L., D. A. Lim, A. Alvarez-Buylla, and M. V. Chao. 2003. Telomerase activity in the 
subventricular zone of adult mice. Mol Cell Neurosci 23:693-702.

252. Venable, M. E., J. Y. Lee, M. J. Smyth, A. Bielawska, and L. M. Obeid. 1995. Role of ceramide in cellular senescence. J Biol Chem 270:30701-30708.

253. Venable, M. E., and X. Yin. 2009. Ceramide induces endothelial cell senescence. Cell Biochem Funct 27:547-551.

254. Venable, M. E., L. M. Webb-Froehlich, E. F. Sloan, and J. E. Thomley. 2006. Shift in sphingolipid metabolism leads to an accumulation of ceramide in senescence. Mech Ageing Dev 127:473-480.

255. Sacket, S. J., H. Y. Chung, F. Okajima, and D. S. Im. 2009. Increase in sphingolipid catabolic enzyme activity during aging. Acta Pharmacol Sin 30:1454-1461.

256. Crocker, A. C., and S. Farber. 1958. Niemann-Pick disease: a review of eighteen patients. Medicine (Baltimore) 37:1-95.

257. Sugita, M., J. T. Dulaney, and H. W. Moser. 1972. Ceramidase deficiency in Farber's disease (lipogranulomatosis). Science 178:1100-1102.

258. Levade, T., H. W. Moser, A. H. Fensom, K. Harzer, A. B. Moser, and R. Salvayre. 1995. Neurodegenerative course in ceramidase deficiency (Farber disease) correlates with the residual lysosomal ceramide turnover in cultured living patient cells. J Neurol Sci 134:108-114.

259. Ehlert, K., M. Frosch, N. Fehse, A. Zander, J. Roth, and J. Vormoor. 2007. Farber disease: clinical presentation, pathogenesis and a new approach to treatment. Pediatr Rheumatol Online J 5:15.

260. Adams, D. O. 1976. The granulomatous inflammatory response. A review. Am J Pathol 84:164-192.

261. Suzuki, K. 1985. Genetic galactosylceramidase deficiency (globoid cell leukodystrophy, Krabbe disease) in different mammalian species. Neurochem Pathol 3:53-68.

262. Kanazawa, T., S. Nakamura, M. Momoi, T. Yamaji, H. Takematsu, H. Yano, H. Sabe, A. Yamamoto, T. Kawasaki, and Y. Kozutsumi. 2000. Inhibition of cytokinesis by a lipid metabolite, psychosine. J Cell Biol 149:943-950.

263. White, A. B., M. I. Givogri, A. Lopez-Rosas, H. Cao, R. van Breemen, G. Thinakaran, and E. R. Bongarzone. 2009. Psychosine accumulates in membrane microdomains in the brain of krabbe patients, disrupting the raft architecture. J Neurosci 29:6068-6077.

264. Farooqui, A. A., L. A. Horrocks, and T. Farooqui. 2007. Modulation of inflammation in brain: a matter of fat. J Neurochem 101:577-599.

265. Suzuki, K. 1994. A genetic demyelinating disease globoid cell leukodystrophy: studies with animal models. J Neuropathol Exp Neurol 53:359-363.

266. Brady, R. O., J. N. Kanfer, R. M. Bradley, and D. Shapiro. 1966. Demonstration of a deficiency of glucocerebroside-cleaving enzyme in Gaucher's disease. J Clin Invest 45:1112-1115.

267. Orvisky, E., J. K. Park, M. E. LaMarca, E. I. Ginns, B. M. Martin, N. Tayebi, and E. Sidransky. 2002. Glucosylsphingosine accumulation in tissues from patients with Gaucher disease: correlation with phenotype and genotype. Mol Genet Metab 76:262-270.

268. Brady, R. O., J. N. Kanfer, M. B. Mock, and D. S. Fredrickson. 1966. The metabolism of sphingomyelin. II. Evidence of an enzymatic deficiency in Niemann-Pick diseae. Proc Natl Acad Sci U S A 55:366-369.

269. Zhang, J. R., T. Coleman, S. J. Langmade, D. E. Scherrer, L. Lane, M. H. Lanier, C. Feng, M. S. Sands, J. E. Schaffer, C. F. Semenkovich, and D. S. Ory. 2008. Niemann-Pick C1 protects against atherosclerosis in mice via regulation of macrophage intracellular cholesterol trafficking. $J$ Clin Invest 118:2281-2290.

270. Lampert, P., J. Hooks, C. J. Gibbs, Jr., and D. C. Gajdusek. 1971. Altered plasma membranes in experimental scrapie. Acta Neuropathol 19:81-93.

271. Svennerholm, L., K. Bostrom, C. G. Helander, and B. Jungbjer. 1991. Membrane lipids in the aging human brain. J Neurochem 56:2051-2059.

272. Smith, H. L., M. C. Howland, A. W. Szmodis, Q. Li, L. L. Daemen, A. N. Parikh, and J. Majewski. 2009. Early stages of oxidative stress-induced membrane permeabilization: a neutron reflectometry study. J Am Chem Soc 131:3631-3638.

273. Vetrivel, K. S., and G. Thinakaran. Membrane rafts in Alzheimer's disease beta-amyloid production. Biochim Biophys Acta 1801:860-867.

274. Cordy, J. M., I. Hussain, C. Dingwall, N. M. Hooper, and A. J. Turner. 2003. Exclusively targeting 
beta-secretase to lipid rafts by GPI-anchor addition up-regulates beta-site processing of the amyloid precursor protein. Proc Natl Acad Sci U S A 100:11735-11740.

275. Tun, H., L. Marlow, I. Pinnix, R. Kinsey, and K. Sambamurti. 2002. Lipid rafts play an important role in A beta biogenesis by regulating the beta-secretase pathway. J Mol Neurosci 19:31-35.

276. Marlow, L., M. Cain, M. A. Pappolla, and K. Sambamurti. 2003. Beta-secretase processing of the Alzheimer's amyloid protein precursor (APP). J Mol Neurosci 20:233-239.

277. Vetrivel, K. S., H. Cheng, S. H. Kim, Y. Chen, N. Y. Barnes, A. T. Parent, S. S. Sisodia, and G. Thinakaran. 2005. Spatial segregation of gamma-secretase and substrates in distinct membrane domains. J Biol Chem 280:25892-25900.

278. Urano, Y., I. Hayashi, N. Isoo, P. C. Reid, Y. Shibasaki, N. Noguchi, T. Tomita, T. Iwatsubo, T. Hamakubo, and T. Kodama. 2005. Association of active gamma-secretase complex with lipid rafts. J Lipid Res 46:904-912.

279. Yanagisawa, K., A. Odaka, N. Suzuki, and Y. Ihara. 1995. GM1 ganglioside-bound amyloid betaprotein (A beta): a possible form of preamyloid in Alzheimer's disease. Nat Med 1:1062-1066.

280. Mao, Y., Z. Shang, Y. Imai, T. Hoshino, R. Tero, M. Tanaka, N. Yamamoto, K. Yanagisawa, and T. Urisu. Surface-induced phase separation of a sphingomyelin/cholesterol/ganglioside GM1planar bilayer on mica surfaces and microdomain molecular conformation that accelerates Abeta oligomerization. Biochim Biophys Acta 1798:1090-1099.

281. Choo-Smith, L. P., and W. K. Surewicz. 1997. The interaction between Alzheimer amyloid beta(140) peptide and ganglioside GM1-containing membranes. FEBS Lett 402:95-98.

282. Hooper, N. M. 2005. Glycosylation and GPI anchorage of the prion protein. Adv Exp Med Biol 564:95-96.

283. Naslavsky, N., R. Stein, A. Yanai, G. Friedlander, and A. Taraboulos. 1997. Characterization of detergent-insoluble complexes containing the cellular prion protein and its scrapie isoform. J. Biol Chem 272:6324-6331.

284. Hooper, N. M. 2005. Roles of proteolysis and lipid rafts in the processing of the amyloid precursor protein and prion protein. Biochem Soc Trans 33:335-338.

285. Fortin, D. L., M. D. Troyer, K. Nakamura, S. Kubo, M. D. Anthony, and R. H. Edwards. 2004. Lipid rafts mediate the synaptic localization of alpha-synuclein. J Neurosci 24:6715-6723.

286. Fabelo, N., V. Martin, G. Santpere, R. Marin, L. Torrent, I. Ferrer, and M. Diaz. Severe alterations in lipid composition of frontal cortex lipid rafts from Parkinson's disease and incidental Parkinson's disease. Mol Med 17:1107-1118.

287. Martin, V., N. Fabelo, G. Santpere, B. Puig, R. Marin, I. Ferrer, and M. Diaz. Lipid alterations in lipid rafts from Alzheimer's disease human brain cortex. J Alzheimers Dis 19:489-502.

288. Ariga, T., W. D. Jarvis, and R. K. Yu. 1998. Role of sphingolipid-mediated cell death in neurodegenerative diseases. J Lipid Res 39:1-16.

289. Nicotera, P., M. Leist, and L. Manzo. 1999. Neuronal cell death: a demise with different shapes. Trends Pharmacol Sci 20:46-51.

290. Satoi, H., H. Tomimoto, R. Ohtani, T. Kitano, T. Kondo, M. Watanabe, N. Oka, I. Akiguchi, S. Furuya, Y. Hirabayashi, and T. Okazaki. 2005. Astroglial expression of ceramide in Alzheimer's disease brains: a role during neuronal apoptosis. Neuroscience 130:657-666.

291. Han, X., M. H. D, D. W. McKeel, Jr., J. Kelley, and J. C. Morris. 2002. Substantial sulfatide deficiency and ceramide elevation in very early Alzheimer's disease: potential role in disease pathogenesis. J Neurochem 82:809-818.

292. Kalanj, S., I. Kracun, H. Rosner, and C. Cosovic. 1991. Regional distribution of brain gangliosides in Alzheimer's disease. Neurol Croat 40:269-281.

293. Huang, Y., H. Tanimukai, F. Liu, K. Iqbal, I. Grundke-lqbal, and C. X. Gong. 2004. Elevation of the level and activity of acid ceramidase in Alzheimer's disease brain. Eur J Neurosci 20:3489-3497.

294. He, X., Y. Huang, B. Li, C. X. Gong, and E. H. Schuchman. Deregulation of sphingolipid metabolism in Alzheimer's disease. Neurobiol Aging 31:398-408.

295. Grimm, M. O., S. Grosgen, T. L. Rothhaar, V. K. Burg, B. Hundsdorfer, V. J. Haupenthal, P. Friess, U. Muller, K. Fassbender, M. Riemenschneider, H. S. Grimm, and T. Hartmann. Intracellular APP Domain Regulates Serine-Palmitoyl-CoA Transferase Expression and Is Affected in Alzheimer's 
Disease. Int J Alzheimers Dis 2011:695413.

296. Adibhatla, R. M., and J. F. Hatcher. 2008. Altered lipid metabolism in brain injury and disorders. Subcell Biochem 49:241-268.

297. Brann, A. B., R. Scott, Y. Neuberger, D. Abulafia, S. Boldin, M. Fainzilber, and A. H. Futerman. 1999. Ceramide signaling downstream of the $p 75$ neurotrophin receptor mediates the effects of nerve growth factor on outgrowth of cultured hippocampal neurons. J Neurosci 19:8199-8206.

298. Schwarz, A., and A. H. Futerman. 1997. Distinct roles for ceramide and glucosylceramide at different stages of neuronal growth. J Neurosci 17:2929-2938.

299. Kolesnick, R. N., and M. Kronke. 1998. Regulation of ceramide production and apoptosis. Annu Rev Physiol 60:643-665.

300. Jarvis, W. D., F. A. Fornari, Jr., J. L. Browning, D. A. Gewirtz, R. N. Kolesnick, and S. Grant. 1994. Attenuation of ceramide-induced apoptosis by diglyceride in human myeloid leukemia cells. J Biol Chem 269:31685-31692.

301. Goodman, Y., and M. P. Mattson. 1996. Ceramide protects hippocampal neurons against excitotoxic and oxidative insults, and amyloid beta-peptide toxicity. J Neurochem 66:869-872.

302. Corazzi, L., L. Binaglia, R. Roberti, L. Freysz, G. Arienti, and G. Porcellati. 1983. Compartmentation of membrane phosphatidylethanolamine formed by base-exchange reaction in rat brain microsomes. Biochim Biophys Acta 730:104-110. 


\section{Chapter 3}

\section{The Expression of the Goodpasture Antigen-Binding Protein (Ceramide Transporter) in Adult Rat Brain}

Chiara Mencarelli, Caroline Hammels, Joost Van Den Broeck, Mario Losen, Hellen Steinbusch, Francisco Revert, Juan Saus, David A Hopkins, Marc H De Baets, Harry W Steinbusch and Pilar Martínez-Martínez 


\begin{abstract}
The Goodpasture antigen-binding protein (GPBP) plays a critical role in brain development. Knockdown of GPBP leads to loss of myelinated tracts in the central nervous system and to extensive apoptosis in the brain during early embryogenesis. GPBP was initially identified as a protein associated with the autoantigen in Goodpasture autoimmune syndrome, where it was shown to be a kinase that regulates type IV collagen organization. GPBP isoforms bind and transport ceramide from the endoplasmic reticulum to the Golgi apparatus and are therefore also known as ceramide transporters (CERT). Ceramide dysregulation is involved in autoimmunity and neurodegenerative disorders.

In order to analyze the possible role of GPBP in neuroinflammation and neurodegeneration we studied the basal GPBP expression in normal rat brain. High levels of immunoreactivity were detected in neurons of the cerebral cortex, hippocampal formation, the basal ganglia, the olfactory bulb and nuclei of the thalamus, the hypothalamus and the septal area. Lower expression levels of GPBP were observed widely throughout the brain, suggesting that GPBP plays an important role in central nervous system neuron function.
\end{abstract}




\section{Introduction}

The Goodpasture antigen-binding protein (GPBP) has attracted attention over the last few years because of the crucial role that it seem to play in a variety of cellular functions in both physiological and pathological conditions (Hanada et al., 2003; Revert et al., 2007; Granero-Molto et al., 2008). Several investigations have revealed a complex story of isoforms and multiple cellular localizations. Raya et al. (1999) characterized a 624 amino acid isoform as a serine/threonine kinase that binds and phosphorylates the noncollagenous NC1 domain of the $\alpha 3$-chain of type IV collagen, the Goodpasture antigen. Therefore, the protein was called Goodpasture antigen-binding protein, GPBP. It was thought that the kinase activity of GPBP might play a role in the etiology of Goodpasture's syndrome, an antibody-mediated autoimmune disorder characterized by rapidly progressive glomerulonephrititis and pulmonary hemorrhage (Stanton and Tange, 1958; Raya et al., 1999). In line with this, altered phosphorylation of specific serines has been shown to change intracellular proteolysis, affecting antigen-processing and presentation (Krebs, 1994).

Subsequently, in 2003, Hanada and colleagues (Hanada et al., 2003) discovered that a shorter variant of GPBP that lacks a serine rich domain of 26 amino acid residues due to an alternative spicing event has a function in the trafficking of the lipid ceramide from the endoplasmic reticulum (ER), where it is produced, to the Golgi apparatus, where it is converted to sphingomyelin. Hence they named this protein, already known as GPBP $\triangle 26$ (Raya et al., 2000), CERT. Hanada et al. (2003) also showed that the longer isoform had ceramide transport properties in vitro and therefore, GPBP was renamed as $C E R T_{L}$.with the consequence that two different names have been used to identify the two variants. Therefore, in order to avoid confusion; we will refer to all isoforms as GPBPs. Thus the longer splice variant is named $G P B P / C E R T_{L}$ and the shorter splice variant is named GPBP $\triangle 26 / C E R T$, in reference to previous papers, while relating the specific isoform to their functions. In keeping with their structural homologies, both proteins function as ceramide transporters. However, the presence of the 26-residue serine-rich motif confers unique properties to the longer isoform GPBP/CERT . This motif allows GPBP/CERTL to be secreted extracellularly and likely is also responsible for its more prominent kinase activity compared to GPBP $\triangle 26 / C E R T$ (Revert et al., 2008). GPBP/CERT $T_{L}$ is also able to bind type IV collagen with high affinity, in contrast to GPBP $\triangle 26 / C E R T$ which has low-affinity binding to type IV collagen (Raya et al., 2000).

In addition, it has been recently shown that GPBP/CERT $T_{L}$ exists, in turn, as 
multiple isoforms due to an alternative translation initiation (Revert et al., 2008). In fact, its mRNA, in addition to the traditional initiation codon, presents a non canonical translation ACG initiation site located upstream of the known AUG. These conventional and alternative start sites result, respectively, in the synthesis of two polypeptides of 77 and $91 \mathrm{kDa}$, harboring different amino terminal domains that confer distinct functions to the isoforms and control their cellular localizations. The $91 \mathrm{kDa}$ product partly enters the secretory pathway where it undergoes covalent modifications to yield a $120 \mathrm{kDa}$ polypeptide (Revert et al., 2008). Similarly, GPBP $\triangle 26 / C E R T$ exists as different isoforms resulting from canonical (approximately $77 \mathrm{kDa}$ ) and noncanonical (91 kDa and $120 \mathrm{kDa}$ ) mRNA translation initiation.

In a zebrafish model, GPBP/CERT $T_{\mathrm{L}}$ has been shown to be an important factor for normal brain ontogenesis and it is mostly expressed at early stages of embryogenesis. In contrast, the levels of its spliced shorter variant GPBP $\triangle 26 / C E R T$ are initially very low and gradually increase at later developmental stages. Specific knockdown of the GPBP/CERT isoform induces extensive apoptosis and tissue loss in brain and muscle (GraneroMolto et al., 2008). The relative expression of these two isoforms varies between tissues, i.e., GPBP $\triangle 26 / C E R T$ is widely expressed in normal adult human tissues, while GPBP/CERT $T_{L}$ accumulates in several autoimmune conditions such as lupus erythematosus, lichen planus, pemphigus and Goodpasture's syndrome (Raya et al., 2000). Transgenic overexpression of human GPBP in mice leads to abnormal organization of the type IV collagen network in the kidney glomerular basement membrane. These disturbances lead to production and deposition of IgA at the glomerular basement membrane (Revert et al., 2007). Moreover, it has been shown that the proinflammatory cytokine TNF $\alpha$ induces transcription of GPBP/CERT $T_{L}$ by increasing nuclear levels of NFKB (Granero et al., 2005). These data further confirm the link between GPBP/CERT $T_{L}$ and the immune system.

Ceramide is a sphingolipid that, in addition to its functional role in the structure of the membranes, acts as a lipid second messenger in various signaling systems that determine cellular fate (Mathias et al., 1998; Hannun and Obeid, 2002). Studies on the role of ceramide signaling in the central and peripheral nervous system have revealed that it is involved in the overall regulation of terminal differentiation of neurons (Bieberich et al., 2001), growth of neurons (Schwarz and Futerman, 1997), cellular senescence and neuronal death (Haimovitz-Friedman et al., 1997). Impaired regulation of the amount of ceramide in the cell was shown to have effects consistent with neuronal death in Parkinson's disease (France-Lanord et al., 1997) and 
Alzheimer's disease (France-Lanord et al., 1997; Cutler et al., 2004). Whether such impaired regulation is due to abnormal expression of GPBPs has yet to be clarified.

Since many aspects of the in vivo physiological function of GPBPs remain unknown, the immunohistochemical study of the localization and abundance of GPBPs in specific tissues is important. The localization of these proteins has already been described for kidney, lung and skin. In this study, we investigate the localization of GPBPs in adult rat brain under basal conditions. We demonstrate that these proteins are present in neuronal cells and are widely distributed throughout the whole brain with particularly high expression in certain regions of the cerebral cortex, forebrain, hippocampus and diencephalon.

\section{Materials and methods}

\section{Animals}

Five-month old male Wistar rats weighing around $600 \mathrm{~g}$ were obtained from the Department of Experimental Animal Services, Maastricht University, The Netherlands, for a research protocol approved by the Committee on Animal Welfare in accordance with Dutch governmental rules.

\section{Tissue preparation}

One group of rats $(n=10)$ was anesthetized $(100 \mathrm{mg} / \mathrm{kg}$ ketamine and 15 $\mathrm{mg} / \mathrm{kg}$ xylazine) and subsequently perfused transcardially with Tyrode solution $(0.1 \mathrm{M})$ and fixative containing $4 \%$ paraformaldehyde in $0.1 \mathrm{M}$ phosphate buffer $(\mathrm{pH} 7.6)$. The solutions were either kept at $4^{\circ} \mathrm{C}$ or at room temperature during perfusion. Brains were removed and post-fixed for $2 \mathrm{~h}$ followed by overnight immersion in increasing sucrose gradient (10\% to $30 \%)$ at $4^{\circ} \mathrm{C}$. Brain tissue was then quickly frozen with $\mathrm{CO}^{2}$ and stored at $-80^{\circ} \mathrm{C}$.

Another group of ten animals was killed by an overdose of pentobarbital (Nembutal, $150 \mathrm{mg} / \mathrm{kg}$ ) and brains were removed and fixed by immersion in $4 \%$ paraformaldehyde, $15 \%$ picric acid and $0.05 \%$ glutaraldehyde in phosphate buffer ( $\mathrm{pH}$ 7.6) for four days. The fixative was either kept at $4^{\circ} \mathrm{C}$ or at room temperature during fixation. The brains were then quickly frozen and stored at $-80^{\circ} \mathrm{C}$ until further processing. For the immunohistochemical analysis, the brains were cut into series of 30 or $50 \mu \mathrm{m}$ coronal cryostat sections which were stored at $-80^{\circ} \mathrm{C}$.

To study the distribution of staining of GPBPs in the brain by immunohistochemistry, we first optimized the fixation method. The brains 
of the perfused animals showed a more intense staining compared to the postfixed brains (data not shown). Additionally, the brains that were fixed in ice-cold buffers showed more intense staining compared to brains fixed with buffers at room temperature (data not shown). All photomicrographs showing immunohistochemical staining are from brain tissue from rats perfused with cold $\left(4^{\circ} \mathrm{C}\right)$ fixative.

\section{Western Blot}

Rat cortex and hippocampus were isolated as described before (Van den Hove et al., 2006) and placed in ice cold lysis buffer containing PBS, $0.1 \%$ SDS, $0.1 \%$ Triton X-100, 1\% glycerol, 1 mM EDTA, 1 mM EGTA, 30 mM NaF, and $16.7 \mathrm{mM} \mathrm{Na}_{3} \mathrm{VO}_{4}$ and a Complete Protease Inhibitor Cocktail tablet per $50 \mathrm{~mL}$ of buffer, following manufacturers recommendations (Roche Diagnostics, Almere, The Netherlands). Glass beads and a bead beater (Biospec products, Bartlesville, OK, USA) were used for the homogenization of the tissue.

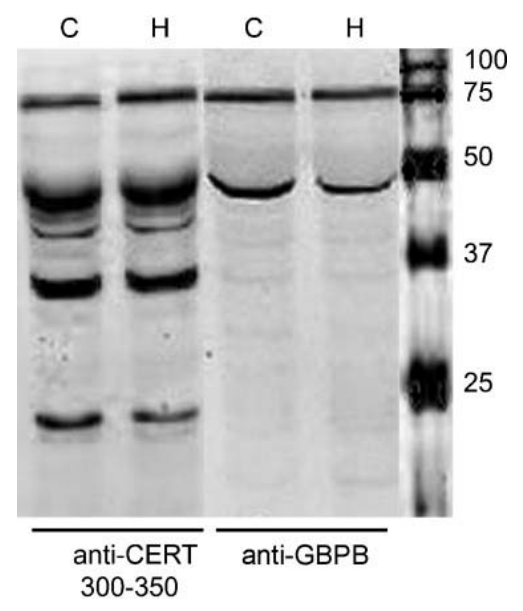

Figure 1. Western blot of GPBPs in rat brain. The proteins were transferred and blotted with polyclonal anti-CERT antibody epitope 300-350 and polyclonal anti-GPBP antibody (Raya et al., 1999) (C = cerebral cortex and $\mathrm{H}=$ hippocampal formation).

(Biospec products, Bartlesville, OK, USA) were used for the homogenization of the tissue. The homogenization consisted of 3 cycles of $30 \mathrm{~s}$ in $350 \mu$ (for hippocampus) or $1.0 \mathrm{ml}$ (for frontal cortex) lysis buffer. 10\% SDS-PAGE gels were loaded with $40 \mu \mathrm{g}$ of total protein and transferred to a $0.45 \mu \mathrm{m}$ nitrocellulose membrane (Millipore, Amsterdam, The Netherlands). The membrane was blocked for $1 \mathrm{~h}$ with Odyssey blocking buffer (Westburg, Leusden, The Netherlands) diluted in PBS (1:1) and incubated with rabbit 
anti-CERT (diluted 1:2500; epitope 300-350 of human GPBP from Bethyl Laboratories, Montgomery, TX, USA) or rabbit anti-GPBP $(1 / 300$; as described in Raya et al., 1999) in the aforementioned blocking buffer overnight at $4^{\circ} \mathrm{C}$. After PBS washes, the membrane was incubated with goat anti-rabbit-Alexa 680 (diluted 1:10,000 in blocking buffer; Rockland, USA) for $1 \mathrm{~h}$ at room temperature. Finally, the membrane was washed with PBS, dried and scanned using the Odyssey infrared imaging system (Westburg, Leusden, The Netherlands).

\section{Immunohistochemistry}

Four antibodies were used. These were a rabbit polyclonal anti-CERT antibody (diluted 1:500; epitope 300-350 of human GPBP, Bethyl Laboratories, USA), a rabbit polyclonal anti-CERT antibody (diluted 1:500; epitope 1-50 of human GPBP, Bethyl Laboratories), a rabbit polyclonal antihuman GPBPs antibody (1:500; as described in Raya et al., 1999) and a monoclonal mouse anti-GPBPs mAb-14 (1:1000; as described in Raya et al., 1999 and characterized by Revert et al. 2008). This latter polyclonal antihuman GPBP was produced by immunizing rabbits with GST-FLAG-GPBP following standard procedures. Briefly, specific antibodies against GPBP were purified sequentially from rabbit serum by immunoadsorption on a GST-FLAG-GPBP-sepharose column and further removal of GST-specific antibodies by immunoadsorption on a GST-sepharose column.

The polyclonal anti-CERT antibody binds to the 300-350 amino acid sequence while the polyclonal anti-GPBP antibody binds to the $\mathrm{N}$-terminal region. Consequently, both antibodies recognize both isoforms. The monoclonal antibody 14 raised against the FFAT epitope, binds to the approximately $77 \mathrm{kDa}$ isoforms of both the GPBP/CERT $T_{L}$ and the GPBP $\triangle 26 / C E R T$. Due to post translational modifications that occur in the secretory pathway, it reacts very weakly with the 91 and $120 \mathrm{kDa}$ products (Revert et al., 2008).

Immunohistochemistry was carried out using $30 \mu \mathrm{m}$ or $50 \mu \mathrm{m}$ thick freefloating sections which were incubated overnight at room temperature with the primary antibody. After rinsing with Tris-buffered saline (TBS) with 50 $\mathrm{mM}$ Triton (TBS-T), sections were incubated with the corresponding secondary antibody: biotinylated donkey anti-mouse IgG (diluted 1:400; Jackson ImmunoResearch Laboratories Europe Ltd., Newmarket, Suffolk, UK) or biotinylated donkey anti-rabbit IgG (diluted 1:800; Jackson ImmunoResearch Laboratories Europe Ltd). Subsequently, sections were incubated with the ABC-kit (Vector Laboratories, Burlingame, CA, USA) for 
$1.5 \mathrm{~h}$. To visualize the horseradish peroxide (HRP) reaction product, the sections were incubated with 3,3'-diaminobenzidine tetrahydrochloride (DAB). No labeling was evident in control experiments in which the primary antibodies were replaced with the pre-immune serum in the immunostaining protocol using tissue from cortex and from hippocampal regions. A control antibody anti-ErbB2 (rabbit IgG anti-human Erb2, Santa Cruz Biotechnology, Santa Cruz, CA, USA) in place of primary polyclonal antibodies resulted in a different patterns of immunoreactivity in the cerebral cortex and hippocampal formation (Supplementary Fig. 2). A mouse IgG1 anti-human rapsyn (Sigma Aldrich, St Louis, MO, USA) isotype control, incubated with the same secondary, did not stain brain tissue (Supplementary Fig. 2). Sections were photographed with an Olympus AX70 microscope (Olympus, Hamburg, Germany). Pictures were taken with Cell P software (Olympus). Brain regions were identified according to the atlas of Paxinos and Watson (1982).

\section{NeuN, GFAP, Ox-42 fluorescent double-labeling immunohistochemistry}

Free floating sections from brain tissue of rats perfused with cold fixative were co-incubated with a rabbit polyclonal anti-CERT antibody (diluted 1:50; epitope 300-350 of human GPBP, Bethyl Laboratories) and a mouse monoclonal antibody raised against NeuN (diluted 1:50; Chemicon International Inc, Temecula, CA, USA), OX-42 (diluted 1:100; BD Biosciences, Breda, The Netherlands) or GFAP (diluted 1:50; Sigma, St. Louis, MO, USA) overnight at room temperature.

After washes, sections were incubated with the corresponding secondary antibodies: Alexa -488-conjugated donkey anti rabbit IgG antibody (diluted 1:100; Jackson ImmunoResearch Laboratories Europe Ltd.), streptavidin Alexa-594 (diluted 1:50; Invitrogen, Breda, The Netherlands) and Alexa-594conjugated donkey anti mouse IgG antibody (diluted 1:100; Invitrogen).

For the GPBP colocalization with NeuN, primary and secondary antibodies for each target were incubated separately in subsequent steps to reduce crossreactivity in antibody-antigen interactions. Negative controls were performed using the secondary antibodies with only one of the primary antibodies. Sections were mounted on coated glasses with $80 \%$ glycerol in TBS. Images were captured using an Olympus AX70 microscope using Cell P software and processed with Adobe Photoshop. 

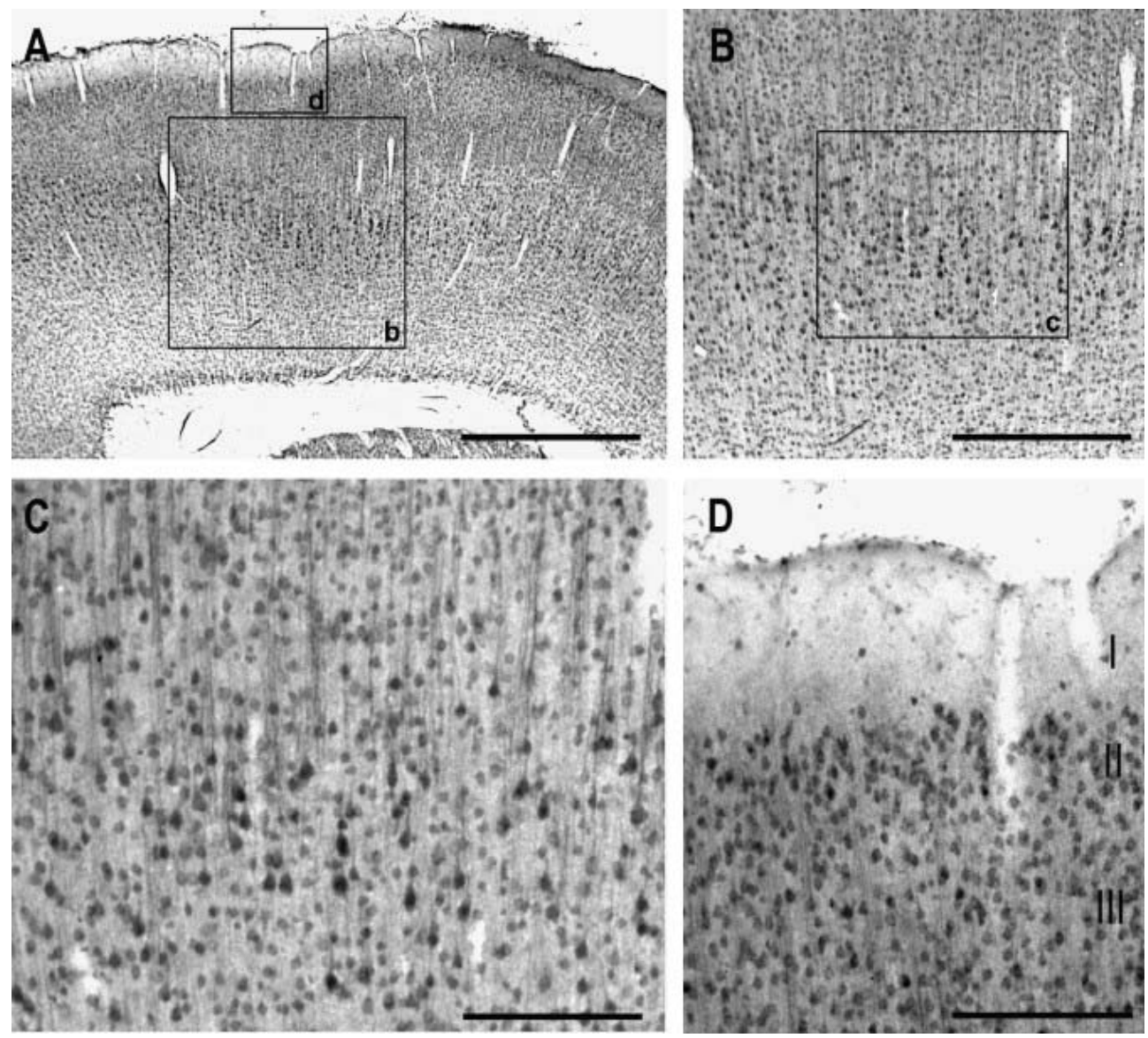

Figure 2. Distribution of GPBPs-positive cells in the cerebral cortex of adult rat brain. (A) Overview of the motor and sensory cortex. (B) Higher magnification of layers IV, V and VI of the sensory cortex. (C) Higher magnification of layer $V$ of the sensory cortex. (D) Magnification of layers I, II and III of the sensory cortex. Scale bars: $A=1 \mathrm{~mm} ; \mathrm{B}=500 \mu \mathrm{m} ; \mathrm{C}, \mathrm{D}=200 \mu \mathrm{m}$.

\section{Results}

\section{Characterization of anti-GPBPs antibodies}

To study the specificity of the antibodies, we performed Western blot analyses using cerebral cortex and hippocampal brain tissue. Both the antiCERT (epitope 300-350) and anti-GPBP polyclonal antibodies detected a band of $77 \mathrm{kDa}$ in the cortex and in the hippocampus (Fig. 1). Additionally, both antibodies recognized a band around $50 \mathrm{kDa}$ which has been previously described (Revert et al., 2008). The anti-CERT antibody showed also 

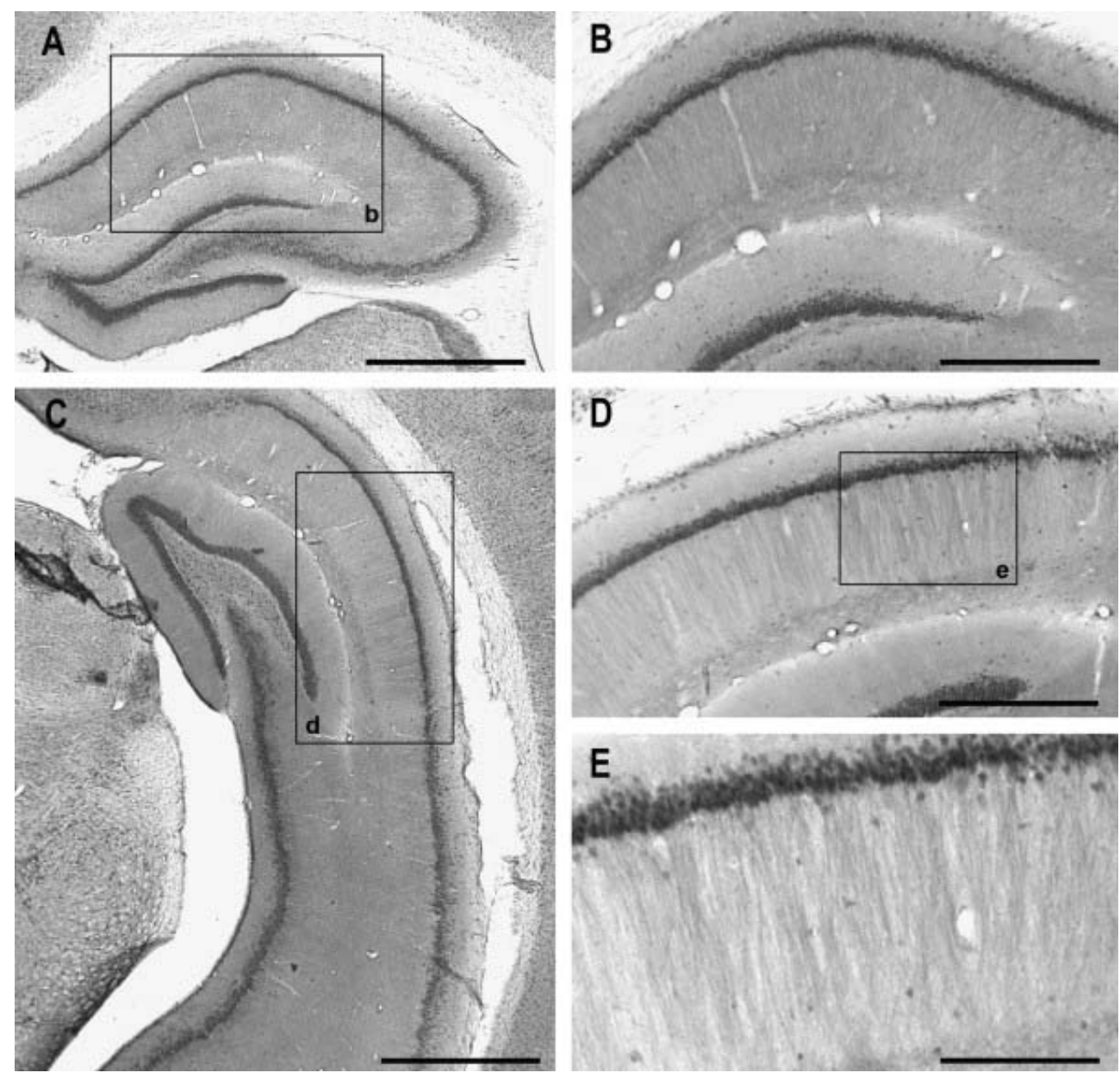

Figure 4. Distribution of GPBPs-positive cells in the basal ganglia of adult rat brain. (A) Caudate putamen.

(B) Globus pallidus.

(C) Overview of substantia nigra.

(D) Substantia nigra.

Scale bars: A, B, D = $200 \mu \mathrm{m} ; \mathrm{C}=500 \mu \mathrm{m}$.

reactivity for a polypeptide band around $30 \mathrm{kDa}$, which has been proposed to correspond to GPBP/CERTL. These molecular weights are comparable to polypeptides described in earlier studies which reported a molecular weight for GPBPs ranging from 30 to $120 \mathrm{kDa}$ (Revert et al., 2008). The specificity of the mouse anti-GPBPs mAb-14 has been previously demonstrated (Raya et al., 1999). A Western blot of cerebral cortex and hippocampal brain tissue that was incubated with the secondary antibodies only (thus omitting the primary antibodies) showed no signal (not shown). 

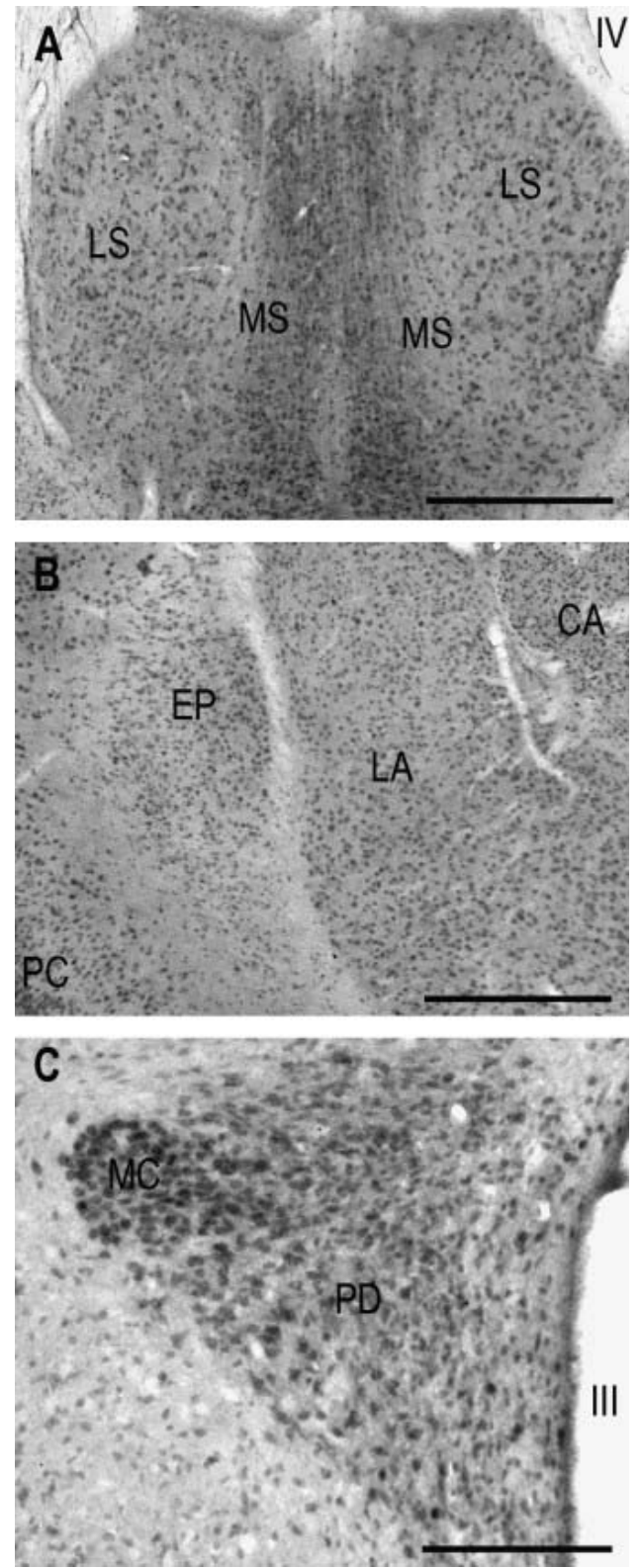

Figure 5. Distribution of GPBPs-positive cells in the septal area, amygdala and hypothalamus of adult rat brain. (A) Septal area. (B) Amygdala. (C) Paraventricular hypothalamic nucleus. Abbreviations: CA, central amygdaloid nucleus; $E P$, endopiriform nucleus; LA, lateral amygdaloid nucleus; LS, lateral septal nucleus; MC, magnocellular division; MS, medial septal nucleus; PD, parvicellular division; PC, piriform cortex; III, third ventricle; IV, fourth ventricle. Scale bars: $A, B=500 \mu \mathrm{m} ; C=200 \mu \mathrm{m}$

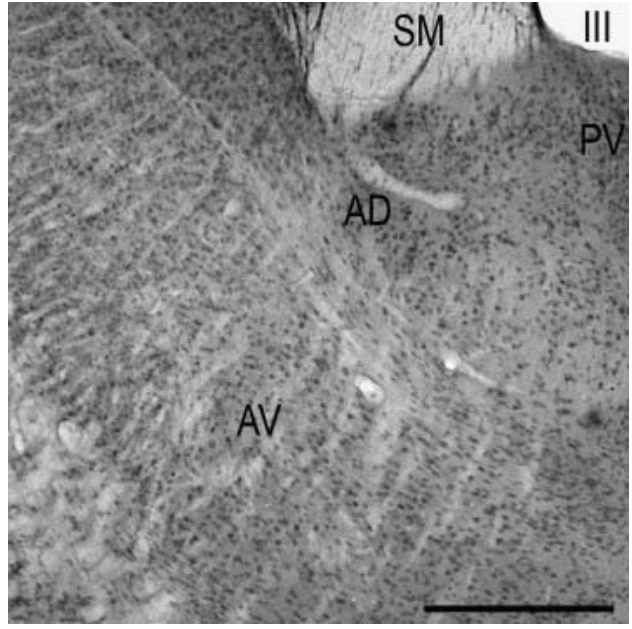

Figure 6. Distribution of GPBPs-positive cells in the anterior thalamus. Abbreviations: SM, stria medullaris of thalamus; $A D$, anterodorsal thalamic nucleus; AV anteroventral thalamic nucleus; PV, paraventricular thalamic nucleus; III, third ventricle. Scale bar $=500 \mu \mathrm{m}$.

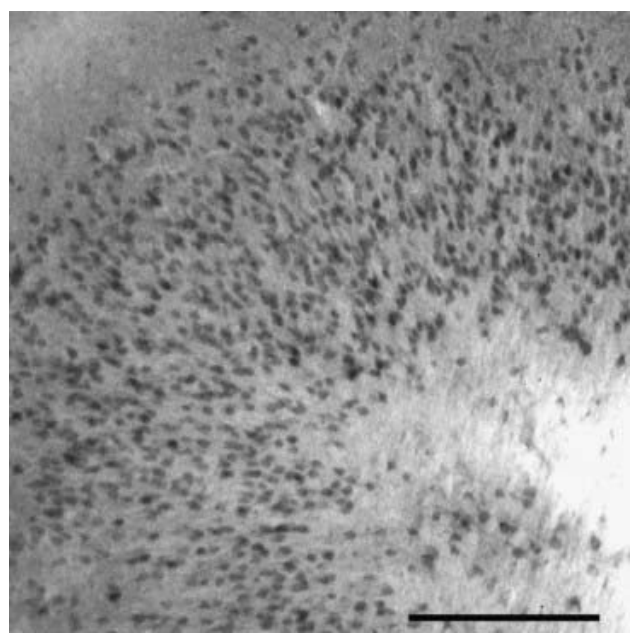

Figure 7. Distribution of GPBPs-positive cells in the olfactory bulb. Scale bar $=200 \mu \mathrm{m}$. 


\section{Immunoreactivity of GPBPs in rat brain}

To demonstrate the specific recognition of GPBPs by the antibodies, we tested four different antibodies: three polyclonal and one monoclonal directed against different epitopes shared by the isoforms, GPBP/CERT $T_{L}$ and GPBP $\triangle 26 / C E R T$. Immunohistochemical staining for each antibody showed a very similar distribution pattern throughout the brain. In supplementary Fig. 1 we show the staining of cortex and hippocampus from three of the antibodies. Together with the Western blot data, these results demonstrate the specific binding of the antibodies to GPBPs.

Staining of GPBPs was observed throughout the rat brain (Figs. 2-7). Representative photomicrographs of the cerebral cortex (Fig. 2), hippocampal formation (Fig. 3), basal ganglia (Fig. 4), septal area, amygdala and hypothalamus (Fig. 5), thalamus (Fig. 6) and olfactory bulb (Fig. 7) illustrate the remarkable abundance of this protein in different brain regions. As can be seen in the photomicrographs, virtually all neurons were positively stained for GPBPs.

In the cerebral cortex positive staining was present in all areas and layers, although the staining intensity varied with respect to the different lamina (Fig. 2). There was a clear difference between the intensely stained layers II and V compared to less intense staining of cells in layers III, IV and VI although neurons in the deepest stratum of layer VI, just above the fibers of the corpus callosum (Fig $2 \mathrm{~A}$ ), showed also a strong positive labeling. In the cell sparse layer I the few neurons present were also positive for GPBPs (Fig 2D). In the cerebral cortex, bundles of apical dendrites were intensely stained (Fig. 2B, C).

Intense staining was observed in the hippocampal formation, in the CA1CA3 fields and the dentate gyrus (Fig. 3). Here, cells gave an impression of very dark staining because their somata were so compactly packed. In fact, strong staining of their cytoplasm was evident and staining extended into their apical dendrites many of which could be followed for a significant part of their entire length (Fig. 3D, E). Comparable intense staining was observed in the indusium griseum and in the dorsal tenia tecta, the dorsal and anterior extensions of the hippocampus, respectively. In the hypothalamus, staining was also widespred with some nuclei, e.g. the paraventricular nuclei (Fig. 5C) and the mammillary nuclei, containing strongly stained neurons. All the nuclei in the thalamus were well stained with the staining mainly restricted to cell bodies (Fig. 6), although some staining of proximal dendrites was evident. Strong staining was observed throughout the olfactory bulb (Fig. 7). No immunoreactivity was seen in the white matter. Thus, axons were not apparently stained but in certain areas there appeared to be staining of neuropil above background. 


\section{Expression of GPBPs in neurons}

The wide distribution and morphology of GPBPs-positive cells in the brain suggested that the GPBPs antibodies stained neurons exclusively. To investigate this possibility, double staining using different cell markers in combination with GPBPs antibodies was carried out.

Double fluorescent labelling of GPBPs together with the neuronal marker NeuN (Fig. 8), the astrocyte marker GFAP (Fig. 9), or the microglial marker OX-42 (Fig. 10) demonstrated that GPBP is expressed in neurons and not astrocytes or microglia.

Colocalization of GPBP with NeuN showed that GPBPs staining was most intense in the cytoplasm of neuronal cell bodies (Fig. 8). Robust staining was also present in many proximal dendrites. Strong staining was observed in the cytoplasm with lighter staining in the nuclei and absence of staining in nucleoli. However some neurons of the hypothalamus did not present a clear nuclear but rather a mainly perinuclear staining.

No positive immunofluorescent staining for GPBPs was found in astrocytes (stained with GFAP, Fig. 9) and in resting microglia (stained with OX-42, Fig. 10).

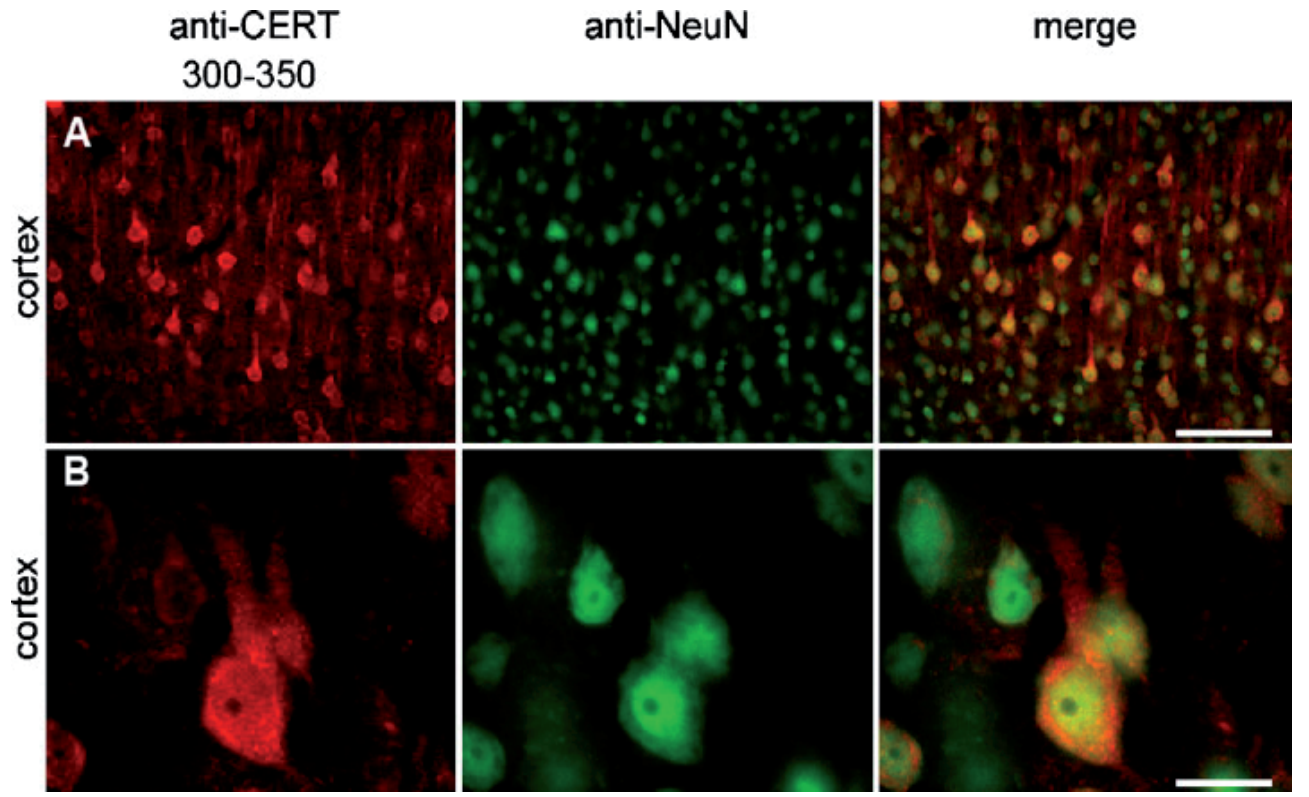

Figure 8. Fluorescent photomicrographs of GPBPs and NeuN staining showing cortical neurons in rat brain. The left column shows fluorescent staining with polyclonal anti-CERT antibody (epitope 300350 ), the middle column shows staining with the monoclonal antibody NeuN and the right column is the merge of the left and the middle column. Note the proximal dendrites in the pyramidal neurons in the lower row. Scale bars: $A=100 \mu \mathrm{m}$ and $B=20 \mu \mathrm{m}$. 


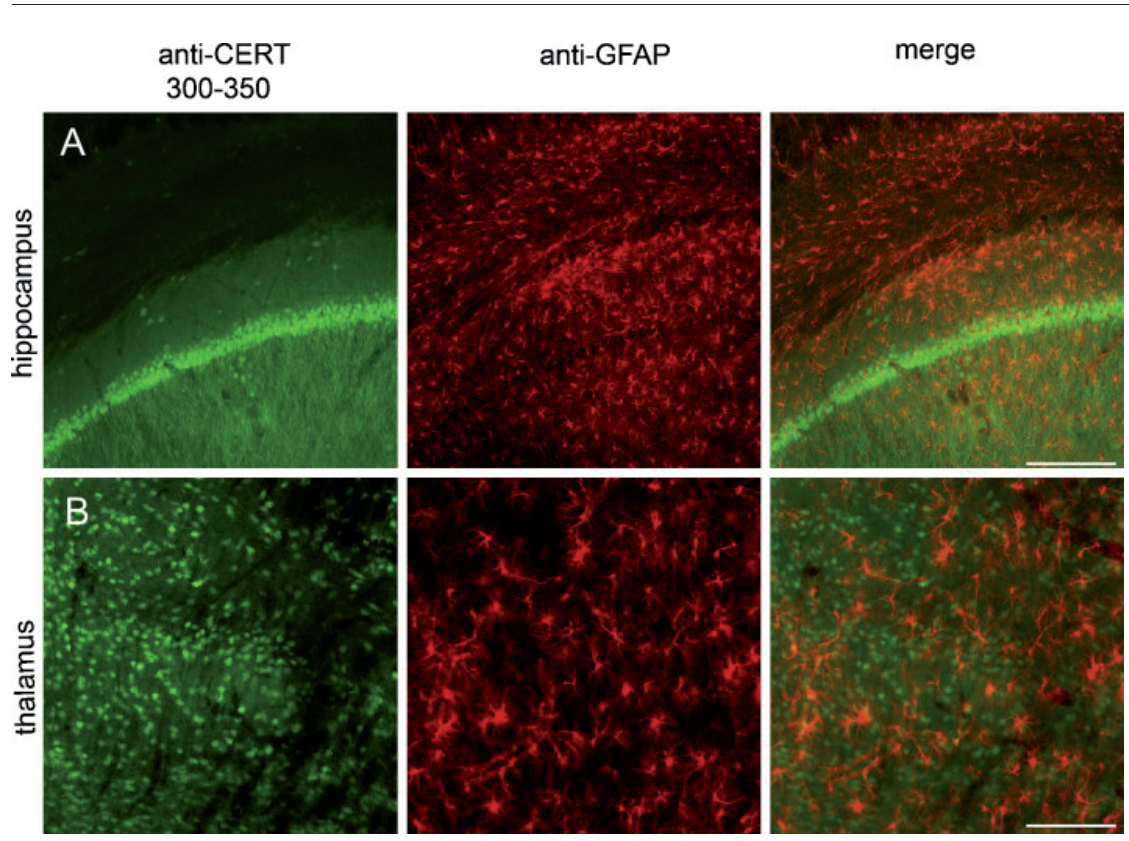

Figure 9. Fluorescent labelling of GPBPs (epitope 300-350) and GFAP in rat brain (A) hippocampus. (B) thalamus. The left column shows fluorescent staining with polyclonal anti-CERT antibody (epitope 300-350) the middle column shows staining with the antibody GFAP; merge on the right. Scale bars $=200 \mu \mathrm{m}$.

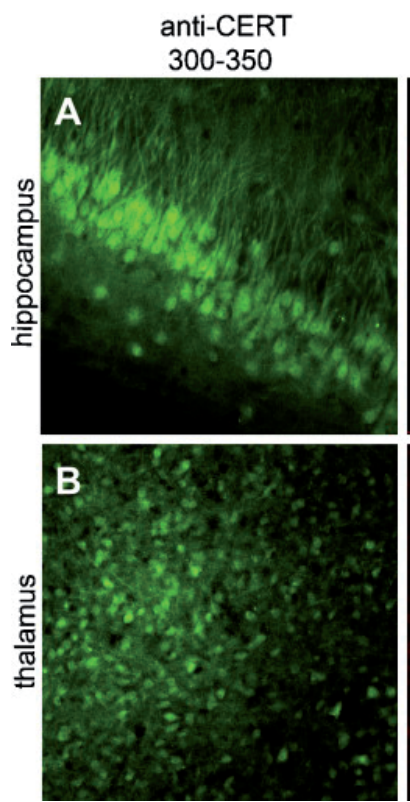

anti-OX-42

merge
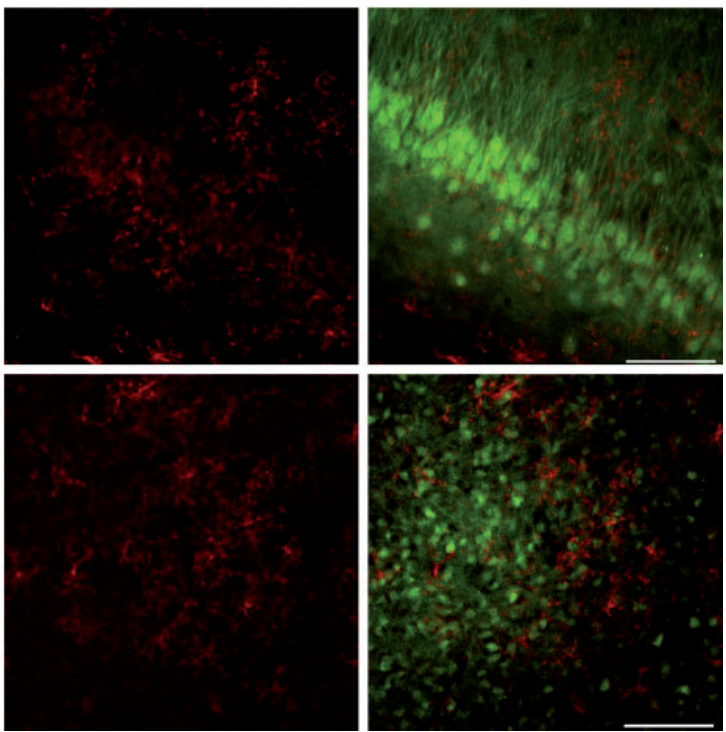

Figure 10. Fluorescent labelling of GPBPs (epitope 300-350) and OX-42 in rat brain (A) hippocampus. (B) thalamus. The left column shows fluorescent staining with polyclonal anti-CERT antibody (epitope 300-350) the middle column shows staining with the antibody OX-42; merge on the right. $A=50 \mu \mathrm{m}$ and $B=200 \mu \mathrm{m}$. 


\section{Discussion}

This study presents a comprehensive analysis of the distribution of GPBPs in neurons in rat brain in basal conditions.

A recent study in zebrafish (Granero-Molto et al., 2008) has shown that GPBPs play a role in development. Both isoforms showed a changing expression during early embryogenesis. Selective GPBP/CERT $T_{L}$ knockdown (leaving the GPBP $\triangle 26 / C E R T$ isoform intact) induced apoptosis and tissue loss with a clear reduction of the myelinated tracts, thin axons and edema during brain development.

The GPBPs' kinase activity and ceramide transport function, along with the presence of several isoforms with distinct localizations inside and outside the cell, reveal a pleiotropic protein that likely exerts numerous important functions, which mostly remain to be investigated. We studied their expression in rat brain tissues where GPBPs immunolabeling was detected in neurons, mainly concentrated in the soma and proximal dendrites. Due to their ceramide trafficking function, the cytoplasmatic signal for GPBPs could be related to their presence in ER and Golgi organelles. However, given the array of isoforms that these proteins display, other subcellular localizations could be present. Moreover, since the nucleus also appears to be lightly stained, additional investigations are needed to further elucidate the GPBPs role in this compartment.

In our study, four different antibodies detected very similar patterns of neuronal expression of GPBPs. However, in glial cells expression of GPBPs was not detected by immunohistochemistry even though these proteins likely are present at a basal level because the ceramide transport function of GPBPs is essential for membrane biogenesis (Hanada et al., 2003). In any case, under normal conditions, neurons are the cell population that shows a stronger expression of GPBPs.

In the present study we demonstrated a widespread distribution of GPBPs throughout the whole brain, although in certain areas the intensity of staining varied among neurons, some of which showed distinct morphology. Such differences may relate to specific functional requirements of these cells. Since we expected GPBPs genes to be ubiquitously expressed in the brain due to their essential role in the transport of ceramide, evidence of different intensities of expression among neuronal populations is of great interest. Ceramide seems to be the key compound at critical points in numerous signaling pathways such that this differential expression pattern among neurons could be related to the activation of specific functional processes. For example staining of the apical dendrites of pyramidal neurons 
in the cerebral cortex and the hippocampus versus minimal or absent dendritic staining in other regions emphasizes the possibility of a distinct regulation among diverse neuronal cell types.

To relate protein levels as revealed in the present immunohistochemical study to gene expression in different brain regions, we compared our findings with the gene expression levels of GPBPs as represented in the Allen Brain Atlas (Lein et al., 2007). Although this atlas is designed for detailed analysis of gene expression profiles in the mouse brain and we used rat brains in our study, very similar patterns for gene and protein expression were apparent and were consitent with our immunohistochemical findings. Thus, high levels of GPBPs gene expression are present in cerebral cortex, in the septal complex, thalamus, hypothalamus, olfactory bulb, the amygdala and in some hippocampal regions.

Some differences were noted between the gene and the protein expression: GPBPs were detected at higher levels than the corresponding mRNAs in some specific regions in the hypothalamus, the hippocampal formation and the olfactory bulb. This could either reflect differences of gene expression between mouse and rat, or alternatively be explained by translational regulation processes.

Ceramide is the fundamental molecule and key intermediate of all sphingolipids that are indispensable constituents of myelin and other membranes of the nervous system (van Echten-Deckert and Herget, 2006). However, they not only contribute to structural function by serving as building constituents, but also appear to be involved in the overall regulation of several other functions such as terminal differentiation of neurons, cellular senescence, proliferation, and cell death (Cutler et al., 2002). GPBPs also act as ceramide transfer proteins and could contribute actively to mechanisms by which ceramide could induce profound changes inside the cell. Moreover, proteins that are involved in complex regulation at the transcriptional and translational level such as GPBPs might act as putative modulators of ceramide metabolism (Revert et al., 2008). In line with this, their activity has been shown to be essential to prevent severe damage related to oxidative stress (Rao et al., 2007; Granero-Molto et al., 2008). In mice the lack of both isoforms affects organogenesis, leading to early embryo death (Wang et al., 2009) in which the major subcellular defect manifests with a ceramide accumulation and consequent degeneration in ER and mitochondria (Wang et al., 2009).

Recent reports of abnormal ceramide metabolism in aging, Alzheimer's disease, Parkinson's disease and stroke (Cutler et al., 2004; Haughey et al., 
2004; Sawai et al., 2005) further suggest that disturbances in ceramide regulation are correlated with neuronal damage and cellular death leading to cognitive impairment or motor dysfunctions, suggesting the strong involvement of ceramide metabolism in neurological diseases (Cutler et al., 2002; Takahashi et al., 2004; Bras et al., 2008). Interestingly, during pathological processes seen in neurodegeneration, GPBPs' isoforms may be differentially expressed (Mencarelli et al. unpublished results). The strong presence of GPBPs that we detected in the brain in the present study together with their intriguing properties such as the presence of different isoforms, the extracellular localization, kinase activity and ceramide transport function suggest involvement for GPBPs in many neuronal functions and possible implication in neurodegenerative processes.

Finally, further analysis with specific antibodies to each of the different splicing variants are needed to elucidate the precise subcellular localizations and expression levels of GPBPs and to facilitate our understanding of their functional role in the central nervous system.

\section{Acknowledgements}

We are very grateful to Marianne Markerink and Santiago Sampedro Millares for their excellent technical assistance. Juan Saus and Francisco Revert were supported by a SAF2006-12520-C02-01 grant from the Plan Nacional I+D+I from the Ministerio de Ciencia e Innovación. 

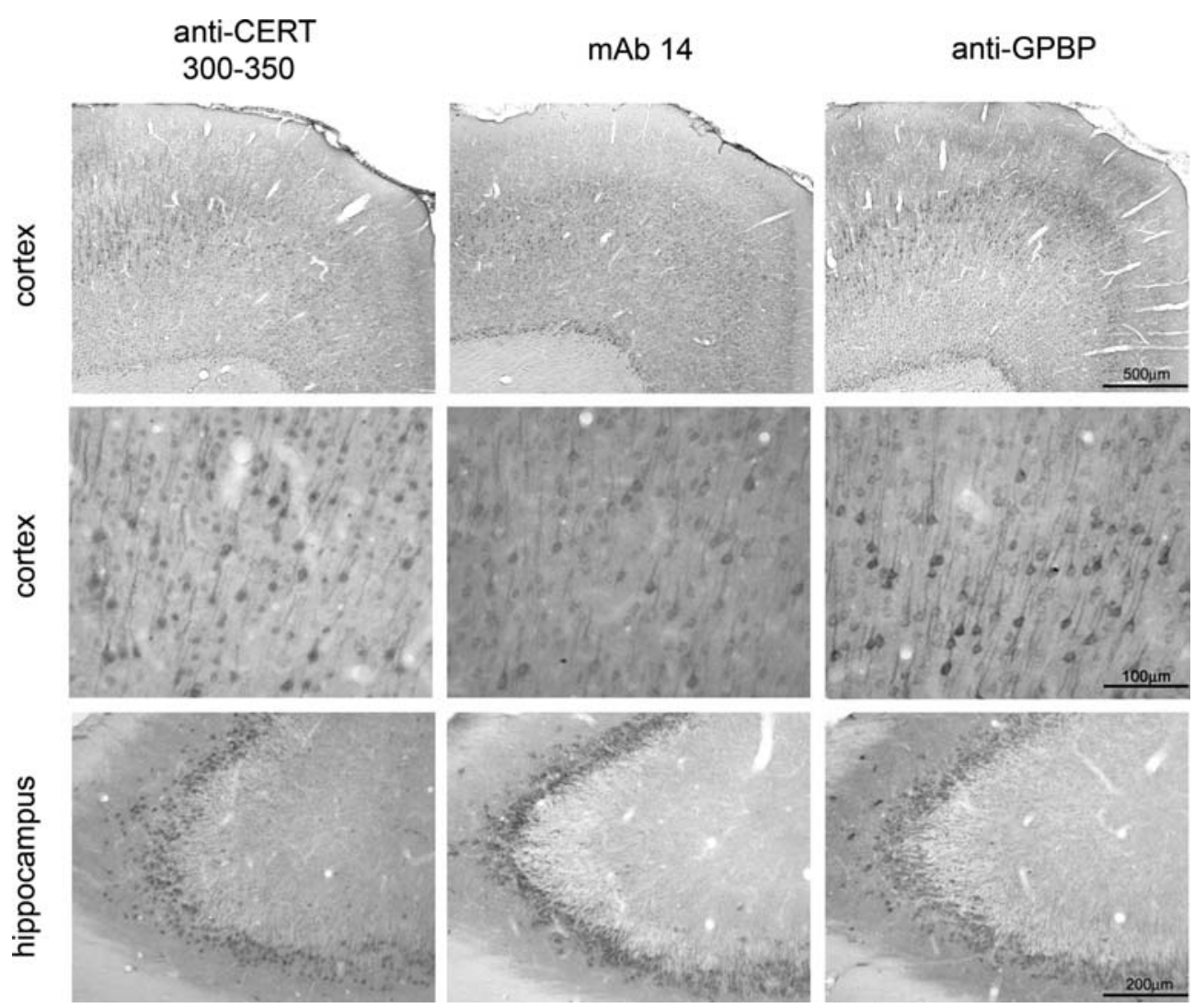

Supplementary Figure 1. Immunohistochemical labelling of GPBPs in rat brain using different antibodies. The upper panel shows an overview of the cortex at bregma $0.2 \mathrm{~mm}$. Scale bar is $500 \mu \mathrm{m}$. The middle panel shows a higher magnification of the cortex sections shown in the upper panel. The lower panel shows pictures of the hippocampus at bregma -2.12. Scale bar is $200 \mu \mathrm{m}$. The left column shows immunostaining with polyclonal anti-CERT antibody (epitope 300-350) the middle column shows staining with mAb 14 (described in Raya et al., 1999) and the right column shows the immunostaining polyclonal anti-GPBP antibody, described in Raya et al., 1999. The corresponding preimmune serum did not show any immunoreactivity on rat brain tissue (not shown). Scale bar $=100 \mu \mathrm{m}$ 

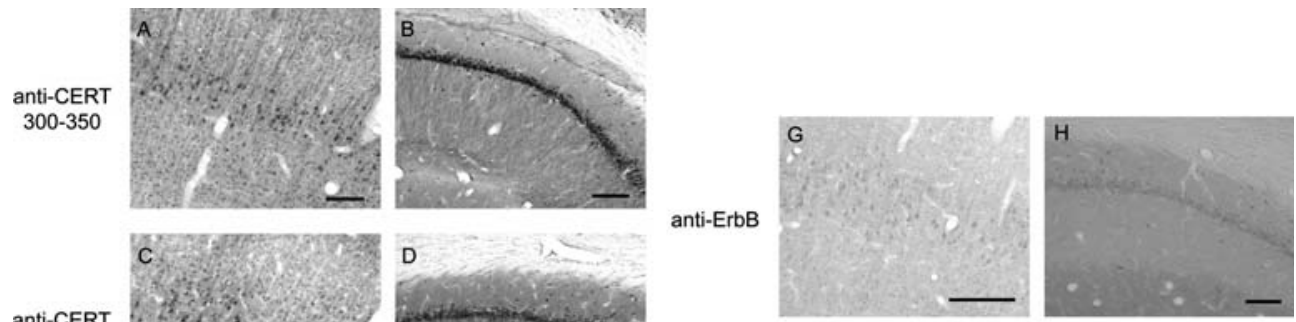

anti-CERT $1-50$
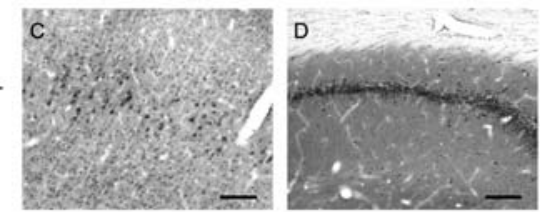

anti-ErbB
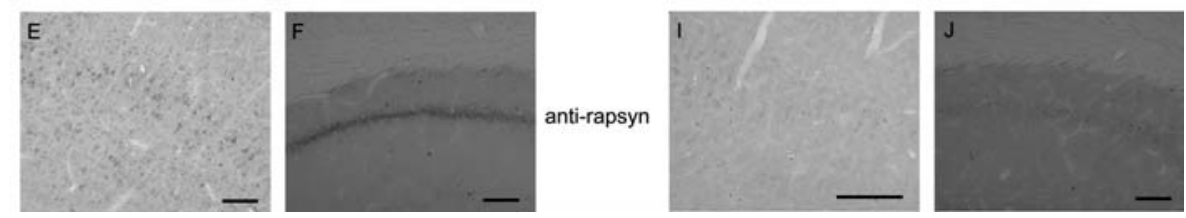

Supplementary Figure 2. Immunohistochemical staining of cerebral cortex and hippocampus with anti-CERT and with isotype control antibodies. A, C, E, G, I show the cortex. B, D, F, H, J show the hippocampus. A, B: staining with polyclonal anti CERT antibody epitope 300-350. C, D: staining with polyclonal anti CERT antibody epitope 1-50. E, F: staining with the mouse monoclonal antibody antiGPBPs mAb-14. G, H: Negative control staining with a polyclonal control antibody (rabbit anti-human ErbB) that, incubated with the same secondary, resulted in a very faint signal, revealing a complete different pattern. I, J Negative control staining with a monoclonal control antibody (mouse IgG1 antihuman rapsyn) that did not reveal any positive signal when incubated with the same secondary as used in E, F. The scale bar in the two panels A and B is $100 \mu \mathrm{m}$. 


\section{References}

Bieberich, E., MacKinnon, S., Silva, J., Yu, R. K., 2001. Regulation of apoptosis during neuronal differentiation by ceramide and b-series complex gangliosides. J Biol Chem. 276, 44396-404.

Bras, J., Singleton, A., Cookson, M. R., Hardy, J., 2008. Emerging pathways in genetic Parkinson's disease: Potential role of ceramide metabolism in Lewy body disease. FEBS J. 275, 5767-73.

Cutler, R. G., Kelly, J., Storie, K., Pedersen, W. A., Tammara, A., Hatanpaa, K., Troncoso, J. C., Mattson, M. P., 2004. Involvement of oxidative stress-induced abnormalities in ceramide and cholesterol metabolism in brain aging and Alzheimer's disease. Proc Natl Acad Sci U S A. 101, 2070-5.

Cutler, R. G., Pedersen, W. A., Camandola, S., Rothstein, J. D., Mattson, M. P., 2002. Evidence that accumulation of ceramides and cholesterol esters mediates oxidative stress-induced death of motor neurons in amyotrophic lateral sclerosis. Ann Neurol. 52, 448-57.

France-Lanord, V., Brugg, B., Michel, P. P., Agid, Y., Ruberg, M., 1997. Mitochondrial free radical signal in ceramide-dependent apoptosis: a putative mechanism for neuronal death in Parkinson's disease. J Neurochem. 69, 1612-21.

Granero-Molto, F., Sarmah, S., O'Rear, L., Spagnoli, A., Abrahamson, D., Saus, J., Hudson, B. G., Knapik, E. W., 2008. Goodpasture antigen-binding protein and its spliced variant, ceramide transfer protein, have different functions in the modulation of apoptosis during zebrafish development. J Biol Chem. 283, 20495-504.

Granero, F., Revert, F., Revert-Ros, F., Lainez, S., Martinez-Martinez, P., Saus, J., 2005. A human-specific TNF-responsive promoter for Goodpasture antigen-binding protein. Febs J. 272, 5291-305.

Haimovitz-Friedman, A., Kolesnick, R. N., Fuks, Z., 1997. Ceramide signaling in apoptosis. Br Med Bull. $53,539-53$.

Hanada, K., Kumagai, K., Yasuda, S., Miura, Y., Kawano, M., Fukasawa, M., Nishijima, M., 2003. Molecular machinery for non-vesicular trafficking of ceramide. Nature. 426, 803-9.

Hannun, Y. A., Obeid, L. M., 2002. The Ceramide-centric universe of lipid-mediated cell regulation: stress encounters of the lipid kind. J Biol Chem. 277, 25847-50.

Haughey, N. J., Cutler, R. G., Tamara, A., McArthur, J. C., Vargas, D. L., Pardo, C. A., Turchan, J., Nath, A., Mattson, M. P., 2004. Perturbation of sphingolipid metabolism and ceramide production in HIV-dementia. Ann Neurol. 55, 257-67.

Krebs, E. G., 1994. The growth of research on protein phosphorylation. Trends Biochem Sci. 19, 439.

Mathias, S., Pena, L. A., Kolesnick, R. N., 1998. Signal transduction of stress via ceramide. Biochem J. 335 ( Pt 3), 465-80.

Paxinos, G., Watson, C., 1982. The Rat brain in stereotaxic coordinates. Academic Press, Sydney ; New York.

Rao, R. P., Yuan, C., Allegood, J. C., Rawat, S. S., Edwards, M. B., Wang, X., Merrill, A. H., Jr., Acharya, U., Acharya, J. K., 2007. Ceramide transfer protein function is essential for normal oxidative stress response and lifespan. Proc Natl Acad Sci U S A. 104, 11364-9.

Raya, A., Revert-Ros, F., Martinez-Martinez, P., Navarro, S., Rosello, E., Vieites, B., Granero, F., Forteza, J., Saus, J., 2000. Goodpasture antigen-binding protein, the kinase that phosphorylates the goodpasture antigen, is an alternatively spliced variant implicated in autoimmune pathogenesis. J Biol Chem. 275, 40392-9.

Raya, A., Revert, F., Navarro, S., Saus, J., 1999. Characterization of a novel type of serine/threonine kinase that specifically phosphorylates the human goodpasture antigen. J Biol Chem. 274, 12642-9.

Revert, F., Merino, R., Monteagudo, C., Macias, J., Peydro, A., Alcacer, J., Muniesa, P., Marquina, R., Blanco, M., Iglesias, M., Revert-Ros, F., Merino, J., Saus, J., 2007. Increased Goodpasture antigen-binding protein expression induces type IV collagen disorganization and deposit of immunoglobulin A in glomerular basement membrane. Am J Pathol. 171, 1419-30.

Revert, F., Ventura, I., Martinez-Martinez, P., Granero-Molto, F., Revert-Ros, F., Macias, J., Saus, J., 2008. Goodpasture Antigen-binding Protein Is a Soluble Exportable Protein That Interacts with 
Type IV Collagen. Identification of novel membrane-bound isoforms. J Biol Chem. 283, 30246-55.

Sawai, H., Domae, N., Okazaki, T., 2005. Current status and perspectives in ceramide-targeting molecular medicine. Curr Pharm Des. 11, 2479-87.

Schwarz, A., Futerman, A. H., 1997. Distinct roles for ceramide and glucosylceramide at different stages of neuronal growth. J Neurosci. 17, 2929-38.

Stanton, M. C., Tange, J. D., 1958. Goodpasture's syndrome (pulmonary haemorrhage associated with glomerulonephritis). Australas Ann Med. 7, 132-44.

Takahashi, K., Ginis, I., Nishioka, R., Klimanis, D., Barone, F. C., White, R. F., Chen, Y., Hallenbeck, J. M., 2004. Glucosylceramide synthase activity and ceramide levels are modulated during cerebral ischemia after ischemic preconditioning. J Cereb Blood Flow Metab. 24, 623-7.

Van den Hove, D. L., Steinbusch, H. W., Scheepens, A., Van de Berg, W. D., Kooiman, L. A., Boosten, B. J., Prickaerts, J., Blanco, C. E., 2006. Prenatal stress and neonatal rat brain development. Neuroscience. 137, 145-55.

van Echten-Deckert, G., Herget, T., 2006. Sphingolipid metabolism in neural cells. Biochim Biophys Acta. 1758, 1978-94.

Wang, X., Rao, R. P., Kosakowska-Cholody, T., Masood, M. A., Southon, E., Zhang, H., Berthet, C., Nagashim, K., Veenstra, T. K., Tessarollo, L., Acharya, U., Acharya, J. K., 2009. Mitochondrial degeneration and not apoptosis is the primary cause of embryonic lethality in ceramide transfer protein mutant mice. J Cell Biol. 184, 143-58. 


\section{Chapter 4}

\section{Unchanged expression of the Ceramide transfer protein in the acute 6-OHDA neurodegenerative model}

Chiara Mencarelli, Gerard H Bode, Rinske Vlamings, Mark L. Janssen, Mario Losen, Marc H De Baets, Harry W. M. Steinbusch, Yasin Temel and Pilar Martínez-Martínez

Published in: Neurosci Lett. 2012 Jan 6;506(1):39-43 


\begin{abstract}
Ceramides are lipids that are abundant in brain tissue where they have an important structural role in cellular membranes. Ceramides are also powerful intracellular signaling molecules controlling cell death, growth and differentiation. So far, the ceramide transfer protein (CERT), a shorter splice variant of the Goodpasture antigen-binding protein (GPBP), is the only known protein with the ability to shuttle ceramide from the endoplasmic reticulum to the Golgi apparatus. GPBP/CERT are widely distributed in the central nervous system where they act as key factors for normal brain development and homeostasis. Ceramide accumulates in neurons during acute neurodegeneration. The objective of this study was to define whether levels of the ceramide transfer protein GPBP/CERT are altered in the acute neurodegenerative process. We used design-based stereology to quantify the number of GPBP/CERT immunoreactive cells in the striatum of 6-hydroxydopamine (6-OHDA) lesioned rats as an animal model of Parkinson's disease (PD). In addition, gray value measurement was performed to quantify GPBP/CERT immunoreactivity-levels within individual cells. No difference in the striatal expression levels of GPBP/CERT proteins was found between diseased and control animals, suggesting that the expression pattern of GPBP/CERT in the striatum is not affected in the 6-OHDA rat model of PD.
\end{abstract}




\section{Introduction}

Ceramides are lipids abundant in brain tissue where they were first discovered by Johann LW Thudichum in 1884 (for a review[38]). They have an important structural role in cellular membranes and also act as signalling molecules inside the cell [1]. The balance of ceramide levels extensively regulates cell functions [14].

Due to their hydrophobic nature, ceramides were thought to function exclusively at the site of their synthesis. The existence in the cell of a protein capable of transfering ceramide between two different locations in the cytoplasm was demonstrated in 2003 by Hanada and colleagues [17]. The ceramide transfer protein (CERT), the shorter splice variant of the Goodpasture antigen-binding protein (GPBP) [28] shuttles ceramide between the endoplasmic reticulum (ER) and the Golgi in a non-vesicular manner. The ceramide transporter GPBP/CERT is widely distributed in the brain with higher expression levels in neurons compared to other cell types [25]. Knock-down of the longer isoform GPBP in zebrafish results in extensive loss of myelinated tracts and cell death in the brain during embryogenesis [16]. Knock-out mice for both isoforms CERT and GPBP, die early as a consequence of heart defects due to ER and mitochondrial degeneration.

Ceramide levels are increased in neurodegenerative diseases such as Alzheimer's disease [10], Parkinson's disease (PD) [9], dementia with Lewy bodies and amyotrophic lateral sclerosis [11]. Ceramides were augmented in the cerebrospinal fluid of Alzheimer's disease patients and serum ceramides are early predictors of cognitive impairment in Alzheimer's disease [30].

We hypothesised that the protein levels of the ceramide transporter also change during acute neurodegeneration.

To study GPBP/CERT levels in a neurodegenerative condition, we used an experimental model to mimic the dopamine depletion. Rats were chronically dopamine (DA) depleted by bilateral striatal injections of 6-hydroxydopamine (6-OHDA). 6-OHDA, being similar to DA, shows high affinity for the dopamine transporter, which carries this neurotoxin inside the dopaminergic neurons. 6-OHDA accumulates in the cytosol and undergoes prompt auto-oxidation, promoting a high rate of free radical formation [12]. As a consequence intra-striatal 6-OHDA injection permanently damages the dopaminergic nigrostriatal pathway. The loss of dopaminergic input to the striatum disrupts the basal ganglia circuit and is responsible for the most prominent symptoms of $P D$ in the extent that the degree of neurological deficit is related to the loss of striatal DA [18]. 
Nigral dopaminergic neurons are naturally exposed to oxidative stress because in the presence of molecular oxygen DA undergoes spontaneous oxidation, leading to the formation of reactive oxygen species (ROS) $[15,23]$. In turn, conditions known to promote elevated cellular levels of ROS can lead to ceramide accumulation ([19]) which is associated with the induction of apoptotic cell death [6, 13, 38].

Here, we have conducted a design-based stereology investigation to quantify GPBP/CERT immunoreactive cells in the striatum of rats treated with bilateral injections of 6-OHDA.

\section{Methods}

All experimental procedures were approved by the Animal Experiments and Ethics Committee of Maastricht University. Animal and surgical procedures used have been described in detail before [36]. Fourteen male Lewis rats at the age of 12 weeks received stereotactic bilateral injections at two sites per hemisphere with either $2 \mu \mathrm{l}$ of 6 -OHDA ( $5 \mu \mathrm{g} / \mu \mathrm{l}$ dissolved in $0.9 \%$ saline and $0.2 \%$ ascorbic acid; Sigma, Zwijndrecht, the Netherlands) or saline $(0.9 \%$ saline and $0.2 \%$ ascorbic acid) in the striatum. To protect noradrenergic neurons from 6-OHDA, the rats received $20 \mathrm{mg} / \mathrm{kg}$ desipramine one hour before surgery.

After 2 weeks post injection, rats were perfused transcardially with Tyrode's medium $(0.1 \mathrm{M})$ and fixative containing $4 \%$ paraformaldehyde, $15 \%$ picric acid and $0.05 \%$ glutaraldehyde in $0.1 \mathrm{M}$ phosphate buffer ( $\mathrm{pH} 7.6)$. Brains were removed and postfixed for $2 \mathrm{~h}$ in the same medium followed by overnight immersion in $15 \%$ sucrose in $0.1 \mathrm{M}$ phosphate buffer at $4^{\circ} \mathrm{C}$. Then brain tissue was quickly frozen with solid $\mathrm{CO}_{2}$ and stored at $-80^{\circ} \mathrm{C}$. The brains were cut serially in $30-\mu \mathrm{m}$ thick coronal sections on a cryostate and were collected free-floating in series. Of every rat, one series was selected for immunohistochemical stainings.

Immunohistochemistry for GPBP/CERT was carried out using free-floating coronal sections which were incubated for 72 hours at $4^{\circ} \mathrm{C}$ with the primary antibody, a rabbit polyclonal anti-GPBP/CERT antibody (diluted 1:500; epitope 1-50 of human GPBP, Bethyl laboratories, USA). After rinsing with Tris-buffered saline including $50 \mathrm{mM}$ Triton, sections were incubated with the secondary antibody, donkey anti-rabbit biotinylated IgG (diluted 1:800; Jackson ImmunoResearch Laboratories Europe Ltd, Suffolk, United Kingdom) at RT. Subsequently, sections were incubated with the ABC-kit (diluted 1:800, Vector laboratories, Peterborough, United Kingdom) for $1.5 \mathrm{~h}$. To visualize the horseradish peroxide reaction product, the sections were 
incubated with 3,3'-diaminobenzidine tetrahydrochloride (DAB). To stop the reaction, the sections were rinsed in TBS. No labeling was evident in control experiments in which the primary antibody was omitted from the immunostaining protocol (not shown). Tyrosine hydroxylase (TH) immunohistochemistry was carried out as previously described [36] using mouse anti-TH (diluted 1:2000, kindly supplied by Dr. C. Cuello, Canada) as primary antibody [37]. After rinsing steps with TBS, and incubation with the secondary antibody (diluted 1:400 donkey anti-mouse biotin; Jackson Immunoresearch Laboratories, West Grove, USA), the labeling was visualized with $A B C / D A B$ procedure as mentioned above.

For the stereologic procedures, a stereology workstation consisting of an Olympus BX51 microscope (Olympus, Tokyo, Japan), motorized specimen stage, color video camera and a PC with Stereolnvestigator stereology software (MBF Bioscience, Vermont, USA) was used. The number of cells expressing GPBP/CERT and labelled with the abovementioned polyclonal antibody were quantified in a part of the striatum, with a rostral boundary at Bregma $1.60 \mathrm{~mm}$ where the corpus callosum crosses the midline and a caudal boundary at Bregma $-0.90 \mathrm{~mm}$ where the fornix enters the diencephalon. The dorsal and lateral boundaries of this region consisted of the corpus callosum and the medial boundary was defined by the lateral ventricle. A ventral boundary was set by drawing a line from the tip of the lateral ventricle to the rhinal fissure [20]. The region of interest was delineated using a $4 x$ objective. The optical fractionator technique [32] was used to determine the total numbers of cells positive for GPBP/CERT. Positive cells were counted using a 100x objective in unbiased virtual counting spaces distributed in a systematic random fashion throughout the delineated region of interest. The total number of positive cells in the region of interest was estimated as a function of the number of cells counted and the sampling probability [32]. For, quantifying the number of $\mathrm{TH}$ immunoreactive (THir) neurons, a similar stereological approach was used. After exactly tracing the boundaries of the substantia nigra pars compacta (SNc) on microscopic video images displayed on a monitor, numbers of neurons were evaluated with the Optical Fractionator [31]. All neurons whose nucleus top came into focus within unbiased virtual counting spaces distributed in a systematic-random fashion throughout the delineated regions were counted. The total numbers of neurons were estimated as a function of the numbers of counted neurons and the corresponding sampling probability. For more details see [36].

GPBP/CERT immunostained neurons were evaluated also by gray value. Mean gray values for regions of interest (bregma 0.7 and - 0.4) were 
calculated using ImageJ software, with images photographed at a magnification of $x 40$. The mean gray value of cells in the selected regions was used as a measurement for the expression levels of GPBP/CERT in the striatum. The statistical analysis of the data was done with GraphPad Prism (Version 5.01 for Windows, GraphPad Software, San Diego CA). The mean and the standard error of the mean (SEM) were determined for the numbers of cells expressing GPBP/CERT and the striatal volume in both 6-OHDA and control rats.

An unpaired two-tailed t-test was performed to compare the means of the 6-OHDA group and the control group, the result was considered statistically significant if its $p$-value was smaller than 0.05. Three unilateral 6-OHDA lesioned rats were used (disease induction and handling similar to animals describes above). Brains were removed, striatal samples were dissected in two hemispheres the 6-OHDA-injected and from the control hemisphere. The samples were quickly frozen with solid $\mathrm{CO}_{2}$ and stored at $-80^{\circ} \mathrm{C}$ striatal brain homogenization is performed as described previously [25]. Proteins were separated by SDS-PAGE using precast Criterion Tris-HCl Glycine 4-20\% gradient gels (Bio-Rad, CA, USA) followed by electroblotting to nitrocellulose membrane (Millipore, Amsterdam Zuid-Oost The Netherlands). The membranes were incubated with the following primary antibodies: rabbit polyclonal anti-GPBP/CERT antibody (epitope 1-50 of human GPBP, Bethyl laboratories, USA) and mouse monoclonal anti-GAPDH antibody (Ab9484, Abcam, Cambrdige, UK), used as a protein loading control. After PBS washes, the membrane was incubated with goat anti-rabbit-Alexa 800 and donkey anti-mouse-Alexa 680 (Rockland, USA). The membrane was washed with PBS, dried and scanned using the Odyssey infrared imaging system (Westburg, The Netherlands). The mean intensity of the GPBP/CERT band was measured in ImageJ and corrected for protein loading with the mean intensity of the GAPDH band.

\section{Results}

Injections of 6-OHDA into the striatum resulted in a substantial loss of THir cells in the SNc as compared to the sham group. High-precision design-based stereological analysis revealed a significant 6-OHDA-induced reduction in the total number of THir cells in the SNc of about $65 \%$ bilaterally $(P<0.01)$ Figure 1. 


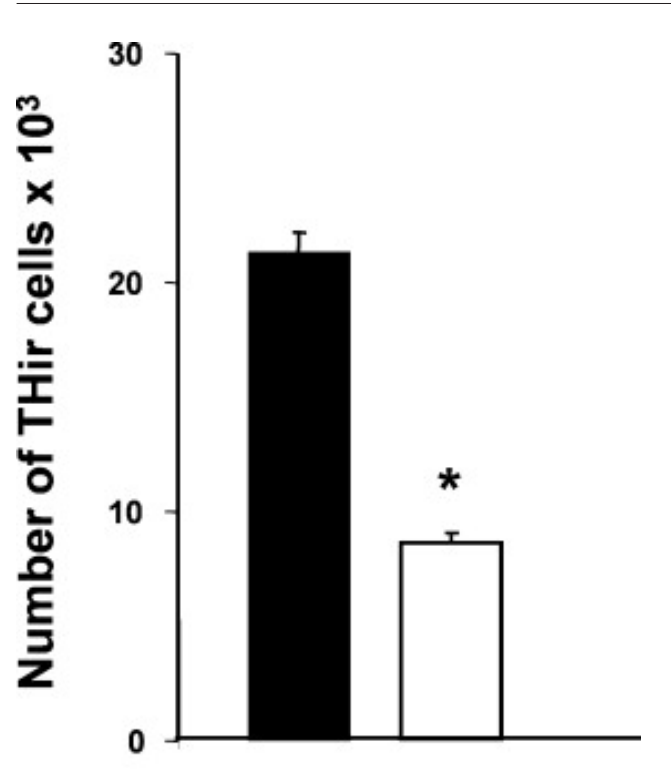

Figure 1: Mean total numbers of THir- neurons of sham-operated rats and rats subjected to dopamine depletion. Data represent means and SEM per group. Since the left and right SNc showed a similar cell count, the data were pooled. The $P$ values from the corresponding post hoc LSD tests are provided as $* P<0.05$

\section{SHAM 6-OHDA}

6-OHDA starts its toxic effects in the striatum with dopamine nerve terminal disruptions and consequent progressive retrograde degeneration of nigrostriatal dopamine neurons in the SNc. Therefore in this study we selected the striatum as area of investigation (Figure $2 \mathrm{C}$ ), instead of the SNc where the massive death of dopaminergic neurons (Figure $2 \mathrm{~A}$ and $\mathrm{B}$ ) would have masked the quantification of GPBP/CERT levels. For the quantification of GPBP/CERT positive cells in diseased and control animals, the striatum was delineated as depicted in Figure 2C. Figure 2D shows a high-power photomicrograph of the striatum with the 100x objective used during the counting procedure. GPBP/CERT positive cells were neurons as described previously [26]. Intensely stained neurons were present in the striatum, although there was considerable regional variation in the intensity of the stained cells. The stereological analysis revealed no differences in the volume of the striatum in 6-OHDA treated rats compared to the group of rats that received a sham treatment $(p=0.61$; Figure $2 E)$. Additionally the quantification of the total numbers of GPBP/CERT positive cells in the striatum using the fractionator technique showed no significant difference between the saline treated group and the 6-OHDA injected group ( $p=0.48$; Figure 2F).

To further confirm these results, a quantitative Western blotting analysis of the striatum of 6-OHDA-treated and -untreated hemispheres was performed with the same antibody anti-GPBP/CERT used in the immunohistochemical study. The result is consistent with the previous analysis since no difference 


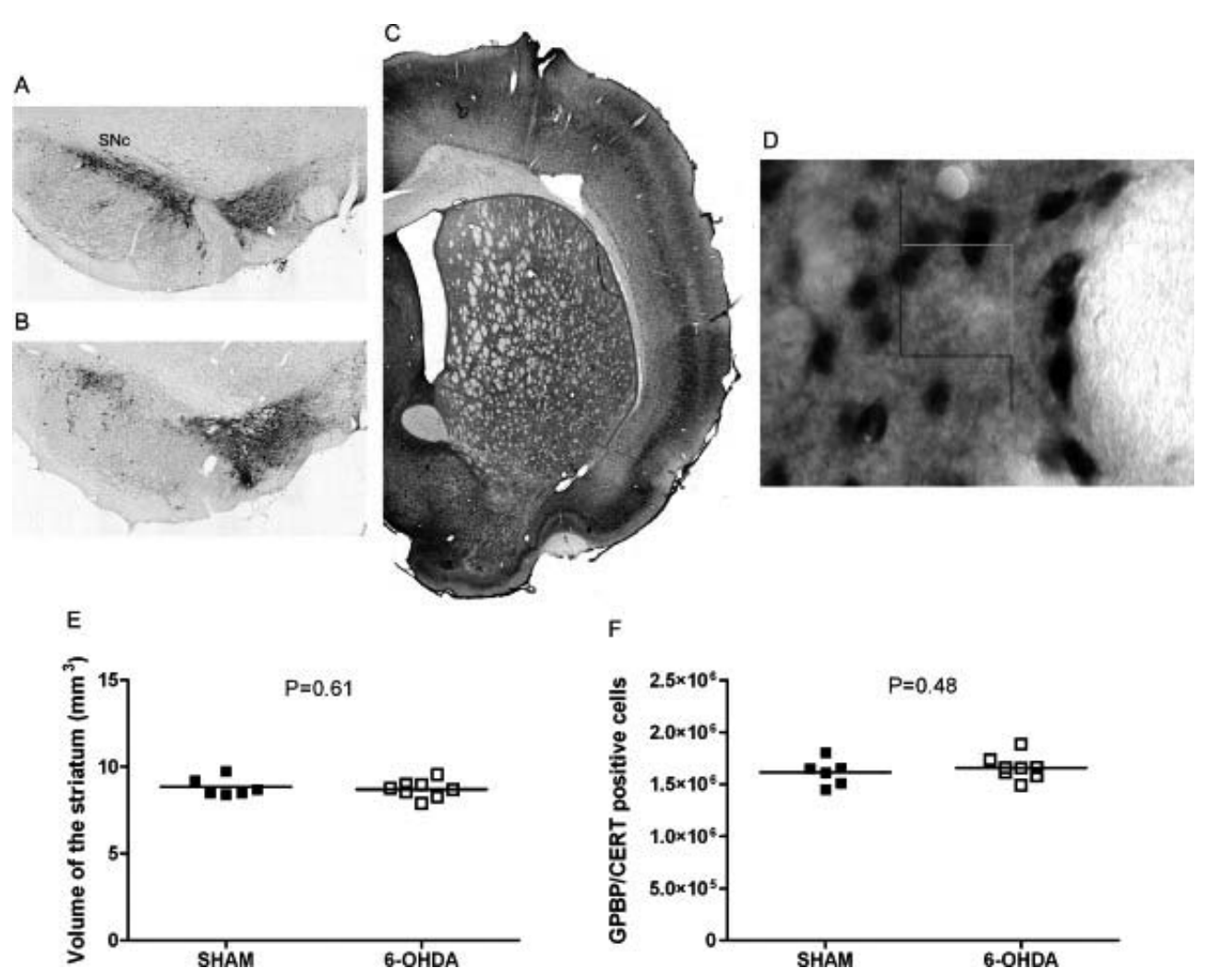

Figure 2: Tyrosine hydroxylase immunohistochemistry of the substantia nigra pars compacta (SNC) of sham treated rats $(A)$ and 6-OHDA treated rats (B). The delineation of the striatum used in the stereological procedure $(C)$ and a representative high-power photomicrograph of the striatum stained for GPBP/CERT (D). The volume of the striatum (E) and the estimated total number of cells positive for GPBP/CERT in the striatum (F) are not different between sham treated and 6-OHDA treated rats. Means were compared with an unpaired two-tailed t-test, data are shown as values of individual animals and the mean of the group.

in GPBP/CERT protein levels were detected in the $72 \mathrm{kDA}$ protein band of untreated and 6-OHDA treated samples (Figure $3 \mathrm{~A}$ and $\mathrm{B}$ ). No significant difference was found in the level of GPBP/CERT expression level within individual cells in the striatum of diseased and control animals $(p=0.07$; Figure 3).

Table 1: Details of the stereologic analysis

\begin{tabular}{|c|c|c|c|c|c|c|c|c|}
\hline Region & Obj & $\mathbf{B}\left(\mu \mathrm{m}^{2}\right)$ & $\mathbf{H}(\mu \mathrm{m})$ & $\mathbf{D}(\mu \mathrm{m})$ & $\boldsymbol{t}(\mu \mathrm{m})$ & $\boldsymbol{\Sigma} \mathrm{OD}$ & $\boldsymbol{\Sigma} \mathbf{Q}-$ & $\mathrm{CE}_{\text {pred }}[\mathrm{n}]$ \\
\hline Striatum & $100 \mathrm{x}$ & 900 & 6 & 400 & 7.57 & 331 & 655 & 0.039 \\
\hline
\end{tabular}

Obj., objective used; $\mathrm{B}$ and $\mathrm{H}$, base and height of the unbiased virtual counting spaces; $\mathrm{D}$, distance between the unbiased virtual counting spaces in mutually orthogonal directions $x$ and $y ; t$, measured 
actual average section thickness after histological processing; $\Sigma O D$, average sum of unbiased virtual counting spaces used; $\Sigma Q D$, average number of counted neurons; $C E_{\text {pred }}[n]$, average predicted coefficient of error of the estimated total neuron numbers using the prediction method described in [31] and [32].
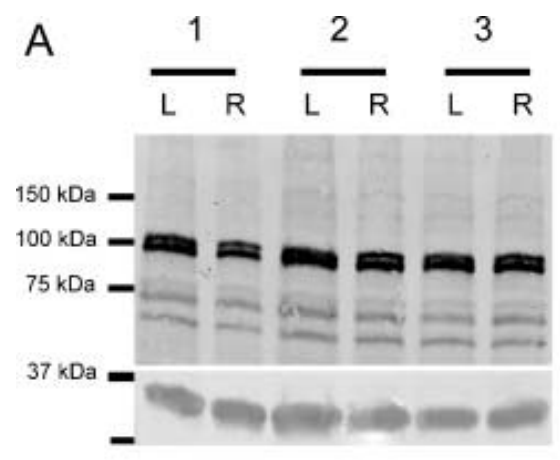

B

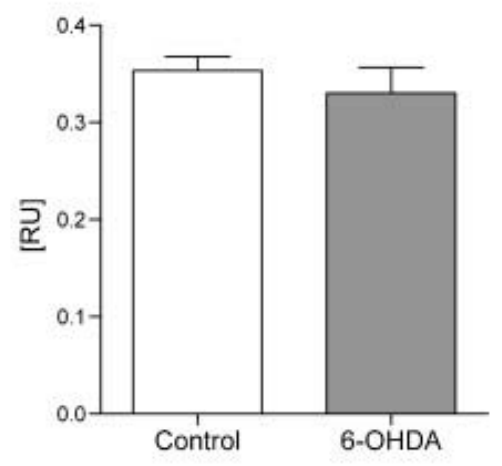

C

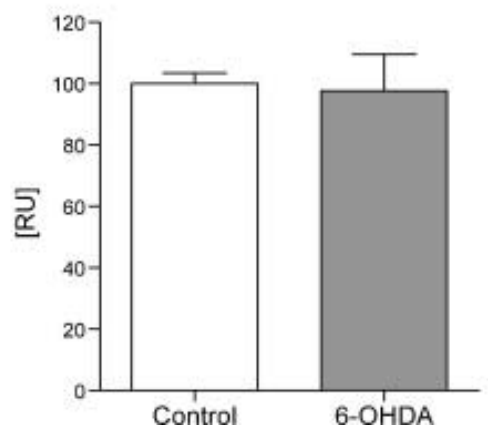

Figure 3: (A) Western blot of striatal brain homogenates detected with antiGPBP/CERT and anti-GAPDH antibodies shows comparable protein amounts between the 6-OHDAinjected (L) and the control (R) anti-GPBP hemisphere in three animals (1-2-3). (1-50) (B) Quantification of the $72 \mathrm{kDa}$ GPBP/CERT band in the Western blot of brain homogenate shown in (A). The mean intensity of the bands was measured and corrected for GAPDH intensity, no significant difference in GPBP/CERT expression was found. (C) Gray value quantification of GPBP/CERT expression in individual cells of the striatum at Bregma -0.4 and 0.7. A minimum of 30 cells per animal were quantified and no statistically significant difference in mean gray value was found between the SHAM and 6-OHDA rats ( $P=0.07)$.

\section{Discussion}

Protein levels of the ceramide transfer protein GPBP/CERT were not altered in the striatum in the acute neurodegenerative process of the 6-OHDA model. This lack of difference might be explained by several reasons. First, 
the mode of action of 6-OHDA: injection of 6-OHDA selectively kills dopaminergic neurons after entering the cells via the dopamine transporter, inducing acute effects which differ significantly from the chronic progressive course of PD [4]. Dopaminergic neurotoxicity of 6-OHDA is associated with membrane lipid alteration, cellular loss of phospholipid asymmetry and membrane blebbing $[5,40]$. This membrane-associated oxidative stress occurs together with accumulation of ceramide species [27, 33]. Additionally, it has been described that 6-OHDA promotes a high rate of free radical formation in the cytosol of neurons and ROS production also leads to ceramide accumulation [2, 19]. In our experiments the analysis of the striatum takes place days after the cellular induced toxicity by 6-OHDA. Conversion of palmitate to ceramide in the de novo pathway requires multiple enzymatic steps and it is responsible for a slow but robust accumulation of ceramide over a period of several hours [22]. We studied levels of GPBP/CERT days after the induction of apoptosis by 6-OHDA to assure the production of ceramide by the de novo pathway.

Second, a defining pathological hallmark of PD is the presence of neuronal Lewy body formed by protein aggregates. After 6-OHDA lesioning, cytoplasmatic inclusions of aggregate proteins do not occur [35]. The role of protein aggregations in the pathogenesis of PD has not been fully determined, but altered protein processing in the cell could have a negative impact on normal cellular function. Some of the genes involved in Lewy body disease have also an effect on ceramide metabolism (for review, see [8]). In this regard, knock down of LASS2, an aging-associated gene that encodes a ceramide synthase, results in a premature increase in the number of inclusions in Caenorhabditis elegans [39]. Therefore, ceramide and its transporters could play a role in protein self aggregation processes.

Moreover, mutations that occur in glucosylcerebrosidase gene have been found to predispose to PD [7] and Lewy body disorders [24]. Glucocerebrosidase is an enzyme that catalyzes the breakdown of the lipid glucosylcerebroside to ceramide and glucose. This enzyme is highly enriched in the brain. Loss of glucocerebrosidase activity and a toxic gain-of-function can cause Parkinson disease-like $\alpha$-synuclein pathology [29].

It is important to bear in mind that post translational refolding of normal protein, including the normal prion protein and the amyloidogenic processing of amyloid precursor protein, is affected by the content of sphingomyelin and cholesterol in lipid rafts at the level of the plasma membrane [3, 21, 34, 36]. Consequently, dysregulation of sphingolipid metabolism, that seems to be strongly involved in protein aggregation in 
many neurodegenerative disorders, is a condition that is missing in a 6OHDA model.

Third, the antibody used in this study recognizes both isoforms, GPBP and CERT. Therefore we cannot rule out the possibility that significant changes in GPBP expression are masked by CERT expression which is higher at basal levels compared to GPBP [28]. These two variants may differ in various properties such as stability, clearance rate, tissue and cellular localization, temporal pattern of expression, up or down regulation mechanisms and responses to agonists or antagonists. Moreover, the presence or level of specific splice variants may vary depending on the pathophysiologic state of a particular condition. Specific antibodies for each isoform were unavailable at the time of this study; the development of these antibodies should help to resolve this issue.

All the data generated using the 6-OHDA model may help to determine if GPBP/CERT could be critical in the molecular pathways leading to degeneration of nigral cells induced by accumulation of toxins. However, our results are only indicative and need post-mortem confirmation to estimate the real occurrence of such processes. Thus to confirm our findings future investigation of intra- and extracellular ceramide abundance and localization in PD brain and thus its possibility to bind to CERT/GPBP are desirable.

\section{Conclusions}

We tested the hypothesis that GPBP/CERT expression levels were affected in the acute brain injury process of a 6-OHDA PD rat model. Using quantitative stereology we did not observe differences in the number of striatal cells expressing GPBP/CERT. Correlating with this result, also gray value quantification did not detect differences in GPBP/CERT expression levels within individual cells in the acute brain injury process of a 6-OHDA PD rat model. Whereas ceramide levels are known to increase in neurodegenerative diseases, this is the first study to report on the expression levels of the ceramide transporter GPBP/CERT, which were found to remain stable in the PD model used.

\section{Acknowledgements}

We would like to thank Mark Janssen for providing the samples used in the Western blot study. 


\section{References}

[1] A.V. Alessenko, The role of sphingomyelin cycle metabolites in transduction of signals of cell proliferation, differentiation and death, Membr Cell Biol 13 (2000) 303-320.

[2] A.V. Alessenko, A.E. Bugrova, L.B. Dudnik, Connection of lipid peroxide oxidation with the sphingomyelin pathway in the development of Alzheimer's disease, Biochem Soc Trans 32 (2004) 144-146.

[3] G.S. Baron, K. Wehrly, D.W. Dorward, B. Chesebro, B. Caughey, Conversion of raft associated prion protein to the protease-resistant state requires insertion of PrP-res ( $\operatorname{PrP}(\mathrm{Sc})$ ) into contiguous membranes, EMBO J 21 (2002) 1031-1040.

[4] R. Betarbet, T.B. Sherer, J.T. Greenamyre, Animal models of Parkinson's disease, Bioessays 24 (2002) 308-318.

[5] D. Blum, S. Torch, N. Lambeng, M. Nissou, A.L. Benabid, R. Sadoul, J.M. Verna, Molecular pathways involved in the neurotoxicity of 6-OHDA, dopamine and MPTP: contribution to the apoptotic theory in Parkinson's disease, Prog Neurobiol 65 (2001) 135-172.

[6] R. Bose, M. Verheij, A. Haimovitz-Friedman, K. Scotto, Z. Fuks, R. Kolesnick, Ceramide synthase mediates daunorubicin-induced apoptosis: an alternative mechanism for generating death signals, Cell 82 (1995) 405-414.

[7] J. Bras, C. Paisan-Ruiz, R. Guerreiro, M.H. Ribeiro, A. Morgadinho, C. Januario, E. Sidransky, C. Oliveira, A. Singleton, Complete screening for glucocerebrosidase mutations in Parkinson disease patients from Portugal, Neurobiol Aging 30 (2009) 1515-1517.

[8] J. Bras, A. Singleton, M.R. Cookson, J. Hardy, Emerging pathways in genetic Parkinson's disease: Potential role of ceramide metabolism in Lewy body disease, FEBS J 275 (2008) 5767-5773.

[9] B. Brugg, P.P. Michel, Y. Agid, M. Ruberg, Ceramide induces apoptosis in cultured mesencephalic neurons, J Neurochem 66 (1996) 733-739.

[10] R.G. Cutler, J. Kelly, K. Storie, W.A. Pedersen, A. Tammara, K. Hatanpaa, J.C. Troncoso, M.P. Mattson, Involvement of oxidative stress-induced abnormalities in ceramide and cholesterol metabolism in brain aging and Alzheimer's disease, Proc Natl Acad Sci U S A 101 (2004) 20702075.

[11] R.G. Cutler, W.A. Pedersen, S. Camandola, J.D. Rothstein, M.P. Mattson, Evidence that accumulation of ceramides and cholesterol esters mediates oxidative stress-induced death of motor neurons in amyotrophic lateral sclerosis, Ann Neurol 52 (2002) 448-457.

[12] B. Ferger, S. Rose, A. Jenner, B. Halliwell, P. Jenner, 6-hydroxydopamine increases hydroxyl free radical production and DNA damage in rat striatum, Neuroreport 12 (2001) 1155-1159.

[13] C.J. Gamard, G.S. Dbaibo, B. Liu, L.M. Obeid, Y.A. Hannun, Selective involvement of ceramide in cytokine-induced apoptosis. Ceramide inhibits phorbol ester activation of nuclear factor kappaB, J Biol Chem 272 (1997) 16474-16481.

[14] A. Gomez-Munoz, Ceramide 1-phosphate/ceramide, a switch between life and death, Biochim Biophys Acta 1758 (2006) 2049-2056.

[15] D.G. Graham, S.M. Tiffany, W.R. Bell, Jr., W.F. Gutknecht, Autoxidation versus covalent binding of quinones as the mechanism of toxicity of dopamine, 6-hydroxydopamine, and related compounds toward C1300 neuroblastoma cells in vitro, Mol Pharmacol 14 (1978) 644-653.

[16] F. Granero-Molto, S. Sarmah, L. O'Rear, A. Spagnoli, D. Abrahamson, J. Saus, B.G. Hudson, E.W. Knapik, Goodpasture antigen-binding protein and its spliced variant, ceramide transfer protein, have different functions in the modulation of apoptosis during zebrafish development, J Biol Chem 283 (2008) 20495-20504.

[17] K. Hanada, K. Kumagai, S. Yasuda, Y. Miura, M. Kawano, M. Fukasawa, M. Nishijima, Molecular machinery for non-vesicular trafficking of ceramide, Nature 426 (2003) 803-809.

[18] O. Hornykiewicz, S.J. Kish, Biochemical pathophysiology of Parkinson's disease, Adv Neurol 45 (1987) 19-34.

[19] I. Ichi, C. Kamikawa, T. Nakagawa, K. Kobayashi, R. Kataoka, E. Nagata, Y. Kitamura, C. Nakazaki, T. Matsura, S. Kojo, Neutral sphingomyelinase-induced ceramide accumulation by oxidative stress during carbon tetrachloride intoxication, Toxicology 261 (2009) 33-40. 
[20] O. Kantor, Y. Temel, C. Holzmann, K. Raber, H.P. Nguyen, C. Cao, H.O. Turkoglu, B.P. Rutten, V. Visser-Vandewalle, H.W. Steinbusch, A. Blokland, H. Korr, O. Riess, S. von Horsten, C. Schmitz, Selective striatal neuron loss and alterations in behavior correlate with impaired striatal function in Huntington's disease transgenic rats, Neurobiol Dis 22 (2006) 538-547.

[21] M. Kivipelto, E.L. Helkala, M.P. Laakso, T. Hanninen, M. Hallikainen, K. Alhainen, H. Soininen, J. Tuomilehto, A. Nissinen, Midlife vascular risk factors and Alzheimer's disease in later life: longitudinal, population based study, BMJ 322 (2001) 1447-1451.

[22] R. Kolesnick, The therapeutic potential of modulating the ceramide/sphingomyelin pathway, J Clin Invest 110 (2002) 3-8.

[23] J. Lotharius, P. Brundin, Pathogenesis of Parkinson's disease: dopamine, vesicles and alphasynuclein, Nat Rev Neurosci 3 (2002) 932-942.

[24] I.F. Mata, A. Samii, S.H. Schneer, J.W. Roberts, A. Griffith, B.C. Leis, G.D. Schellenberg, E. Sidransky, T.D. Bird, J.B. Leverenz, D. Tsuang, C.P. Zabetian, Glucocerebrosidase gene mutations: a risk factor for Lewy body disorders, Arch Neurol 65 (2008) 379-382.

[25] C. Mencarelli, C. Hammels, J. Van Den Broeck, M. Losen, H. Steinbusch, F. Revert, J. Saus, D.A. Hopkins, M.H. De Baets, H.W. Steinbusch, P. Martinez-Martinez, The expression of the Goodpasture antigen-binding protein (ceramide transporter) in adult rat brain, J Chem Neuroanat 38 (2009) 97-105.

[26] C. Mencarelli, M. Losen, C. Hammels, J. De Vry, M.K. Hesselink, H.W. Steinbusch, M.H. De Baets, P. Martinez-Martinez, The ceramide transporter and the Goodpasture antigen binding protein: one protein--one function?, J Neurochem 113 1369-1386.

[27] G.J. Pronk, K. Ramer, P. Amiri, L.T. Williams, Requirement of an ICE-like protease for induction of apoptosis and ceramide generation by REAPER, Science 271 (1996) 808-810.

[28] A. Raya, F. Revert-Ros, P. Martinez-Martinez, S. Navarro, E. Rosello, B. Vieites, F. Granero, J. Forteza, J. Saus, Goodpasture antigen-binding protein, the kinase that phosphorylates the goodpasture antigen, is an alternatively spliced variant implicated in autoimmune pathogenesis, J Biol Chem 275 (2000) 40392-40399.

[29] S.P. Sardi, J. Clarke, C. Kinnecom, T.J. Tamsett, L. Li, L.M. Stanek, M.A. Passini, G.A. Grabowski, M.G. Schlossmacher, R.L. Sidman, S.H. Cheng, L.S. Shihabuddin, CNS expression of glucocerebrosidase corrects alpha-synuclein pathology and memory in a mouse model of Gaucher-related synucleinopathy, Proc Natl Acad Sci U S A 108 12101-12106.

[30] H. Satoi, H. Tomimoto, R. Ohtani, T. Kitano, T. Kondo, M. Watanabe, N. Oka, I. Akiguchi, S. Furuya, Y. Hirabayashi, T. Okazaki, Astroglial expression of ceramide in Alzheimer's disease brains: a role during neuronal apoptosis, Neuroscience 130 (2005) 657-666.

[31] C. Schmitz, P.R. Hof, Design-based stereology in neuroscience, Neuroscience 130 (2005) 813831.

[32] C. Schmitz, P.R. Hof, Recommendations for straightforward and rigorous methods of counting neurons based on a computer simulation approach, J Chem Neuroanat 20 (2000) 93-114.

[33] D.J. Sillence, Apoptosis and signalling in acid sphingomyelinase deficient cells, BMC Cell Biol 2 (2001) 24.

[34] A. Taraboulos, M. Scott, A. Semenov, D. Avrahami, L. Laszlo, S.B. Prusiner, Cholesterol depletion and modification of $\mathrm{COOH}$-terminal targeting sequence of the prion protein inhibit formation of the scrapie isoform, J Cell Biol 129 (1995) 121-132.

[35] Y. Temel, V. Visser-Vandewalle, B. Aendekerk, B. Rutten, S. Tan, B. Scholtissen, C. Schmitz, A. Blokland, H.W. Steinbusch, Acute and separate modulation of motor and cognitive performance in parkinsonian rats by bilateral stimulation of the subthalamic nucleus, Exp Neurol 193 (2005) 43-52.

[36] Y. Temel, V. Visser-Vandewalle, S. Kaplan, R. Kozan, M.A. Daemen, A. Blokland, C. Schmitz, H.W. Steinbusch, Protection of nigral cell death by bilateral subthalamic nucleus stimulation, Brain Res 1120 (2006) 100-105.

[37] V.J. Thannickal, B.L. Fanburg, Reactive oxygen species in cell signaling, Am J Physiol Lung Cell Mol Physiol 279 (2000) L1005-1028.

[38] G. van Echten-Deckert, T. Herget, Sphingolipid metabolism in neural cells, Biochim Biophys Acta 
1758 (2006) 1978-1994.

[39] T.J. van Ham, K.L. Thijssen, R. Breitling, R.M. Hofstra, R.H. Plasterk, E.A. Nollen, C. elegans model identifies genetic modifiers of alpha-synuclein inclusion formation during aging, PLoS Genet 4 (2008) e1000027.

[40] G. Walkinshaw, C.M. Waters, Neurotoxin-induced cell death in neuronal PC12 cells is mediated by induction of apoptosis, Neuroscience 63 (1994) 975-987. 


\section{Chapter 5}

\section{The Goodpasture-Antigen Binding Protein / Ceramide Transporter binds to Human Serum Amyloid P-Component and is present in Brain Amyloid Plaques}

Chiara Mencarelli, Gerard H. Bode, Mario Losen, Mahesh Kularia,

Peter C. Molenaar, Robert Veerhuis, Harry W.M. Steinbusch, Marc H. De Baets, Gerry A.F. Nicolaes and Pilar Martínez-Martínez

Published in: The Journal of Biological Chemistry 2012; 287, 14897-14911. 


\section{SUMMARY}

Serum amyloid $\mathrm{P}$ component (SAP) is a non fibrillar glycoprotein belonging to the pentraxin family of the innate immune system. SAP is present in plasma, basement membranes and amyloid deposits. This study demonstrates, for the first time, that the Goodpasture antigen binding protein (GPBP) binds to human SAP. GPBP is a nonconventional Ser/Thr kinase for basement membrane type IV collagen. Also GPBP is found in plasma and in the extracellular matrix. In the present study we demonstrate that GPBP specifically binds SAP in its physiological conformations, pentamers and decamers. The START domain in GPBP is important for this interaction. SAP and GPBP form complexes in blood and partly colocalize in amyloid plaques from Alzheimer's disease patients. These data suggest the existence of complexes of SAP and GPBP under physiological and pathological conditions. These complexes are important for understanding basement membrane, blood physiology and plaque formation in Alzheimer's disease.

Serum amyloid $\mathrm{P}$ component (SAP) is present in the blood as single uncomplexed pentamers and decamers (1). SAP has been found to decorate amyloid deposits in different amyloid diseases where it was first identified (2). In Alzheimer's disease (AD), SAP colocalizes with amyloid- $\beta$ deposits (Aß) $(3,4)$ in the brain and is thought to protect the amyloid from proteolysis $(5)$. Below we will first introduce known properties of SAP and subsequently of the Goodpasture-antigen binding protein (GPBP), which we identify and characterize as a new SAP binding protein in this paper.

SAP is a $23 \mathrm{kDa}$ glycoprotein (6) of the pentraxin family which is characterized by $\mathrm{Ca}^{2+}$-dependent ligand binding (7-10). SAP self-association and aggregation is also influenced by $\mathrm{Ca}^{2+}(11)$.

SAP binds to proteins involved in immunological responses (12-15) and can activate the classical complement pathway through interaction with $\mathrm{C} 1 \mathrm{q}$ (16). In addition, SAP interacts with extracellular matrix (ECM) components such as proteoglycans $(8,17)$, fibronectin (18), laminin (10) and collagen IV (9). Collagen molecules are heterotrimers composed of three alpha chains. In collagen IV, each of these $\alpha$-chains consists of an amino-terminal $7 \mathrm{~S}$ domain, a central helical structure and a carboxyl-terminal globular noncollagenous (NC1) domain. The distribution of SAP in basal membranes (BMs) coincides with the restricted localization of the $\alpha 3-\alpha 4-\alpha 5$ heterotrimer of collagen IV (17).

The NC1 domain of the collagen IV $\alpha 3$ subunit ( $\alpha 3$ (IV)NC1) is the autoantigen in Goodpasture (GP) syndrome, an autoimmune disease in 
which autoantibodies are observed along glomerular and alveolar BMs, causing glomerulonephritis and lung hemorrhage (19).

The Goodpasture antigen binding protein (GPBP) binds to the $\alpha 3$ (IV)NC1 in the glomerular basal membrane (GBM) of GP patients (20). GPBP exist in different isoforms which are found in the extracellular compartment; either soluble or associated with the surface of the plasma membrane $(21,22)$ and in blood (23). A shorter splicing isoform, CERT, is located inside the cell and functions as carrier for ceramide from the ER to the Golgi apparatus (24). GPBP and CERT (also known as CERTL and GPBP $\triangle 26$, respectively) are identical in sequence with the exception of an additional 26 amino acid domain present only in GPBP (25).

Because both SAP and GPBP have been reported to self aggregate $(11,25)$ and have similar properties the question arose as to whether SAP and GPBP could bind to each other. Thus, the aim of the present study was to characterize in detail the direct interaction between these proteins using surface plasmon resonance (SPR), far Western blotting and microscale thermophoresis technology (MST). We report, for the first time, that SAP binds to GPBP and moreover, that SAP and GPBP are co-localized in amyloid plaques from $A D$ patients. Our data suggest the existence of complexes of SAP and GPBP under normal and pathological conditions.

\section{EXPERIMENTAL PROCEDURES}

\section{Purification of SAP protein from human serum}

SAP was purified from human plasma through an immuno-affinity procedure applying $\mathrm{Ca}^{2+}$-ion dependent interactions of SAP with complement factor C4b-binding protein (C4BP). A monoclonal antibody against C4BP (CLBC4BP), which is directed against the alpha chains of human C4BP [a kind gift from Dr Jan van Mourik, Sanquin Research, Central Laboratory of the Blood Transfusion Service (CLB), Amsterdam, the Netherlands] was coupled to CNBr-activated Sepharose 4B (GE healthcare, Hoevelaken, the Netherlands) according to manufacturers instructions. Human plasma was fractionated by barium citrate precipitation and eluted with $30 \%$ ammonium sulfate. After precipitation with $70 \%$ ammonium sulfate the protein fraction was dialyzed against Tris buffered saline (TBS: $50 \mathrm{mM}$ Tris- $\mathrm{HCl} \mathrm{pH} \mathrm{7.4,} 150 \mathrm{mM} \mathrm{NaCl}$ ) supplemented with $3 \mathrm{mM} \mathrm{CaCl}_{2}$ and applied to the anti-C4BP column. After binding of the C4BP-SAP complex, the column was washed with TBS containing $3 \mathrm{mM} \mathrm{CaCl} 2$ until $\mathrm{OD}_{280 \mathrm{~nm}}<0.05$. Subsequently, SAP was specifically eluted with TBS containing $2 \mathrm{mM}$ EDTA. Purified human SAP appeared as a single band ( $>95 \%$ purity) on a Coomassie Blue-stained $4-15 \%$ 
SDS gel and fractions were pooled and frozen at $-80^{\circ} \mathrm{C}$ until use. The identity of SAP was confirmed by peptide mass fingerprinting using a tandem MALDI-TOF protein analyzer (Applied Biosystems 4800)

\section{Production of recombinant GPBP and CERT proteins}

For recombinant expression of GPBP and CERT we used the vector pHILD2 (Invitrogen, Breda, the Netherlands). The expression cassettes were synthesized (GeneArt, Regensburg, Germany) using the cDNA sequences that encode the human GPBP protein (NP_005704.1) and the human CERT protein (NP_112729.1) preceded by a cassette including an EcoRI restriction site, a standard Kozak consensus for translation initiation, followed by a sequence encoding for MAPLA and a FLAG tag peptide (DYKDDDDK). An EcoRI site was introduced after the stop codon. The plasmids were transfected and expressed in Pichia pastoris (Invitrogen). FLAG-tagged recombinant proteins were purified from the cell lysate with an anti-FLAG M2 affinity agarose gel column (Sigma, A2220, Zwijndrecht, the Netherlands) according to the manufacturer's instructions. The unbound material was washed off the column with TBS and FLAG-tagged proteins were eluted using 100 Mg/mL FLAG peptide (Sigma, F3290).

CERT and CERT mutants constructs were synthesized by LifeTechnologies, GeneArt (Regensburg, Germany) in pET28b (Novagen) expression vectors through a PCR-based method. Flag-tagged proteins were produced by overexpression in E. coli BL21(DE3) pLYSs (Promega, UK), induced with $1 \mathrm{mM}$ IPTG for 4 hours at $37^{\circ} \mathrm{C}$. Recombinant protein was isolated using the FLAGtag as described above.

\section{Sample preparation and SPR analysis}

SAP self-aggregation was controlled by optimization of the buffers. To this end, native SAP was diluted at final concentrations of 25, 50 and $100 \mathrm{nM}$ in: 1) sodium acetate buffer $\mathrm{pH} 4.5 ; 2$ ) sodium acetate buffer $\mathrm{pH} 4.5$ with $5 \mathrm{mM}$ $\mathrm{Ca}^{2+}$; 3) $25 \mathrm{mM}$ HEPES buffer $\mathrm{pH} 7.4$; 4) $25 \mathrm{mM}$ HEPES buffer $\mathrm{pH} 7.4$ and sonicated; 5) $25 \mathrm{mM}$ HEPES buffer with $0.01 \%$ Tween 20 at pH 7.4 and sonicated. Sonication was performed before SPR experiments using a probe (Beun-De Ronde B.V., Abcoude, the Netherlands) for 3 pulses of $30 \mathrm{~s}$ each with a $30 \mathrm{~s}$ rest on ice between pulses. Each sample was centrifuged at $20,000 \mathrm{~g}$ for $5 \mathrm{~min}$ to remove protein aggregates immediately before SPR analysis.

SPR experiments were performed on a Biacore T100 apparatus (GE healthcare) (26). The guidelines from the manufacturer were followed for the preparation of the sensor surfaces and interpretation of the 
sensorgrams. Purified human SAP, GPBP and CERT $(50 \mu \mathrm{g} / \mathrm{mL}$ in $10 \mathrm{mM}$ sodium acetate buffer $\mathrm{pH} 4.5$ ) were covalently coupled via amine groups onto the carboxymethylated dextran surface of CM5 sensor chips (GE healthcare) resulting in a signal of up to 15000 resonance units (RU). Injection of specific antibodies recognizing both GPBP and CERT demonstrated the presence of the proteins immobilized in each flow cell [rabbit polyclonal anti-GPBP/CERT, epitope 1-50 of human GPBP/CERT, Bethyl Laboratories, Montgomery, TX; rabbit polyclonal anti SAP (P-16), Santa Cruz Biotechnology, CA]. Analytes for binding studies were prepared in $25 \mathrm{mM}$ HEPES buffer $\mathrm{pH} 7.4,150 \mathrm{mM} \mathrm{NaCl}$ with $0.01 \%$ Tween 20. To perform binding experiments, protein samples (purified SAP, human collagen IV (Sigma), human laminin (Sigma), bovine serum albumin (BSA, Sigma), were injected onto the chip over a concentration range of $100 \mathrm{nM}$ $1 \mu \mathrm{M}$ at a flow rate of $10 \mu \mathrm{L} / \mathrm{min}$ for $5 \mathrm{~min}$ at $25^{\circ} \mathrm{C}$. To test the effect of $\mathrm{Ca}^{2+}$ on protein-protein interaction, the same buffer with addition of $5 \mathrm{mM} \mathrm{Ca}^{2+}$ was used for some of the experiments.

Wild type and five mutant CERT proteins were serially diluted in $25 \mathrm{mM}$ HEPES, $150 \mathrm{mM} \mathrm{NaCl}, 0.01 \%$ Tween 20, pH 7.4, over a wide concentration range (up to $500 \mathrm{nM}$ ) by using 2-fold dilution steps. Samples were injected over a SAP-coated surface of CM5 sensor chip (density, $5000 \mathrm{RU}$ ), for $3 \mathrm{~min}$ at a flow rate of $30 \mu \mathrm{L} / \mathrm{min}$, at $25^{\circ} \mathrm{C}$. At the end of each run, the sensor surface was regenerated (removal of bound complex) by using $25 \mathrm{mM} \mathrm{NaOH}$ before additional samples were injected. As an internal reference, a control channel was routinely activated and blocked in absence of protein. The signals from the control channel were subtracted from the signals generated by the flow cells containing immobilized protein. Analysis was performed on the data using BIAevaluation 3.0 software. Sensorgrams were recorded and normalized to a base line of $0 \mathrm{RU}$.

\section{Microscale Thermophoresis binding analyses}

Microscale thermophoresis (MST) is a new immobilization-free technique for the analysis of biomolecules interaction (27-29). The term Microscale Thermophoresis refers to the directed movement of molecules in optically generated microscopic temperature gradients. This thermophoretic movement is determined by the entropy of the hydration shell around molecules. The microscopic temperature gradient is generated by an IRLaser. The readout method of the interaction analysis is based on fluorescence. In a typical MST-experiment the concentration of the labeled molecule is kept constant, while the concentration of the unlabeled interaction partner is varied. The MST signal will detect the binding by a 
quantification of the change in the normalized fluorescence (27).

MST analysis was performed on the Monolith NT.115 instrument (NanoTemper, München, Germany). In brief, a constant concentration of 1$50 \mathrm{nM}$ of NT647-labeled GPBP was incubated for $20 \mathrm{~min}$ at room temperature in the dark with different concentrations of SAP (up to 5000 $\mathrm{nM}$ ) in PBS/0.01\% Tween 20. Afterwards, 3-5 $\mu \mathrm{L}$ of the samples were loaded into glass capillaries (Monolith NT Capillaries, Cat \# K002) and the thermophoresis analysis was performed (LED 40-51\%, IR laser 80\%). Statistical analysis was performed with Origin8.5 software.

\section{Gel filtration chromatography}

A Superose 6 column with a bed volume of $24 \mathrm{~mL}$ (Perkin-Elmer Series 4 FPLC system) connected to a FPLC system (GE healthcare) was washed with ethanol $(20 \% \mathrm{v} / \mathrm{v})$ and $0.5 \mathrm{M} \mathrm{NaOH}$, and pre-equilibrated with 3 column volumes of $25 \mathrm{mM}$ HEPES buffer (pH 7.4) with $150 \mathrm{mM} \mathrm{NaCl}$. Samples of purified SAP were run on this column with a buffer flow rate of $0.4 \mathrm{~mL} / \mathrm{min}$. The approximate molecular mass of the fractionated proteins was calculated from peak elution volumes by comparison with molecular weight standards(thyroglobulin, $669 \mathrm{kDa}$; ferritin, $440 \mathrm{kDa}$; fibrinogen, $340 \mathrm{kDa}$; IgG, 160 kDa; BSA, 67 kDa; ribonuclease A, 13.7 kDa; GE healthcare).

\section{Immunoprecipitation and Western blot}

Immunoprecipitation and co- immunoprecipitation of SAP and GPBP from human serum were performed after depletion of albumin (ProteoExtract Albumin Removal Kit; Calbiochem, La Jolla, CA) to increase the resolution of the lower-abundance proteins of interest. Albumin depleted serum was centrifuged at 20,000 g for $30 \mathrm{~min}$. Pull down of endogenous SAP and endogenous GPBP was performed with mAb 4E8 (Sigma) and mAb 3A1-C1, respectively. Rabbit polyclonal anti Dok-7 antibody $(\mathrm{H}-77$, Santa Cruz Biotechnology, Heidelberg, Germany) and a mouse monoclonal anti syntaxin 6 (clone 3D10, Abcam, Cambridge, UK) were used as isotype controls. After incubation ( $1 \mu \mathrm{g}$ antibody per $15 \mu \mathrm{L}$ serum; at room temperature for $1 \mathrm{~h}$ ), samples were centrifuged at $20000 \mathrm{~g}$ for $30 \mathrm{~min}$ at $4^{\circ} \mathrm{C}$. Pellets were washed three times in $50 \mu \mathrm{L}$ PBS and boiled in reducing sample buffer containing mercaptoethanol to dissolve immunocomplexes.

Brain tissue from 8 months old control and Alzheimer's transgenic mice (APPswe PS1 $\triangle \mathrm{E} 9 \mathrm{C} 57 \mathrm{BL} / 6$ ) were thawed and homogenized as described (30). In brief rat cortex was placed in ice cold lysis buffer containing PBS, $0.1 \%$ SDS, $0.1 \%$ Triton X-100, 1\% glycerol, 1 mM EDTA, 1 mM EGTA, 30 mM NaF, and $16.7 \mathrm{mM}$ sodium orthovanadate and a Complete Protease Inhibitor 
Cocktail tablet (Roche Diagnostics, Almere, the Netherlands) per $50 \mathrm{ml}$ of buffer, following the manufacturers recommendations. Glass beads and a bead beater (Biospec products, Bartlesville, OK) were used for the homogenization of the tissue. The homogenization consisted of 3 cycles of $30 \mathrm{~s}$ in $1.0 \mathrm{ml}$ lysis buffer.

Total protein concentration was determined by a conventional method (BCA protein assay Kit, Pierce). For immunoprecipitation, $2 \mathrm{mg}$ brain homogenates were incubated for $1 \mathrm{~h}$ at room temperature with $3 \mu \mathrm{g}$ of one of the following mAbs: anti-SAP (4E8), anti-GPBP (3A1-C1) or anti-A? (human recombinant antibodies bapineuzumab, solanezumab and 20C2, produced recombinantly in house, based on published sequences). Negative controls consisted of IgG mAb anti syntaxin 6 (clone 3D10) or anti-rapsyn (clone 1234, Sigma). Next we added goat anti-mouse (Euroegentec, Maastricht, the Netherlands) during $30 \mathrm{~min}$ at room temperature (1 $\mathrm{\mu g}$ per sample). Samples were centrifuged at $20000 \mathrm{~g}$ for $30 \mathrm{~min}$ at $4^{\circ} \mathrm{C}$ and immunocomplexes were processed as described above.

Proteins were separated by SDS and native-PAGE using precast Criterion Tris- $\mathrm{HCl}$ glycine $4-20 \%$ gradient gels (Bio-Rad, Veenendaal, the Netherlands) followed by electroblotting to nitrocellulose membrane (Millipore, Amsterdam Zuid-Oost, the Netherlands). The membranes were incubated with primary antibodies specific for SAP (4E8), or GPBP using either mAb 3A1-C1, or polyclonal rabbit anti-GPBP epitope 1-50 (Bethyl laboratories). or specific for $A \beta$ using anti-A $\beta$ (6E10). After PBS washes, the membrane was incubated with goat anti-rabbit-IRdye 800 and donkey anti-mouse-IRdye 680 (Rockland Immunochemicals, Gilbertsville, PA). Finally, the membrane was washed with PBS, dried and scanned using the Odyssey infrared imaging system (Westburg, Leusden, the Netherlands).

\section{Far Western}

For far-Western experiments SAP (80 ng) and BSA (2 $\mu \mathrm{g}$ ) (Sigma) were separated by SDS-PAGE under reducing conditions and transferred to Immobilon $\mathrm{P}$ membranes (Millipore). For renaturation of SAP, the membranes were incubated in TBS with Tween 20 (0.05\%) over night. Renatured proteins were probed for $1 \mathrm{~h}$ at $37^{\circ} \mathrm{C}$ with either GPBP, CERT or CERT mutants $(30 \mu \mathrm{g} / \mathrm{mL})$ in the same buffer $(20)$. Next, membranes were blocked with 5\% BSA. Bound material was detected using anti-GPBP (3A1C1), anti-SAP (4E8) and donkey anti-mouse-Alexa 680 followed by detection as described above. BSA was detected by standard Coomassie staining. 


\section{Immunohistochemistry in kidney}

Sections of monkey control kidney tissue (macaques) (Probetex, San Antonio, TX) were incubated over night at room temperature with primary antibodies [mouse monoclonal anti-GPBP antibody (3A1-C1) and anti-SAP (4E8)], followed by the corresponding secondary antibody [donkey antimouse biotinylated IgG (Jackson ImmunoResearch Laboratories Europe Ltd., Newmarket, Suffolk, UK)]. Subsequently, sections were incubated with the ABC-kit (Vector Laboratories, Burlingame, CA) followed by 3,3diaminobenzidine tetrahydrochloride (DAB).

Slides were mounted with $80 \%$ glycerol in TBS. Images were acquired using an Olympus AX70 microscope (Olympus, Zoeterwoude, the Netherlands) and recorded using Cell $\mathrm{P}$ software (Olympus).

\section{Immunohistochemistry in human brain}

In order to investigate the presence and localization of GPBP in human brain, post mortem specimens from 3 male and 3 female donors were studied by immunohistochemistry. This material was obtained from the Netherlands Brain Bank (Amsterdam, the Netherlands). Staging of AD was neuropathologically evaluated according to the Braak and Braak criteria (see Table 1) (31). For immunohistochemical staining, $5 \mu \mathrm{m}$ cryosections were mounted on coated glass slides (Menzel Gläser super frost PLUS, Braunschweig, Germany), and fixed in acetone for $10 \mathrm{~min}$. Next, sections were incubated overnight with primary antibodies, including rabbit anti-SAP (Dako), mouse monoclonal anti-A $\beta$ (clone 6F/3D; Dako), affinity purified rabbit antibody specific for the residue 300-350 of human GPBP/CERT (Bethyl laboratories) or polyclonal rabbit anti-GPBP/CERT epitope 1-50. Subsequently, sections were incubated with EnVision goat-anti-mouse horseradish peroxidise (HRP) or EnVision goat-anti-rabbit HRP (Dako). Peroxidase labeling was visualized by EnVision DAB (EV-DAB; Dako). Sections were counterstained with hematoxylin. For co-localization studies, cryosections were incubated in thioflavin $S$ solution to stain $A \beta$ fibrils and washed subsequently three times in ethanol $70 \%$. Sections were incubated with a mix of primary antibodies: anti-SAP (mAb-14) (32) in combination with anti-GPBP/CERT 1-50 or 300-350 diluted in PBS containing $1 \%$ BSA. After washing in PBS, sections were incubated with a mix of secondary antibodies: biotin conjugated goat-anti-rabbit (Dako) and EnVision goatanti-mouse HRP (Dako). Upon washing with PBS, sections were incubated with streptavidin Alexa-633; HRP signal was developed with rhodamin 
tyramide (in presence of $0.01 \% \mathrm{H}_{2} \mathrm{O}_{2}$ ). Slides were covered with AquaPoly/Mount (Polysciences Inc, Warrington, PA).

\section{RESULTS}

\section{Binding of SAP and GPBP to type IV collagen}

Previously it has been reported that both SAP and GPBP specifically bind to $\alpha 3($ IV)NC1 monomer $(20,33)$. In order to analyze if this binding occurs in vivo, we studied whether SAP and GPBP colocalize in glomerular basal membrane (GBM), which expresses collagen IV. To this end, frozen monkey kidney sections were stained by immunohistochemistry. SAP showed a linear staining pattern along the GBM as described (34) (Figure $1 \mathrm{~A}$ upper panel). A monoclonal antibody that recognizes GPBP specifically (mAb3A1$\mathrm{C} 1$ ) also resulted in a strong staining of the GBM (Figure $1 \mathrm{~A}$ middle panel). Thus, the reported immunoreactivity of polyclonal antibodies against both GPBP and CERT to tubules and glomerulus in human kidney (20) can be at least partially attributed to the expression of the longer isoform GPBP.

We further examined the binding of SAP and GPBP to collagen IV by SPR technology. Collagen IV bound to immobilized human GPBP and human SAP (Figure 1B and C).

Binding of SAP to several ligands is dependent on the presence of $\mathrm{Ca}^{2+}$ $(7,8,35)$. Binding of collagen IV to SAP was enhanced by $3-4$ fold by the addition of $5 \mathrm{mM} \mathrm{Ca}^{2+}$ (Figure $1 \mathrm{C}$ ). In contrast, binding of collagen IV to GPBP was independent of the presence of $\mathrm{Ca}^{2+}$ (Figure 1B). Binding of BSA to immobilized SAP or GPBP was minimal (data not shown). Kinetic analysis of the binding of soluble collagen IV to immobilized SAP and to GPBP was performed by SPR. Collagen IV (concentrations ranging between 10 to 250 $\mathrm{nM}$ ) bound to GPBP strongly; increasing the concentration of collagen IV up to $250 \mathrm{nM}$ did not saturate this binding (Figure $2 \mathrm{~A}$ ). As expected, collagen IV also bound to immobilized SAP (Figure 2B) and in this case binding was already almost saturated at $10 \mathrm{nM}$ collagen IV. These data suggest that once collagen IV has bound to immobilized GPBP, additional collagen IV can bind by forming GPBP-collagen-collagen complexes. In contrast, SAP binding to collagen IV does not induce formation of larger collagen aggregates Binding of collagen IV to CERT was also studied and compared with GPBP (Figure 2C). Collagen IV rapidly associated with both immobilized proteins. However, collagen IV dissociated faster from CERT than from full-length GPBP. 
A

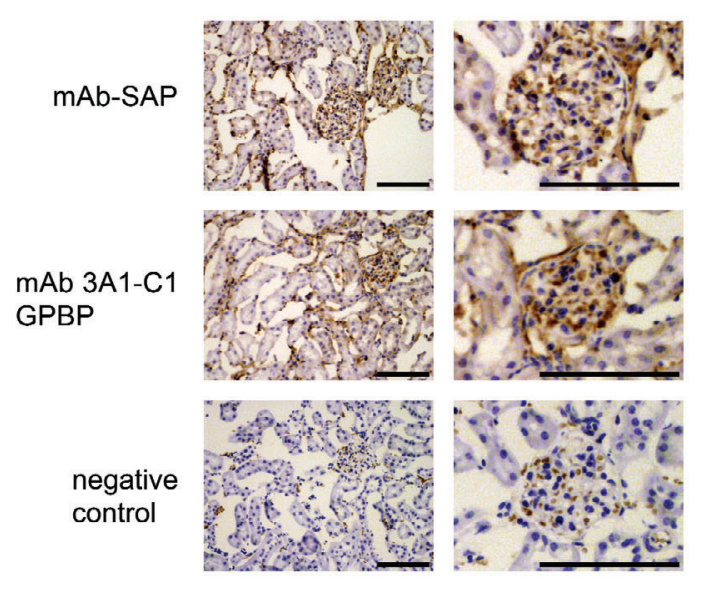

Figure 1

B

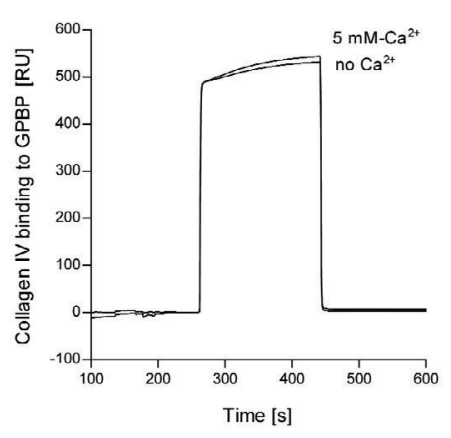

C

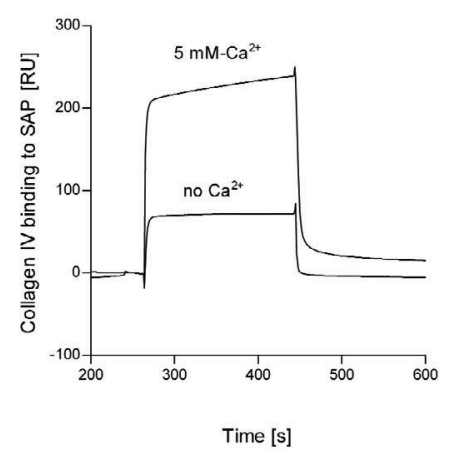

Figure 1. Collagen IV binds to SAP and to GPBP

(A) Representative monkey kidney sections with glomeruli stained for GPBP and SAP; SAP with mAb; GPBP with $m A b 3 A 1-C 1$. No staining was observed when the primary antibodies were omitted. Scale bars represent $100 \mu \mathrm{m}$. (B-C) The detection of the protein-protein interaction was performed with specific antibodies against SAP and GPBP using SPR technology. (B) Collagen IV was filtered $(0.45-\mu \mathrm{m}$ Millipore filter), and then injected (100 nM) over immobilized GPBP (101 RU; flow rate, $15 \mu \mathrm{L} / \mathrm{min}$; injected volume, $60 \mu \mathrm{L}$ ) in $25 \mathrm{mM}$ HEPES buffer $\mathrm{pH} 7.4,150 \mathrm{mM} \mathrm{NaCl}$ (either without $\mathrm{Ca}^{2+}$ or with $5 \mathrm{mM} \mathrm{Ca}^{2+}$ ). In panel (C) collagen IV was injected at $100 \mathrm{nM}$ over immobilized SAP (101 RU; flow rate, $15 \mu \mathrm{L} / \mathrm{min}$; injected volume, $60 \mu \mathrm{L}$ ) in $25 \mathrm{mM} \mathrm{HEPES}$ buffer $\mathrm{pH} 7.4,150 \mathrm{mM} \mathrm{NaCl}$ (either without $\mathrm{Ca}^{2+}$ or with $5 \mathrm{mM} \mathrm{Ca}^{2+}$ ).

\section{Binding of laminin to immobilized GPBP}

SAP has been shown to bind laminin, another important component of basement membranes (10). However, the binding of GPBP to laminin has yet to be reported. By SPR binding experiments we found that laminin binds to immobilized GPBP (Figure3). Binding of laminin to GPBP was enhanced by approximately $25 \%$ with the addition of $5 \mathrm{mM} \mathrm{Ca}^{2+}$ (Figure 3 ). 
A

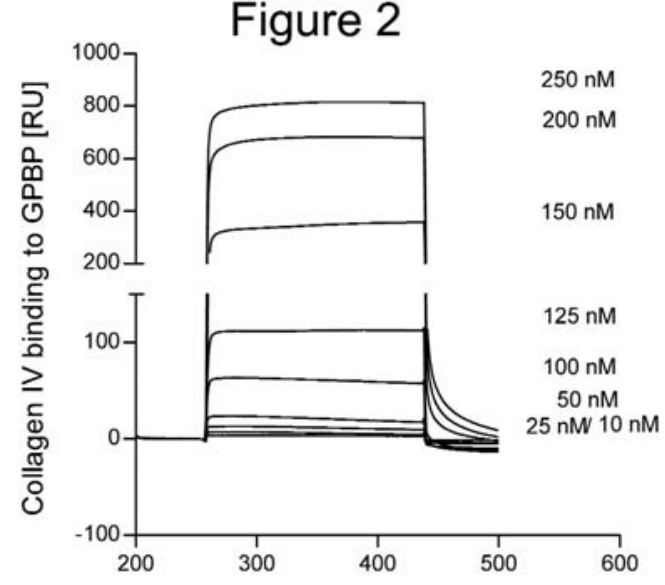

B

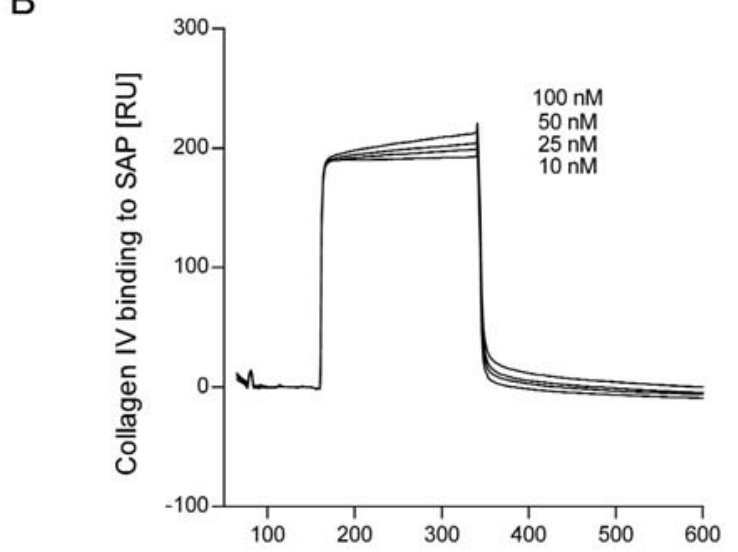

C

Time [s]

Time [s]

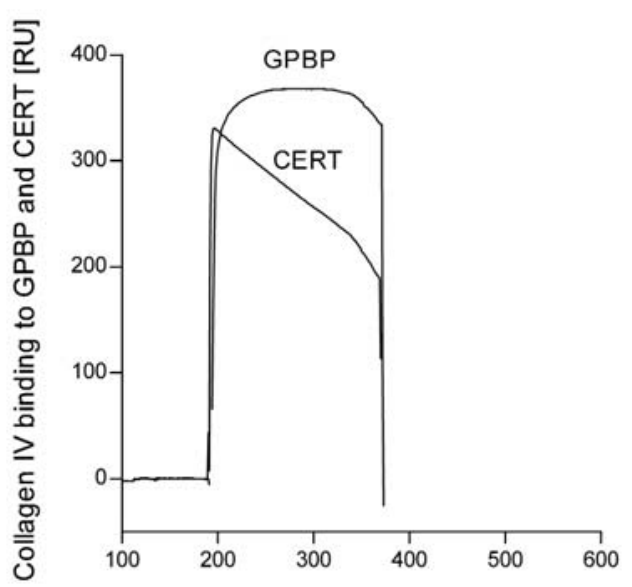

Figure 2. Collagen IV binds to SAP, GPBP and CERT Overlay of sensograms resulting from the injection of different concentrations (10-250 nM) of collagen IV over immobilized GPBP (96 RU, flow rate, 15 $\mu \mathrm{L} / \mathrm{min}$; injected volume, $60 \mu \mathrm{L}$ ) (A) and over immobilized SAP (96 $\mathrm{RU}$, flow rate, $15 \mu \mathrm{L} / \mathrm{min}$; injected volume, $60 \mu \mathrm{L})(\mathrm{B})$. Binding of collagen IV (100 nM) to immobilized GPBP and CERT (50 $\mu \mathrm{g} / \mathrm{mL}$ in $10 \mathrm{mM}$ sodium acetate $\begin{array}{llll}\text { buffer } \mathrm{pH} & 4.5) & \text { (C). The }\end{array}$ sensograms were corrected for the signal in the empty cell (i.e. calculated as the difference between the signal in Fc2 (flow channel 2) that contained the immobilized ligand and the signal in Fc1 (empty channel), which includes injection noise, instrument drift, and nonspecific binding).

Time [s] 


\section{Figure 3}

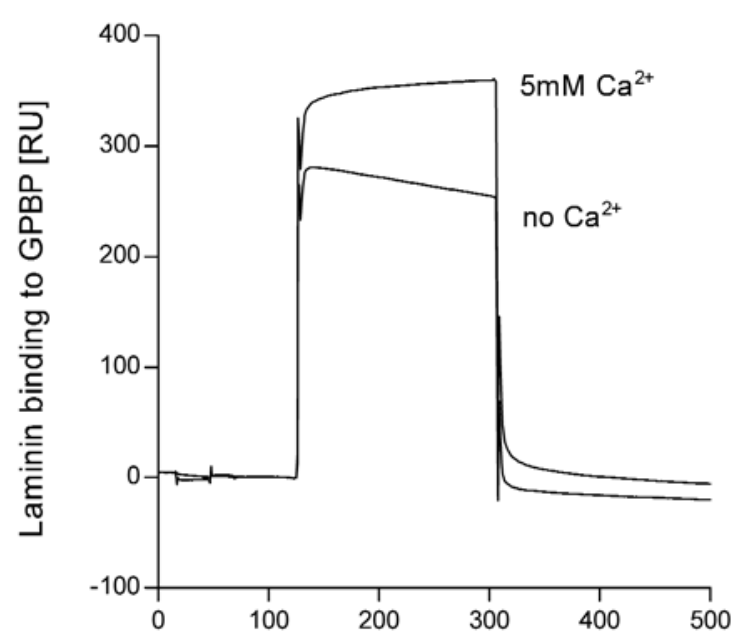

Figure 3. Laminin binds to GPBP

(A) Binding of laminin (100 $\mathrm{nM})$ to immobilized GPBP (215 RU; flow rate, $15 \mu \mathrm{L} / \mathrm{min}$; injected volume, 60 $\mu \mathrm{L}$ ) in buffer containing $5 \mathrm{mM} \mathrm{Ca}^{2+}$ or buffer without $\mathrm{Ca}^{2+}$. The binding was first recorded in the absence of added $\mathrm{Ca}^{2+}$. The experiments were performed by SPR technology.

Time $[\mathrm{s}]$

\section{Binding of SAP to immobilized GPBP}

Since SAP and GPBP bind to collagen IV, and colocalize at GBM, we asked the question whether they could interact with each other. We measured the binding of GPBP to immobilized SAP by far-Western (Figure $4 A)(36,37)$. For this purpose, membranes containing SAP (80 ng) and BSA (2,000 ng) as negative control were incubated in renaturation buffer over night and subsequently probed with GPBP. Our experiment showed that GPBP strongly bound to SAP but not to BSA, suggesting that SAP and GPBP interact. This interaction is dependent on renaturation of SAP on the membrane since Western blot separation of SAP followed by immediate membrane incubation with GPBP without renaturation did not lead to significant binding of GPBP to SAP (Figure 4A).

We further investigated the molecular characteristics and the kinetics of this binding by SPR. SAP is a highly interactive protein prone to extensive selfaggregation (38). We found that by careful selection of buffer conditions as $\mathrm{pH}$, presence/absence of $\mathrm{Ca}^{2+}$ and of detergent, it was possible to control the process of self association (Figure 4B). Human SAP was found to be highly aggregated ( $>250 \mathrm{kDa}$ ) at $\mathrm{pH} 7.4$ (with or without $\mathrm{Ca}^{2+}$ ) and did not migrate into a $4 \%$ polyacrylamide gel under native and non-reducing conditions. However, it was found that sonication of SAP in HEPES buffer $\mathrm{pH} 7.4$ with $0.01 \%$ Tween 20 to a large extent prevented this protein aggregation and precipitation; sonication disrupted aggregates and the presence of the 
detergent stabilized SAP in physiological pentameric and decameric species. High temperature treatment, high salt and organic solvent were also tested but resulted in irreversible denaturation (data not shown). We studied the binding of fluid phase SAP to immobilized GPBP and CERT by SPR (Figure 4C and D). Interestingly, we found that SAP (stabilized as pentamers and decamers, as described above) binds both GPBP and CERT in the absence of $\mathrm{Ca}^{2+}$. Conversely, in the presence of $5 \mathrm{mM} \mathrm{Ca}^{2+}$ this binding was reduced 5-7fold.

SAP interaction with both GPBP and CERT was characterized by a rapid association rate; however, SAP binding to GPBP was stronger than to CERT. To explore in more detail the different affinity of SAP for the two protein isoforms, we immobilized SAP on the sensor chip and applied as analyte a peptide containing 14 (385-398) of the 26 amino acids encoded by exon 11 of GPBP. Exon 11 encodes a short domain that is absent in CERT. This peptide was shown to bind immobilized SAP (Figure 4E) which supports the notion that this region of GPBP participates in the interaction with SAP. Kinetic analysis of SAP binding to immobilized GPBP was performed by varying the concentrations of SAP added (ranging from $25 \mathrm{nM}$ to $100 \mathrm{nM}$ ) (Figure 5). We found that the binding of SAP to GPBP does not saturate, suggesting that GPBP-SAP-SAP complexes can be formed, in analogy to what is described for type IV collagen binding above (Figure $2 \mathrm{~A}$ and $\mathrm{B}$ ). Therefore, these data indicate that SAP binding to GPBP in solid phase is non saturable, making it difficult to reliably estimate the binding constant. In this respect, the SPR data should be regarded as qualitative evidence, demonstrating the direct binding of proteins involved.

\section{Binding of SAP to GPBP in solution}

Microscale thermophoresis (MST) was performed in order to determine the dissociation constant of SAP to fluorescently labeled GPBP in fluid phase. 10 nM of NT-647 labeled GPBP was mixed with increasing SAP concentrations. After a short incubation time the samples were loaded into glass capillaries and a thermophoretic analysis was performed on the Monolith.NT115 using 51\% LED-Power and $80 \%$ IR-Laser power. The normalized fluorescence Fnorm is plotted for different concentrations of SAP. An apparent $K_{D}$ of 5.7 $\mathrm{nM}+/-2.66 \mathrm{nM}$ was determined for this interaction (Figure 6).

\section{Binding of different molecular weight species of SAP to immobilized GPBP} To further study the capacity of the different SAP species to interact with GPBP, we isolated fractions of SAP by size exclusion chromatography for immediate SPR analysis. Three peaks were separated by gel filtration FIGURE 
A

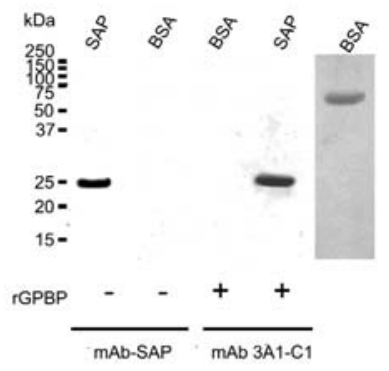

B
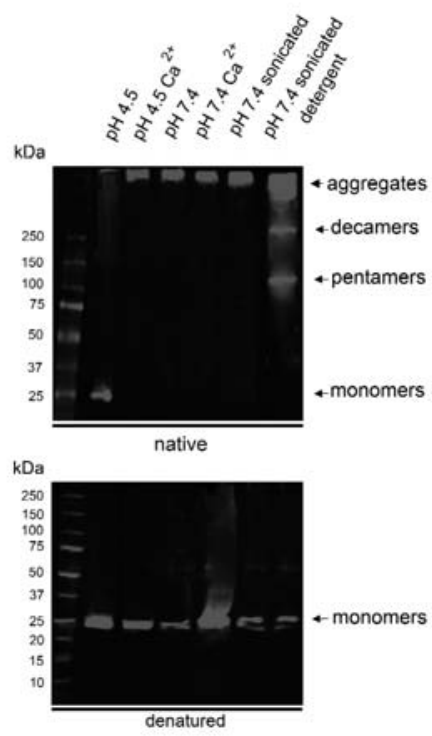

C
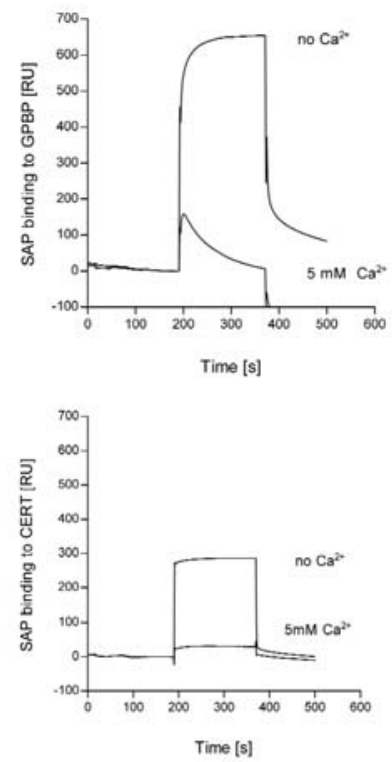

$\mathrm{E}$

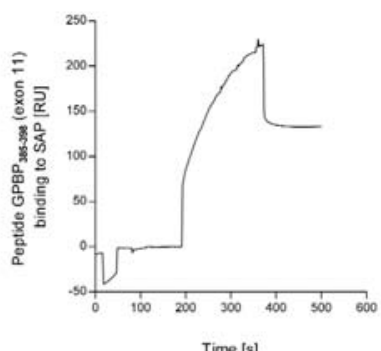

Figure 4

Figure 4. Solid phase interaction of SAP with GPBP

(A) Far-Western blot experiments. Human SAP and BSA were separated by SDS-PAGE, transferred to a nitrocellulose membrane and renatured. As a negative control for the renaturation, SAP was kept in $6 \mathrm{M}$ urea ('SAP without renaturation'). After blocking, membranes were incubated with either GPBP or with CERT as a probe using immobilized SAP as bait. Bound proteins were detected with mAb antiSAP, anti GPBP (3A1-C1) or a polyclonal antibody against GPBP/CERT. The presence of BSA was confirmed by Coomassie. Both GPBP and CERT bound specifically to renatured SAP, but not to BSA or denatured SAP.

(B) SAP aggregation is influenced by $\mathrm{pH}$, the composition of the buffer and the presence or absence of $\mathrm{Ca}^{2+}$. The treatment of SAP before the Western blot was performed as follows: SAP was diluted at $10 \mathrm{ng} / \mathrm{\mu L}$ : (lane 1) in $10 \mathrm{mM}$ sodium acetate buffer $\mathrm{pH} \mathrm{4.5}$; (lane 2) in sodium acetate buffer $\mathrm{pH} 4.5$ in the presence of $5 \mathrm{mM}$ calcium; (lane 3) in $25 \mathrm{mM}$ HEPES buffer pH 7.4; (lane 4) in HEPES buffer pH 7.4 in the presence of $5 \mathrm{mM}$ calcium; (lane 5) in HEPES buffer $\mathrm{pH} 7.4$ followed by sonication with a probe sonicator for 3 pulses of $30 \mathrm{~s}$ each with a $30 \mathrm{~s}$ rest on ice between each pulse; (lane 6) in $25 \mathrm{mM}$ HEPES buffer $\mathrm{pH} 7.4$ followed by sonication as aforementioned in the presence of $0.01 \%$ Tween 20 . Different percentages of Tween 20 (1\%, $0.1 \%$ and $0.001 \%)$ were tested before choosing the optimal at $0.01 \%$. SAP was separated using native-PAGE and SDS-PAGE 4-20\% gradient gels. The proteins were transferred to nitrocellulose membranes and incubated with anti-SAP antibody. $10 \mathrm{ng} / \mu \mathrm{L} \mathrm{SAP}$ diluted 
in sodium $10 \mathrm{mM}$ acetate buffer $\mathrm{pH} 4.5$ and run in native conditions separated unique SAP species of $25 \mathrm{kDa}$ (monomers). $10 \mathrm{ng} / \mu \mathrm{L}$ SAP diluted in HEPES buffer $\mathrm{pH} 7.4$, sonicated in the presence of $0.01 \%$ Tween and run in native PAGE separated SAP species corresponding to: high molecular aggregates > $250 \mathrm{kDa}, 250 \mathrm{kDa}$ (decamers) and $100 \mathrm{kDa}$ (pentamers). As expected, independently of the buffer in which SAP has been diluted, in SDS-PAGE, SAP separated as a band of $25 \mathrm{kDa}$ (monomers).

(C) Binding of SAP to immobilized GPBP (215 RU; flow rate, $15 \mu \mathrm{L} / \mathrm{min}$; injected volume, $60 \mu \mathrm{L}$ ). The binding was recorded in $25 \mathrm{mM}$ HEPES buffer $\mathrm{pH} 7.4,150 \mathrm{mM} \mathrm{NaCl}$. The presence of $5 \mathrm{mM} \mathrm{Ca}{ }^{2+}$ decreased the binding of SAP to immobilized GPBP.

(D) Binding of SAP to immobilized CERT (215 RU; flow rate, $15 \mu \mathrm{L} / \mathrm{min}$; injected volume, $60 \mu \mathrm{L}$ ). The binding was first recorded in the absence of added $\mathrm{Ca}^{2+}$ in $25 \mathrm{mM}$ HEPES buffer $\mathrm{pH} 7.4,150 \mathrm{mM} \mathrm{NaCl}$. The presence of $5 \mathrm{mM} \mathrm{Ca}^{2+}$ decreased the binding of SAP to immobilized CERT. The general shape of the curves revealed that SAP had very fast association rates with both proteins, although SAP remained bound to GPBP for a longer period at the end of the injection.

(E) Binding of a peptide containing amino acids 385-398 from GPBP exon 11 to immobilized SAP (215 $\mathrm{RU}$; flow rate, $15 \mu \mathrm{L} / \mathrm{min}$; injected volume, $60 \mu \mathrm{L}$ ) in $25 \mathrm{mM}$ HEPES buffer $\mathrm{pH}$ 7.4, $150 \mathrm{mM} \mathrm{NaCl}$.

chromatography from SAP (sonicated in HEPES buffer pH 7.4 with $0.01 \%$ Tween 20) (Figure 7A). SAP peaks I to III corresponded to high molecular aggregates (> $250 \mathrm{kDa})$, decamers $(250 \mathrm{kDa})$ and pentamers $(125 \mathrm{kDa})$ as judged from native-PAGE gels (Figure 7B, native). SAP peaks separated by SDS-PAGE under reducing conditions corresponded to $25 \mathrm{kDa}$ (monomers) (Figure 7B, denatured). SAP decamers and pentamers (peaks II and III, respectively) bound immobilized GPBP, whereas SAP aggregates (peak I) did not (Figure 7C-E). Likewise, peak IV which consists of benzamidine was found not to bind to GPBP (Figure 7F). In summary, these data indicate that SAP pentamers and decamers, the physiologically active species, bind to GPBP and that the binding observed (in the previous experiments, Figures $4 C$ and $D$ and 6 ) was not a result of non-specific binding of SAP aggregates.

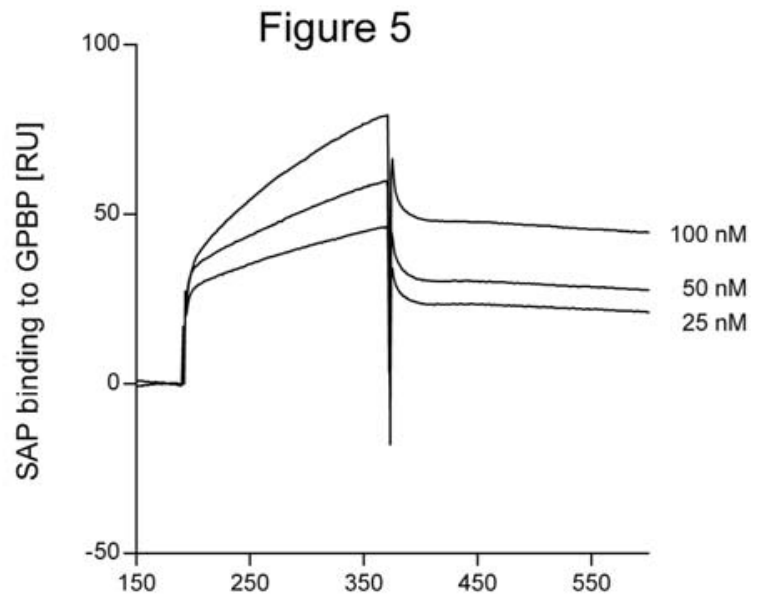

Figure 5. Overlay of sensograms resulting from the injection of different concentrations (25-100 $\mathrm{nM}$ ) of SAP over immobilized GPBP (96 RU, flow rate, $15 \mu \mathrm{L} / \mathrm{min}$; injected volume, $60 \mu \mathrm{L}$ ). The sensograms were corrected for the signal in the empty cell (i.e. calculated as the difference between the signal in Fc2 and the signal in Fc1, which includes injection noise, instrument drift, and nonspecific binding). 


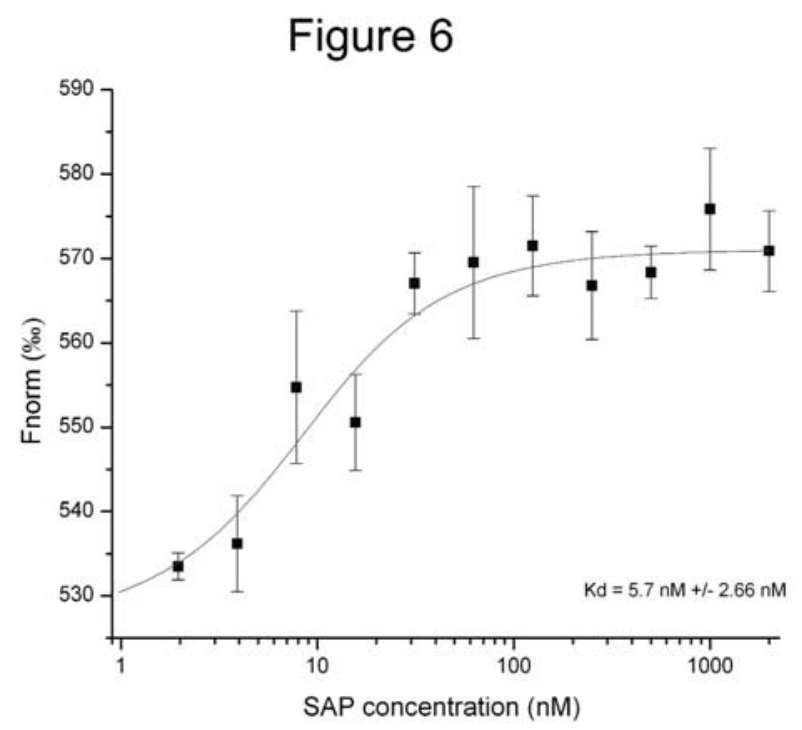

Figure 6. SAP binds to GPBP in solution Microscale thermophoresis (MST) was performed in order to determine the dissociation constant of SAP to fluorescently labeled GPBP. $10 \mathrm{nM}$ of NT-647 labeled GPBP was mixed with increasing SAP concentrations. The normalized fluorescence Fnorm is plotted for different concentration of SAP. A Kd of $5.7 \mathrm{nM}+/-2.66 \mathrm{nM}$ was determined for this interaction.

\section{SAP and GPBP form complexes in blood under physiological conditions}

SAP is present in human serum at a concentration between 30 and $50 \mathrm{mg} / \mathrm{L}$ $(37,38)$. Recently, the presence of GPBP in human serum has been described (23). To study whether SAP associates with GPBP in serum, coimmunoprecipitation experiments were performed. After precipitation with anti-SAP antibodies, both SAP and GPBP were detected by Western blot. Antibodies against GPBP epitopes 1-50 (Figure 8) and 300-350 (data not shown) detected a GPBP fragment of approximately 35-37 kDa which has been previously described (22). This fragment was not present in a pulldown performed with an isotype control antibody, when detected with the same GPBP-specific antibodies. Based on the antibody specificities, these results suggest that SAP associates in the blood with a $\sim 37 \mathrm{kDa}$ GPBP fragment containing the $\mathrm{N}$-terminal region and the middle domain.

\section{GPBP is present in brain amyloid plaques}

Since SAP is a universal component of all types of amyloid deposits, possible associations of GPBP with amyloid deposits in human brain were studied by immunohistochemistry. Stainings were performed on cryostat sections of post mortem temporal cortex specimens from aged donors, including: nondemented controls, control cases with amyloid deposits and with cortical changes (though not sufficient to be classified as AD), and AD patients (Table 1).

Considerable SAP immunoreactivity was found to be associated with $A ß$ plaques in the $A D$ and demented cases $(81,135$ and 294, Figure 9A middle 

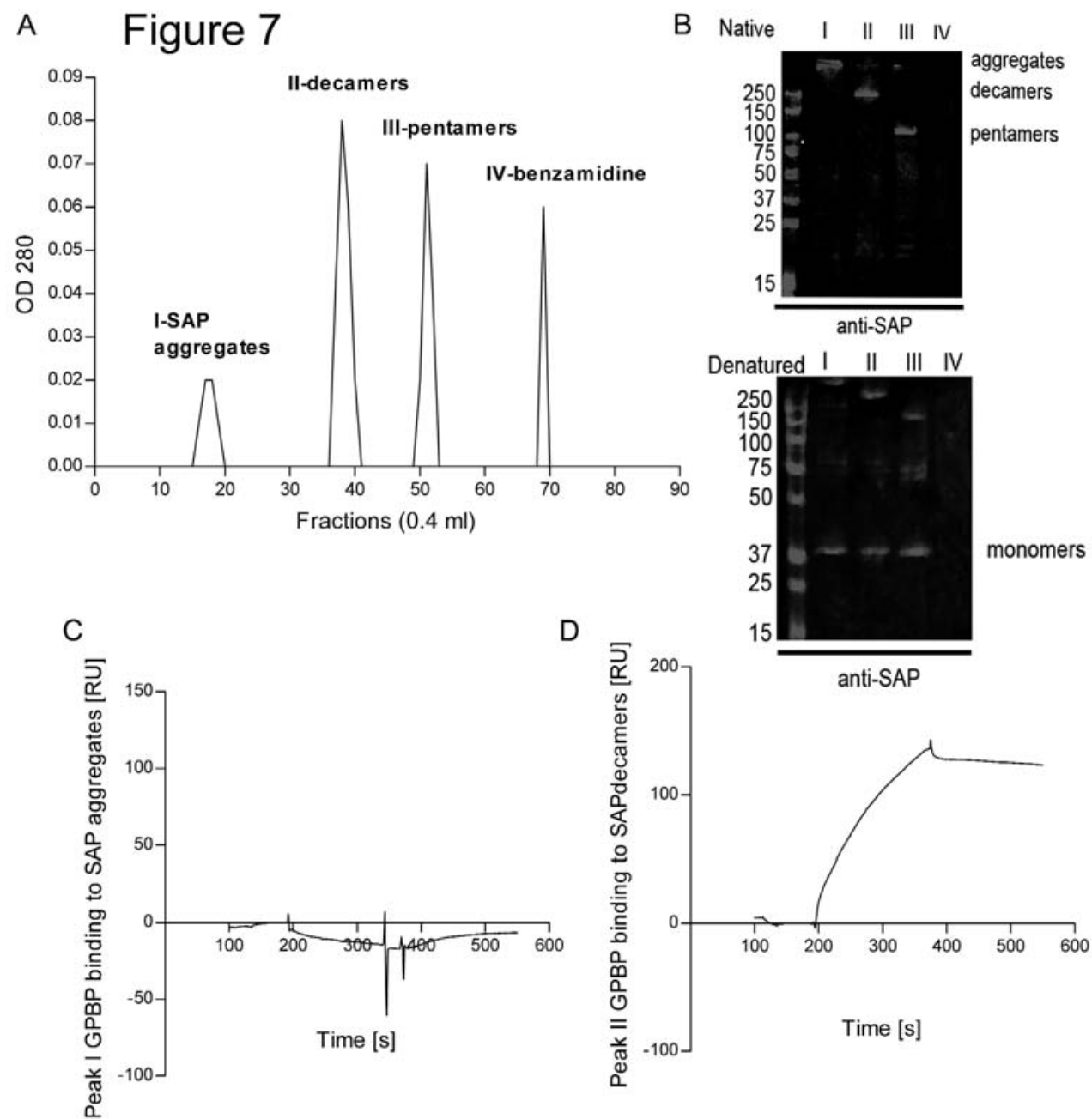

E

F
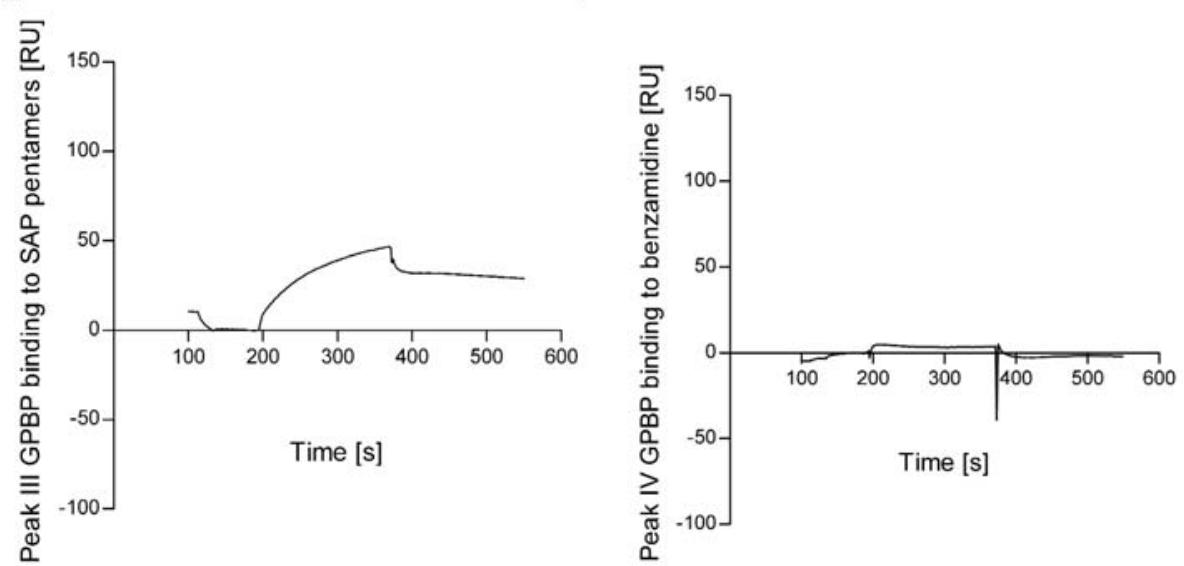
Figure 7. SAP decameric and pentameric species bind to GPBP

Purification of different SAP species was performed by Superose 6 column size exclusion chromatography. Samples diluted in $25 \mathrm{mM}$ HEPES buffer (pH 7.4), $150 \mathrm{mM} \mathrm{NaCl}$ were then injected at a concentration of $0.5 \mathrm{mg} / \mathrm{mL}$ and were chromatographed at a flow rate of $0.4 \mathrm{~mL} / \mathrm{min}$. Four peaks were observed. (B) Fractions from peaks I to IV from the Superose 6 gel filtration column were separated using native-PAGE and SDS-PAGE $4-20 \%$ gradient gels. The proteins were transferred to nitrocellulose membranes and incubated with anti-SAP antibody. Upper panel, native electrophoresis. Lower panel, denatured electrophoresis. The anti-SAP antibody detected bands of molecular weights: $>250 \mathrm{kDa}$ in peak I, $250 \mathrm{kDa}$ (decamers) in peak II and $100 \mathrm{kDa}$ (pentamers) in peak III in native conditions, and $25 \mathrm{kDa}$ (monomers) in denatured conditions in fractions from peaks I to III. (C to F) Sensograms resulting from the injection of peaks I to IV over immobilized GPBP (96 RU, flow rate, $15 \mu \mathrm{L} / \mathrm{min}$; injected volume, $60 \mu \mathrm{L}$ ). (C) No binding was observed with SAP peak I which corresponds to high molecular weight SAP aggregates. (D and E) 50-150 RU were observed in SAP peak fractions II and III, which correspond to decamers and pentamers respectively (F) Peak IV corresponds to benzamidine and did not bind to immobilized GPBP.

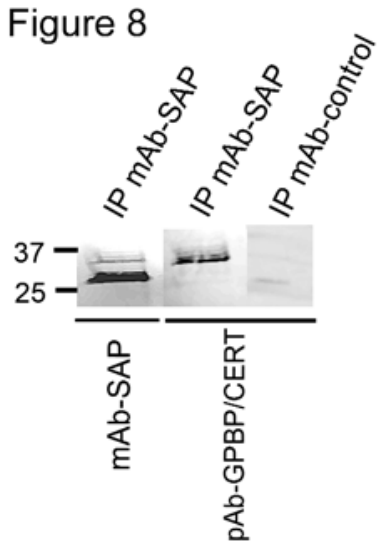

Figure 8. SAP-GPBPs complexes in plasma

SAP was immunoprecipitated with mouse mAb anti SAP, (clone 4E8, Sigma) followed by immunoblotting with the same antibody to detect immunoprecipitated SAP (first lane) and a polyclonal antibody against GPBP/CERT1-50 detect GPBPs (second lane). The control using an isotype control mAb (mouse monoclonal anti-syntaxin 6, clone 3D10) for immunoprecipitation was negative when detected with the same polyclonal antibody against GPBP (third lane).

GPBP is efficiently co-precipitated with SAP in a band of $\sim 37 \mathrm{kDa}$, suggesting that a part of GPBP molecule corresponding to the amino terminal domains of the protein interacts with SAP. Results shown are representative of 5 experiments.

right panel). SAP was less abundant but also associated with $A ß$ plaques in the non demented control cases (not shown). Polyclonal antibodies reacting with GPBP/CERT stained vague, globular plaque-like structures (e.g. case 47, Figure 9A upper right panel and case 294, Figure 9A middle left panel). Occasional dense deposits, possibly representing plaque cores were observed (case 115, not shown). Plaque-associated microglia were immunoreactive in the AD cases (e.g. case 264, Figure 9B). Additionally, microglia in the white matter were strongly immunopositive for GPBP/CERT, in all cases (e.g. case 47; Figure 9A, upper left panel); In the demented control case 294 , plaques and associated microglia in the grey matter were strongly immunoreactive (Figure 9A, lower panel), as were white matter microglia.

In order to determine possible colocalization of GPBP/CERT with SAP in tissue specimens, double immunofluorescent stainings were performed. To visualize fibrillar Aß deposits, sections were also stained with Thioflavin S. In 
Table 1. Overview of cases included for the immunohistochemical part of this study ${ }^{\mathrm{a}}$

\begin{tabular}{|c|c|c|c|c|c|c|c|}
\hline Case & Diagnosis $^{\mathrm{b}}$ & Braak $^{c}$ & $\begin{array}{l}\text { Amyloid }^{d} \\
(0, A, B, C)\end{array}$ & $\begin{array}{l}\text { Age } \\
\text { (years) }\end{array}$ & Gender ${ }^{e}$ & $\begin{array}{l}\text { PMD }^{f} \\
\text { (h:min) }\end{array}$ & $\begin{array}{l}\text { APOE } \\
\text { genotype }\end{array}$ \\
\hline 47 & Non-demented CTL & 1 & B & 98 & M & $8: 40$ & $3 / 3$ \\
\hline 115 & Non-demented CTL & 1 & B & 83 & M & $4: 35$ & $3 / 3$ \\
\hline 81 & $A D$ & 5 & C & 78 & M & $7: 45$ & $4 / 4$ \\
\hline 264 & $A D$ & 5 & C & 85 & $\mathrm{~F}$ & $6: 10$ & $4 / 3$ \\
\hline 135 & AD/Lewy body variant & 4 & B & 95 & $\mathrm{~F}$ & $5: 15$ & $3 / 3$ \\
\hline 294 & Dementia with cortical changes & 2 & B & 91 & $\mathrm{~F}$ & 3:35 & $3 / 3$ \\
\hline
\end{tabular}

a Upon immunostaining for $A B$, the two $A D$ cases (Braak $5 C$ ) were found to have many $A ß$ plaques, however no classical or neuritic plaques. The AD / Lewy body variant case (case 135) did show all types of $A ß$ plaques, ranging from diffuse to neuritic, as did the demented case that did not fulfill the neuropathological criteria of AD (case 294). The non-demented controls (cases 47 and 115) were selected to have many cerebral $A ß$ deposits, and had many $A ß$ plaques ranging from diffuse to classical type.

${ }^{\mathrm{b}}$ Clinical diagnosis with neuropathological confirmation (CTL: control; AD: Alzheimer's disease)

${ }^{\mathrm{C}}$ Neuropathological staging of cases based on occurrence and distribution of neurofibrillary changes according to the criteria of Braak \& Braak (1991)

${ }^{d}$ Neuropathological staging of cases based on occurrence and distribution of amyloid deposits according to the criteria of Braak \& Braak (1991)

${ }^{e} \mathrm{M}$ : male, F: female

${ }^{f}$ Post mortem delay time (hours : minutes)

reference:

Braak,H., and Braak, E. Neuropathological stageing of Alzheimer-related changes. Acta Neuropathol. 82 (1991) 239-259.

AD case 264 , SAP was found to completely colocalize with fibrillar $A ß$ in plaques, whereas GPBP/CERT was associated with cellular structures in the centre of the plaque, possibly representing recruited microglia partially colocalizing with SAP (Figure 9B).

A number of GPBP immunopositive neuronal cells were observed, also in plaques; occasionally the endothelial cell lining as well as the basement membrane of a blood vessel were GPBP immunopositive (Figure 9B upper panel).

Additionally we performed immunoprecipitation experiments using homogenates from control and $A D$ mouse brains to confirm the interaction of SAP with GPBP and to distinguish between GPBP and CERT (Figure 9C). Immunoprecipitation of either GPBP (mAb 3A1-C1) or SAP from brain lysates from the $A D$ mouse model co-isolated $A ß$ (detected with 6E10) in a few bands of $\sim 100 \mathrm{kDa}$. The same bands were also found in a control experiment following immunoprecipitation of $A ß$ from $A D$ mouse brain with $a$ 
A
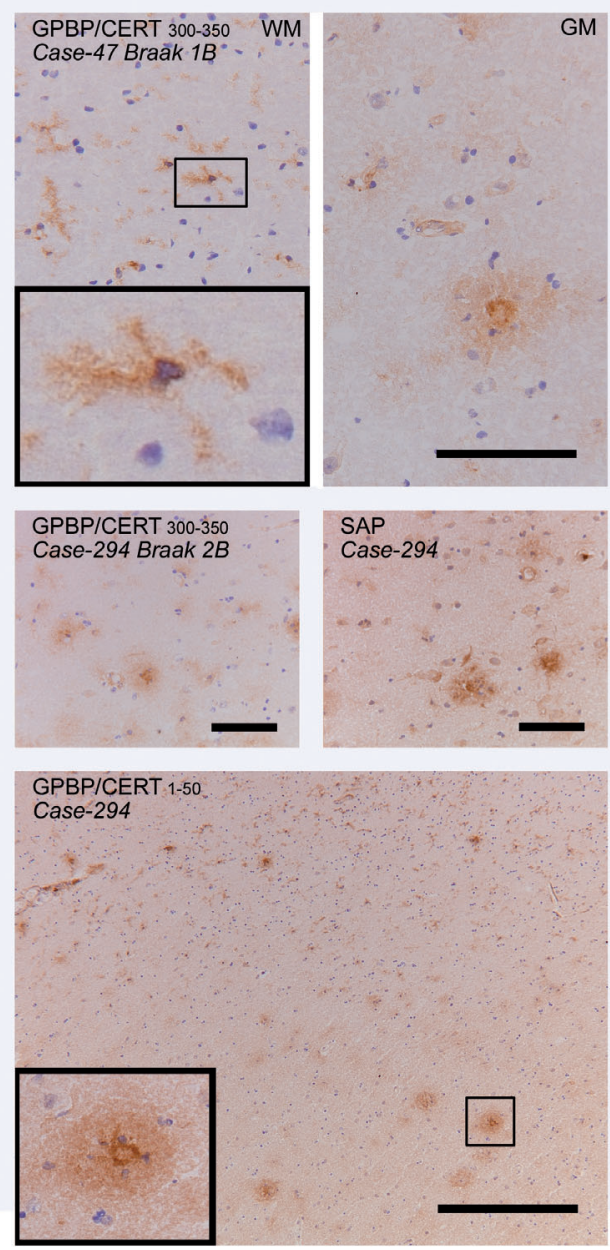

C

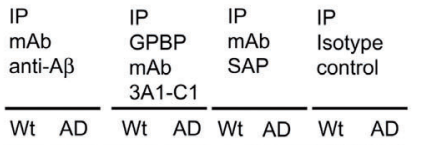

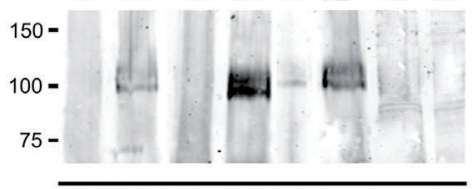

$\mathrm{mAb}$ anti-A $\beta$
B
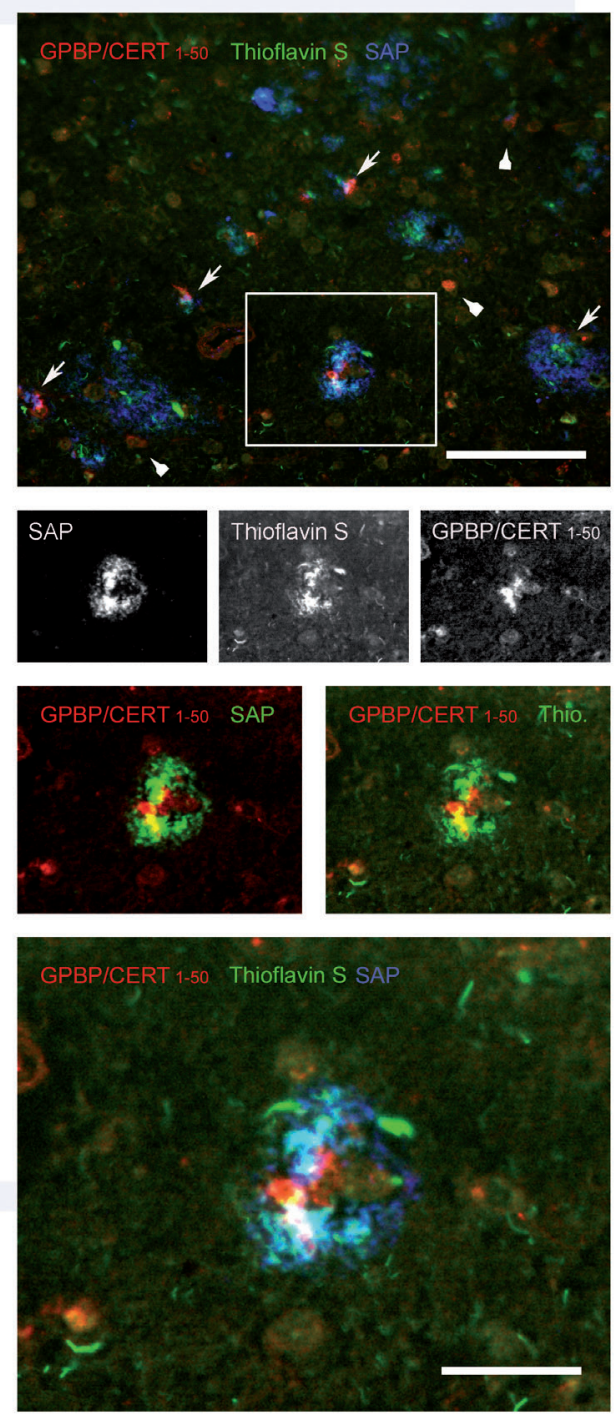

Figure 9

Figure 9. GPBP is present in amyloid plaques

Immunohistochemical stainings of GPBP/CERT and SAP in midtemporal cortex of AD and demented and non-demented control cases (cryostat sections). (A) Upper panel: Control case 47 (Braak 1B) white matter (WM) immunostained with anti-GPBP/CERT 300-350 shows many ramified microglia (see insert) and to some extent endothelial lining of blood vessels, whereas in the grey matter (GM) amyloid plaque staining and intense GPBP staining around the plaque core, reminiscent of clustered 
microglia, and in addition cytoplasmatic staining of neuronal cells is seen. Lower panel: Demented control case (\#294) with cortical changes but not sufficient to be classified as AD (Braak 2B). GPBP/CERT $1-50$ immunostaining is seen in Aß plaques and microglia, especially microglia in the white matter (upper right) and near the core of a classical plaque (see also higher magnification insert). Similar as with anti-GPBP/CERT 1-50, plaque and microglial staining was seen with anti-GPBP/CERT 300-350, but less pronounced. With anti SAP, in addition to plaques, also some cytoplasmatic neuronal staining was observed (two central panels). (B) Immunofluorescence staining was performed to further investigate co-localization of GPBP and SAP. Fibrillar Aß deposits in an AD case (case \# 264) were visualized with Thioflavin S, SAP with monoclonal SAP-14 followed by goat-anti-mouse HRP and rhodamine-tyramide and GPBP with anti-GPBP/CERT $1-50$ and $\mathrm{Cy} 5$ labeled goat-anti-rabbit. Whereas both SAP and GPBP immunoreactivity co-localize with thioflavin positivity, their exact distribution differs (black and white Figures showing complete overlap in localization of thioflavin and SAP, but not of GPBP). GPBP seems present in small cells resembling microglia clustered around A 3 and SAP deposits (arrow and lower panel (magnification)), as well as in many neuronal cells (arrowheads). Partial overlap in localization of GPBP and SAP within Aß plaques was more clearly seen, when in the separate channels the GPBP signal was visualized as red and thioflavin or SAP as green (inserts). Scale bars represent $100 \mu \mathrm{m}$. (C) Western blotting with a mAb anti-Aß revealed that immunoprecipitation of either GPBP or SAP from brain lysates from an AD mouse model (APPswe/PS1 $\triangle E 9$ ), but not from wild type littermates, co-isolated $A ß$, which suggests the presence of $A ß-S A P$ and $A ß-G P B P$ complexes in $A D$ model mouse brain. $A B, G P B P$ and SAP were immunoprecipitated from brain homogenates of control and Alzheimer's transgenic mice using mouse mAb anti SAP, clone 4E8, Sigma; mAb GPBP clone 3A1-C1; mAb B Amyloid clone 6E10, Covance. immunoprecipitation with nonspecific immunoglobulins was performed for control. Results shown are representative of 3 experiments.

combination of recombinant human antibodies recognizing different aggregation forms of $A ß$ (bapineuzumab directed against plaques, $20 \mathrm{C} 2$ directed against fibrils, solanezumab directed against monomers). In wild type littermates, these bands were not observed. The observed $A ß$ bands ( $100 \mathrm{kDa})$ could correspond to $A ß$ aggregates which are preserved using the tissue disruption protocol and/or to amyloid precursor protein (APP). The possible presence of APP would not be surprising since it is several times upregulated in this animal model. Lower $A ß$ molecular weight forms were not detected using anti-A $\beta$ (6E10) as reported previously (41). Western blotting with a monoclonal anti-Aß revealed that immunoprecipitation of either GPBP ( $m A b 3 A 1-C 1$ ) or SAP from brain lysates from an AD mouse model, but not from wild type littermates, co-isolated $A ß$, which suggests the presence of Aß-SAP and Aß-GPBP complexes in AD model mouse brain. Immunoprecipitation with nonspecific immunoglobulins performed as a control did not co-isolate $A ß$.

\section{Functional implications of SAP to GPBP binding and protein-protein interaction interface prediction}

In order to identify the binding site of GPBP on SAP, we used two well-known ligands of SAP [C1q and PE $(16,32)$ ] and analyzed by SPR if they could compete with GPBP. To test this, either SAP alone, or SAP that had been 

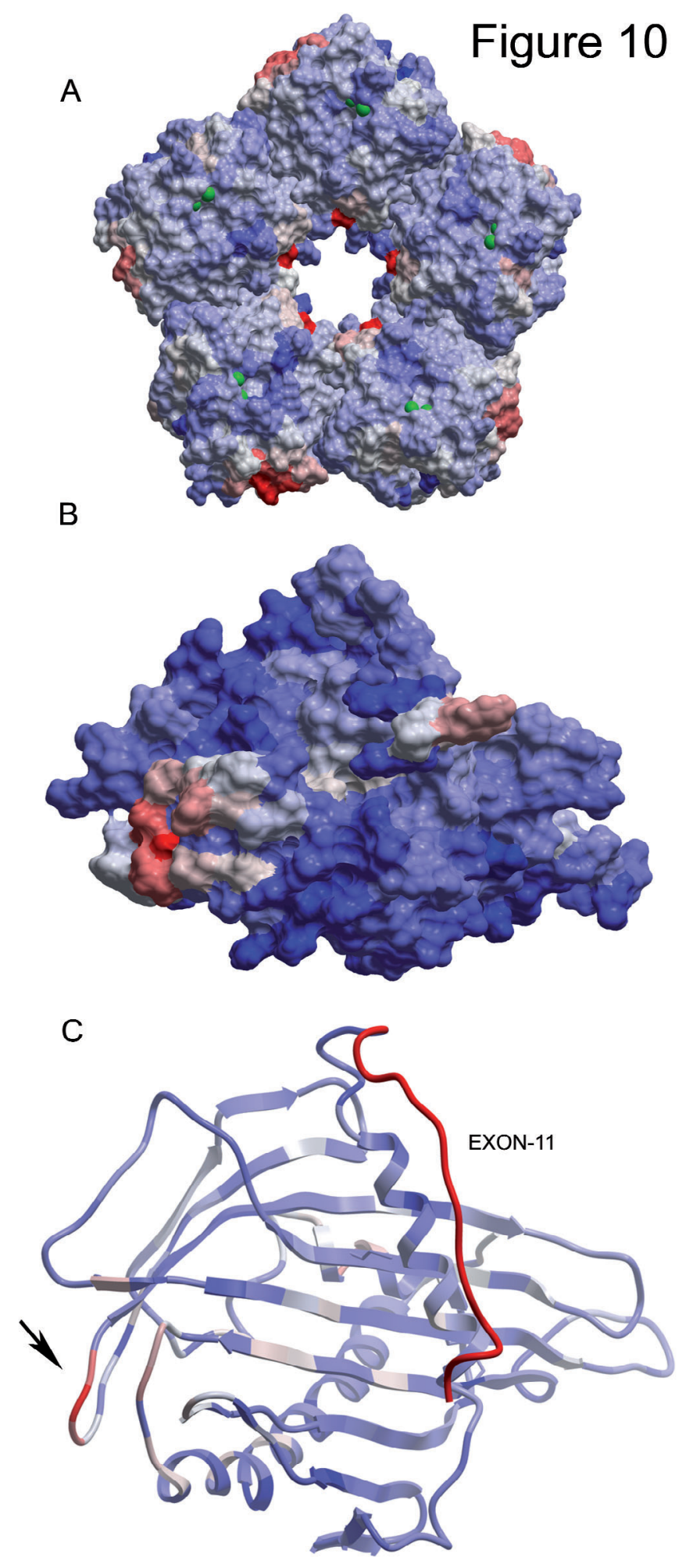

Figure 10. Protein-protein interaction interface prediction of SAP with GPBP

(A) Human SAP pentameric structure and predicted proteinprotein interaction hotspots as obtained after structural analysis using the ICM Pro package of the published coordinates from 2a3y.pbd (46).

(B) Homology model for the structure of GPBP including the region important for the interaction with SAP (shown in red). The homology model was built using the Whatlf-Yasara Twinset and ICM Pro package, while the coordinate file 2E3O.pdb (CERT START domain structure) was used as a template.

(C) GPBP structure and predicted protein-protein interaction hotspots based on the homology model as shown in (B), a structural bioinformatics analysis was performed using ICM Pro to predict potential protein-protein interactions. Interaction scores are color-coded with red having high potential for interaction and blue low potential. On the right, exon 11 containing 26 aa is indicated in red. The arrow indicates a hypothetical proteinprotein interaction region 
preincubated with either PE or C1q were added as analytes and flown over a surface onto which GPBP was immobilized. Using an equimolar ratio of SAP and C1q, binding of SAP to GPBP was inhibited by $59 \%$. In contrast SAP preincubated with $\mathrm{PE}$ even at a 3-fold molar ratio of $\mathrm{PE}$ as compared to SAP had no effect on the binding of SAP to GPBP.

Since the crystal structures of SAP and the GPBP START domain are published (PDB IDs 2A3Y and 2E3O) we attempted to predict the possible protein-protein interaction surfaces by structural bioinformatics analysis using the ICM-pro package (Figure 10). For SAP, our in silico analysis indicated the presence of two potential protein interaction hotspots with a five-fold symmetry in the pentamer: one on the internal surface of the pentameric ring (Figure 10A, red) around Glu86 and a second one more dispersed on the outer side of the ring, around residues Gly122-Phe124 (light red). In the GPBP START domain an interactive region is located at the protein surface near Ala501 (Figure 10B and C, arrow).

\section{Binding of CERT mutants to SAP}

In order to experimentally test the importance of the START domain for SAP binding, we generated 5 CERT mutants containing 2 amino acid substitutions each. We targeted the region near Ala501 and three additional regions with hydrophobic amino acids near the protein surface. Protein surface hydrophobicity is known to be a good determinant of protein-protein recognition (42). For consistency with the numbering used above we will refer to the GPBP amino acid numbering throughout (see Table 2).

Mutant 1: lle439 (present in a short ?-strand that flanks the N-terminus of Ala591-Ala618 helix) and Trp588 (located in a loop structure that precedes

Table 2. Mutagenesis of GPBP $\Delta 26 / C E R T$ protein to identify amino acids relevant for SAP interaction

\begin{tabular}{l|l|l|l|l|l|}
\hline Mutant $^{\mathrm{a}}$ & \multicolumn{2}{|l|}{ mutation at GPBP } & protein level & $\begin{array}{l}\text { Corresponding } \\
\text { protein level }\end{array}$ & mutation at CERT $^{\mathrm{c}}$ \\
\hline 1 & I439A & W588A & I413A $\quad$ W562A \\
\hline 2 & N460A & Y461A & N434A & Y435A \\
\hline 3 & Y461A & F462A & Y435A & F436A \\
\hline 4 & V498A & W499A & V472A & W473A \\
\hline 5 & P500G & A501Q & P474G & A475Q \\
\hline
\end{tabular}




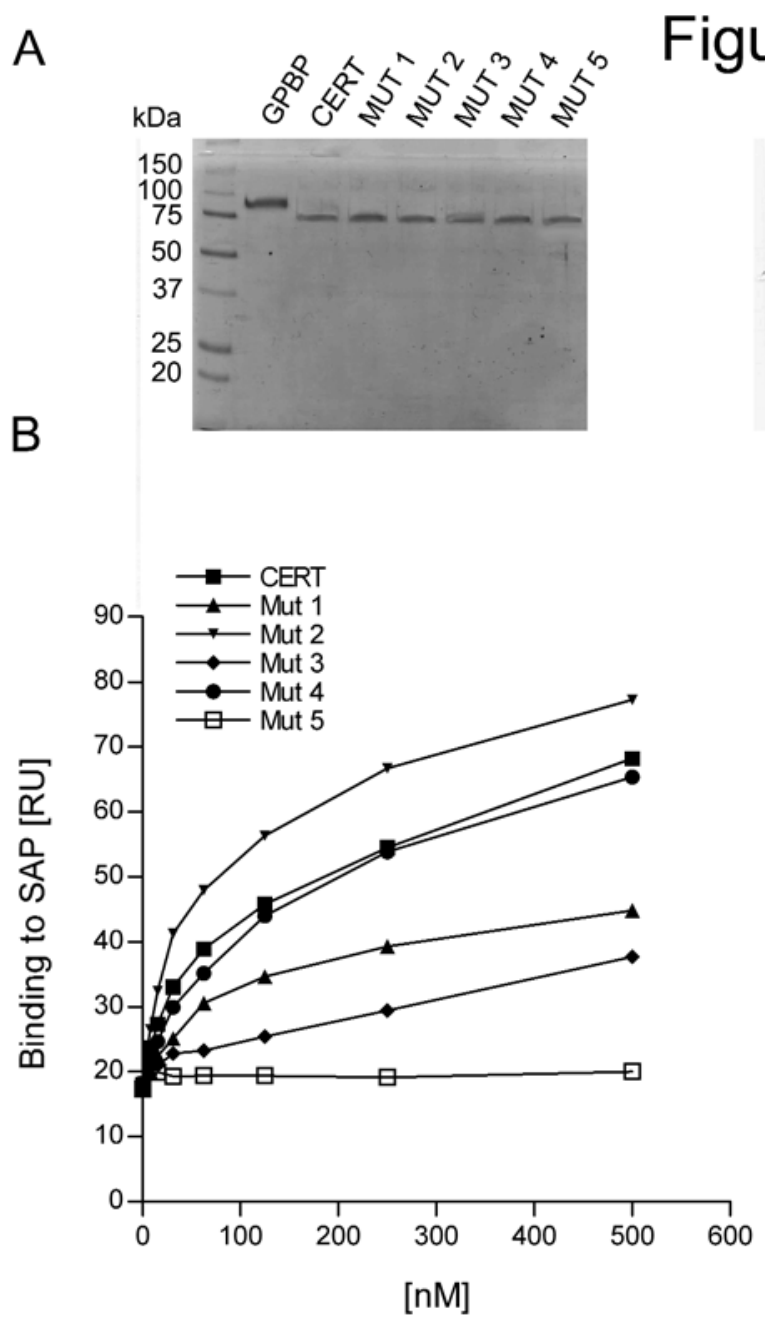

Figure 11. Binding of CERT and CERT mutants to SAP

(A) Coomassie staining of immunopurified wild type and (1-5) mutant CERT proteins ( $2 \mu \mathrm{g}$ of each sample were loaded per lane).

(B) Two-fold serial dilutions (3.9-500 nM) of wild type and mutant (1-5) CERT proteins in $25 \mathrm{mM}$ HEPES pH 7.4, $150 \mathrm{mM} \mathrm{NaCl}$ with $0.01 \%$ Tween 20 were tested for binding on immobilized SAP by SPR. At each concentration, the highest binding signal was measured.

(C) SAP was separated on a $12 \%$ SDS-PAGE gel, electroblotted to nitrocellulose and prepared for farWestern analyses as described in Figure 4A. The membrane with renatured SAP was cut into strips and probed with CERT mutants (1 to 5), WT (6) or mAb anti SAP (7). Membrane strips incubated with CERT proteins were detected with anti-GPBP/CERT300-350.

Ala591-Ala618 helix) are predicted to be arranged closely in the 3D structure of GPBP. This hydrophobic pair represents a potential protein contact site which was effectively removed by substitution for two less hydrophobic Ala residues. Mutant 2: Asn460 and the adjacent Tyr461 (present in a short 
alpha-helix that is located on the opposite side of the molecule as compared to the other mutations) are substituted for two Ala residues; thereby removing a potential protein interacting site. Mutant 3: Adjacent to the changed amino acids of mutant 2, the hydrophobic Tyr461 and Phe462 residues were replaced with Ala residues. Phe462 faces the core of the protein. Mutant 4: We substituted Val498 and Trp499 with two Ala residues. These hydrophobic residues are located in an unstructured loop. Mutant 5: The adjacent Pro500 and Ala501 were substituted with Gly and GIn, respectively.

All mutants described above and the wild type protein were expressed in $\mathrm{E}$. coli and purified on a Flag column (Figure 11A). Using SAP as ligand, the relative affinity of CERT and CERT mutant (1-5) proteins were tested by SPR (Figure 11B). The binding of Mutants 2 and 4 to SAP was similar to the wild type CERT, while mutants 1 and 3 showed reduced binding, and mutant 5 showed a greatly reduced binding for SAP.

The relative affinity of CERT and CERT mutant (1-5) proteins were also tested by far-Western blot with in blot-renaturation (Figure 11C). The results were similar to those obtain by SPR, and showed reduced binding of mutants 1, 3 and 5 to SAP.

In conclusion, the START domain of GPBP and CERT significantly contributes, or might even be essential for SAP binding.

\section{DISCUSSION}

Our results demonstrate, for the first time, that GPBP binds SAP. Both, GPBP and SAP are present in amyloid plaques and co-precipitate with $A ß$. Therefore, the interaction of GPBP with SAP might be involved in protein aggregation in Alzheimer's disease and the resulting innate immune response.

SAP is a very compact and highly structured molecule. Its incorporation within specific types of BM may contribute to the structural conformation and consequently the correct functionality of extracellular matrix proteins. This is supported by its altered distribution in the GBM in glomerular diseases $(33,43)$.

Our SPR analysis has shown that GPBP binds type IV collagen, laminin and $S A P$, while our immunohistochemical studies have shown the presence of SAP and GPBP in GBMs. Intriguingly, this raises the possibility that SAP and GPBP interact to support matrix extracellular proteins, helping to maintain 
their biologically active conformations in a particular group of tissues, including kidney, lungs and choroid plexus; tissues that perform a filtering function and are therefore more vulnerable.

We also found SAP and GPBP interaction in human blood. By immunoprecipitation studies in human sera we were able to pull down complexes of SAP and a N-terminal $37 \mathrm{kDa}$ fragment of GPBP which has been previously described (22). However, it is worth noting that proteolysis of GPBP remains a possibility as our in vitro mutagenesis show that the (Cterminal) START domain of GPBP is important for interaction with SAP. Moreover, full length GPBP is the only isoform which has been described so far that is secreted and present in blood (23). Since this amino-terminal domain is identical in the GPBP and CERT isoforms, our results demonstrate that both GPBP and the shorter isoform CERT could form complexes with SAP under physiological conditions. Several studies have investigated the 3D structure of SAP in order to establish whether SAP stably associates with another protein or exists free in solution (44-46). Despite these efforts, it remains unclear how SAP can remain in physiological conformation (i.e. avoid aggregation) in a high $\mathrm{Ca}_{2+}$ environment. One suggestion is that SAP forms a complex with an as yet unidentified low molecular weight component that prevents self-association (6). To date, no such factor or protein has been reported. In our experiments, aggregation of SAP by $\mathrm{Ca}_{2+}$ might have reduced binding to GPBP, because GPBP specifically binds to pentamers and decamers.

Our molecular characterization of the SAP GPBP/CERT interaction suggests that residues P500 and A501 (mutant 5) of the START domain of GPBP/CERT are essential. Although, we cannot rule out the possibility that the loss of SAP to CERT binding affinity seen with mutant 5 is due to drastic changes in protein conformation, our results are in line with what is known about this domain. The START domain of CERT binds one ceramide molecule in its central amphiphilic cavity and mediates ceramide transfer from donor to acceptor membranes (24). The $\Omega 1$ loop region of the CERT START domain (496KRVWPAS502 in GPBP) is an important regulatory element for the binding of ceramide $(47,48)$. This $\Omega 1$ loop has been proposed to function as a gate of the cavity. Specifically, the interaction between the $W 499$ residue of the $\Omega 1$ loop and the membrane results in a conformational change of the protein which allows opening the cavity. We found that substitution of either the V498 or W499 had no effect on the SAP to GPBP binding, whereas mutation of the P500 and A501 abolishes SAP-GPBP interaction. This suggests that GPBP binding to SAP is independent of the ceramide transfer 
function. This would be consistent with the notion that ceramide function is important within the cell and that the SAP GPBP interaction described here occurs primarily extracellularly.

SAP has been observed decorating the majority of $A ß$ plaques in $A D$ (49), where it has been found to enhance $A ß$ fibrilization. Also, SAP has been shown to hamper the uptake of $A ß$ by adult human microglia in vitro (50). The binding of SAP and GPBP to plaques in AD raises the important question of whether this interaction has a role in disease progression. It may be the case that GPBP and SAP are found in the pathological plaques of AD because these plaques, which consist of amyloid deposits, are 'sticky', and thus incorporate GBPB and SAP from the extracellular matrix. On the other hand, it has been reported that binding of SAP to amyloid fibrils slows proteolysis of plaque material and contributes to the pathogenesis of amyloidosis (5). Here we show that GPBPs are present in A $\beta$ plaques, localized in the core and partially colocalizing with SAP. In agreement with this, pull-downs of extracts of $A D$ mouse brain with antibodies against $A \beta$ yield high molecular weight aggregates containing GPBP, indicating that GPBP, similarly to SAP, interacts with $A \beta$.

Additionally, we observed GPBP staining in the white matter corresponding to round and ramified microglia. Interestingly, clustering of microglia was only observed in SAP and C1q immunopositive Aß deposits, and has been shown to precede neurodegenerative changes in $A D$ brain (4).

$\mathrm{SAP}$, when aggregated, can bind $\mathrm{C} 1 \mathrm{q}$ and initiate the activation of the complement system (16). Our finding that C1q and GPBP can compete for their binding to SAP raises the question as to whether GPBP and C1q share an identical SAP binding site. This implies that when SAP binds to GPBP, the C1q binding site on the SAP molecule is blocked and this might help to control the activation of the complement system.

These findings may then have important implications in several human diseases where complement activation plays a role and SAP and GPBP are in close proximity e.g. in $A D$. Our results further raise the question of whether GPBP, similarly to SAP, could serve as an innate immune system regulator.

\section{Acknowledgements}

We are very grateful to Eline van der Esch and Marlies Jacobs for their excellent technical assistance, to Anna Carrano (Pathology dept, VUmc, Amsterdam) for preparing the human brain fluorescence micrographs and to Roy L.J. Schrijver for his excellent technical assistance with the SPR technology. M.L. was supported by grant F2008(1)-28 from the 
Hersenstichting Nederland. This work was supported by grant no. 91107006 from the Netherlands Organization for Scientific Research (N.W.O. to G.A.F.N.) and a grant from the transnationale Universiteit Limburg (tUL, to G.A.F.N.). The authors wish to thank Prof. T. Hackeng from the Department of Biochemistry, Cardiovascular Research Institute Maastricht, Maastricht University, for his kind gift of the purified SAP and advice with the FPLC. We also wish to thank to Moran Jerabek-Willemsen for his help with the MST technology. We are very grateful to Prof. W. Buurman for critical reading of the manuscript, advice and encouragement.

\section{REFERENCES}

1. Ashton, A. W., Boehm, M. K., Gallimore, J. R., Pepys, M. B., and Perkins, S. J. (1997) J Mol Biol 272, 408-422

2. Cathcart, E. S., Comerford, F. R., and Cohen, A. S. (1965) N Engl J Med 273, 143-146

3. Schwab, C., and McGeer, P. L. (2008) J Alzheimers Dis 13, 359-369

4. Veerhuis, R., Van Breemen, M. J., Hoozemans, J. M., Morbin, M., Ouladhadj, J., Tagliavini, F., and Eikelenboom, P. (2003) Acta Neuropathol 105, 135-144

5. Tennent, G. A., Lovat, L. B., and Pepys, M. B. (1995) Proc Natl Acad Sci U S A 92, 4299-4303

6. Painter, R. H., De Escallon, I., Massey, A., Pinteric, L., and Stern, S. B. (1982) Ann N Y Acad Sci 389, 199-215

7. Hamazaki, H. (1995) J Biol Chem 270, 10392-10394

8. Hamazaki, H. (1987) J Biol Chem 262, 1456-1460

9. Zahedi, K. (1996) J Biol Chem 271, 14897-14902

10. Zahedi, K. (1997) J Biol Chem 272, 2143-2148

11. Nielsen, E. H., Sorensen, I. J., Vilsgaard, K., Andersen, O., and Svehag, S. E. (1994) APMIS 102, 420-426

12. de Beer, F. C., Baltz, M. L., Holford, S., Feinstein, A., and Pepys, M. B. (1981) J Exp Med 154, 1134-1139

13. Bristow, C. L., and Boackle, R. J. (1986) Mol Immunol 23, 1045-1052

14. Hutchcraft, C. L., Gewurz, H., Hansen, B., Dyck, R. F., and Pepys, M. B. (1981) J Immunol 126, 1217-1219

15. Garcia de Frutos, P., Hardig, Y., and Dahlback, B. (1995) J Biol Chem 270, 26950-26955

16. Ying, S. C., Gewurz, A. T., Jiang, H., and Gewurz, H. (1993) J Immunol 150, 169-176

17. Dyck, R. F., Lockwood, C. M., Kershaw, M., McHugh, N., Duance, V. C., Baltz, M. L., and Pepys, M. B. (1980) J Exp Med 152, 1162-1174

18. Tseng, J., and Mortensen, R. F. (1986) Immunol Invest 15, 749-761

19. Stanton, M. C., and Tange, J. D. (1958) Australas Ann Med 7, 132-144

20. Raya, A., Revert, F., Navarro, S., and Saus, J. (1999) J Biol Chem 274, 12642-12649

21. Mencarelli, C., Losen, M., Hammels, C., De Vry, J., Hesselink, M. K., Steinbusch, H. W., De Baets, M. H., and Martinez-Martinez, P. J Neurochem 113, 1369-1386

22. Revert, F., Ventura, I., Martinez-Martinez, P., Granero-Molto, F., Revert-Ros, F., Macias, J., and Saus, J. (2008) J Biol Chem 283, 30246-30255

23. Saus, J. V., ES) , and Revert, F. M., ES) (01/28/2010 ) Goodpasture Antigen Binding Protein and Its Detection (Application, U. S. P. ed., United States

24. Hanada, K., Kumagai, K., Yasuda, S., Miura, Y., Kawano, M., Fukasawa, M., and Nishijima, M. (2003) Nature 426, 803-809 
25. Raya, A., Revert-Ros, F., Martinez-Martinez, P., Navarro, S., Rosello, E., Vieites, B., Granero, F., Forteza, J., and Saus, J. (2000) J Biol Chem 275, 40392-40399

26. Jonsson, U., Fagerstam, L., Ivarsson, B., Johnsson, B., Karlsson, R., Lundh, K., Lofas, S., Persson, B., Roos, H., Ronnberg, I., and et al. (1991) Biotechniques 11, 620-627

27. Jerabek-Willemsen, M., Wienken, C. J., Braun, D., Baaske, P., and Duhr, S. Assay Drug Dev Technol 9, 342-353

28. Baaske, P., Wienken, C. J., Reineck, P., Duhr, S., and Braun, D. Angew Chem Int Ed Engl 49, 2238-2241

29. Wienken, C. J., Baaske, P., Rothbauer, U., Braun, D., and Duhr, S. Nat Commun 1, 100

30. Mencarelli, C., Hammels, C., Van Den Broeck, J., Losen, M., Steinbusch, H., Revert, F., Saus, J., Hopkins, D. A., De Baets, M. H., Steinbusch, H. W., and Martinez-Martinez, P. (2009) J Chem Neuroanat 38, 97-105

31. Braak, H., and Braak, E. (1995) Neurobiol Aging 16, 271-278; discussion 278-284

32. Familian, A., Zwart, B., Huisman, H. G., Rensink, I., Roem, D., Hordijk, P. L., Aarden, L. A., and Hack, C. E. (2001) J Immunol 167, 647-654

33. Melvin, T., Kim, Y., and Michael, A. F. (1986) Am J Pathol 125, 460-464

34. al-Mutlaq, H., Wheeler, J., Robertson, H., Watchorn, C., and Morley, A. R. (1993) Histochem J 25, 219-227

35. Potempa, L. A., Kubak, B. M., and Gewurz, H. (1985) J Biol Chem 260, 12142-12147

36. Baltz, M. L., De Beer, F. C., Feinstein, A., and Pepys, M. B. (1982) Biochim Biophys Acta 701, 229-236

37. Pepys, M. B., Dash, A. C., Markham, R. E., Thomas, H. C., Williams, B. D., and Petrie, A. (1978) Clin Exp Immunol 32, 119-124

38. Bottazzi, B., Doni, A., Garlanda, C., and Mantovani, A. Annu Rev Immunol 28, 157-183

39. Young, L., Jernigan, R. L., and Covell, D. G. (1994) Protein Sci 3, 717-729

40. Dyck, R. F., Evans, D. J., Lockwood, C. M., Rees, A. J., Turner, D., and Pepys, M. B. (1980) Lancet 2, 606-609

41. Hohenester, E., Hutchinson, W. L., Pepys, M. B., and Wood, S. P. (1997) J Mol Biol 269, 570-578

42. Thompson, D., Pepys, M. B., Tickle, I., and Wood, S. (2002) J Mol Biol 320, 1081-1086

43. Haverkate, F., Thompson, S. G., Pyke, S. D., Gallimore, J. R., and Pepys, M. B. (1997) Lancet 349, 462-466

44. Zhan, S. S., Veerhuis, R., Kamphorst, W., and Eikelenboom, P. (1995) Neurodegeneration 4, 291-297

45. Familian, A., Eikelenboom, P., and Veerhuis, R. (2007) Neurosci Lett 416, 87-91

46. Ho, J. G., Kitov, P. I., Paszkiewicz, E., Sadowska, J., Bundle, D. R., and Ng, K. K. (2005) J Biol Chem 280, 31999-32008 


\section{Chapter}

Goodpasture antigen-binding protein (GPBP) down modulates $A \beta$ aggregation in vitro and decreases toxicity of $A \beta$ to neurons

Chiara Mencarelli et al. 


\section{Abstract}

Alzheimer's disease (AD) is a complex multifactorial syndrome characterized by intra- and extracellular deposits of amyloid beta $(A \beta)$, neurofibrillary tangles, dystrophic dendrites and increased levels of ceramide in the cerebrospinal fluid.

Goodpasture antigen-binding protein (GPBP) and its shorter variant, CERT, are the only proteins known to carry the lipid ceramide. GPBP and CERT localize in amyloid plaques from $A D$ patients and are capable of binding serum amyloid $\mathrm{P}$ component (SAP), a protein thought to stabilize aggregates by preventing proteolytic cleavage. GPBP expression is regulated by tumor necrosis factor (TNF-alpha) which has been shown to induce a cellular response able to protect neurons against $A \beta$ toxicity. We hypothesize that GPBP plays a role in the pathogenesis of neurodegenerative diseases that are characterized by the formation of protein aggregates. GPBP gene and protein levels are increased in HEK cells over-expressing the amyloid precursor protein (APP). Here GPBP is enriched at the plasma membrane where it colocalizes with ceramide. GPBP is secreted and forms extracellular complexes with $A \beta$. We showed that GPBP reduces $A \beta$ aggregation and has a protective effect against $A \beta$-induced toxicity in cultured neurons. Our results indicate that GPBP takes part in the cellular response against $A \beta$ induced toxicity and is involved in the pathophysiological mechanisms associated with neurodegenerative processes. 


\section{Introduction}

Protein aggregation is a complex process implicated in a variety of neurodegenerative disorders such as Alzheimer's (AD) and Parkinson's diseases, amyotrophic lateral sclerosis, motor neuron disorders, as well as diseases of peripheral tissue like familial amyloid polyneuropathy (FAP). Native normally functional proteins can spontaneously self-organize into fibrous aggregates containing misfolded proteins in a $\beta$-sheet conformation, termed amyloid. Sporadic neurodegenerative diseases are generally associated with aging which is accompanied by oxidative modifications of proteins.

GPBP is a non conventional Ser/Thr kinase that regulates protein folding and secretion (2-4). More specifically, GPBP regulates molecular organization of structural proteins at both extracellular and intracellular compartments. It was shown that GPBP can bind and phosphorylate the non collagenous domain of type IV collagen, seemingly inducing glomerular basement membrane collagen network organization (2). In skeletal muscle development, GPBP is critical for myogenesis, directing myofibrillar organization through the targeting of GIP130 (GPBP-interacting protein of $130 \mathrm{kDa}$ ), a protein component of myofibrils (5). Many proteins have been shown to be multi-functional (6) and indeed, this seems to be the case for GPBP. In fact, the human gene encoding GPBP, COL4A3BP, encodes for a shorter protein isoform named CERT, generated by alternative splicing (7). CERT is identical to GPBP but lacks a serine-rich domain of 26 amino acids. The absence of this domain reduces kinase activity in this isoform (8). The name CERT stands for ceramide transporter, a function attributed to this protein shortly after discovery of GPBP. However, the GPBP isoform can also bind the lipid ceramide in vitro (7). The supramolecular organization of structural proteins seems to be more dependent on kinase rather than on ceramide transfer activities of GPBP proteins. In fact, CERT cannot fully rescue GPBP function in defective cell lineages (5). These two isoforms are highly conserved in evolution and have the distinct functions of protein structural organization and ceramide traffic inside the cell [for a review (9)]. In basal condition, GPBP and CERT are widely distributed throughout the brain and particularly abundant in neurons (10), indicating an important role in the brain. Resting microglia show a very low expression of GPBP and CERT but a positive signal for these proteins is detected in activated microglia of AD human brain (11).

Various animal models have clearly pointed the importance of these two splicing variants in the CNS. In zebrafish GPBP is mostly expressed at early 
stages of embryogenesis relative to CERT and knockdown of GPBP leads to the loss of myelinated tracts and extensive apoptosis during early development (12). Loss of functional CERT in Drosophila causes increased oxidative stress, accelerated aging and reduced life span (13). GPBP and CERT knockout mice are not viable due to defective development associated with mitochondria degeneration, ER alterations and defective cell proliferation (14). We have recently described the interaction that occurs between GPBP and CERT with Serum Amyloid P component (SAP), a universal component of amyloid deposits. Amyloid plaques are composed of extracellular accumulations of amyloid- $\beta$ peptide $(A \beta)$ and other plaqueassociated proteins, surrounded by large, swollen axons and dendrites (dystrophic neurites) and activated glia. We have detected a colocalization of GPBP and CERT with SAP and A $\beta$ fibrils in plaques of human $A D$ brains (11). $A \beta$-peptides are generated from a much larger precursor protein, the amyloid precursor protein (APP), a ubiquitous type I cell surface protein of as yet unknown physiological function. Proteolysis dictates both the level of $A \beta$-peptides generated and the rate at which they are degraded (15). APP can be processed via a non-amyloidogenic route involving $\alpha$-secretase cleavage within the $A \beta$ domain. This latter cleavage precludes $A \beta$ peptide formation, generating instead a soluble APP ectodomain (SAPP $\alpha$ ) along with a C-terminal fragment (CTF) of 83 amino acids (C83) (16). Alternatively, APP can be proteolytically processed via an amyloidogenic pathway which involves initial cleavage by $\beta$-secretase ( $\beta$-site APP-cleaving enzyme 1 ; BACE1) to generate a soluble $\mathrm{N}$-terminal fragment termed SAPP $\beta$ along with a $C$ terminal membrane associated fragment (CTF) of 99 amino acids $(17,18)$. The C99 fragment is then further processed by a $\gamma$-secretase complex producing the A $\beta$-peptides and the APP intracellular domain (AICD) $(19,20)$ [for a review (21)]. AICD has been suggested to regulate gene transcription of serine-palmitoyl transferase (SPT) (22), the enzyme that catalyzes the first step of de novo biosynthesis of ceramide (23). CERT and GPBP are the only proteins known to shuttle de novo synthesized ceramide. Considering that GPBP associates with amyloid plaques and binds protein at the extracellular level it seems likely that GPBP and CERT play important roles in the molecular organization and self-association processes of amyloid fibrils. Here we show that GPBP is upregulated by APP overexpression. Secreted GPBP interacts directly with $A \beta_{1-42}$ and is able to structure $A \beta_{1-42}$ into insoluble less toxic aggregates. This has a protective effect against $A \beta$ induced toxicity in cultured neurons, suggesting a key role for this protein in the pathogenesis of AD. 


\section{Material and methods}

\section{Human Embryonic Kidney (HEK) 293 cell culture}

Normal HEK293 and HEK-293 cells that stably express either wild type APP (APPwt) or APP with the double mutation K651N/M652L, known as the 'Swedish' mutation (APPsw) (24), were cultured in Dulbecco's modified Eagle's medium supplemented with $10 \%$ heat-inactivated fetal calf serum, 50 units $/ \mathrm{ml}$ penicillin, $50 \mu \mathrm{g} / \mathrm{ml}$ streptomycin, $2 \mathrm{mmol} / \mathrm{L}$ glutamine at $37^{\circ} \mathrm{C}$ in a humidified incubator containing $5 \% \mathrm{CO}_{2}$. Stable transfected cells expressing the APP construct were maintained in G418 at a final concentration of $200 \mu \mathrm{g} / \mathrm{ml}$. The APP levels of APP-transfected HEK cells were analyzed by Western blot to confirm that the over-expression of APP protein level was the same in HEK APPwt and HEK APPsw cell lines.

\section{Preparation of cell lysates and Western blot}

HEK, HEK APP and HEK APPsw cells cultured in $25 \mathrm{~cm}^{2}$ tissue culture flasks (80-90\% confluency) were lysed via repeated passage through a $28 \mathrm{~g}$ needle in $25 \mathrm{mM}$ Tris, $25 \mathrm{mM} \mathrm{NaCl}, 0.1 \mathrm{mM}$ EDTA, pH 7.4 containing PI cocktail. Lysis efficiency was verified $>99 \%$ by trypan blue staining. The resultant lysate was centrifuged at $20,000 \times \mathrm{g}$ for $30 \mathrm{~min}$ and the supernatant collected. Protein content was determined by a conventional method (BCA protein assay Kit). Before Western blot analysis, an aliquot of $10 \mu \mathrm{g}$ of protein extract from each individual sample was processed for Western blot analysis and probed with anti GAPDH antibody to ensure the same protein loading [mouse monoclonal antibody (mAb) anti-GAPDH, Sigma] to (data not shown). Based on the previous results, $40 \mu \mathrm{g}$ of proteins were separated by SDS-PAGE using precast Criterion Tris- $\mathrm{HCl}$ glycine 4-20\% gradient gels (BioRad, Veenendaal, the Netherlands) followed by electroblotting to nitrocellulose membrane (Millipore, Amsterdam Zuid-Oost, the Netherlands). The membranes were incubated with primary polyclonal antibody specific for APP [APP140, raised against the C-terminal 20 amino acids of human APP (1)] and with specific mouse mAb clone 3A1-C1 against GPBP [mAb GPBP 3A1-C1 have been described in (25)]. After PBS washes, the membrane was incubated with goat anti-rabbit-IRdye 800 and donkey anti-mouse-IRdye 680 (Rockland Immunochemicals, Gilbertsville, PA). Finally, the membrane was washed with PBS, dried and scanned using the Odyssey infrared imaging system (Westburg, Leusden, the Netherlands). 


\section{Immunoprecipitation analysis}

Protein extracts $(100 \mu \mathrm{g})$ were used for immunoprecipitation experiments performed in a volume of $500 \mu \mathrm{L}$. Pull down of endogenous GPBP and stably overexpressed APPsw was performed with $1 \mu \mathrm{g}$ mAb 3A1-C1 and 6E10 respectively, added to the samples for 1 hour incubation, at room temperature. Mouse mAb anti syntaxin 6335 (clone 3D10, Abcam, Cambridge, MA) was used as isotype control ( $1 \mu \mathrm{g}$ antibody per $15 \mu \mathrm{L}$ ). Samples were thereafter centrifuged at $20,000 \times \mathrm{g}$ for $30 \mathrm{~min}$. Pellets were washed three times in $50 \mu \mathrm{L}$ PBS and boiled in reducing sample buffer containing mercaptoethanol to dissolve immunocomplexes. Proteins were separated by SDS-PAGE using precast Criterion Tris- $\mathrm{HCl}$ glycine $4-20 \%$ gradient gels (Bio-Rad, Veenendaal, the Netherlands) followed by electroblotting to nitrocellulose membrane (Millipore, Amsterdam ZuidOost, the Netherlands). The membranes were incubated with primary antibodies against APP (6E10) or GPBP using polyclonal rabbit anti-GPBP epitope 1-50 (Bethyl laboratories). After phosphate buffered saline (0.1 M PBS, $\mathrm{pH}$ 7.4) washes, membranes were incubated with donkey anti-mouseIRdye 680 and goat anti-rabbit IRdye 800 (Rockland Immunochemicals, Gilbertsville, PA) followed by detection as described above.

\section{Subcellular fractionation}

Subcellular fractionation was performed as briefly described. 5 million HEK APPsw cells were harvested in $1 \mathrm{ml}$ of homogenization buffer $(0.25 \mathrm{M}$ sucrose, $10 \mathrm{mM} \mathrm{KCl}, 1.5 \mathrm{mM} \mathrm{MgCl} 2,1 \mathrm{mM}$ EDTA, $1 \mathrm{mM}$ EGTA, $1 \mathrm{mM}$ DTT and $20 \mathrm{mM}$ HEPES $\mathrm{pH}$ 7.4) and lysed via repeated passage through a $28 \mathrm{~g}$ needle containing a cocktail of protease inhibitors (PI) (Roche Diagnostics, Almere, the Netherlands). After an incubation of $20 \mathrm{~min}$ in ice, homogenates were centrifuged at $1,000 \times \mathrm{g}$ for $5 \mathrm{~min}$ to pellet nuclei and any cell debris. Postnuclear supernatant was centrifuged at $200,000 \times$ g at $4^{\circ} \mathrm{C}$ for 1 hour using an SW41 ultracentrifuge rotor (Beckman, Mississauga, Ontario, Canada) to obtain a membrane/organelle-enriched pellet and cytosolenriched supernatant. The membrane pellet was solubilized in $100 \mu \mathrm{l}$ of STEN-lysis buffer (50mM Tris pH 7.6, 150mM NaCl, 2 mM EDTA, 1\% NP-40, $\mathrm{PI}$ cocktail). After an incubation of $20 \mathrm{~min}$ on ice, resuspended pellet were cleared by a spin at $16,000 \times \mathrm{g}$ at $4^{\circ} \mathrm{C}$ for $15 \mathrm{~min}$. Protein content was measured by BCA assay and equal amounts of material ( $40 \mu \mathrm{g}$ each) were employed for immunoblotting analysis as described above.

\section{Far Western}

For far Western experiments, human recombinant GPBP (80ng) and A $\beta$ 
peptide 1-42 (80ng) (Anaspec, San Jose, CA, USA) were analyzed by SDSPAGE under reducing conditions. A $17 \mathrm{kDa}$ Lama antibody fragment (H6) with myc and his6 tags, [a kind gift of Dr. A.J. Groot (26)], was used as a negative control (80ng). Proteins were transferred to nitrocellulose membranes (Bio-Rad Laboratories BV, Veenendaal, Netherlands), renatured in Tris-buffered saline in the presence of Tween $20(0.05 \%)$ and probed for $1 \mathrm{~h}$ at $37^{\circ} \mathrm{C}$ with $30 \mu \mathrm{g} / \mathrm{mL}$ of GPBP or A $\beta$ peptide in the same buffer. Bound material was detected using polyclonal rabbit anti-GPBP epitope 1-50 (Bethyl laboratories), mouse mAb anti-human $A \beta$ (6E10, Covance, Rotterdam, the Netherlands) and mouse mAb anti-human c-Myc (clone 9E10, Invitrogen, Breda, the Netherlands). Incubation with secondary goat anti-rabbit-IRdye 800 and donkey anti-mouse-IRdye 680 (Rockland, USA) was followed by detection as described above.

\section{Cell surface biotinylation}

HEK, HEK APPwt and HEK APPsw cells were grown to $90 \%$ confluency and labeled with PBS containing sulfo-N-hydroxy- succinimidobiotin (sulfo-NHSSS-biotin) $(0.5 \mathrm{mg} / \mathrm{ml})$ for $30 \mathrm{~min}$ at $4^{\circ} \mathrm{C}$. At the end of incubation, excess free sulfo-NHS-SS-biotin was quenched with two times washings with 20 $\mathrm{mM}$ Glycine. The last washing was incubated for additional $15 \mathrm{~min}$ on ice. Quenching solution was aspirated and cells washed three times with ice-cold PBS. Biotin-labeled cells were lysed and the lysate was clarified by centrifugation at $14,000 \times \mathrm{g}$ for $5 \mathrm{~min}$ at $4^{\circ} \mathrm{C}$. The supernatant, containing biotinylated and soluble cytoplasmic proteins, was collected. An aliquot of supernatant was saved for examination of cytoplasmic protein actin (antiactin polyclonal rabbit antibody, Sigma) by Western blot analysis. Biotinylated proteins were isolated by binding the streptavidin-agarose beads for $2 \mathrm{hr}$ at $4^{\circ} \mathrm{C}$. Proteins labeled with the sulfo-NHS-SS-biotin were eluted from the beads with Laemmli buffer containing $50 \mathrm{mM}$ dithiothreitol (DTT) (1:1) for $5 \mathrm{~min}$ at $95-100^{\circ} \mathrm{C}$. The eluted proteins were separated from the beads by centrifugation and analyzed by $4-15 \%$ gradient SDS-PAGE as described above.

\section{Quantitative real time PCR Experiments}

To investigate the expression of GPBP and CERT mRNA levels in HEK and HEK APPsw cell lines, total RNA was extracted from confluent (70-80\%) cells using TRIzol reagent (Invitrogen, Breda, the Netherlands) according to manufacturers' protocols. Quality and quantity of the RNA were determined using a Nanodrop ND-1000 spectrophotometer (Thermo Scientific, Wilmington, MA). Total RNA ( $2 \mu \mathrm{gs})$ were reverse-transcribed using 
RevertAid First Strand cDNA synthesis kit (Fermentas, St. Leon Rot, Germany), according to the manufacturer's protocol. Real-time (RT) PCR primers were designed using Primer3plus (http://www.bioinformatics.nl/cgi-bin/primer3plus/primer3plus.cgi) for the human GPBP, CERT, 18s rRNA, $\beta$-Actin, and ubiquinolcytochrome-c reductase complex component (RIP).

All samples were analyzed using the LightCycler 480 SYBR Green I Master kit (Roche, Almere, the Netherlands). Each RT-PCR analysis was performed twice with independent cell cultures and the values are means \pm SD from triplicate samples. Human 18s rRNA, $\beta$-Actin and RIP were used as internal controls. Samples without reverse transcriptase were used as negative control to ensure non genomic contaminations. The RT-PCR was performed on a LightCycler 480 system (Roche Applied Science, CA). The relative amounts of GPBP and CERT expression levels compared with the 3 housekeeping genes were calculated using the $\Delta \Delta \mathrm{Ct}$ method. Statistical analysis was performed using unpair t-test. The following primer sequences were used: human GPBP: 5'- GATTCAGCTCCCAGGTTGAA -3' and 3'GGATCCAGAACAATCCCATTT -5'; human CERT:5'-ATAGAAGAACAGTCACA GAGTG-3' and 3'-CTGCACCATCTC TTCAACCTTTTG -5'; human $\beta$-Actin: 5'CTTCCTGGGCATGGAGTC-3' and 5'-AGCACTGTGTTGGCGTACGTG-3'; human RIP: 5'-TGTCACGGTTCCCATTAT GATATT-3' and 3'-TGGAAT TTCCAAGTTC AATGGA-5'; human 18s rRNA:

5'-GTAACCCGTTGAACCCCATT-3' and 3'-CCATCCAATCGGTAGTAGCG-5'.

\section{Immunofluorescence on HEK and HEK APPsw cells}

HEK and HEK APPsw cells were seeded into 6-well plates containing sterile glass coverslips for reattachment. Cells (80\% confluent) were fixed with $3.7 \%$ paraformaldehyde (PFA) at $37^{\circ} \mathrm{C}$ for $15 \mathrm{~min}$, carefully washed three times with PBS and incubated for $5 \mathrm{~min}$ in $500 \mu \mathrm{l}$ of $0.5 \%$ bovine serum albumin (BSA)-DMEM at room temperature. Without permeabilization, cells were stained for GPBP (3A1-C1), for APP [pAb 5313 recognizing the N-terminal domain of APP (27)], for ceramide (MID 15B4, Alexis, Grünberg, Germany) and for alpha1 sodium/potassium ATPase plasma membrane marker ( $\alpha 1 \mathrm{Na}+/ \mathrm{K}+$ ATPase) (mAb7671, Abcam, Cambridge, MA) in 0.5\% BSA-DMEM for $60 \mathrm{~min}$ at $37^{\circ} \mathrm{C}$. Cells were than washed three times with PBS and were incubated with the corresponding secondary antibodies: Alexa-488conjugated donkey anti-rabbit IgG antibody (diluted 1:100; Jackson ImmunoResearch Laboratories Europe Ltd. Newmarket, Suffolk, UK) and Alexa-594-conjugated donkey anti-mouse IgG antibody (diluted 1:100; Invitrogen, Breda, the Netherlands) for $30 \mathrm{~min}$ at room temperature in the 
dark. Coverslips were washed two times in PBS and one time in water to remove all traces of PBS and mounted on slides using glycerol $10 \%$. Negative controls by omission of the primary antibody resulted in no signal (not shown). Images were captured using an Olympus AX70 microscope. Immunofluorescence signal was quantified using ImageJ software, the average intensity of 50 individual cells is shown (bar graph). Datasets were analyzed via analysis of variance with t-test.

\section{Immunohistochemistry in rat brain}

Immunohistochemistry was carried out using $50 \mu \mathrm{m}$ thick sections of rat brains fixed by immersion in 4\% PFA, 15\% picric acid and $0.05 \%$ glutaraldehyde in phosphate buffer $(\mathrm{pH}$ 7.6) for four days as described in (10). Free-floating sections were incubated overnight at room temperature with mAb anti GPBP (3A1-C1). After rinsing with Tris-buffered saline (TBS, $50 \mathrm{mM}$ Tris, $150 \mathrm{mM} \mathrm{NaCl}$, pH 7.4) with $50 \mathrm{mM}$ Triton (TBS-T), sections were incubated with secondary antibody: donkey anti-mouse biotinylated IgG (diluted 1:400; Jackson ImmunoResearch Laboratories Europe Ltd., Newmarket, Suffolk, UK). Subsequently, sections were incubated with the ABC-kit (Vector Laboratories, Burlingame, CA) for 1.5 hours. To visualize the horseradish peroxide (HRP) reaction product, the sections were incubated with 3,3'-diaminobenzidine tetrahydrochloride (DAB). No labeling was evident in control experiments in which primary antibodies were omitted from the immunostaining protocol (data not shown). Sections were photographed with an Olympus AX70 microscope (Olympus, Hamburg, Germany). Pictures were taken with Cell P software (Olympus).

\section{Microscale Thermophoresis binding analyses}

Microscale thermophoresis (MST) is a new immobilization-free technique for the analysis of biomolecules interaction (27-29) as described in (11). MST analysis was performed on the Monolith NT.115 instrument (NanoTemper, München, Germany). In brief, 20 nM of NT647-labeled GPBP was incubated for $20 \mathrm{~min}$ at room temperature in the dark with different concentrations of either $A \beta_{1-42}(3-100000 \mathrm{nM})$ or a control $17 \mathrm{kDa}$ Lama antibody fragment (H6) (1-35000 nM) in PBS/0.01\% Tween 20. Afterwards, 3-5 $\mu \mathrm{L}$ of the samples were loaded into glass capillaries (Monolith NT Capillaries, Cat \# K002) and the thermophoresis analysis was performed (LED 40-51\%, IR laser $80 \%)$. Statistical analysis was performed with Origin8.5 software.

\section{Cell viability assay}

To measure cell viability, SHSY-5Y cells were cultured in DMEM/F12 
(Invitrogen, Breda, the Netherlands) supplemented with 10\% FBS, glutamine, penicillin and streptomycin. The cells were plated on flat bottom tissue culture treated 96-well plates (Sigma, Zwijndrecht, the Netherlands) at a density of $1 \times 10 \mathrm{e} 5$ cell per well and subsequently allowed to attach for 24 hours in a humidified $5 \% \mathrm{CO}_{2}$ incubator at $37^{\circ} \mathrm{C}$. After exchanging the medium with serum-free DMEM/F12 and incubating the cells for another 24 hours, the medium was removed, replaced with $100 \mu \mathrm{L}$ of serum-free DMEM/F12 containing 0 (control) or $10 \mu \mathrm{M}$ of $A \beta_{1-42}$ and $0,0.5$ or $1 \mu \mathrm{M}$ of GPBP and cells were then incubated for another 24 hours. Cell viability was assessed by quantifying methyl-thiazolyl-diphenyltetrazolium bromide (MTT) reduction. $10 \mu \mathrm{L}$ of a $5 \mathrm{mg} / \mathrm{mL}$ stock solution of sterile filtered MTT (Sigma) dissolved in PBS was added to each well and incubated at $37^{\circ} \mathrm{C}$ for 3 hours. The resulting formazan crystals were dissolved in acidified isopropanol with $10 \%$ Triton $\mathrm{x}-100$ and the absorbance at $595 \mathrm{~nm}$ was measured on a Victor X3 plate reader (Perkin-Elmer, Groningen, the Netherlands).

\section{Aggregation assay}

$A \beta_{1-42}$ was purchased from (Anaspec, San Jose, CA). The peptide was solubilised in $0.22 \mu \mathrm{m}$ filtered PBS, $0.1 \%$ trifluoroacetic acid (TFA) at the concentration of $2 \mathrm{mM}$ and frozen in stock aliquots. Stock aliquots were diluted at the final concentration of $20 \mu \mathrm{M}$ in a total volume of $400 \mu \mathrm{l}$ containing 0,1 or $2.5 \mu \mathrm{M}$ of affinity purified recombinant GPBP. The solutions were prepared in $1.5 \mathrm{~mL}$ low-binding microcentrifuge tubes (Eppendorf, Hamburg, Germany), which were contained in $50 \mathrm{~mL}$ falcon tubes that were placed in a rotary shaking incubator (New Brunswick, Nijmegen, the Netherlands) at $37^{\circ} \mathrm{C}$. Samples were taken from the solution immediately and at different time points after preparation $(1,2,4,8,12$ and 24 hours) for thioflavin T (ThT) fluorescence and Western blot analysis. ThT fluorescence was analysed by adding $5 \mu \mathrm{L}$ of the sample to $95 \mu \mathrm{L}$ of $20 \mu \mathrm{M}$ ThT in a 96-well optiplate (Perkin-Elmer) and measuring fluorescence with excitation at $450 \mathrm{~nm}$ and emission at $486 \mathrm{~nm}$ in a Victor X3 plate reader (PERKIN-ELMER). Western blot analysis was performed by electrophoretically separating $15 \mu \mathrm{l}$ of sample under either native nonreducing or denaturing and reducing conditions on $4-16 \%$ precast TGX gradient gels (Bio-Rad). The samples were transferred to nitrocellulose membrane, blocked with 5\% BSA in PBS and probed with mouse mAb anti GPBP antibody (3A1-C1) and human mAbs against $A \beta$ (mAb 20C2, 3D6 and $\mathrm{m} 266)$ as described previously in (11). Bound antibodies were visualized by scanning the membranes with an Odyssey imager (Li-Cor, Westburg, 
Leusden, the Netherlands) after incubating with IRdye800 conjugated goat anti-human IgG and IRdye 680 conjugated donkey anti-mouse.

\section{Results}

\section{Subcellular localization of GPBP}

In an effort to characterize the function of endogenous GPBP, we examined its subcellular localization in normal rat brain by confocal microscopy.

A mAb directed against the 26 amino acid domain that characterises the longer variant, GPBP, was used. Survey of the coronal brain sections shows a heterogeneous distribution of GPBP throughout the central nervous system (CNS), all neuronal cells were found to be positive for GPBP without enrichment in any specific neuronal population. Immunostaining shows that endogenous GPBP associates with neuronal plasma membranes and localises in the neuropil. This is in agreement with previous studies that describe GPBP as a membrane-bound isoform that can be secreted (2).

A level of discrete staining could be observed in the processes of large myelinated axons ( $\geq 1 \mu \mathrm{m}$ ) whereas the signal was only found extracellularly in smaller unmyelinated axons $(\leq 1 \mu \mathrm{m})$. This result suggests GPBP is found associated with the myelin sheath, an extended oligodendroglial plasma membrane that wraps around axons. The neuronal cytoplasm remains unstained. GPBP immunoreactivity is restricted to the grey matter, enriched in neurons with no detectable signal in glial cells (astrocytes, oligodendroglia, ependymal cells and microglia), consistent with our previous study (10).

The specificity of the antibody used was confirmed by blocking the binding after pre-incubation with the antigenic peptide; under these conditions, there was no detectable signal (data not shown). A previous study using an antibody directed against both variants (GPBP and CERT) produced both intracellular and extracellular staining (10). In the current study we demonstrate that GPBP is responsible for the extracellular and membrane associated signal but is not detected intracellularly. Overall, GPBP and CERT have distinct complementary cellular expression patterns.

\section{HEK APPwt/sw cells are characterized by overexpression of GPBP}

We have recently shown that GPBP and CERT partially colocalize with A $\beta$ fibrils in plaques of human AD brains (11). To investigate the role of GPBP in the processing of APP, we have used a cell model with elevated levels of secreted A $\beta$ peptide. Specifically, we use HEK APPwt and HEK APPsw, cell lines which have been extensively used as a model system for the study of 
APP metabolism (28-31).

Cell lysates prepared from HEK and HEK cells overexpressing APPwt or APPsw were blotted and probed with mAb anti-GPBP antibody (3A1-C1). Actin was used as a loading control. A single band with a molecular mass of $120 \mathrm{kDa}$ was detected in the HEK, APPwt and APPsw lines, however the GPBP expression was higher in the APPwt and APPsw overexpressing -line. The Swedish double mutation in the APP gene results in a markedly increased $A \beta$ secretion compared with HEK cells overexpressing APPwt. However, no difference in the overexpression of GPBP was detected between APPwt and APPsw HEK cells. Therefore, these results show that GPBP expression is associated with APP protein increase at the plasma membrane and not dependent on $A \beta$ levels.

APP and GPBP cell surface distribution was further analyzed by immunofluorescence staining on non-permeabilised HEK and HEK APPsW cells. GPBP and APP levels were significantly increased in the HEK APPsw cell surface relative to HEK cells (Figure $1, \mathrm{~B}$ ). The plasma membrane marker, $\alpha 1 \mathrm{Na}^{+} / \mathrm{K}^{+}$ATPase, used as positive control was equally distributed in the two cell lines (data not shown). Negative controls by omission of the primary antibodies resulted in no signal.

RT-PCR was also used to verify the expression levels of GPBP and CERT in HEK and APPsw cell lines (Figure $1 \mathrm{C}$ ). In line with the Western blot and staining data, GPBP transcript levels are significantly up regulated in APPsw relative to HEK $(p<0.016)$. A less significant difference was observed in the mRNA expression levels of the CERT isoform, again relative to HEK $(p<0.2)$. In summary, we have shown that stable overexpression of either APPwt or APPsw in HEK293 cells results in increased levels of endogenous GPBP.

\section{GPBP is over-expressed at plasma membrane level}

In order to further characterize the localization of GPBP overexpression, equal amounts of protein from plasma membrane and cytoplasmic subcellular fractions of HEK and HEK APPsw were blotted with mAb detecting GPBP (3A1C1) and APP (6E10). GPBP and APP levels were increased in the membrane fraction of HEK-APPsw relative to HEK (Figure $3 \mathrm{~A}$ ). In the membrane fraction of APPsw cells a large band of 100 kDa was detected for APP and high molecular weight bands above 250 and $\sim 100 \mathrm{kDa}$ were detected for GPBP. Very low levels of APP and GPBP were detected in normal HEK cells. Neither GPBP nor APP was found in the cytosolic fractions of HEK and APPsw cell lines. To test for cross contamination, membrane and cytosolic fractions were probed with markers for subcellular compartments: $\alpha 1 \mathrm{Na}^{+} / \mathrm{K}^{+}$ATPase (plasma 


\section{A}
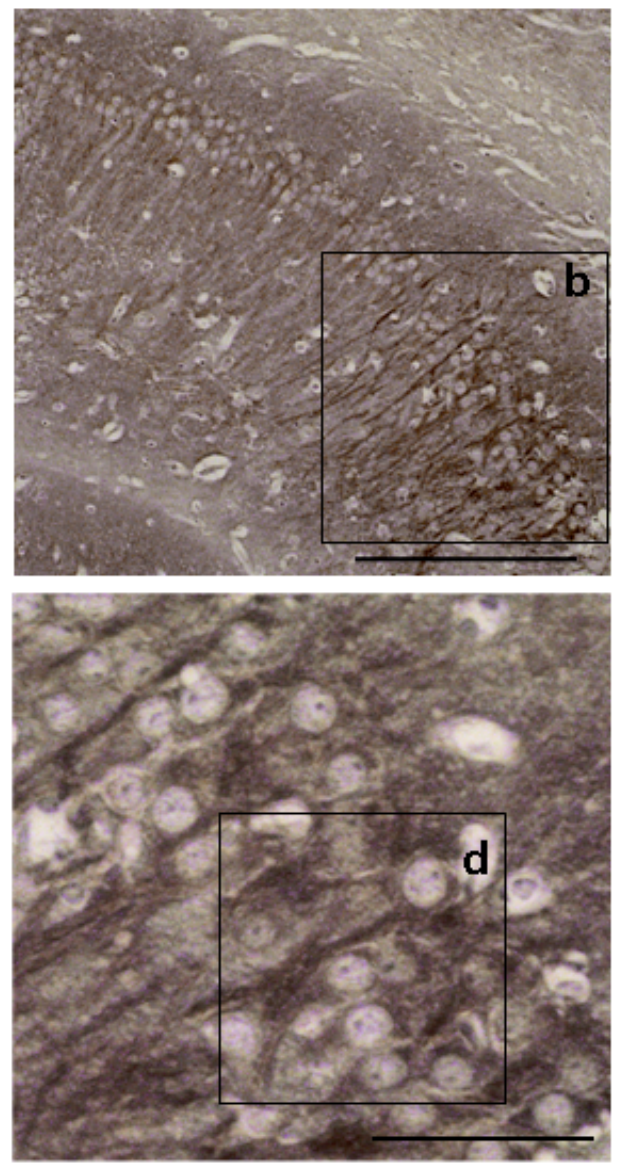

C
B
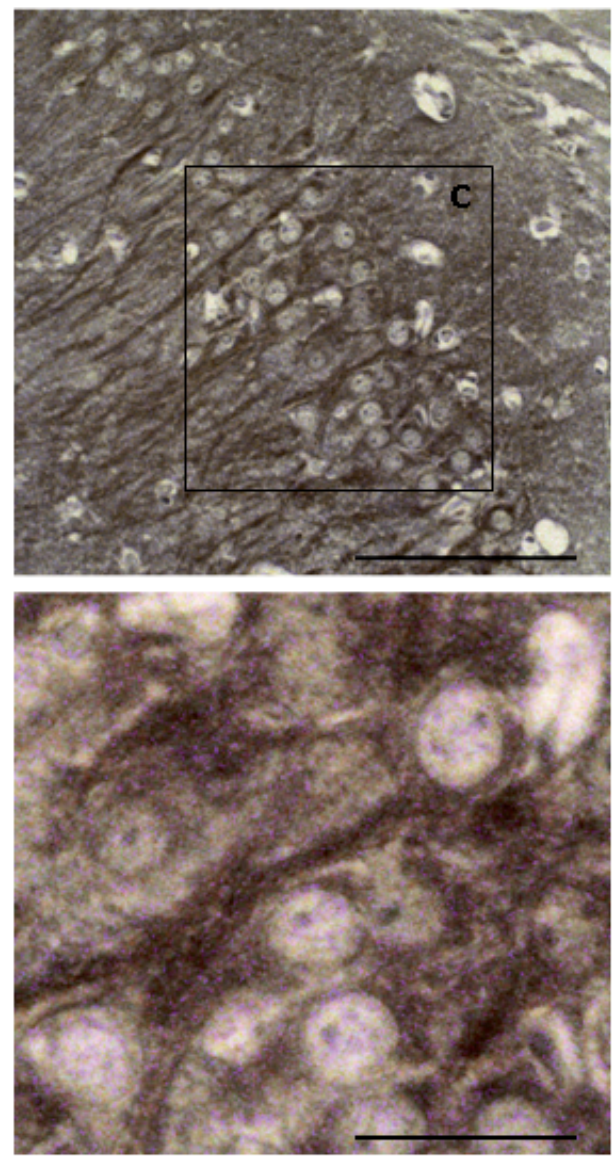

D

Figure 1. Immunohistochemical localization of GPBP in hippocampal neurons in normal rat brain. Light microscopy of neurons in the hippocampus (CA2) shows that GPBP staining is restricted to the plasma membrane. GPBP immunostains diffusely in the neuropil. Bars in A represents $200 \mu \mathrm{m}$, in B 80 $\mu \mathrm{m}$ and in $\mathrm{C} 20 \mu \mathrm{m}$, in $\mathrm{D} 10 \mu \mathrm{m}$.

membrane) and GAPDH (cytosol) (Figure 3 A).

These results suggested that overexpression of GPBP in HEK APPsw occurs at the plasma membrane level and does not accumulate inside the cell. An effective way to study membrane proteins is via surface biotinylation. Membrane proteins are labelled when a portion of the molecule that is exposed to the extracellular space is linked to biotin that covalently attaches to primary amines (e.g. Iysine) present within the protein sequence; Western blot analysis can then be used to characterize the biotinylated protein. This approach was used to detect GPBP levels at the plasma 


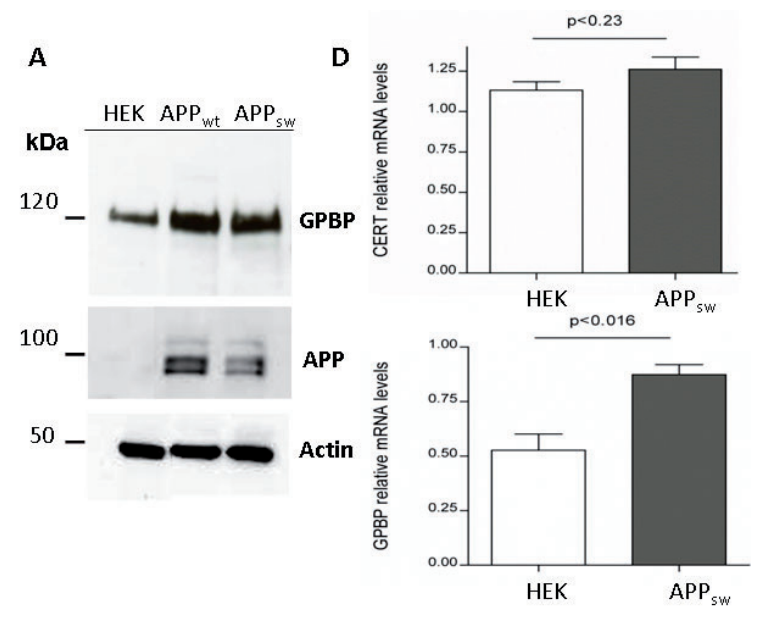

B

APP

GPBP

HEK
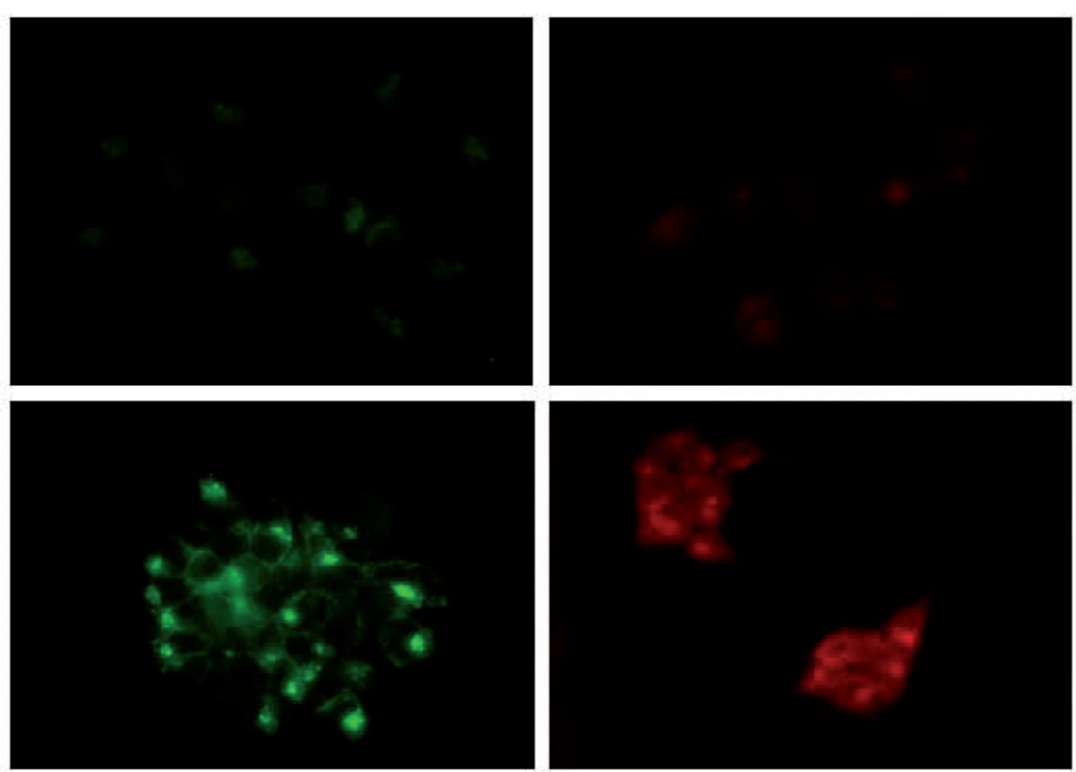

C
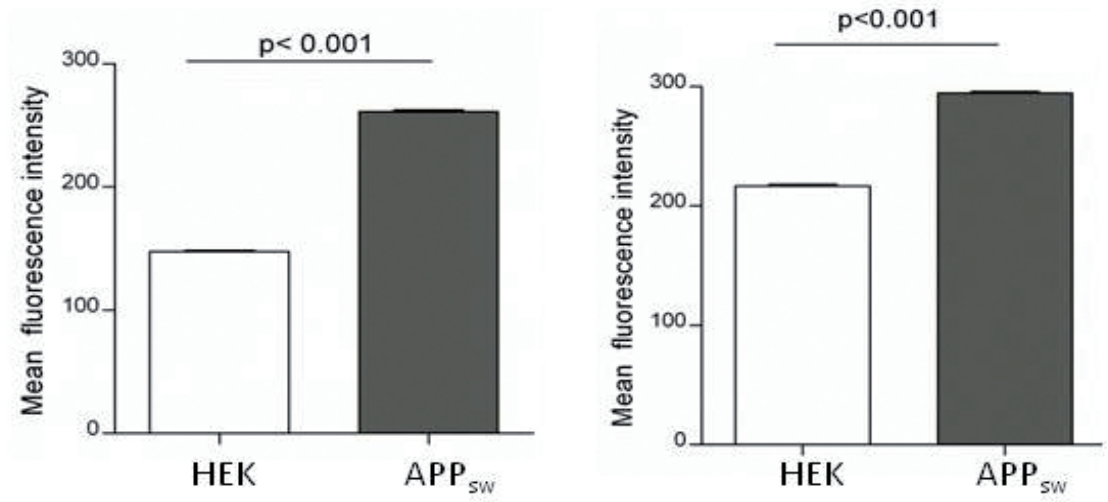
Figure 2 Stable overexpression of either APPwt or APPsw in HEK293 cells results in increased levels of endogenous GPBP A) Whole cell extracts ( $40 \mu \mathrm{g}$ protein) were analyzed by immunoblotting with antibodies against GPBP (3A1C1), APP (APP140) (1), Actin (Sigma).

B-C) HEK and HEK APP cells were stained for GPBP (mAb 3A1C1) and APP (pAb 5313). Immunofluorescence signal was quantified using ImageJ software, the average intensity of 50 individual cells is shown (bar graph). Datasets were analyzed via analysis of variance with t-test and significant $p$-values are shown.

D) To investigate the expression of GPBP and CERT mRNA levels in HEK and HEK APP cell lines, total RNA was extracted and analyzed by RT-PCR. The relative amounts of GPBP and CERT expression compared with the 3 housekeeping genes (human 18s rRNA, RIP, $\beta$-actin) were calculated using the $\Delta \Delta \mathrm{Ct}$ method. Statistical analysis was performed using unpair t-test. Significant differences $(p<0.05)$ are shown above the panel.

membrane in HEK, APPwt and APPsw. Biotinylation of cell surface proteins was consistent with immunostaining results and revealed an increase in GPBP levels at the plasma membrane of both APPwt and APPsw cells (Figure $3 \mathrm{~B}$ ). Detection of actin expression in the cell lysate was used as a loading control for the three cell lines and indicates the same amount of loaded protein.

The distribution of GPBP in plasma membrane was not always uniform across the cell surface and we consistently observed distinct concentrated patches and streaks of GPBP immunolabelling in HEK APPsw (Figure 2 B). Since ceramide enriched platforms have been shown to be involved in the regulation of APP processing and in A $\beta$ peptide formation, we analyzed the surface distribution of ceramide by immunofluorescence staining of HEK and APPsw. Higher intensity ceramide staining was consistently observed in APPsw cells relative to HEK cells (Figure $3 \mathrm{C}$ ). Furthermore, dual-label immunostaining demonstrated virtually complete co-localization of ceramide and GPBP on the cellular surface of the HEK APPsw plasma membrane (Figure $3 \mathrm{D}$ ). In summary, the dramatic increase of GPBP expression in APPsw occurs at the plasma membrane level and GPBP colocalises with ceramide-rich platforms in these cell lines. 
A

Membrane Cytosol

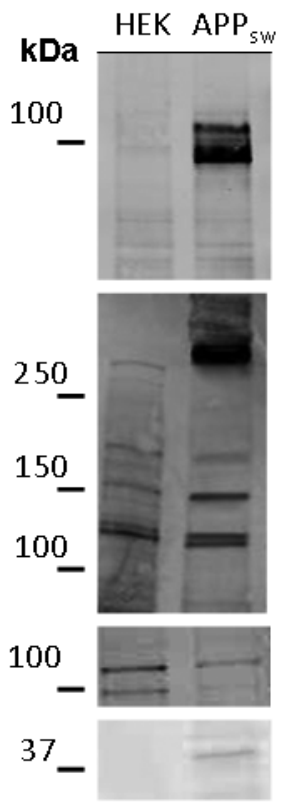

C

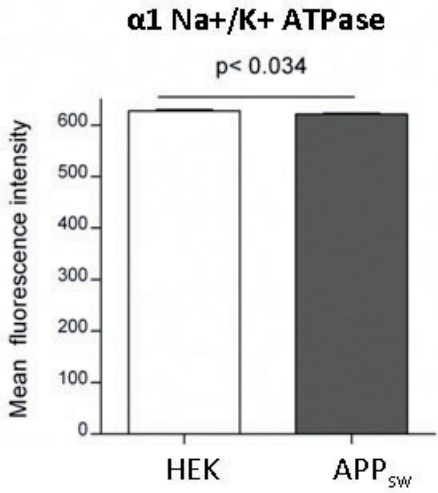

B

\section{Total Cell lysate}

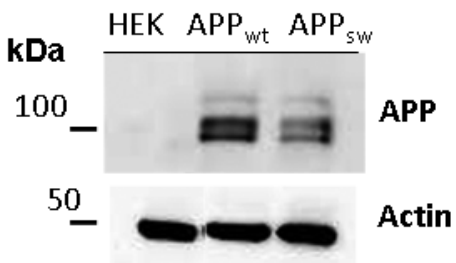

Biotinylated fractions
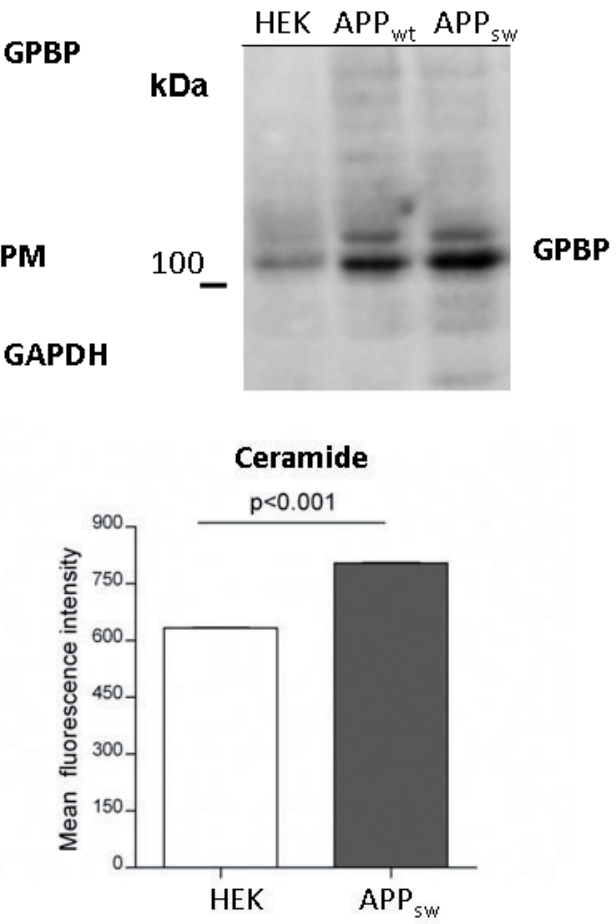

D

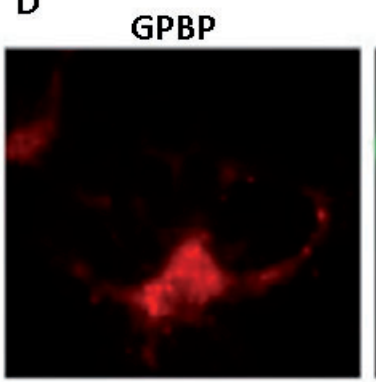

Ceramide
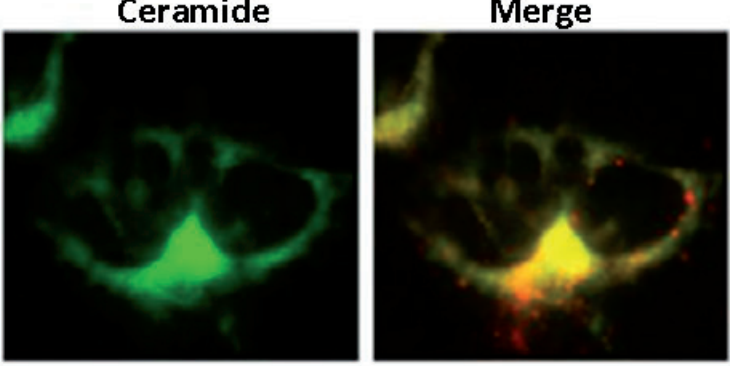
Figure 3 Protein levels of GPBP are increased at the plasma membrane in HEK APPsw compared to HEK cells. A) HEK and HEK APPsw were fractionated into membrane and cytosol. Membrane and cytosol extracts were separated by SDS-PAGE transferred to nitrocellulose and detected with mAb anti-GPBP (3A1C1) and PAb anti-APP (140 Ab). In the membrane fraction of HEK-APP cells, a large band of $\sim 100 \mathrm{kDa}$ is detected for APP and high molecular weight bands above 250 and $100 \mathrm{kDa}$ are detected for GPBP. Both proteins are hardly detected in normal HEK cells. To test for cross contaminations, membrane and cytosolic fractions were probed with markers for subcellular compartments: $\alpha 1 \mathrm{Na}^{+} / \mathrm{K}^{+}$ATPase (plasma membrane), GAPDH (cytosol). B) Membrane surface proteins of HEK (lane 1), HEK APPwt (lane 2) and HEK APPsw (lane 3) were selectively biotinylated. Biotin-labeled cells were lysed and the biotinylated proteins were pulled down with streptavidin, separated by $4-15 \%$ gradient SDS-PAGE, transferred to membrane and probed with mAb anti-GPBP. Detection of actin expression in the cell lysate was used as a loading control used for the three different samples. Two independent experiments were performed and a representative blot is shown. C) Immunofluorescence signal for ceramide and $\alpha 1 \mathrm{Na}^{+} / \mathrm{K}^{+}$ATPase was quantified using ImageJ software, the average intensity of 50 individual cells is shown (bar graph). Datasets were analyzed via analysis of variance with t-test and significant $p$ values are shown. Ceramide levels are significantly increased in the HEK APP cell surface compared to HEK cells. The plasma membrane marker is equally distributed in the two cell lines. D) Immunofluorescence stainings for GPBP and ceramide were carried out on both cell lines; here the HEK APP cells are shown, only. Colocalization (yellow) in the merged images is particularly intense in the plasma membrane.

\section{GPBP binds $A \boldsymbol{\beta}_{1-42}$}

The results reported so far demonstrate that GPBP expression is upregulated in response to constitutive overexpression of either APPwt or APPsw. Also a colocalization between ceramide and GPBP at the level of the plasma membrane is reported. In this context, we tested the hypothesis whether GPBP might interact with APP.

As APPsw cells express endogenous GPBP, they are suitable for testing the in vivo interaction of APP and GPBP. To explore the possibility that APP and GPBP form a complex, we performed reciprocal immunoprecipitation (IP) with monoclonal anti-A $\beta$ (6E10) and anti-GPBP antibodies (3A1-C1) in APPsw cellular lysates. Western blot analysis illustrated efficient IP of GPBP and APP by their respective antibodies, APP was detected as a band 100 kDa using mAb 6 E10 and GPBP was detected as band of approximately 200 kDa using polyclonal antibodies against GPBP epitopes 1-50 (Figure 4 A). This high molecular weight GPBP band suggests that the protein is somehow aggregated or that dimerization has occurred as already reported (8). Western blots of APP IPs have shown that GPBP co-precipitated with APP. The inverse IP strategy produced a similar result (Figure 4 A-B). IP using an isotype control mAb (mAb antisyntaxin 6, Clone 3D10) was negative when probed with the same GPBP and APP specific antibodies. The results are representative of three independent experiments. However, the fact that GPBP is secreted and that is found in amyloid plaques raises the question whether GPBP is capable of amyloid $\beta$ peptide binding. In order to further 
investigate whether $A \beta_{1-42}$ associates with GPBP, we utilized a far Western blotting technique in which membranes containing comparable amounts of GPBP were probed with $A \beta_{1-42}$ peptide and inversely, membranes containing comparable amounts of $A \beta_{1-42}$ peptide were probed with GPBP. By this method we were able to demonstrate that GPBP can directly bind to the $A \beta_{1-42}$ peptide probe and viceversa (this has been already proved in the PhD thesis of Dr Pilar Martínez-Martínez, La fosorilacion de serinas y el pigmento de autoantigenos: Caracterizacion de GPBP, una nueva quinasa implicada en autoinmunidad, Universidad de Valencia, July 2003) suggesting a direct interaction between these two proteins (Figure 4 C-D). To exclude the possibility that the binding event was an artifact of the covalent immobilization of each protein, we investigated GPBP-A $\beta_{1-42}$ interaction in free solution by MST. The GPBP/A $\beta_{1-42}$ dissociation constant (KD) was found to be $2.5 \mu \mathrm{M}+/-284 \mathrm{nM}$, indicating $A \beta_{1-42}$ binding to fluorescently labeled GBPB (Figure $4 \mathrm{E}$ ). No binding was observed when the experiment was performed using a negative control peptide (not shown).

\section{GPBP reduces $A \beta$ aggregation and has a protective effect against $A \beta$ - induced toxicity in cultured neurons}

Having shown that GPBP directly binds the $A \beta_{1-42}$ peptide, we next tested whether binding of GPBP to $A \beta_{1-42}$ has a direct influence upon the in vitro aggregation pattern of $A \beta_{1-42}$. This was determined by allowing $A \beta_{1-42}$ monomers to aggregate in the presence or absence of GPBP. The aggregation of $A \beta_{1-42}$ was followed by ThT fluorescence and Western blotting. In the absence of GPBP the ThT fluorescence of $A \beta_{1-42}$ peaked after 12 hours, with the addition of GPBP $(2.5 \mu \mathrm{M}) A \beta_{1-42}$ maximum ThT fluorescence was halved. At a lower concentration of $1 \mu \mathrm{M}, \mathrm{GPBP}$ was less effective at preventing $A \beta_{1-42}$ fibrilization. This was consistent with Western blot analysis where the amount of low molecular weight $A \beta_{1-42}$ species (below $20 \mathrm{kDa}$ ) was reduced by the addition of GPBP at both $1 \mu \mathrm{M} 2.5 \mu \mathrm{M}$ concentrations, suggesting that GPBP is able to structure $A \beta_{1-42}$ into insoluble aggregates.

The toxicity effect of $A \beta$ for neuronal cells, both in vitro and in vivo, is well documented and this toxicity appears to play an important role in the pathogenesis of AD (32). Using SHSY-5Y cells we were able to examine the functional effects of GPBP on cell viability under stress from $A \beta$ accumulation. The addition of $A \beta_{1-42}$ to the culture medium of SHSY-5Y cells resulted in a $38 \%$ reduction in viability after 24 hours, as measured by MTT reduction relative to control conditions. Interestingly, simultaneous addition of GPBP ameliorated the toxic effect of $A \beta_{1-42}$ in a concentration dependent 
A

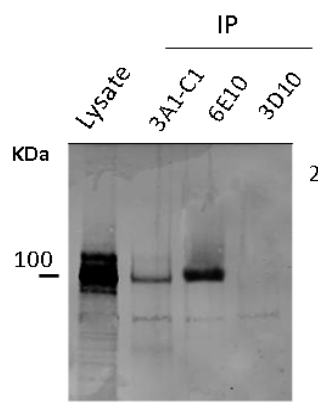

$6 \mathrm{E} 10$
B

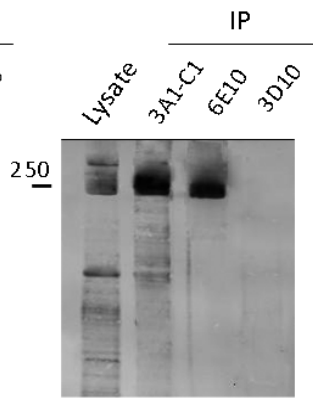

pAb $\alpha G P B P$

$\mathbf{E}$

C

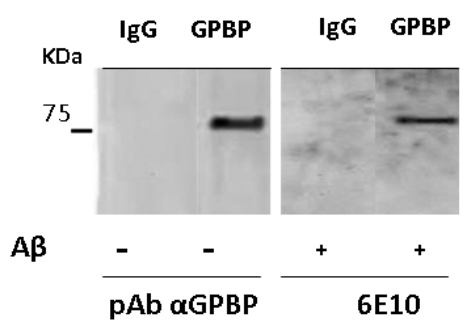

H6 A

H6 AB

H6 AB

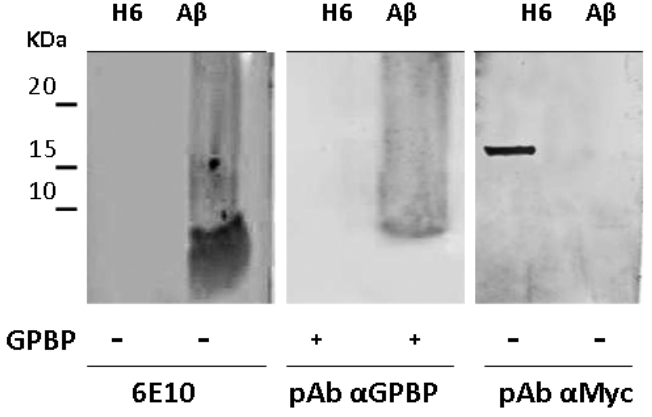

Evaluation Points / Fitted Curves

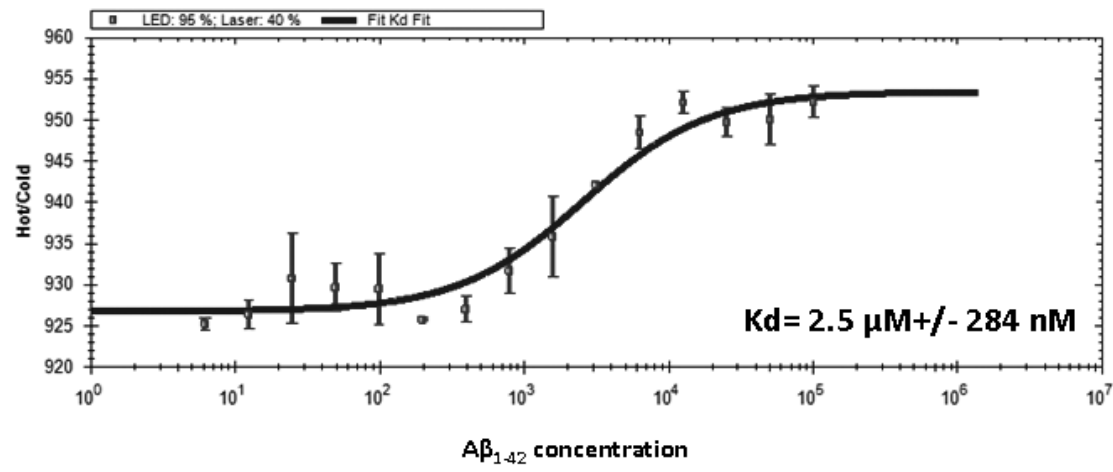

Figure 4 GPBP binds $\left.A \beta_{1-42} A-B\right)$ Cellular lysates were immunoprecipitated (IP) with anti-Aß mAb $6 E 10$, with mAb anti GPBP (3A1-C1) separated on a 4-15\% gradient SDS-PAGE and probed with 6E10 (A) and rabbit pAb anti-GPBP (epitope 1-50 of human GPBP, Bethyl Laboratories) antibodies (second blot), respectively. APP was co-IP by anti-GPBP mAb and was detected with mAb anti-A $\beta$ in a band around $100 \mathrm{kDa}$ (lane 2, A). GPBP was co-IP by anti-Aß mAb and detected with pAb anti-GPBP and visible in a band of approx $250 \mathrm{kDa}$ (lane 3, B). Control using an isotype control mAb (mAb antisyntaxin 6, Clone 3D10, Abcam) for IP was negative when detected with the same antibodies against $A B$ and GPBP (lane 4, A-B). Molecular weight markers are indicated $(\mathrm{kDa})$. The results are representative of three independent experiments. C-D) For far Western Analysis of GPBP interaction with $A \beta 1-42$ peptide GPBP, $A \beta_{1-42}$ peptide, IgG (negative control) and a $17 \mathrm{kDa}$ Lama antibody fragment (H6) (negative control) were loaded on SDS-PAGE and transferred into nitrocellulose membrane. Membranes were incubated with $A \beta_{1-42}$ peptide (C) and recombinant GPBP (D) followed by detection with pAb anti-GPBP and 6 E10 (C, D). The $17 \mathrm{kDa}$ Lama antibody fragment (H6) was detected with $\mathrm{pAb}$ anti Myc tag. E) A dissociation constant of $2.5 \mu \mathrm{M}+/-284 \mathrm{nM}$ for $A \beta_{1-42}$ binding to GPBP was determined by MST measurements. 
manner, with a $26 \%$ reduction in viability with $0.5 \mu \mathrm{M}$ of GPBP and a $20 \%$ reduction in viability with $1 \mu \mathrm{M}$ of GPBP compared to $38 \%$ with $A \beta_{1-42}$.

The interaction of GPBP with $A \beta_{1-42}$ seemed to change the aggregation pattern of $A \beta_{1-42}$ and the reduction of $A \beta_{1-42}$ toxicity in SHSY-5Y cells by GPBP suggest that this protein was able to organize $A \beta_{1-42}$ into less toxic structures.

A

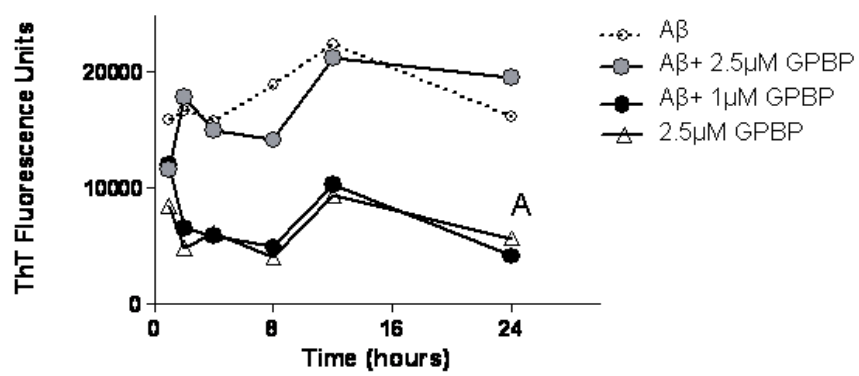

B

$\frac{\mathrm{Oh}}{1234} \frac{2 \mathrm{~h}}{1234} \quad \frac{4 \mathrm{~h}}{1234} \frac{8 \mathrm{~h}}{1234} \frac{12 \mathrm{~h}}{1234}$

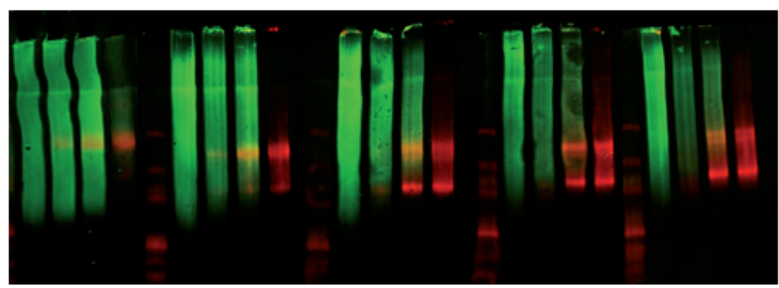

C
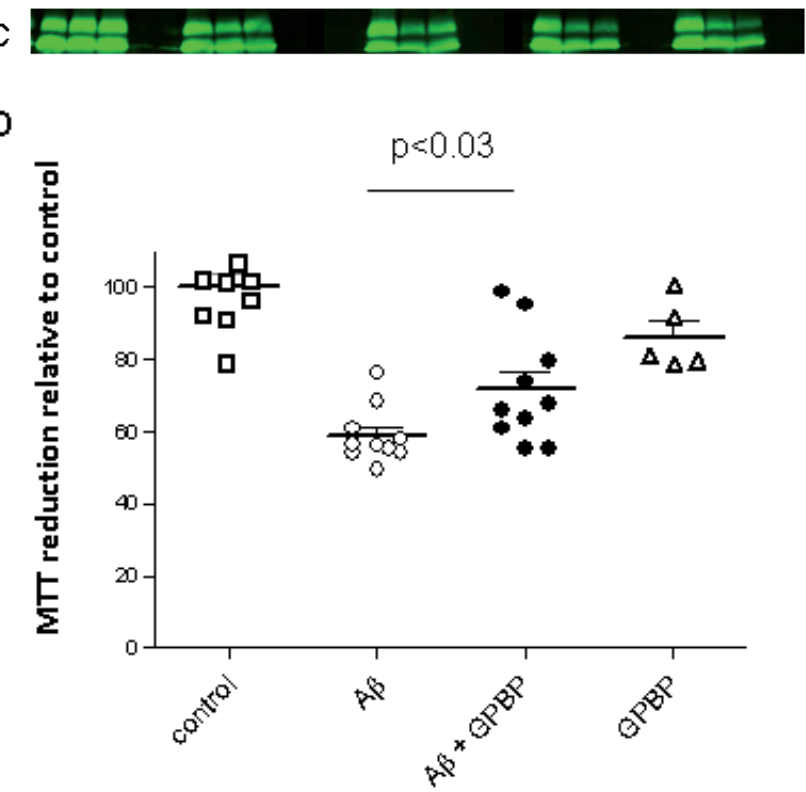
Figure 5 GPBP prevents the formation of thioflavin T positive $A \beta$ aggregates $A) 20 \mu M A \beta_{1-42}(A \beta)$ was incubated with $1 \mu \mathrm{M}$ or with $2.5 \mu \mathrm{M}$ GPBP in $100 \mu \mathrm{l}$ of $20 \mu \mathrm{M}$ ThT in a 96-well plate at $25^{\circ} \mathrm{C}$. Fluorescence intensity was measured every 4 minutes with excitation at $450 \mathrm{~nm}$ and emission at 486 $\mathrm{nm}$, each data point represents the mean fluorescent intensity of three wells. GPBP structures $A \beta_{1-42}$ into insoluble aggregates $\left.B-C\right) A \beta_{1-42}(1), A \beta_{1-42}+1 \mu \mathrm{M}$ GPBP (2), $A \beta_{1-42}+2.5 \mu \mathrm{M}$ GPBP (3) and GPBP (4), were incubated at $37^{\circ} \mathrm{C}$ for 24 hours and $15 \mu \mathrm{l}$ of each samples were taken at different time points $(0,2,4,8,12$ hours are shown) and separated under either native non-reducing (B) or denaturing and reducing (C) conditions on $4-16 \%$ precast gels for Western blot analysis. Samples with GPBP (red signal) at both $1 \mu \mathrm{M}$ and $2.5 \mu \mathrm{M}$ concentrations show a reduction in the amount of low molecular weight $A \beta_{1-42}$ species (green signal) (C) suggesting that GPBP is able to structure $A \beta_{1-42}$ into insoluble aggregates which fail to migrate into a 4\% PAGE under native, nonreducing conditions Recombinant GPBP reduces $A \beta$ toxicity in a SHSY-5Y cell culture model D) SHSY-5Y cells were exposed to $10 \mu \mathrm{M} \mathrm{A} \beta_{1-42}(\mathrm{~A} \beta)$ in the presence or in the absence of $1 \mu \mathrm{M}$ GPBP for 24 hours. MTT reduction was assessed by incubating the cells with $0.5 \mathrm{mg} / \mathrm{ml}$ MTT for 3 hours and measuring absorbance at $595 \mathrm{~nm}$. The results were normalized to cells that were not exposed to $A \beta_{1-42}$ or GPBP, each dot in the graph represents a single well and data from two independent experiments were pooled. The means of the $A \beta_{1-42}$ and $A \beta_{1-42}+$ GPBP groups were statistically significant $(p<0.03)$ in an unpaired t-test.

\section{Discussion}

Here we have shown that in the brain GPBP associates with neuronal plasma membranes and is found in the neuropil, conversely the shorter splice variant CERT stains neuronal cells intracellularly (10). We found that GPBP accumulates at the plasma membrane level in response to APP overexpression, suggesting a regulation that might occur upstream of $A \beta$ production. Also, secreted GPBP interacts directly with $A \beta_{1-42}$ and promotes the formation of high-molecular weight $A \beta$ aggregates while simultaneously reducing the $A \beta \beta$-sheet aggregation pathway, interestingly resulting in reduced $A \beta_{1-42}$ peptide toxicity in cultured neurons. Positive GPBP staining was found in activated microglia in AD human brains indicating that GPBP may have a role in the immune and /or immunoeffector function of these cells (11). Activated microglia classically cluster around amyloid plaques and release pro-inflammatory cytokines into the milieu $(33,34)$. Consistent with a role in amyloid aggregate response, GPBP expression is induced by the pro-inflammatory cytokine TNF (35). Additionally, we found that $\mathrm{C} 1 \mathrm{q}$, the first component of the complement cascade, and GPBP may share a common binding site on the SAP molecule. C1q is present in fibrillar amyloid plaques and, through activation of complement, has a role in the pathogenesis of AD. SAP bound to C1q can activate the classical complement pathway and GPBP could be involved in the regulation of complement activation by inhibition of C1q-SAP binding. Many proteins have alternative isoforms that possess distinct functions (6). Since proteins are only present in their active form in the specific 
compartment where they are needed, subcellular localization of proteins can be a useful indicator of protein function. The distinct cellular distribution of GPBP and CERT, together with the fact that these splice variants have been widely conserved during evolution, suggest isoformspecific functional roles for these proteins. If the function of CERT is to transport the lipid ceramide from the ER to the Golgi (7), the longer isoform GPBP has been reported to regulate molecular/supramolecular organization of structural proteins and to direct their assembly intra and extracellularly $(2,5)$. This may be of significance when we consider that GPBP has been found associated with plaques from human AD patients and was also found to interact with SAP, a universal component of amyloid deposits (11). This suggests a possible role for GPBP in binding proteins prone to misfolding and aggregation (3), such as $A \beta$.

APP is a ubiquitously expressed cell surface protein that, as well as generating $A \beta$, has many reported functions (36). Several data support a role for APP in mediating cell-cell or cell-matrix interactions, indeed APP has been shown to directly bind type I collagen and other extracellular matrix (ECM) molecules (37-40). Although most commonly linked to pathological processes, several potential non-pathogenic functions have been attributed to $A \beta$, including activation of kinase enzymes (41), protection against oxidative stress $(42,43)$, regulation of cholesterol transport $(44,45)$ and functioning as a transcription factor $(46,47)$. In healthy cells, it appears that both amyloidogenic and non-amyloidogenic APP processing pathways operate and that a precise balance between the two is maintained. Our results indicate that GPBP is upregulated in response to APP overexpression, and that this response appears to be independent of $A \beta$ peptide levels. However, we cannot exclude the possibility that very low levels of $A \beta$ peptide production may be responsible for the increase in GPBP expression. The processing of APP has been shown to influence the expression levels of many genes. For example, as well as $A \beta$ peptides, amyloidogenic processing of APP produces the APP intracellular domain (AICD), which has been reported to affect expression levels of several genes by acting as a transcription factor in the nucleus (48). Indeed, abnormal gene dosage of APP can unbalance the amyloidogenic and non-amyloidogenic APP processing pathways in neurons, resulting in abnormalities that can contribute to neurodegeneration and consequent dementia in AD (49). We were able to retrieve complexes of GPBP and APP in total cell lysate, suggesting that this interaction occurs at the plasma membrane level and prior to APP processing. Converging evidence from a number of studies indicates that amyloidogenic processing occurs in ceramide-enriched 
membrane raft microdomains $(50,51)$. This is consistent with our finding that ceramide colocalises with APP/GPBP complexes at the plasma membrane. It is possible that the role of GPBP at the plasma membrane is dependent upon cell expression of ceramide, however, the precise mechanism of APP-mediated up- regulation of GPBP remains to be elucidated.

The toxicity of $A \beta$ for neuronal cells is well established both in vitro and in vivo, and this toxicity seems to play an important role in the pathogenesis of $A D$ (32). GPBP exists in several isoforms with molecular weight ranging from 30 to $120 \mathrm{kDa}(32,50,60,77,91,120 \mathrm{kDa})(2,8)$ and it is possible that each isoform has a distinct function. The GPBP $77 \mathrm{kDa}$ polypeptide was described as soluble extracellular isoform capable of interacting with type IV collagen in the extracellular matrix. In this context, the finding that GPBP is able to bind $A \beta$ is not surprising. In vitro we demonstrate that GPBP strongly promotes the formation of high-molecular weight $A \beta$ aggregates while simultaneously reducing the $A \beta \beta$-sheet aggregation pathway. $\beta$-sheet oligomers and protofibrillar species, formed by $A \beta_{1-42}$ or $A \beta_{1-40}$, are neurotoxic and powerful inducers of apoptosis. Our cell culture data show that GPBP reduces the toxicity of $A \beta_{1-42}$ peptide species, suggesting that GPBP can organize $A \beta$ into less toxic aggregates. Protein aggregation is a complex process, involving several types of intermediate and resulting in different forms of fibers or amorphous aggregates. However, it is not established if and how these different aggregates are related to the pathogenesis of $A D$. Although there is a large body of data on the conformation and "cross- $\beta$ " packing of $A \beta$ in amyloid fibrils $(52,53)$, which are the end-products of aggregation, little is known about the basic building blocks of the oligomers and protofibrils that precede them.

What is known is that $A D$ is linked to the formation of neurotoxic oligomeric aggregates of the $A \beta$-peptide in the brain (54). In the present study, we have presented data that supports a direct interaction between APP and GPBP and have shown that GPBP binds $A \beta$ and organizes $A \beta$ aggregate structure. Proteins in the plasma membrane typically help the cell interact with its environment; GPBP may switch roles between; (i) stabilizing normal levels of APP and (ii) reducing levels of cytotoxic $A \beta$ by organizing these small peptides into more structured non toxic species. Importantly, these interactions are not limited to cell culture systems. We have previously reported evidence for the molecular association of GPBP and APP in samples prepared from AD mouse brains. We also found GPBP to localize in amyloid plaques of post-mortem $A D$ human brain (11), demonstrating that the in vitro results obtained in the present study are functionally significant and 
with in vivo relevance. More experimental evidence will be necessary to demonstrate a critical function of GPBP in the pathology of AD, which could lead us to a better understanding of the pathological process that take places in neurodegenerative disorders. 


\section{References}

1. Heneka, M. T., Nadrigny, F., Regen, T., Martinez-Hernandez, A., Dumitrescu-Ozimek, L., Terwel, D., Jardanhazi-Kurutz, D., Walter, J., Kirchhoff, F., Hanisch, U. K., and Kummer, M. P. Proc Natl Acad Sci U S A 107, 6058-6063

2. Revert, F., Ventura, I., Martinez-Martinez, P., Granero-Molto, F., Revert-Ros, F., Macias, J., and Saus, J. (2008) J Biol Chem 283, 30246-30255

3. Revert, F., Merino, R., Monteagudo, C., Macias, J., Peydro, A., Alcacer, J., Muniesa, P., Marquina, R., Blanco, M., Iglesias, M., Revert-Ros, F., Merino, J., and Saus, J. (2007) Am J Pathol 171, $1419-1430$

4. Fugmann, T., Hausser, A., Schoffler, P., Schmid, S., Pfizenmaier, K., and Olayioye, M. A. (2007) J Cell Biol 178, 15-22

5. Revert-Ros, F., Lopez-Pascual, E., Granero-Molto, F., Macias, J., Breyer, R., Zent, R., Hudson, B. G., Saadeddin, A., Revert, F., Blasco, R., Navarro, C., Burks, D., and Saus, J. J Biol Chem 286, 35030-35043

6. Rassow, J., Voos, W., and Pfanner, N. (1995) Trends Cell Biol 5, 207-212

7. Hanada, K., Kumagai, K., Yasuda, S., Miura, Y., Kawano, M., Fukasawa, M., and Nishijima, M. (2003) Nature 426, 803-809

8. Raya, A., Revert-Ros, F., Martinez-Martinez, P., Navarro, S., Rosello, E., Vieites, B., Granero, F., Forteza, J., and Saus, J. (2000) J Biol Chem 275, 40392-40399

9. Mencarelli, C., Losen, M., Hammels, C., De Vry, J., Hesselink, M. K., Steinbusch, H. W., De Baets, M. H., and Martinez-Martinez, P. J Neurochem 113, 1369-1386

10. Mencarelli, C., Hammels, C., Van Den Broeck, J., Losen, M., Steinbusch, H., Revert, F., Saus, J., Hopkins, D. A., De Baets, M. H., Steinbusch, H. W., and Martinez-Martinez, P. (2009) J Chem Neuroanat 38, 97-105

11. Mencarelli, C., Bode, G. H., Losen, M., Kulharia, M., Molenaar, P. C., Veerhuis, R., Steinbusch, H. W., De Baets, M. H., Nicolaes, G. A., and Martinez-Martinez, P. J Biol Chem

12. Granero-Molto, F., Sarmah, S., O'Rear, L., Spagnoli, A., Abrahamson, D., Saus, J., Hudson, B. G., and Knapik, E. W. (2008) J Biol Chem 283, 20495-20504

13. Rao, R. P., Yuan, C., Allegood, J. C., Rawat, S. S., Edwards, M. B., Wang, X., Merrill, A. H., Jr., Acharya, U., and Acharya, J. K. (2007) Proc Natl Acad Sci U S A 104, 11364-11369

14. Wang, X., Rao, R. P., Kosakowska-Cholody, T., Masood, M. A., Southon, E., Zhang, H., Berthet, C., Nagashim, K., Veenstra, T. K., Tessarollo, L., Acharya, U., and Acharya, J. K. (2009) J Cell Biol 184, 143-158

15. Palmert, M. R., Podlisny, M. B., Golde, T. E., Cohen, M. L., Kovacs, D. M., Tanzi, R. E., Gusella, J. F., Whitehouse, P. J., Witker, D. S., Oltersdorf, T., and et al. (1989) Prog Clin Biol Res 317, 971-984

16. Allinson, T. M., Parkin, E. T., Turner, A. J., and Hooper, N. M. (2003) J Neurosci Res 74, 342-352

17. Sinha, S., and Lieberburg, I. (1999) Proc Natl Acad Sci U S A 96, 11049-11053

18. Vassar, R., Bennett, B. D., Babu-Khan, S., Kahn, S., Mendiaz, E. A., Denis, P., Teplow, D. B., Ross, S., Amarante, P., Loeloff, R., Luo, Y., Fisher, S., Fuller, J., Edenson, S., Lile, J., Jarosinski, M. A., Biere, A. L., Curran, E., Burgess, T., Louis, J. C., Collins, F., Treanor, J., Rogers, G., and Citron, M. (1999) Science 286, 735-741

19. Sastre, M., Steiner, H., Fuchs, K., Capell, A., Multhaup, G., Condron, M. M., Teplow, D. B., and Haass, C. (2001) EMBO Rep 2, 835-841

20. Weidemann, A., Eggert, S., Reinhard, F. B., Vogel, M., Paliga, K., Baier, G., Masters, C. L., Beyreuther, K., and Evin, G. (2002) Biochemistry 41, 2825-2835

21. Selkoe, D. J. (2001) Physiol Rev 81, 741-766

22. Grimm, M. O., Grosgen, S., Rothhaar, T. L., Burg, V. K., Hundsdorfer, B., Haupenthal, V. J., Friess, P., Muller, U., Fassbender, K., Riemenschneider, M., Grimm, H. S., and Hartmann, T. Int J Alzheimers Dis 2011, 695413

23. Hanada, K. (2003) Biochim Biophys Acta 1632, 16-30

24. Tomita, S., Kirino, Y., and Suzuki, T. (1998) J Biol Chem 273, 6277-6284 
25. Mencarelli, C., Bode, G. H., Vlamings, R., Janssen, M. L., Losen, M., De Baets, M. H., Steinbusch, H. W., Temel, Y., and Martinez-Martinez, P. Neurosci Lett 506, 39-43

26. Groot, A. J., El Khattabi, M., Sachs, N., van der Groep, P., van der Wall, E., van Diest, P. J., Sonnenberg, A., Verrips, C. T., and Vooijs, M. (2009) Mol Immunol 46, 2022-2028

27. Walter, J., Fluhrer, R., Hartung, B., Willem, M., Kaether, C., Capell, A., Lammich, S., Multhaup, G., and Haass, C. (2001) J Biol Chem 276, 14634-14641

28. Selkoe, D. J., Podlisny, M. B., Joachim, C. L., Vickers, E. A., Lee, G., Fritz, L. C., and Oltersdorf, T. (1988) Proc Natl Acad Sci U S A 85, 7341-7345

29. Borg, J. P., Yang, Y., De Taddeo-Borg, M., Margolis, B., and Turner, R. S. (1998) J Biol Chem 273, 14761-14766

30. Peng, Y., Jiang, L., Lee, D. Y., Schachter, S. C., Ma, Z., and Lemere, C. A. (2006) J Neurosci Res 84, 903-911

31. King, G. D., Cherian, K., and Turner, R. S. (2004) J Neurochem 88, 971-982

32. Stadelmann, C., Deckwerth, T. L., Srinivasan, A., Bancher, C., Bruck, W., Jellinger, K., and Lassmann, H. (1999) Am J Pathol 155, 1459-1466

33. Akiyama, H., Arai, T., Kondo, H., Tanno, E., Haga, C., and Ikeda, K. (2000) Alzheimer Dis Assoc Disord 14 Suppl 1, S47-53

34. Combs, C. K., Karlo, J. C., Kao, S. C., and Landreth, G. E. (2001) J Neurosci 21, 1179-1188

35. Granero, F., Revert, F., Revert-Ros, F., Lainez, S., Martinez-Martinez, P., and Saus, J. (2005) FEBS J 272, 5291-5305

36. Kang, J., Lemaire, H. G., Unterbeck, A., Salbaum, J. M., Masters, C. L., Grzeschik, K. H., Multhaup, G., Beyreuther, K., and Muller-Hill, B. (1987) Nature 325, 733-736

37. Yamazaki, T., Koo, E. H., and Selkoe, D. J. (1997) J Neurosci 17, 1004-1010

38. Beher, D., Hesse, L., Masters, C. L., and Multhaup, G. (1996) J Biol Chem 271, 1613-1620

39. Sondag, C. M., and Combs, C. K. (2004) J Biol Chem 279, 14456-14463

40. Kibbey, M. C., Jucker, M., Weeks, B. S., Neve, R. L., Van Nostrand, W. E., and Kleinman, H. K. (1993) Proc Natl Acad Sci U S A 90, 10150-10153

41. Tabaton, M., Zhu, X., Perry, G., Smith, M. A., and Giliberto, L. Exp Neurol 221, 18-25

42. Zou, K., Gong, J. S., Yanagisawa, K., and Michikawa, M. (2002) J Neurosci 22, 4833-4841

43. Baruch-Suchodolsky, R., and Fischer, B. (2009) Biochemistry 48, 4354-4370

44. Yao, Z. X., and Papadopoulos, V. (2002) FASEB J 16, 1677-1679

45. Igbavboa, U., Sun, G. Y., Weisman, G. A., He, Y., and Wood, W. G. (2009) Neuroscience 162, 328-338

46. Maloney, B., and Lahiri, D. K. Gene 488, 1-12

47. Bailey, J. A., Maloney, B., Ge, Y. W., and Lahiri, D. K. Gene 488, 13-22

48. Muller, T., Meyer, H. E., Egensperger, R., and Marcus, K. (2008) Prog Neurobiol 85, 393-406

49. Neve, R. L., McPhie, D. L., and Chen, Y. (2000) Brain Res 886, 54-66

50. Riddell, D. R., Christie, G., Hussain, I., and Dingwall, C. (2001) Curr Biol 11, 1288-1293

51. Vetrivel, K. S., Cheng, H., Kim, S. H., Chen, Y., Barnes, N. Y., Parent, A. T., Sisodia, S. S., and Thinakaran, G. (2005) J Biol Chem 280, 25892-25900

52. Maji, S. K., Wang, L., Greenwald, J., and Riek, R. (2009) FEBS Lett 583, 2610-2617

53. Nelson, R., Sawaya, M. R., Balbirnie, M., Madsen, A. O., Riekel, C., Grothe, R., and Eisenberg, D. (2005) Nature $435,773-778$

54. Roychaudhuri, R., Yang, M., Hoshi, M. M., and Teplow, D. B. (2009) J Biol Chem 284, 47494753 
Summary and general discussion 
Precise regulation of protein function in the cell can occur by many mechanisms, at any stage in the flow of information from gene to protein. Protein function can be regulated by temporal and spatial control of the gene product which can be targeted to specific cellular compartments as required. Protein activity can also be regulated by the binding of effector molecules, which often work by inducing conformational changes that produce inactive or active forms of the protein. The various strategies of functional control are not mutually exclusive and any one protein may be subject to several modes of regulation. GPBP and its spliced variant CERT, encoded by the collagen gene COL4A3BP, represent a good example of this finely tuned cellular regulation. These two proteins differ solely by a 26 amino acid domain that appears to be sufficient to produce dramatically different biological activities. In chapter 1 of this thesis we have summarized the current available knowledge of these proteins, attempting to present an integrated view of the background concerning their structure, properties and functions. Throughout, we remain careful to consider each isoform individually, as in much of the literature they can be mistakenly treated as one and the same protein. On the contrary, the two isoforms have many distinguishing properties. The shorter isoform CERT localizes inside the cell and carries out the role of ceramide transporter, while GPBP associates with membranes, can be secreted extracellularly and is likely to regulate molecular organization of structural proteins. Moreover, the additional 26residue serine rich motif that distinguishes GPBP from CERT results in an increased kinase activity. The role of CERT is intimately linked to ceramide function, whereas a clear function for GPBP remains elusive. However, CERT and GPBP share a common ceramide binding capability and are the only proteins known to transport ceramide. Ceramide plays an important role in a wide variety of physiological neuronal processes, ranging from lipid raft formation in cell membranes to regulation of differentiation and apoptosis (chapter 2). By implication, CERT and GPBP must underlie the regulation of many physio-pathological processes. To investigate further, in chapter $\mathbf{3}$ we first characterized the cellular localization and expression of these ceramide transporters in normal rat brain. High levels of immunoreactivity were observed throughout the brain, suggesting that GPBP and CERT play an important role in central nervous system (CNS) neuron function. Strong immunoreactivity was found in neurons of the cortex, hippocampus, the basal ganglia, the olfactory bulb and some nuclei of the thalamus, the hypothalamus and the septal area. Glial cells do not show immunoreactivity for GPBP and CERT, suggesting that under basal conditions these proteins 
have very low levels of expression in non-neuronal cells. In chapter 4 , in order to further investigate the role of these proteins in the brain, we examined the expression levels of GPBP and CERT in the acute neurodegenerative process of the 6-OHDA rat model of Parkinson's disease (PD). We found that GPBP and CERT expression levels were not altered in diseased animals as compared to the control group. 6-OHDA induces a vigorous inflammation and mimics the selective neuronal degeneration that characterizes PD, however, this model does not produce all of the pathological and clinical features of human parkinsonism. A defining pathological hallmark of PD is the presence of neuronal Lewy body formed by protein aggregates. After 6-OHDA lesioning, deposit of aggregate proteins does not occur. The role of protein aggregation in the pathogenesis of PD has not been fully determined, but altered protein processing in the cell is known to have a negative impact on normal cellular function. Moreover, dysregulation of sphingolipid metabolism, that seems to be strongly involved in many neurodegenerative disorders, is a condition that is missing in a 6-OHDA model. Therefore, in chapter 5 we have investigated the expression levels of GPBP and CERT in human and transgenic mouse Alzheimer's disease (AD) brain tissues characterized by aberrant protein aggregation and progressive neuronal degeneration. We found GPBP and CERT colocalised in amyloid plaques in post-mortem AD human brain. This led us to study the relationship between these proteins and serum amyloid $P$ component (SAP), a ubiquitous amyloid deposit associated protein. We found that GPBP interacts strongly with SAP, further supporting a role for GPBP in amyloid disease. Notably, GPBP-SAP binding is reduced by C1q, a well known ligand of SAP, raising the possibility that GPBP and C1q share a common binding site on SAP molecule. SAP binds to proteins involved in immunological responses and can activate the classical complement pathway through interaction with C1q. This might indicate a role for GPBP in the regulation of the complement system by inhibiting the C1q-SAP interaction by steric hindrance. Moreover, we observed GPBP staining in activated microglia of $A D$ tissues, whereas in the non-disease state this protein is found only in neuronal cells. Considering that GPBP associates with amyloid plaques and has been shown to induce intra and extracellular structural protein organization, it seems likely that GPBP has an important role in the molecular organization and self-association processes of amyloid fibrils. Also, GPBP could be involved in the removal of misfolded proteins by activated microglia at the site of the $A D$ plaques. Amyloid plaques are extracellular structures composed of 38-43 amino acid peptides called 
amyloid beta $(A \beta)$ peptides. A $\beta$-peptides are generated by aberrant proteolysis of a much larger precursor protein, the amyloid precursor protein (APP), a ubiquitous type I cell surface protein of as yet unknown physiological function. In chapter 6, we have shown that in the brain GPBP associates with neuronal plasma membranes and is found in the neuropil, conversely the shorter splice variant CERT localizes in the cytoplasm of neuronal cells. We next investigated whether GPBP has a role in the processing of APP using a cell culture model overexpressing APP that results in elevated levels of secreted $A \beta$ peptide. We found that GPBP accumulates at the plasma membrane level in response to APP over-expression, suggesting a regulation that might occur upstream of $A \beta$ production. This suggests that perturbation at the plasma membrane level, due to overexpression of APP and ceramide accumulation, may be sufficient for the upregulation of GPBP levels. However, we cannot exclude the possibility that very low levels of $A \beta$ peptide production may be responsible for the increase in GPBP expression. Secreted GPBP interacts directly with $A \beta_{1-42}$ and promotes the formation of high-molecular weight $A \beta$ aggregates while simultaneously reducing the $A \beta \beta$-sheet aggregation pathway, interestingly resulting in reduced $A \beta_{1-42}$ peptide toxicity in cultured neurons. Importantly, the interaction between GPBP and $A \beta_{1-42}$ is not limited to cell culture systems. We have detected a molecular association of GPBP and A $\beta$ aggregates in samples prepared from $A D$ mouse brains demonstrating that the in vitro results have are functionally significant in vivo. Taken together these findings suggest that GPBP has a role in the progression of brain diseases that are characterized by protein misfolding/aggregation rather than merely in response to neuron degeneration or damage. In line with this role, high expression levels of GPBP are found in many autoimmune diseases in which antigens may arise from abnormal protein domain organization. GPBP was first identified as a collagen binding protein in Goodpasture syndrome, an autoimmune disease in which autoantibodies are observed along glomerular and alveolar basement membranes, causing glomerulonephritis and lung hemorrhage. Recent evidence suggests that the pathophysiology of neurodegenerative and inflammatory neurological diseases has an immunological component involving complement, an innate humoral immune defence system. Although historically viewed as an immune-privileged organ, the CNS contains and synthesizes many components of the immune system. Complement components play a central role in the amplification of $A D$ risk factors and neuronal death. $\mathrm{C} 1 \mathrm{q}$, the first component of the complement cascade, is present in fibrillar amyloid 
plaques and, through activation of complement, has a role in the pathogenesis of AD. Our finding that $\mathrm{C} 1 \mathrm{q}$ reduces the binding of GPBP to $\mathrm{SAP}$, could suggest a cross talk between these three molecules at the plaque deposition site. Additionally, in innate immune reactions of the brain, microglial activation is the main cellular response to CNS dysfunction. We found positive GPBP staining in activated microglia in AD human tissue indicating that GPBP may have a role in the immune and/or immunoeffector function of these cells. The rapid clearance of abnormally structured proteins by microglia is important to inhibit inflammation as well as autoimmune responses against neo-antigens.

Together, our findings provide new insight into the physiopathological roles of GPBP protein. We suggest that GPBP may be involved in the innate immune response in the specific context of protein misfolding/aggregation. Through interaction with SAP, GPBP may inhibit SAP-mediated activation of the complement cascade. This raises the possibility that GPBP is able to modulate the innate immune response, placing this protein in a key position in the regulation of autoimmunity, inflammation and neurodegeneration. More research is required to fully characterize the mechanism of action of GPBP; however, the data presented here provide further detail of the increasingly apparent link between chronic inflammatory diseases such as neurodegeneration and autoimmunity. 
Curriculum vitae 


\section{Curriculum vitae}

Chiara Mencarelli was born on January 26th 1983 in Pistoia (Tuscany, Italy). In 2002, she graduated from secondary school at "Niccolo' Forteguerri" Classical Lyceum of Pistoia. Later that year, she started her Bachelor in Biotechnology (2002-2005) and thereafter her Master in Medical Biotechnology (2005-2007) at the University of Florence (Italy). During this period, she performed a one year internship at the School of Biosciences, Cardiff University (Wales, UK) where she studied the molecular and cellular mechanisms involved in protein misfolding. In 2007, she obtained the degree of M.Sc. in Medical Biotechnology. Four months later, she started her $\mathrm{PhD}$ project at the department of Psychiatry and Neuropsychology at the University of Maastricht (the Netherlands), under the supervision of Prof. De Baets, Prof. Steinbusch and Dr. Martínez-Martínez. Within this period she travelled abroad visiting other labs for collaborations in Southampton (UK), Leuven (Belgium) and Bonn (Germany). During this project, she investigated the role of ceramide transporters in neuroinflammation and neurodegeneration. The results of her work are described in this thesis. 


\section{List of publications}




\section{List of publications}

Mencarelli C, Losen M, Hammels C, De Vry J, Hesselink MK, Steinbusch HW, De Baets MH, Martínez-Martínez P (2010) The ceramide transporter (CERT) and the Goodpasture antigen binding protein (GPBP). One protein - one function? J Neurochem, 113:1369-86.

Mencarelli C, Hammels C, Van Den Broeck J, Losen M, Steinbusch H, Revert F, Saus J, Hopkins DA, De Baets MH, Steinbusch HW, Martínez-Martínez P (2009) The expression of the Goodpasture antigen-binding protein (ceramide transporter) in adult rat brain. J Chem Neuroanat, 38:97-105.

Mencarelli C, Bode $\mathrm{G} \mathrm{H}$, Vlamings $\mathrm{R}$, Janssen $\mathrm{M} \mathrm{L}$, Losen $\mathrm{M}$, De Baets $\mathrm{MH}$, Steinbusch HW, Temel $Y$ and Martínez-Martínez P (2012) Unchanged expression of the Ceramide transfer protein in the acute 6-OHDA neurodegenerative model, Neuroscience Letters, 506:39-43.

Mencarelli C, Bode G H, Losen M, Kularia M, Revert F, Molenaar P, Saus J, Veerhuis R, Nicolaes G, Steinbusch HW, De Baets MH and Martínez-Martínez $P$ (2012) The Goodpasture-antigen binding protein / Ceramide transporter binds to human serum amyloid P-component and is present in brain amyloid plaques, J. Biol. Chem. 287: 14897-14911.

Mencarelli C and Martínez-Martínez P

Ceramide metabolism in the brain: when a slight tilt is enough, Cellular and Molecular Life Sciences, (invited review) In revision

Mencarelli C, et al. Goodpasture antigen-binding protein (GPBP) down modulates $A ß$ aggregation in vitro and decreases toxicity of $A ß$ to neurons. In preparation

Bode G H, Losen M, Mencarelli C, Molenaar P M, De Baets M H, Daha M and Martínez-Martínez $P$, Goodpasture-antigen binding protein/Ceramide transporter activates the classical complement pathway1 by binding to the globular heads of C1q. In preparation 
Vlassaks E, Mencarelli C, Strackx E, Nikiforou M, Guimaraes da Lomba Ferraz M J, Aerts H J M F G, Vles H J S, De Baets M H, Antonio Gavilanes A W D, Martínez-Martínez $\mathrm{P}$, Mild fetal asphyxia during brain development induces changes in the ceramide pathway and in brain immunological responses. In preparation

\section{Oral presentations}

Mencarelli C, Losen M, Steinbusch HW, De Baets MH and Martínez-Martínez P, The role of ceramide transporter protein CERT in neuroinflammation and neurodegenerationin neurodegenerative diseases

3rd Marie Curie fellow meeting at March 25 ${ }^{\text {th }}, 2009$, Maastricht, the Netherlands

Mencarelli C, Bode G H, Losen M, Kularia M, Molenaar P C., Veerhuis R, Steinbusch H W M, De Baets M H, Nicolaes G A F, and Martínez-Martínez $P$, Ceramide Transporter binds to Human Serum Amyloid P-Component and is present in Brain Amyloid Plaques Aachen-Maastricht Neuromuscular Research Meeting, November 2010, Aachen, Germany

Mencarelli C, Tosheva S, Bode G H, Gangolf M, Losen M, De Baets M H, Walter J. and Martínez-Martínez $P$, Goodpasture antigen-binding protein (GPBP) down modulates $A ß$ aggregation in vitro and decreases toxicity of $A ß$ to neurons. In preparation

$15^{\text {th }}$ EURON PhD days of the European Graduate School of Neuroscience, September 22- 23, 2011, Bonn, Germany

\section{Poster presentations}

Mencarelli C, Bode G H, Losen M, Kularia M, Molenaar P C, Veerhuis R, Steinbusch H W M, De Baets M H, Nicolaes G A F, and Martínez-Martínez P, The Goodpasture-Antigen Binding Protein / Ceramide Transporter binds to Human Serum Amyloid P-Component and is present in Brain Amyloid Plaques

- $\quad 2^{\text {nd }}$ European Congress of Immunology (ECI), September 13-16, 2009 Berlin, Germany 
Mencarelli C, Bode $\mathrm{G} \mathrm{H}$, Vlamings R, Losen M, De Baets $M H$, Steinbusch H $W$ M., Temel $Y$ and Martínez-Martínez $P$, Unchanged expression of the Ceramide transfer protein in the acute 6-OHDA neurodegenerative model - $\quad 4^{\text {th }}$ ESN (European Society for Neurochemistry) Conference on Advances in Molecular Mechanisms of Neurological Disorders, July 11-14 2009, Leipzig, Germany 
Acknowledgments 


\section{Acknowledgments}

I would like to thank my supervisors Prof. Marc De Baets and Prof. Harry Steinbusch. In particular, I would like to express my gratitude to Prof. Marc De Baets whose support and feedback was always greatly received.

I wish to thank my co-supervisor Dr. Pilar Martínez-Martínez for her contribution of time and ideas to make my Ph.D. experience productive and stimulating.

To my close friends and colleagues: Alejandro, Gerard, Kathleen, Jo, Marjorie, Els, Anne-Hilde. I thank you all for providing such a pleasurable and friendly working atmosphere. I am very thankful for your unconditional friendship and support throughout these years. You have made Maastricht a home away from home and always found ways to make life exciting!

Apart from the above-mentioned, there are many colleagues who have helped me with my study in some way. Thank you to everyone who has made this possible, it has certainly been one of the hardest and most rewarding periods of my life. I really appreciate it. Thank you.

I am profoundly grateful to my family. Although they could not be here with me during my PhD process, they always paid great attention to every little aspect of my life and research; without them I would not have come this far. 
Affiliations of co-authors 


\section{Affiliations of co-authors}

Bode G

De Baets $M$

De Vry J

Duimel H

Frederik P

Gangolf M

Groot A

Hackeng $T$

Hammels C

Hesselink M

Janssen M

Losen M
Division of Neuroscience, School for Mental Health and Neuroscience, Faculty of Health, Medicine and Life Sciences, Maastricht University, The Netherlands Division of Neuroscience, School for Mental Health and Neuroscience, Faculty of Health, Medicine and Life Sciences, Maastricht University, The Netherlands School of Life Sciences, Biomedical Research Institute and translationale Universiteit Limburg, Hasselt University, Belgium

Division of Neuroscience, School for Mental Health and Neuroscience, Faculty of Health, Medicine and Life Sciences, Maastricht University, The Netherlands Electron Microscopy Unit, Department of Molecular Cell Biology, Maastricht University, The Netherlands Electron Microscopy Unit, Department of Molecular Cell Biology, Maastricht University, The Netherlands Division of Neuroscience, School for Mental Health and Neuroscience, Faculty of Health, Medicine and Life Sciences, Maastricht University, The Netherlands Department of Radiation Oncology (MAASTRO lab), Maastricht University, The Netherlands

Department of Biochemistry, Cardiovascular Research Institute, Maastricht University, The Netherlands

Division of Neuroscience, School for Mental Health and Neuroscience, Faculty of Health, Medicine and Life Sciences, Maastricht University, The Netherlands School for Nutrition, Toxicology and Metabolism, Faculty of Health, Medicine and Life Sciences, Maastricht University, The Netherlands

Division of Neuroscience, School for Mental Health and Neuroscience, Faculty of Health, Medicine and Life Sciences, Maastricht University, The Netherlands Division of Neuroscience, School for Mental Health and Neuroscience, Faculty of Health, Medicine and Life Sciences, Maastricht University, The Netherlands 
Martinez-Martinez P

Molenaar P

Nicolaes G

Schrijver R

Steinbusch H

Temel $Y$

Van den Broeck J

Van der Esch $\mathrm{E}$

Vlamings $\mathrm{H}$

Vlassaks $\mathrm{E}$

Veerhuis $\mathrm{R}$

Verheyen $\mathrm{F}$

Walter J

Zonneveld G
Division of Neuroscience, School for Mental Health and Neuroscience, Faculty of Health, Medicine and Life Sciences, Maastricht University, The Netherlands Division of Neuroscience, School for Mental Health and Neuroscience, Faculty of Health, Medicine and Life Sciences, Maastricht University, The Netherlands Department of Biochemistry, Cardiovascular Research Institute, Maastricht University, The Netherlands

Department of Biochemistry, Cardiovascular Research Institute, Maastricht University, The Netherlands

Division of Neuroscience, School for Mental Health and Neuroscience, Faculty of Health, Medicine and Life Sciences, Maastricht University, The Netherlands Division of Neuroscience, School for Mental Health and Neuroscience, Faculty of Health, Medicine and Life Sciences, Maastricht University, The Netherlands Division of Neuroscience, School for Mental Health and Neuroscience, Faculty of Health, Medicine and Life Sciences, Maastricht University, The Netherlands Division of Neuroscience, School for Mental Health and Neuroscience, Faculty of Health, Medicine and Life Sciences, Maastricht University, The Netherlands Division of Neuroscience, School for Mental Health and Neuroscience, Faculty of Health, Medicine and Life Sciences, Maastricht University, The Netherlands Division of Neuroscience, School for Mental Health and Neuroscience, Faculty of Health, Medicine and LifeSciences, Maastricht University, The Netherlands Department of Psychiatry, University Medical Center, Amsterdam, The Netherlands

Electron Microscopy Unit, Department of Molecular Cell Biology, Maastricht University, The Netherlands Department of Neurology, University of Bonn, Germany Toscheva SDepartment of Neurology, University of Bonn, Germany

Graphical Department, Maastricht University, The Netherlands 
